Florida International University

FIU Digital Commons

4-8-2019

\title{
Retrofitting of Bridge Elements Subjected to Predominantly Axial Load Using UHPC Shell
}

Mahsa Farzad

mfarz003@fiu.edu

Follow this and additional works at: https://digitalcommons.fiu.edu/etd

Part of the Civil Engineering Commons

\section{Recommended Citation}

Farzad, Mahsa, "Retrofitting of Bridge Elements Subjected to Predominantly Axial Load Using UHPC Shell" (2019). FIU Electronic Theses and Dissertations. 4016.

https://digitalcommons.fiu.edu/etd/4016

This work is brought to you for free and open access by the University Graduate School at FIU Digital Commons. It has been accepted for inclusion in FIU Electronic Theses and Dissertations by an authorized administrator of FIU Digital Commons. For more information, please contact dcc@fiu.edu. 


\section{FLORIDA INTERNATIONAL UNIVERSITY}

Miami, Florida

\section{RETROFITTING OF BRIDGE ELEMENTS SUBJECTED TO PREDOMINANTLY AXIAL LOAD USING UHPC SHELL}

A dissertation submitted in partial fulfillment of

the requirements for the degree of

DOCTOR OF PHILOSOPHY

in

CIVIL ENGINEERING

by

Masoumeh Farzad

2019 
To: Dean John L. Volakis

College of Engineering and Computing

This dissertation, written by Masoumeh Farzad, and entitled Retrofitting of Bridge Elements Subjected to Predominantly Axial Load Using UHPC Shell, having been approved in respect to style and intellectual content, is referred to you for judgment.

We have read this dissertation and recommend that it be approved.

Ton-Lo Wang

Arindam Gan Chowdhury

Seung Jae Lee

Kingsley Lau

Wallied Orabi

Atorod Azizinamini, Major Professor

Date of Defense: April 8, 2019

The dissertation of Masoumeh Farzad is approved.

Dean John L. Volakis College of Engineering and Computing

Andrés G. Gil

Vice President for Research and Economic Development and Dean of the University Graduate School

Florida International University, 2019 
(C) Copyright 2019 by Masoumeh Farzad

All rights reserved. 


\section{DEDICATION}

I dedicate this dissertation to my treasured grandmother, loving parents, and my supportive sister and brothers for their unconditional love. 


\section{ACKNOWLEDGMENTS}

I would like to thank my dissertation committee members, family, friends and who helped me learn more!

The research study, results of which reported in this dissertation were fully sponsored by Accelerated Bridge Construction University Transportation Center (ABCUTC) at Florida International University. ABC-UTC is a Tier 1 UTC funded by U.S. DOT. I would like to acknowledge and thank the sponsors for their support. The author is also thankful to Ductal ${ }^{\circledR}$ by LafargeHolcim, for providing the UHPC material. 


\title{
ABSTRACT OF THE DISSERTATION \\ RETROFITTING OF BRIDGE ELEMENTS SUBJECTED TO PREDOMINANTLY \\ AXIAL LOAD USING UHPC SHELL
}

\author{
by
}

\section{Masoumeh Farzad}

Florida International University, 2019

Miami, Florida

\section{Professor Atorod Azizinamini, Major Professor}

In the United States, $\sim 30 \%$ of the $\sim 600,000$ highway bridges are categorized as structurally deficient or functionally obsolete. These bridges should be replaced or upgraded to sustain the transportation needs of the growing public and private sectors of the U.S. economy. It is not uncommon for structures to have advanced levels of corrosioninduced damage where major repair and maintenance works are required. However, the transportation infrastructure may undergo disruption during rehabilitation causing interruption to critical economic public, civil and commercial activities. This mandates the development of new techniques and materials for accelerated rehabilitation and resilience.

To address this issue, a repair method has been developed at Florida International University (FIU), using Ultra High-Performance Concrete (UHPC) for members under axial load. This research investigates the mechanical and durability performance of the proposed retrofit method through experimental and numerical studies. The properties of UHPC, such as high compressive and tensile strength, workability, and impermeability make it a suitable choice as a repair material for retrofitting the damaged body of the marine 
piles, and application of UHPC could provide an efficient solution to address the pressing issue of bridge rehabilitation.

This research firstly aims to investigate the mechanical performance of UHPC repair for damaged bridge columns. To achieve this goal, an experimental study was designed to evaluate the mechanical performance of the repaired columns under a combination of static axial and cyclic lateral loads (to simulate operational conditions).

Moreover, the extent of macrocell development between the dissimilar concrete materials was monitored to identify the possible beneficial properties of UHPC related to corrosion. Conclusions and recommendations for capacity restoration and corrosion protection are made based on the results which can be used in evaluating the suitability of UHPC as a strengthening compound in concrete structures for any given application. 


\section{TABLE OF CONTENTS}

CHAPTER

PAGE

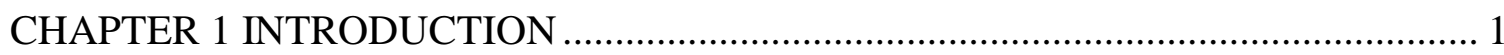

1.1 TYPICAL DEfiCIENCIES OF CONCRETE BRIDGES........................................................ 1

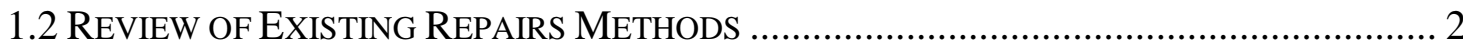

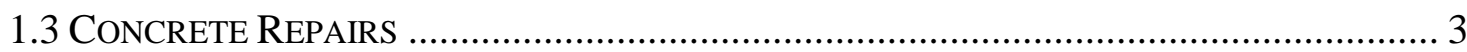

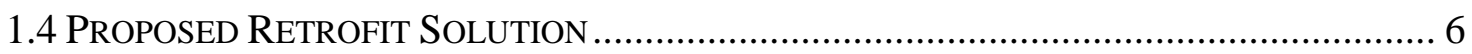

1.5 UltRA High-PERFORMANCE CONCRETE AS A REPAIR MATERIAL ............................. 7

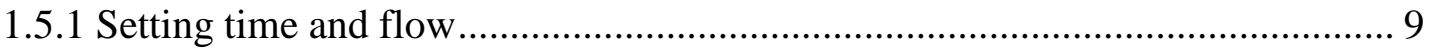

1.5.2 Shrinkage and creep of UHPC .............................................................. 9

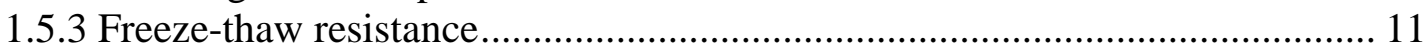

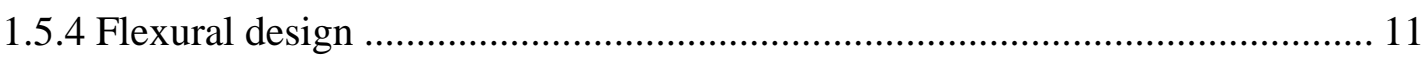

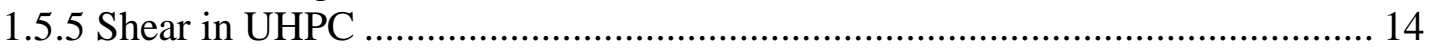

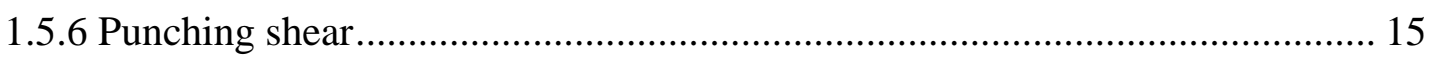

1.5.7 Development length of steel reinforcement in UHPC ...................................... 15

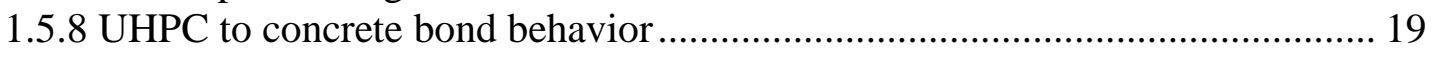

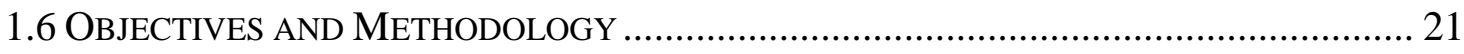

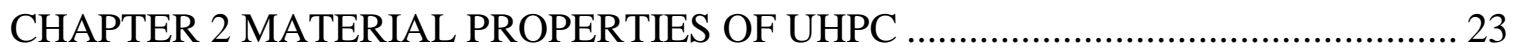

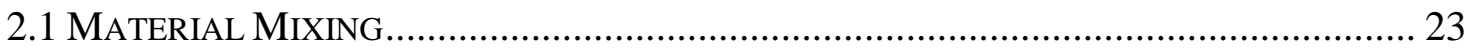

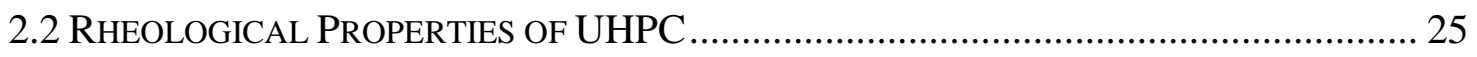

2.2.1 Slump flow test (unrestricted flow) ............................................................ 25

2.2.2 J-ring test (restricted flow) ......................................................................... 26

2.2.3 Static and dynamic flowability ..................................................................... 26

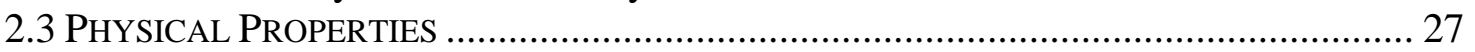

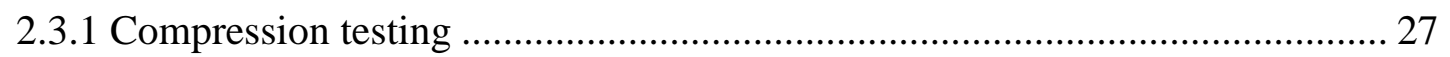

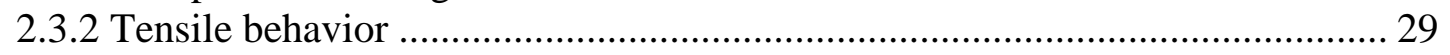

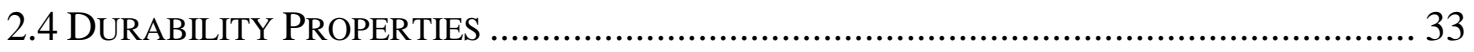

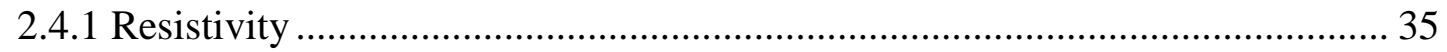

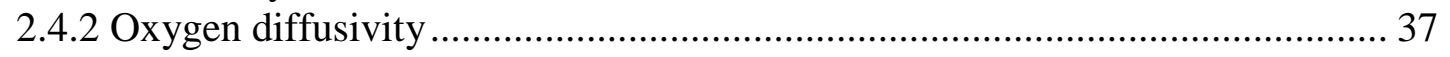

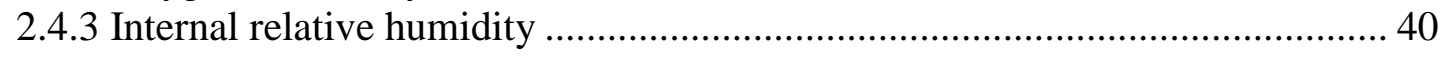

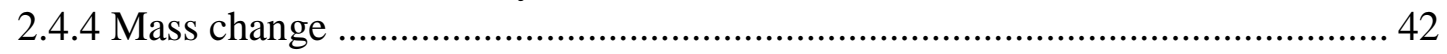

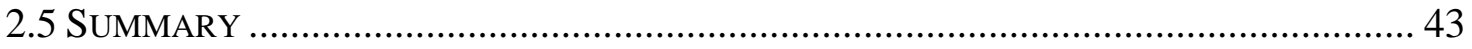

CHAPTER 3 BOND PERFORMANCE BETWEEN UHPC AND SUBSTRATE ......... 44

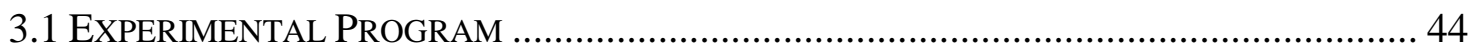

3.1.1 Bond strength estimation ............................................................................... 45

3.1.2 Chloride penetration at cold joints of structural members with dissimilar

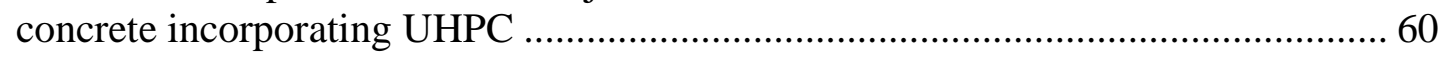

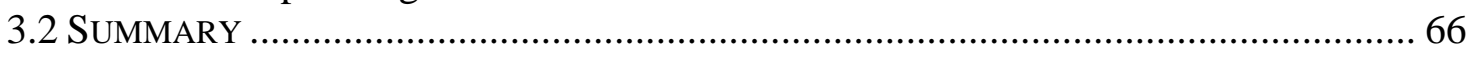

CHAPTER 4 MECHANICAL PERFORMANCE OF UHPC REPAIR IN AXIALY

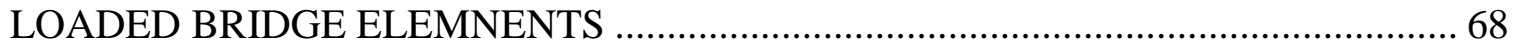




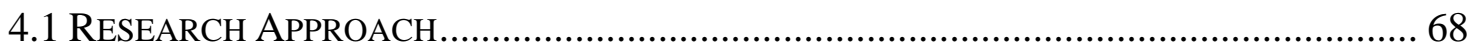

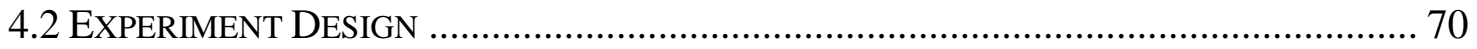

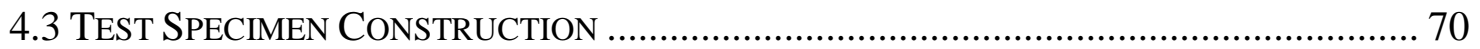

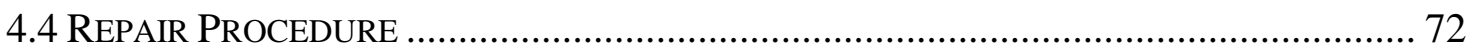

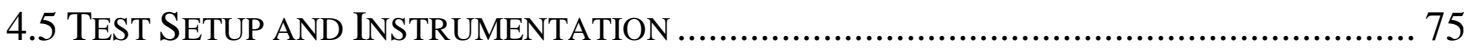

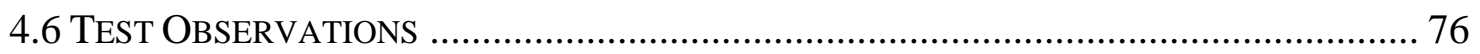

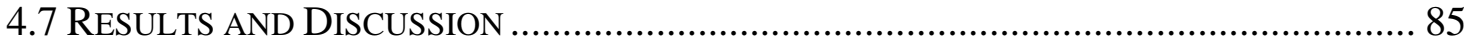

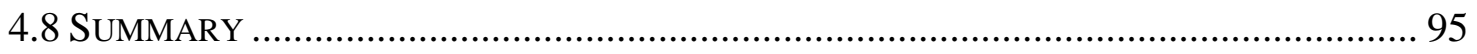

CHAPTER 5 NUMERICAL AND ANALYTICAL APPROACH................................. 97

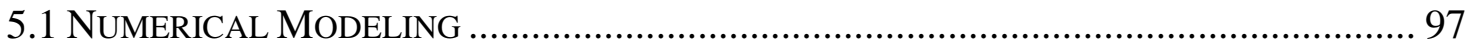

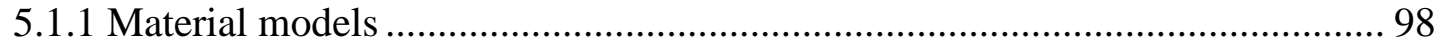

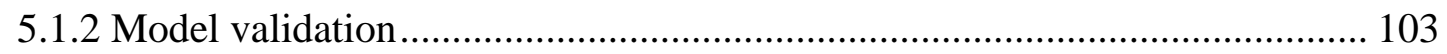

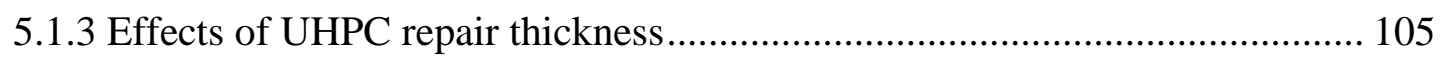

5.2 BENDING MOMENT CAPACITY FOR CIRCULAR RC COLUMNS WITH UHPC SHELL

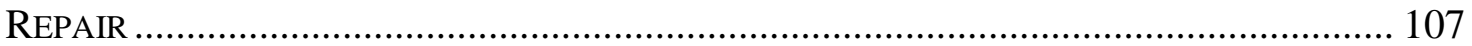

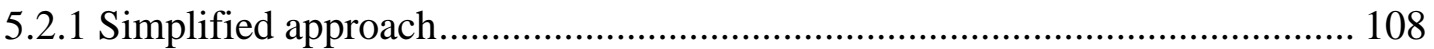

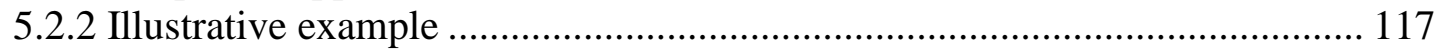

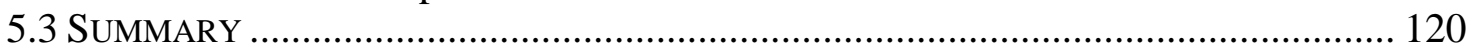

CHAPTER 6 DURABILITY OF UHPC REPAIR OF MARIN SUBSTRUCTURE .... 121

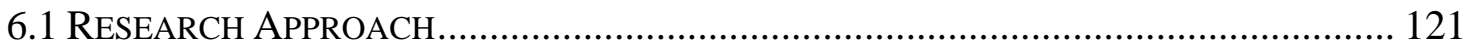

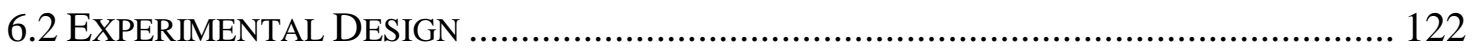

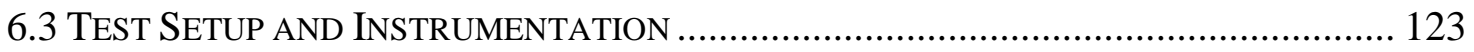

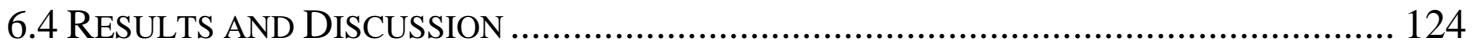

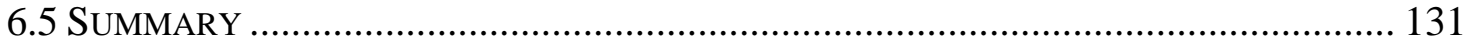

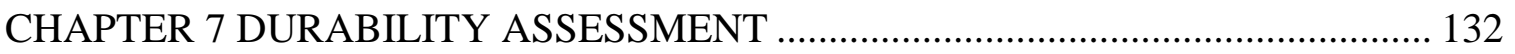

7.1 CHLORIDE DIFFUSION THROUGH UHPC SHELL ……...................................... 132

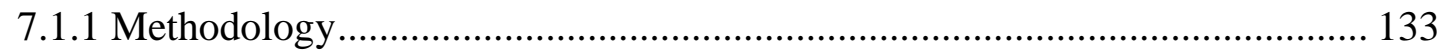

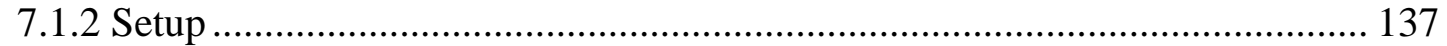

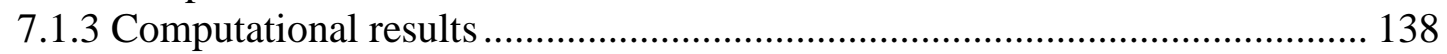

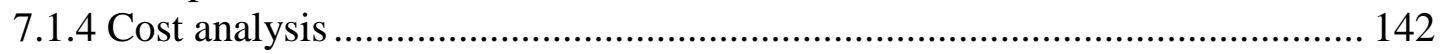

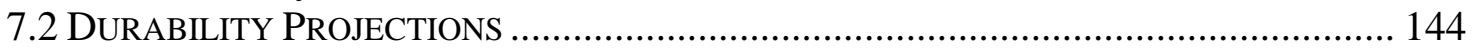

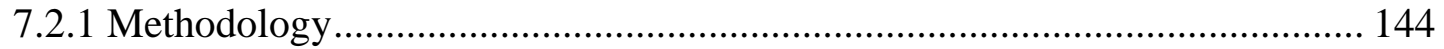

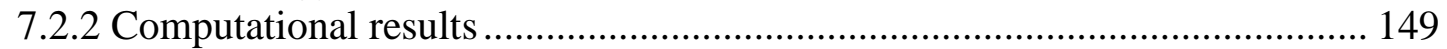

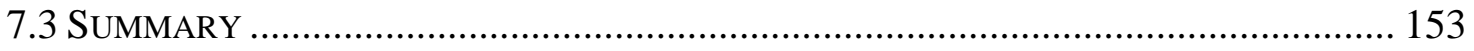

CHAPTER 8 PRELIMINARY DESIGN AND CONSTRUCTION

RECOMMENDATIONS FOR UHPC REPAIR ……………................................ 154

8.1 EVALUATION OF THE SUBSTRATE CONDITION.............................................. 154

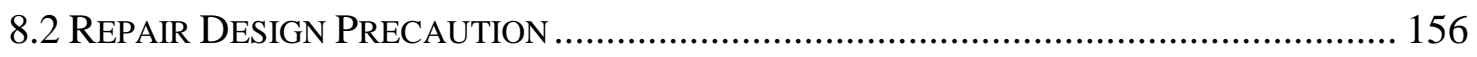

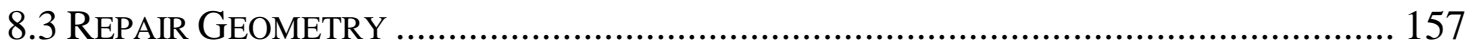

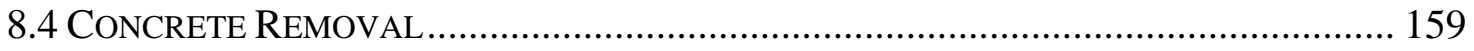

8.4.1 Precautions prior to concrete removal .......................................................... 159 


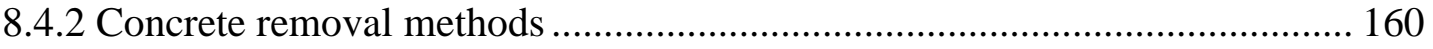

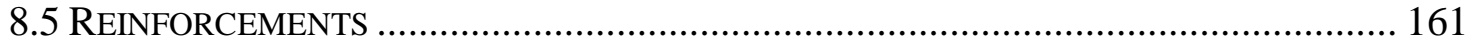

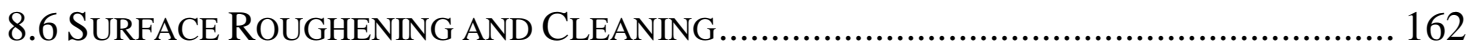

8.7 PRotecting THE PREPAREd AREA .................................................................... 163

8.8 Moisture Conditioning OF THE CONCRETE SubSTRATE .................................. 163

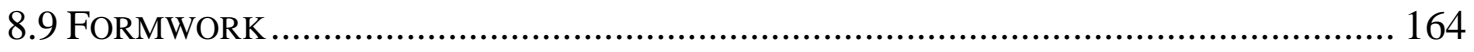

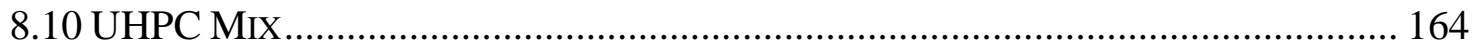

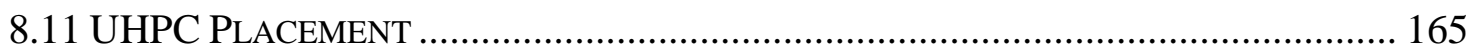

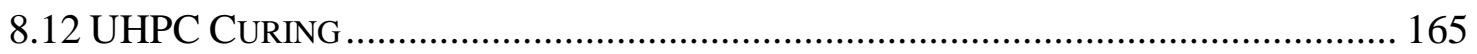

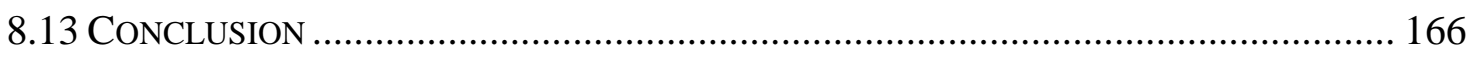

CHAPTER 9 SUMMARY OF THE FINDINGS AND FUTURE STUDY ................. 168

9.1 UltRA HIGH-PERFORMANCE CONCRETE APPLICATION FOR REPAIR....................... 168

9.2 MATERIAL PROPERTIES OF UHPC AS A REPAIR MATERIAL .................................. 169

9.3 BOND STRENGTH AND DURABILITY BETWEEN UHPC AND SUBSTRATE ................ 170

9.4 MECHANICAL PERFORMANCE OF UHPC REPAIRED COLUMNS............................. 171

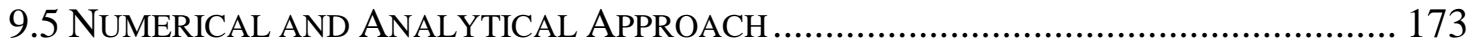

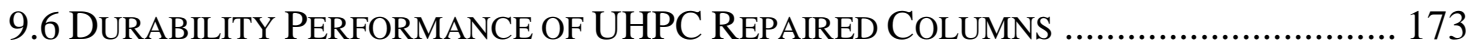

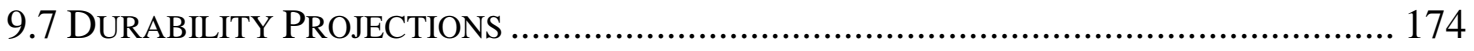

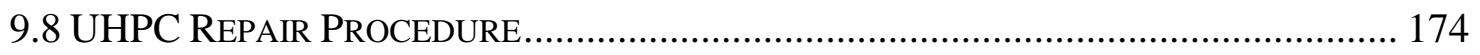

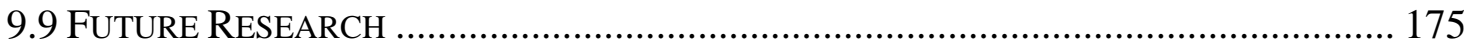

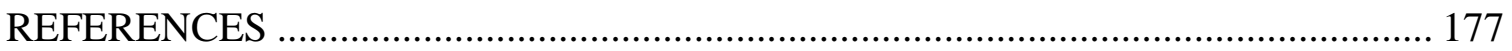

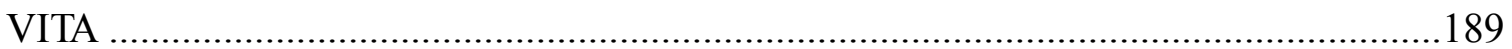




\section{LIST OF TABLES}

TABLE

PAGE

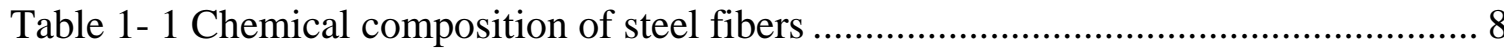

Table 1- 2 Summary of existing research on bond behavior of rebar in UHPC.............. 17

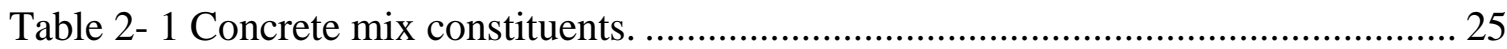

Table 2- 2 Compressive cylinder test results. ........................................................... 28

Table 2- 3 Dimension of the small samples.......................................................... 34

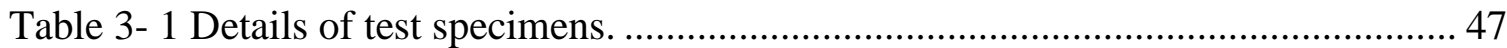

Table 3- 2 Quantitative bond quality in term of bond strength.................................... 58

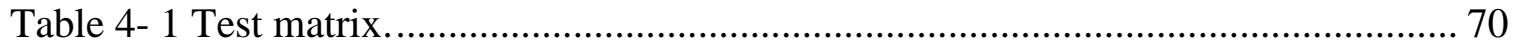

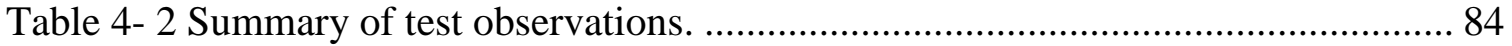

Table 5- 1 Experimental vs. analytical ................................................................ 105

Table 5- 2 Basic dimensions and reinforcement of prototypes................................. 105

Table 5- 3 Results of simplified method vs. MATLAB program................................ 118

Table 6- 1 OCP (mVCSE) ............................................................................. 125

Table 7- 1 Calculated service life by UHPC and NSC protective layers....................... 140

Table 7- 2 Calculated service life of UHPC and NSC repaired piers with varying $\mathrm{L}_{3} \ldots 142$

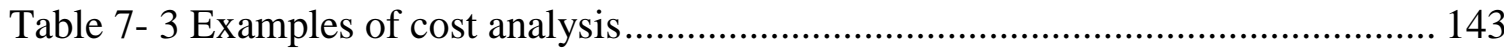

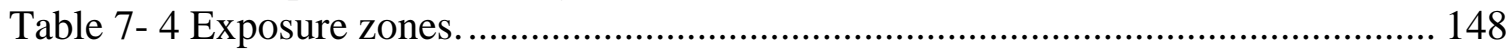

Table 7- 5.Concrete and environmental conditions ................................................. 148 


\section{LIST OF FIGURES}

Figure 1- 1 Influencing factors on the durability of concrete repairs ............................... 4

Figure 1- 2 Typical UHPC Ductal composition ………….......................................... 8

Figure 1- 3 Stress distribution assumption of previously suggested methods................. 13

Figure 1- 4 Outline of the Report.............................................................................. 22

Figure 2- 1 Mix design and proportion of UHPC used in this research. ......................... 24

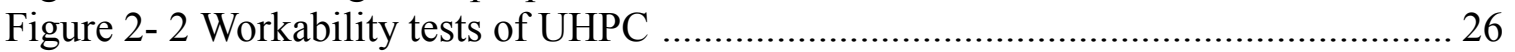

Figure 2- 3 The stress-strain curve based on cylinder test of the specimens .................... 29

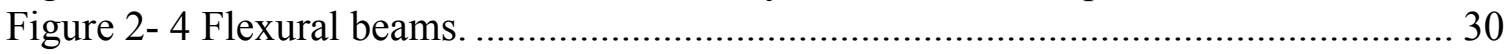

Figure 2- 5 Load-displacement curve for beam test of the specimens ............................. 31

Figure 2- 6 Briquette samples before test ................................................................. 33

Figure 2- 7 Stress-displacement curves of the briquette specimens ............................... 33

Figure 2- 8 Setup of four-point bulk resistivity test..................................................... 36

Figure 2- 9 Bulk resistivity for UHPC and NSC in moisture exposure environments.... 36

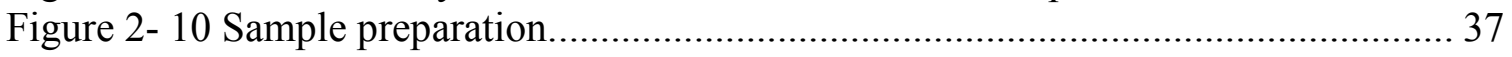

Figure 2- 11 Examples of curve fitting procedure on cathodic polarization scans........... 39

Figure 2- 12 Oxygen diffusivity of NSC and UHPC moisture exposure environments... 40

Figure 2- 13 Sample preparation............................................................................ 40

Figure 2- 14 Internal relative humidity and temperature of UHPC and NSC in moisture

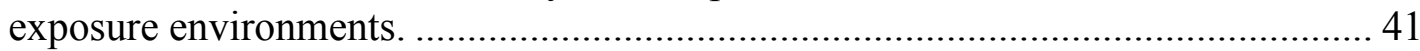

Figure 2- 15 Mass change for UHPC and NSC in moisture exposure environments....... 42

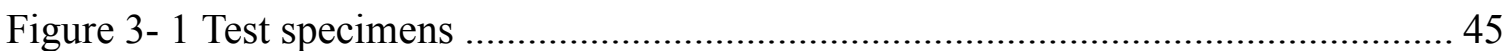

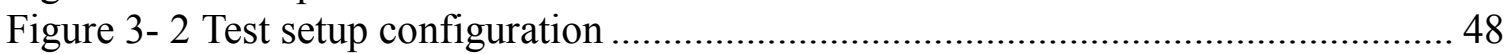

Figure 3- 3 Failure mode observed through third-point flexural test............................... 49

Figure 3- 4 Ultimate flexural strength of composite NSC and UHPC beams. ................. 49

Figure 3- 5 Percent reduction of flexural strength of NSC and UHPC composite

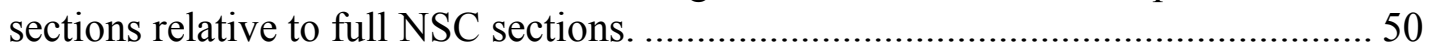

Figure 3- 6 Failure mode observed through direct shear test........................................... 51

Figure 3- 7 Ultimate shear strength of composite NSC and UHPC prisms..................... 52

Figure 3- 8 Percent reduction of flexural strength of NSC and UHPC composite

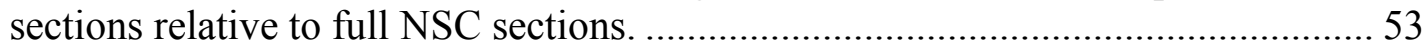

Figure 3- 9 Failure modes observed through slant shear test......................................... 54

Figure 3-10 Ultimate applied stress on composite NSC and UHPC cylinders................ 55

Figure 3- 11 The process of sample preparation.......................................................... 56

Figure 3-12 Split tensile strength (T) for each humidity exposures. ………….............. 57

Figure 3-13 Failure modes of the samples at each exposure condition........................... 59

Figure 3-14 Experimental setup for accelerated chloride migration test......................... 61

Figure 3-15 Cumulative charge passed through specimens at each different exposure. . 63

Figure 3-16 Chloride penetration depth for each sample................................................ 65

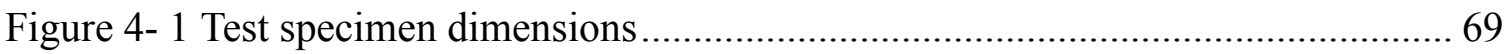


Figure 4- 2 The construction process of a typical specimen..................................... 71

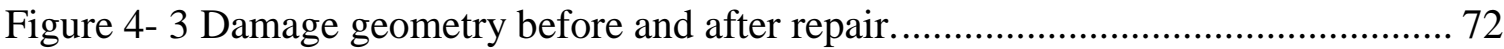

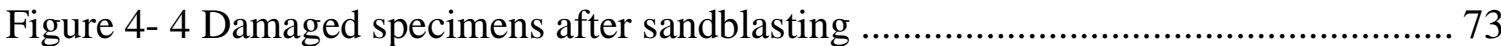

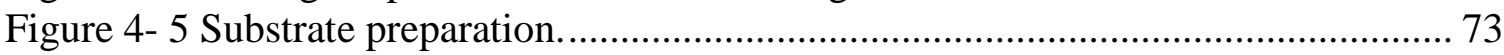

Figure 4- 6 Different forming used in this study to place UHPC. ................................ 74

Figure 4- 7 Test setup, and the experimental definition of first yield displacement. ...... 75

Figure 4- 8 Test specimen at the end of each loading cycle (Unit 1). ........................... 77

Figure 4- 9 Test specimen at the end of each loading cycle (Unit 2). ............................. 77

Figure 4- 10 Test specimen at the end of each loading cycle (Unit 3). .......................... 78

Figure 4- 11 Test specimen at the end of each loading cycle (Unit 4). .......................... 79

Figure 4- 12 Test specimen at the end of each loading cycle (Unit 5). .......................... 79

Figure 4- 13 Test specimen at the end of each loading cycle (Unit 6). .......................... 80

Figure 4-14 Test specimen at the end of each loading cycle (Unit 7). .......................... 80

Figure 4- 15 Test specimen at the end of each loading cycle (Unit 8). ......................... 81

Figure 4- 16 Test specimen at the end of each loading cycle (Unit 9). ......................... 81

Figure 4- 17 Test specimen at the end of each loading cycle (Unit 10). ........................ 82

Figure 4- 18 Test specimen at the end of each loading cycle (Unit 11). ........................ 83

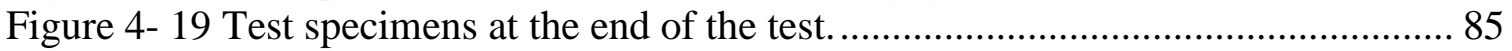

Figure 4- 20 Force-displacement, and moment-displacement hysteretic responses

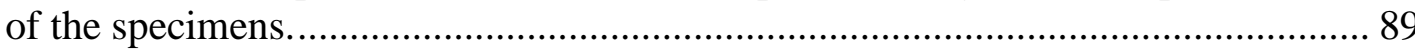

Figure 4- 21 Moment-displacement hysteretic responses of Unit 1 through $11 \ldots \ldots \ldots . . . . .90$

Figure 4- 22 Curvatures measured along the columns Unit 1 through Unit $11 \ldots \ldots \ldots \ldots . . . .93$

Figure 4- 23 Strain measured along the columns Unit 8 through Unit 11...................... 94

Figure 4- 24 Stiffness of the specimens during the test.............................................. 94

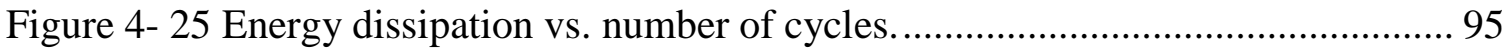

Figure 5- 1 Mander's concrete stress-strain model.................................................... 99

Figure 5- 2 Design stress-strain behavior of UHPC. ................................................ 101

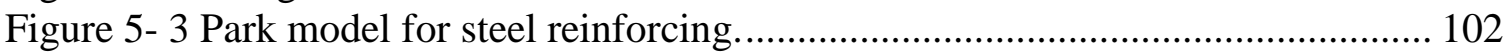

Figure 5- 4 Moment Curvature Curve. ...................................................................... 102

Figure 5- 5 Comparison of the measured and calculated force-displacement response envelopes of the column-foundation systems. ................................................ 104

Figure 5- 6 Trend lines of the increased moment capacity of the prototype column sections repaired with UHPC shell under various axial load level....................... 106

Figure 5- 7 Diagrams for analysis of circular cross-section with UHPC repair. ............ 108

Figure 5- 8 Diagrams for calculation of compressive force in substrate concrete.......... 109

Figure 5- 9 Computation of the area of a circular segment. ....................................... 109

Figure 5- 10 Diagrams for calculation of compressive and tensile force of UHPC

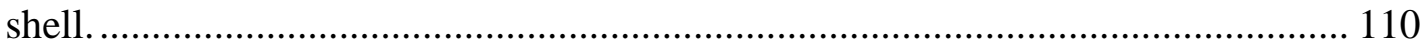

Figure 5- 11 Computation of the area of the UHPC shell. ........................................ 111

Figure 5-12 Diagrams for calculation of compressive and tensile force of equivalent steel ring

Figure 5- 13 Diagrams for analysis of circular cross-section with UHPC repair (rectangular stress distribution for UHPC in compression). 


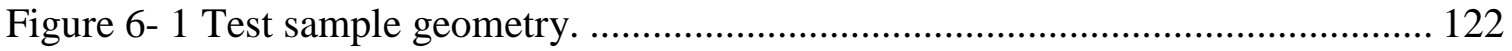

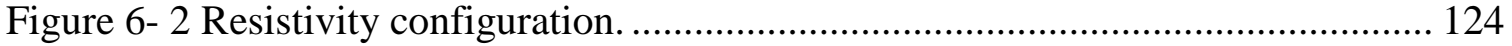

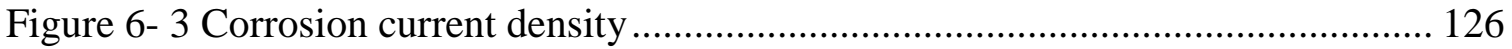

Figure 6- 4 Macrocell current of steel rebar embedded in repair and substrate concrete 127

Figure 6- 5 Effect of cathode-to-anode (c/a) ratio for rebar embedded in UHPC or NSC

repair concrete with vestigial chlorides in substrate concrete in wet condition. .... 128

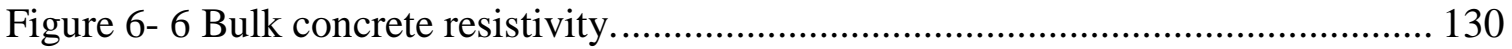

Figure 7- 1 Problem concept................................................................................. 134

Figure 7- 2. Calculated $t_{\text {critical }}$ for pier with no protective layer ................................... 138

Figure 7- $3 t_{\text {critical }}$ vs. the thickness of protective layer............................................... 139

Figure 7- 4 Extended service life for full cover repair with UHPC or NSC................. 141

Figure 7- 5 Output results for hypothetical cases with varying repair thickness

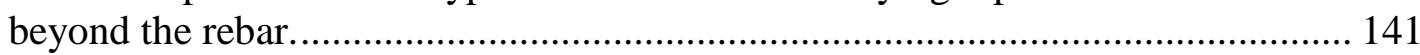

Figure 7- 6 Macrocell current densities ................................................................. 146

Figure 7- 7 Calculation approach to compare repair service time............................... 147

Figure 7- 8 Calculation approach to assess repair application..................................... 148

Figure 7-9 Calculation results for repair service time. ......................................... 150

Figure 7-10 Compile graph of calculations for repair service time ............................ 151

Figure 7- 11 Output results for conjectural cases. ................................................ 152

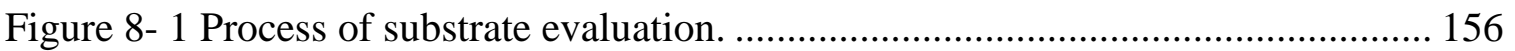

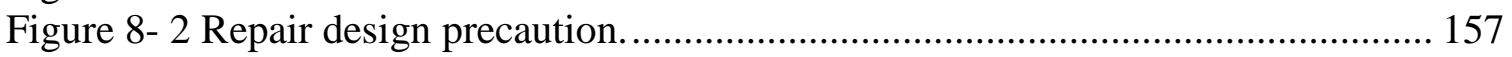

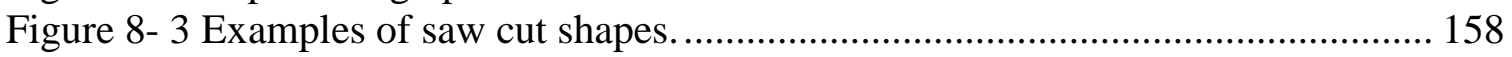

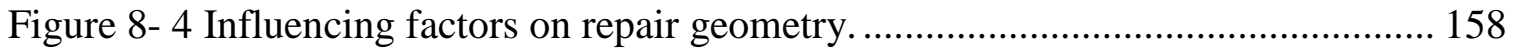

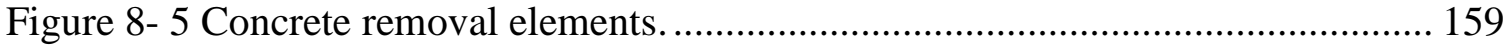

Figure 8- 6 Concrete removal precautions................................................................ 160

Figure 8- 7 Preparation of reinforcements prior to repair patch placement.................... 162

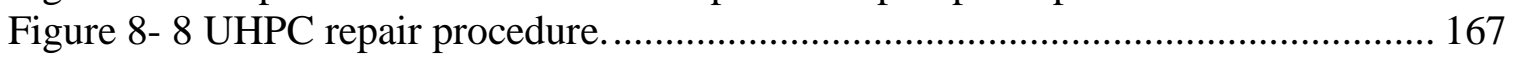

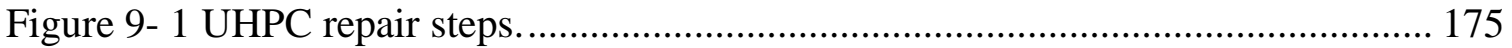




\section{CHAPTER 1 INTRODUCTION}

One of the great challenges for the American Association of State Highway Transportation Officials (AASHTO) and many state Departments of Transportation (DOTs) is the degradation and maintenance costs of infrastructure. Due to the statistics reported by the American Society of Civil Engineers in 2017, $30 \%$ of United States bridges $(166,000$ of 615,000$)$, were classified as structurally and functionally outdated, majorly due to material deterioration [1]. As a result, the US spends over a billion dollar annually on bridge maintenance and damage control that is mainly a result of chloride attack on substructure elements [2]. Such undesired phenomenon requires the development of new techniques and materials to restore the deficient structure in a timely manner. The rehabilitation process should increase the service level and achieve a longer life expectancy of the structure.

\subsection{TYPICAL DEfiCIENCIES OF CONCRETE BRIDGES}

Environmental actions and poor maintenance will accelerate the degradation of reinforced concrete $(\mathrm{RC})$ over time. Such actions can be categorized as chemical, physical and biological degradation mechanisms:

- $\quad$ Chemical-related degradations could be due to concrete carbonation, bar corrosion, salt actions, alkali-silica reaction, etc.

- $\quad$ Physical-related degradations are usually due to water penetration, freezethaw cycles, environmental vibrations, and thermal variations. 
- Biological-related degradations are due to the accumulation of soil, debris, etc., along with biological organisms' activity.

Corrosion of RC infrastructures poses a drastic danger to marine constructs especially. Wave impacts, wet-dry cycling, and high concentrations of chlorides result in the accelerated deterioration of marine concrete substructure, often commencing with the rusting of reinforcing steel. This mechanism is principally due to steel depassivation by chloride ions (or carbonation of the concrete pore water by carbon dioxide at higher and dryer elevations). In the absence of such aggressive chemical compounds, alkaline concrete generates a film of iron oxides on the steel surface that protects it from corrosion [3], [4]. $\mathrm{RC}$ in marine environments, especially in marine tidal regions, is susceptible to an influx of chloride to cover depth of steel reinforcing bars and subsequent corrosion initiation. Ongoing electrochemical reactions after corrosion initiation, leading to the accumulation of expansive iron corrosion that generates tensile stress in surrounding concrete of corroding steel reinforcement. As a result, concrete will crack and spall, exacerbates the progressive damage, affecting the durability of the structure.

\subsection{REVIEW OF EXISTING REPAIRS METHODS}

A retrofitting process indirectly supports the structure to maintain the global sustainability under service load and to guarantee the safety comforting to the current standards. Live-load bridge capacity is one of the main factors that should be restored based on structure type and its current state.

Conventional repair strategies for restoration of structural capacity include Fiber Reinforced Polymer (FRP) wrapping and concrete jacketing [5]-[10]. [5]-[10]. FRP has 
been used to restore the mechanical strength of damaged structural elements and its low permeability characteristics provide some level of corrosion mitigation. However, difficulties associated with surface preparation and possible delamination of the FRP sheets from the concrete substrate have been reported [11], [12].

Concrete jacketing, the most conventional repair method, performs well in providing the necessary strength, stiffness, and ductility [13]-[18]. Though, it can escalate cross-sectional dimensions and structure's dead weight, which could significantly alter the dynamic characteristics of the system. Besides, restoring the structure through concrete jacketing creates concrete overlays, which induces additional stresses due to increased stiffness and results in de-bonding and new layer cracks [15], [19], [20]. Moreover, concrete piles retrofitted with repair jackets, which ideally would limit the chloride and oxygen ingress to the embedded steel, have been documented to have continued steel corrosion [21].

\subsection{CONCRETE REPAIRS}

The word "compatibility" has become common terminology in the repair industry. It mainly refers to sufficient load-carrying capacity and durability of the repaired structure. Compatibility may be defined as a balance of physical, chemical and electrochemical properties and dimensions between a repair material and substrate. It is responsible for the repair's resistance towards all volume change-related stresses applied. It also suggests that the infrastructure will not be affected by chemical and electrochemically involved deterioration [22]. For instance, if substrate concrete has been deteriorated due to aggressive exposure to the environment, a repair material with higher strength and more 
chemical resistance might be more efficient; though in the cases of rapid setting, hardening, and early strength gain, special repair materials with high early heat of reaction, might be the best option.

Figure 1- 1 summarizes several considerations influencing the compatibility of repair materials [22]. One of the most important factors may be the strength of repaired area to resist volume changes without loss of bond and delamination, commonly referred to as 'dimensional compatibility'. It suggests the ability of the repaired area to carry its share of applied load without distress. Meanwhile, "chemical compatibility" involves a material selection such that they don't employ any conflicting effects on repaired components or structures. The release of chloride ions can be an example of such an adverse effect, as they may interfere with reinforcing steel in substrate concrete. Finally, in RC structures electrochemical compatibility should also be considered to avoid corrosion induced deteriorations [22], [23].

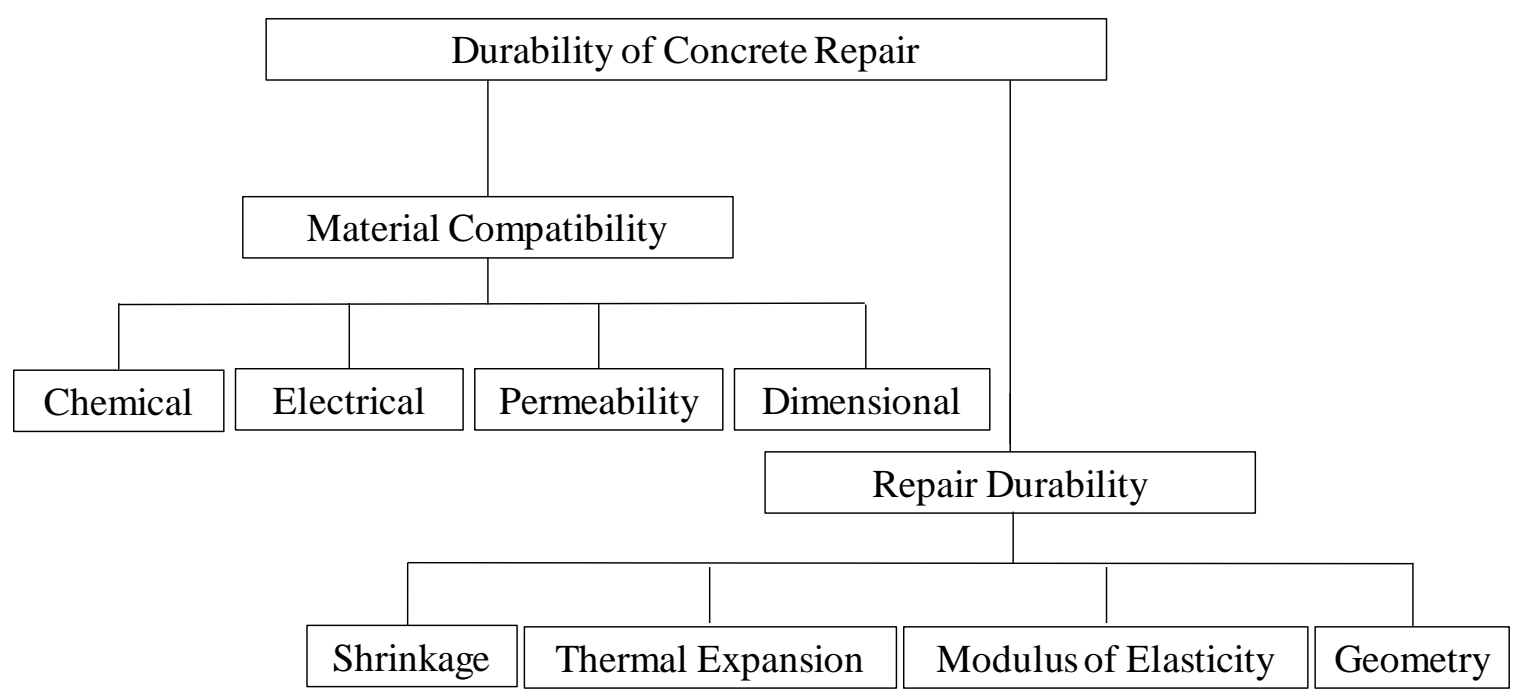

Figure 1- 1 Influencing factors on the durability of concrete repairs [22]. 
A durable repair material is highly essential in the durability of concrete repair. Such a choice would constitute a volumetrically stable option with elasticity and thermal expansion modules as close to the original concrete as possible. Despite the best efforts to produce such material, choosing the best option seems to be an arduous task. Hence, the best choice is to repair with materials having a proper modulus of elasticity and adequately low volume change capacity. The inclusion of fibers (steel and synthetic) is favored for minimization of cracking and many repair materials now incorporate fibers.

The other critical aspects of the compatibility between substrate and repair material is a lasting and sufficient bond. Repair-to-Substrate bond is known to be influenced by a variety of factors including substrate surface condition, compaction method, curing process, mechanical properties of the material, use of bonding agents, and the age of the chemical bonds [24]-[26]. The hardening of the added mixture inside the open cavities of the substrate surface, and the physical anchorage resulting from it is responsible for the mechanical adhesion in such composite members [26]. Capillary absorption significantly contributes to the anchorage as it pulls repair paste into cavities of the substrate. The amount of paste towed into the surface depend on the size of the cavities and the moisture condition of the existing surface [26].

Consistency, compaction method and other stated properties of the repair material have a substantial effect on mechanical anchorage and bond strength. Bond strength also relies on the cohesion of the repair material, which is directed to its binder strength (cement, fly ash, etc.), its mineralogical components, and curing condition [26]. 


\subsection{Proposed Retrofit Solution}

Innovative rehabilitation designs for bridges are required to reduce the cost of corrosion damage retrofit. Such techniques must be durable, structurally effective and easy to implement while minimizing interruptions to traffic and increasing work zone safety.

Accelerated Bridge Construction (ABC), a newly embraced construction philosophy, is a paradigm shift in bridge delivery method that includes planning, design, construction, and maintenance. Ultra-High-Performance Concrete (UHPC) has been widely considered for $\mathrm{ABC}$ application due to its enhanced mechanical properties and durability [27]-[29] and make it a material of interest for structural rehabilitation of concrete structures. Use of UHPC can potentially result in both technical and economic advantages, including decreased reinforcement corrosion activity and an increase in service life. Because it is becoming more common to apply UHPC for rehabilitation, improved protection against corrosion would serve as a complimentary benefit of this treatment [30].

An $\mathrm{ABC}$ concept to enhance the mechanical strength of axially loaded substructural reinforced concrete elements is proposed. The retrofit methodology comprises of replacement of existing surface concrete and shell encapsulation with UHPC. Importantly, this retrofit concept is more pertinent to RC substructure elements subjected to corrosion damage. Therefore, the corrosion durability considerations for this retrofit methodology, which may have possible steel augmentation and possible corrosion macrocell development of existing steel rebar in the dissimilar concrete, should be made. 


\subsection{Ultra High-Performance Concrete as a Repair Material}

UHPC is known as a cementitious material developed with an optimized gradation of granular constituents, a water-to-cementitious material ratio less than 0.2 , and a high percentage of internal fiber reinforcement. The water content is very low for UHPC [31]. One benefit for it is that it can achieve the required rheological properties through a mix of granular packing and high-range water reducing admixtures. The resulting product is concrete with improved strength, ductility, and workability, as well as self-consolidating properties, and durability relative to normal or even high-performance concrete [32], [33]. Furthermore, UHPC can rapidly gain strength, approximately $10 \mathrm{ksi}$ (68 MPa ) after five days of ambient air curing [34], [35], which is ideal to improve the speed of construction. Adding silica fume as an ultra-fine aggregate is mainly responsible for UHPC's characteristics. The dense microstructural properties of this material provide a durable cementitious material with remarkably low permeability.

These characteristics make UHPC a smart choice as a repair material for retrofitting the damaged body of marine piles, and application of UHPC could provide an efficient solution to address the pressing issue of bridge rehabilitation [36]. Currently, Ductal, a product by Lafarge is the only commercially available UHPC in North America. In this study, this concrete is independently evaluated as a repair material for bridge elements under a combination of axial load and lateral loads. A typical composition of this material is presented in Figure 1-2. 


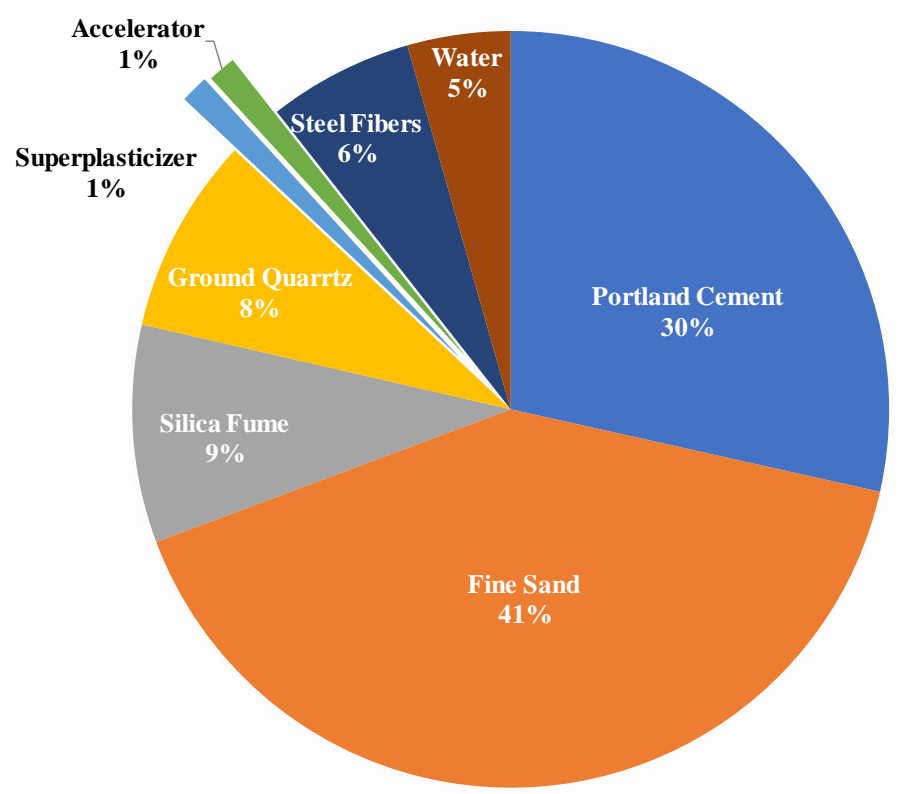

Figure 1- 2 Typical UHPC Ductal composition [27].

Steel fibers make up the largest portion of the mix, from a dimension point of view. Here, our fibers were distinguished with a diameter of $0.008 \mathrm{in} .(0.2 \mathrm{~mm})$ and a length of $0.5 \mathrm{in} .(12.7 \mathrm{~mm})$. The chemical composition of fibers is shown in Table 1- 1. Fibers have a very high tensile strength, greater than $377 \mathrm{ksi}(2,600 \mathrm{MPa})$.

Fine sand, defined as particles with a diameter between 0.006 and 0.02 in. (150 and $600 \mu \mathrm{m})$, is dimensionally the largest granular material. Cement makes the second large granular particle with an average diameter of 0.0006 in. $(15 \mu \mathrm{m})$. The smallest particle is silica fume, which due to its size it'll fill the interstitial voids between the cement and the crushed quartz particles.

Table 1- 1 Chemical composition of steel fibers [27].

\begin{tabular}{cc}
\hline Element & Composition $(\%)$ \\
\hline Carbon & $0.69-0.76$ \\
Silicon & $0.15-0.30$ \\
Manganese & $0.46-0.60$ \\
Phosphorus & $\leq 0.025$ \\
Sulfur & $\leq 0.025$ \\
Chromium & $\leq 0.08$ \\
Aluminum & $\leq 0.03$ \\
\hline
\end{tabular}




\subsubsection{Setting time and flow}

Fine aggregate and water admixture contents, and fiber geometry can affect the followability of UHPC. A study has been done by FHWA on six different material developed commercially as "UHPC-class" material [31]. This report indicates that these materials had an initial setting time between 4 and 9 hours, and the final setting time was between 7 and 24 hours. The thixotropic formulation of UHPC permits placement on bridge decks with up to $10 \%$ slope [37]. Static flow measurements of this material ranged between 4 and $10 \mathrm{in.}$

\subsubsection{Shrinkage and creep of UHPC}

The mix design of UHPC includes large quantities of active and passive powders such as cement, silica fume, fillers, and other micro fillers. These components have an influence on shrinkage and creep, which are deformations that include a time variable in their values.

Early-age shrinkage of UHPC can be divided into three parts: chemical shrinkage (due to the chemical reactions), autogenous shrinkage caused by self-drying (hydration), and drying shrinkage (evaporation) caused by external drying [38]. In critical low water/cement ratios, the remaining water is taken up for hydration and dryness of cement creates new capillaries. High surface tension within these capillaries leads to autogenous shrinkage and finally, cracking. UHPC which has very low water to cement ratio is more prone to develop autogenous shrinkage [31]. Additionally, UHPC materials are designed to have large contents of very fine and reactive cementitious materials, which increase the chemical shrinkage of the system. On the other hand, the lower the w/c of a cementitious 
system, the smaller capillary pores will form in the cement matrix and lower drying shrinkage. This may explain why UHPC materials do not show considerable higher shrinkage with respect to their autogenous shrinkage. It is an essential factor to consider that a large amount of fiber reinforcement can prevent forming shrinkage cracking [31]. In accordance with ASTM C157 [39], the ultimate shrinkage of UHPC, depending on the method of steam curing, was reported to a range from 620 to $766 \mu$ s, and for untreated specimens $555 \mu$ s [34]. The initial shrinkage rate of UHPC was also reported to be $64 \mu$ s /hour. Approximately $400 \mu$ s of shrinkage was measured in the first 24 hours for untreated specimens and any residual shrinkage was taken care of by steam curing [29], [34] [40] [41].

FHWA tested six different commercially UHPC material and reported that the shrinkage of different UHPC was varied from $294 \mu$ s to $1262 \mu \mathrm{s}$ [31]. They indicated that UHPCs commonly exhibit proportionally more autogenous shrinkage than conventional concretes, particularly at early ages (before 24 hours).

As has been stated in a study by Acker [42], creep and shrinkage are related behaviors that cannot be considered separately. He pointed out that shrinkage is initiated by self-desiccation of the concrete binder causing the irreversible failure of calciumsilicate-hydrate $(\mathrm{CSH})$ sheets. Furthermore, he indicated that concrete creep is more noticeable when it occurs while the concrete is dehydrating [42]. Consequently, the failed CSH microstructure and low water content of the mix work to diminish UHPC creep [43]. 


\subsubsection{Freeze-thaw resistance}

UHPC has been tested for deterioration, starting 5-6 weeks after casting and very little degradation has been observed through 690 cycles of freeze-thaw [44]-[47].

Another study conducted by Magureanu et al. [48] compared the values of compressive strength, static modulus of elasticity, and dynamic modulus of elasticity after 1,098 freeze-thaw cycles between UHPC and control specimens. Their results suggested much higher values for each of the properties, which all are of great importance in the design of repair material. Müller et al. [49] also concluded that UHPC mixes have an enormously high freeze-thaw resistance to water despite the presence of deicing salts that may attribute to its very low moisture content.

\subsubsection{Flexural design}

There are some analytical solutions that can be used to calculate the flexural capacity of UHPC beams [50]-[54]. These analyses use internal stresses based on the stress-strain distribution to estimate the moment capacity. In the following are the used notations defined as:

\footnotetext{
$a \quad$ depth of a rectangular stress block

$A_{s} \quad$ area of steel rebar in tension

$b \quad$ width of the beam

c depth to the neutral axis

$d \quad$ depth from extreme compressive fiber to centroid of rebar steel

$d_{f} \quad$ diameter of the fibers

$E_{f s} \quad$ modulus of elasticity of fibers

$E_{U H P C}$ modulus of elasticity of UHPC

$f_{c} \quad$ compression strength of UHPC

$f_{t} \quad$ tensile stress of UHPC

$f_{y} \quad$ yield strength of steel rebar

$h \quad$ height of the beam

$l_{f} \quad$ length of fibers

$\rho_{s} \quad$ rebar percentage

$\sigma_{f y} \quad$ fiber yielding stress

$\tau_{f} \quad$ fiber-concrete bond strength

$\beta_{1} \quad$ stress block parameter
} 
An approach to calculating the moment capacity of a UHPC section can be the same as normal strength concrete considering its compressive strength and ignoring its tensile strength. In this approach, UHPC stresses in compression can be represented by an equivalent rectangular stress block which is proposed for high strength concrete. This procedure can be adopted from equations related to moment capacity of normal concrete beams suggested by ACI 318 [55]. This code provides minimum requirements for the material, analysis, design, and detailing of normal concrete.

$$
\begin{array}{ll}
M_{n}=A_{s} f_{y}\left(d-\frac{a}{2}\right) & \text { Equation 1- } 1
\end{array}
$$

Another approach can be adopted from ACI 544 [56] which is an available standard of fiber reinforced concrete. In this method, the tensile stress of concrete is assumed to be uniformly distributed over an area with a height of $\left(h_{e}\right)$. The distance from the extreme compression line to the top of the uniform tensile block (e) is calculated by the equations (Equation 1- 2 to Equation 1-7). The depth of the neutral axis (c) is calculated by the equilibrium equation of the section. The coefficient $\beta_{1}$ is equal to 0.65 for concrete strengths of more than $8 \mathrm{ksi}$. Based on the literature, $\tau_{\mathrm{f}}$ can be taken as $0.6 \mathrm{ksi}$ [57]-[59] for fiber-reinforcement concrete.

According to this code, the flexural capacity of a Steel Fiber Reinforced Concrete (SFRC) section with a rectangular $\mathrm{h} \times \mathrm{b}$ cross-section is calculated by the following equation:

$$
\begin{aligned}
& M_{n}=A_{s} f_{y}\left(d-\frac{a}{2}\right)+f_{t} b(h-e)\left(\frac{h+e-a}{2}\right) \\
& \mathrm{c}=\frac{A_{s} f_{y}+f_{t} h}{f_{t} \frac{\varepsilon_{f}+0.003}{0.003}+0.85 \beta_{1} f_{c}}
\end{aligned}
$$$$
\text { Equation 1-2 }
$$$$
\text { Equation 1- } 3
$$ 


$$
\begin{aligned}
& e=\frac{\varepsilon_{f}+0.003}{0.003} c \\
& a=\beta_{1} c \\
& \sigma_{f s}=2 \tau_{f}\left(\frac{l_{f}}{d_{f}}\right) \leq \sigma_{f y} \\
& \varepsilon_{f}=\frac{\sigma_{f s}}{E_{f s}}
\end{aligned}
$$

Equation 1- 4

Equation 1- 5

Equation 1- 6

Equation 1- 7

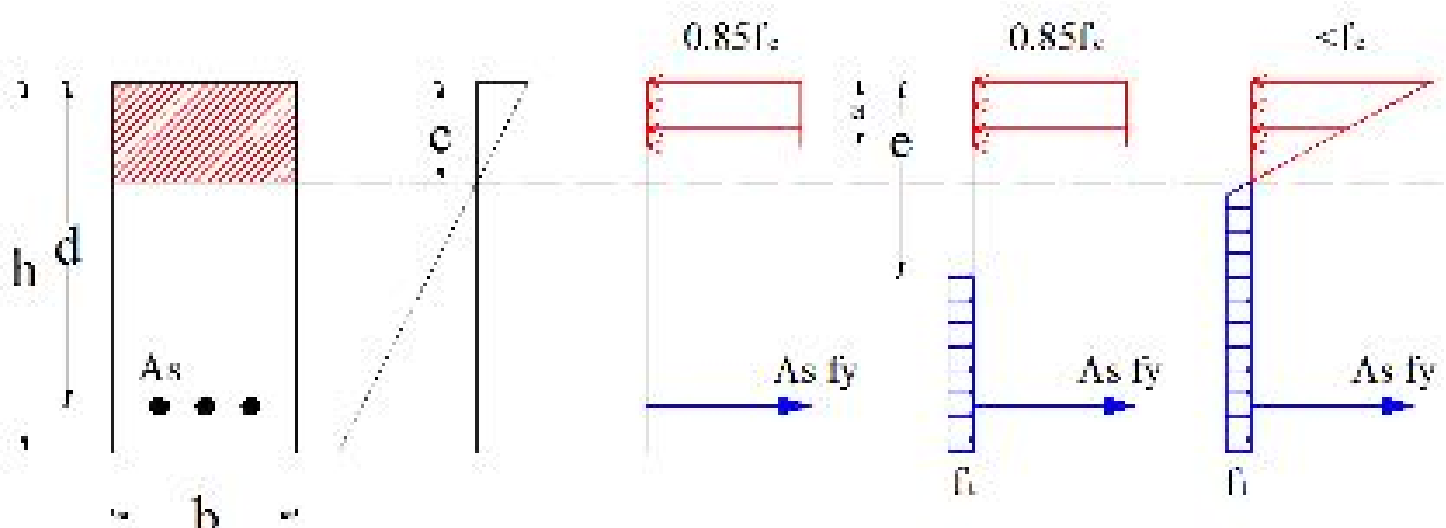

Strain distribution b) ACI 318[55] c) ACI 544 [56] d) FHWA [50]

Figure 1- 3 Stress distribution assumption of previously suggested methods.

Another method of calculating the flexural capacity of rectangular UHPC beams is based on one of the Federal Highway Administration (FHWA) reports [50]. In this model, using the equilibrium equation and strain compatibility, the moment capacity of a UHPC beam is estimated when either the extreme compression or tension strain reaches its limiting value. In this method, when the tension limit state controls, the following equation can be used for estimating the moment capacity of the section.

$$
\begin{aligned}
& M_{n}=A_{s} f_{y}\left(d-\frac{c}{3}\right)+f_{t} b(h-c)\left(\frac{3 h-c}{6}\right) \\
& c=\left(\frac{\rho_{s f_{y}+f_{t}}}{f_{t}+0.0035 E_{U H P C}\left(\frac{c}{h-c}\right)}\right)
\end{aligned}
$$


Note that estimating the neutral axis depth can be done by solving a quadratic equation or by an iterative process. To estimate the modulus of elasticity of UHPC some other equations are provided by previous studies [27], [54], [60].

$$
\begin{array}{lll}
E_{U H P C}=50000 \sqrt{f_{c}}(p s i)=4200 \sqrt{f_{c}}(M P a) & (\text { Sritharan }) & \text { Equation 1- 10 } \\
E_{U H P C}=46200 \sqrt{f_{c}}(p s i)=3840 \sqrt{f_{c}}(M P a) & (\text { Graybeal }) & \text { Equation 1- 11 } \\
E_{U H P C}=260000 \sqrt[3]{f_{c}}(p s i)=9500 \sqrt[3]{f_{c}}(M P a) & (\text { AFGC 2013) } & \text { Equation 1- 12 }
\end{array}
$$

\subsubsection{Shear in UHPC}

Use of UHPC increases the shear capacity and may cause total or partial elimination of conventional transverse steel reinforcement. Parra-Montesinos recommended the use of deformed steel fibers as an alternate option to conventional minimum shear reinforcement [61].

A design manual is presented by the Association Française de Génie Civil (AFGC) Interim Recommendations for Ultra High-Performance Fiber-Reinforced Concretes (2002), where they describe the effects of fiber reinforcement to shear capacity [54]. In this provision, the ultimate shear strength of the cross-section is made up of three parts, concrete, fibers and transverse steel reinforcement.

The effect of concrete on shear capacity, $V c$, is defined by Equation 1- 13, where $\gamma_{\mathrm{E}}$ and $\gamma_{\mathrm{b}}$ are safety factors, compressive strength is $f_{c}{ }^{\prime}, b_{0}$ is the web width, and $z$ is the lever arm at the ultimate moment.

$$
V_{c}=\frac{0.24}{\gamma_{E} \gamma_{b}} \sqrt{f_{c}^{\prime}} b_{0} Z
$$

The lever arm is defined as the distance from the center of the compression block to the center of tension reinforcement. All measurements are in SI units. AFGC suggested 
Equation 1- 14 for the fiber portion $\left(V_{f},\right)$. In this equation, $S$ is the area of the shear plane which is $90 \%$ of the web width multiplied by the depth to the centroid of tension reinforcement. $\sigma_{p}$ is the average tensile stress carried by the fibers which can be assumed as $1 \mathrm{ksi}$ for UHPC with $2 \%$ of fiber [62]. The variable $\gamma_{b f}$ is a factor of safety.

$$
V_{f}=\frac{S \sigma_{p}}{\gamma_{b f} \tan 40}
$$

Equation 1- 14

Graybeal validated the abovementioned equations with several tests exploring the shear capacity of UHPC beams [62]. He tested several prestressed UHPC girders and focused on the shear capacity and found that although this method is more reliable than other suggested equations for UHPC shear capacity analysis, it still underestimates such value for UHPC sections.

\subsubsection{Punching shear}

To estimate the punching shear of UHPC slabs, Harris and Roberts-Wollmann [63] suggested the following equation based on the work by Fuchs et al [64].

$$
P_{N}=k_{1} f_{t} \frac{(3 h+c)^{2}-c^{2}}{\sqrt{h}}
$$

In this equation, $\mathrm{f}_{\mathrm{t}}$ is the split cylinder tensile strength (ksi) and $\mathrm{k}_{1}$ is empirical constant which can be assumed 0.38 for UHPC. $h$ and $c$ are representing the slab thickness and loading plate width in inches. This equation was compared to the test results and a curve fitting software was used for determination of empirical constant $\mathrm{k}_{1}$.

\subsubsection{Development length of steel reinforcement in UHPC}

A comprehensive investigation was conducted by Yuan and Graybeal on the development length of reinforcing steel in UHPC [65]. They evaluated the effect of 
embedment length, concrete side cover, bar spacing, bar size, bar type and compressive strength of UHPC by testing more than 200 pullout specimens. Their study focused on a commercially available UHPC containing $2 \%$ steel fiber (by volume) and different bar sizes. They suggested $10 d_{b}$ as the minimum embedment length (where $d_{b}$ is the diameter of the bar) when the minimum side cover is more than $3 \mathrm{~d}_{\mathrm{b}}$.

Another study designed for modified pull-out and beam tests with rebar splices was conducted by Ronanki et al [66]. They evaluated the bond between UHPC and different sizes of steel reinforcement (\#4 to \#7). The embedment length and side cover for pull-out tests were varied from $6 \mathrm{db}$ to $8 \mathrm{db}$ and $1 \mathrm{db}$ to $3.5 \mathrm{db}$, respectively. Their results indicated that because of enhanced tensile mechanical properties of UHPC, bond strength was higher and development length is significantly shorter than regular concrete. Results showed that development length required for rebar in UHPC is in the order of $20-30 \%$ of that in regular concrete.

Another investigation on the tension development of UHPC was done by Zachary et al [67]. They evaluated the material properties of different commercially available UHPC and used them for connecting prefabricated bridge deck connections. They tested two types of specimens, direct tension pullout, and prefabricated bridge deck connections. Results showed that the lap-splice guidance presented by Graybeal [65] was applicable to the UHPC specimens and for the rebar size \#5 and smaller, they suggests $10 \mathrm{~d}_{\mathrm{b}}$ as the embedment length of steel reinforcement $\left(f_{y} \geq 74 \mathrm{ksi}\right)$ in UHPC when the clear cover is between 1 in. and $3 \mathrm{~d}_{\mathrm{b}}$. They also concluded that the lap splices of straight lengths of deformed steel reinforcement shall be at least 0.75 times of the embedment length. Table 1- 2 summarizes the results of the existing pullout and beam tests on bond behavior of steel 
reinforcement in UHPC considering different parameters such as UHPC compressive strength $\left(\mathrm{f}^{\prime}{ }_{\mathrm{c}}\right)$, fiber content, bar size, the loading setup, the embedment length $\left(l_{\mathrm{d}}\right)$, the side concrete cover $\left(\mathrm{C}_{\mathrm{b}}\right)$, and bar spacing $\left(\mathrm{S}_{\mathrm{b}}\right)$.

Table 1- 2 Summary of existing research on bond behavior of rebar in UHPC.

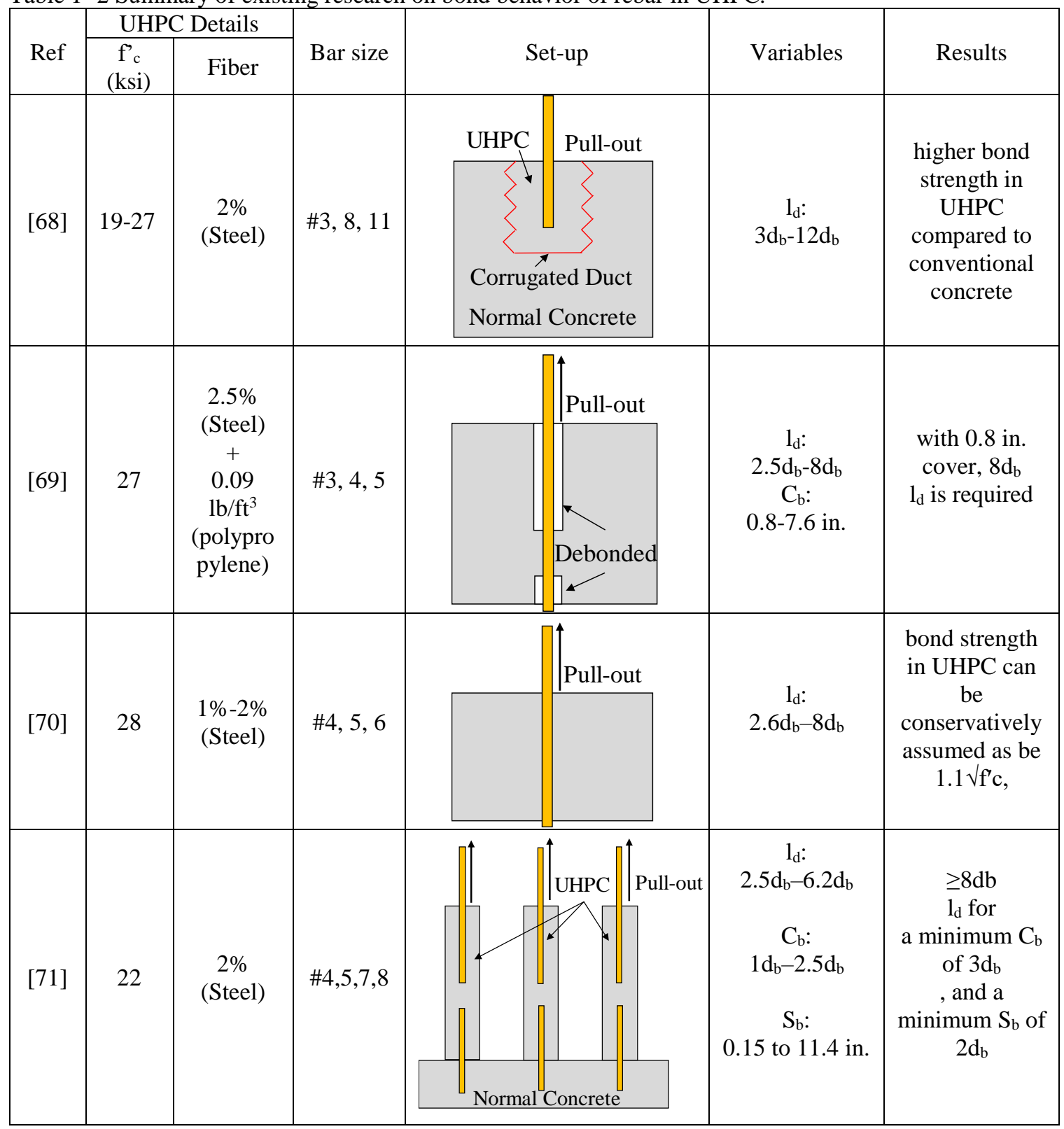




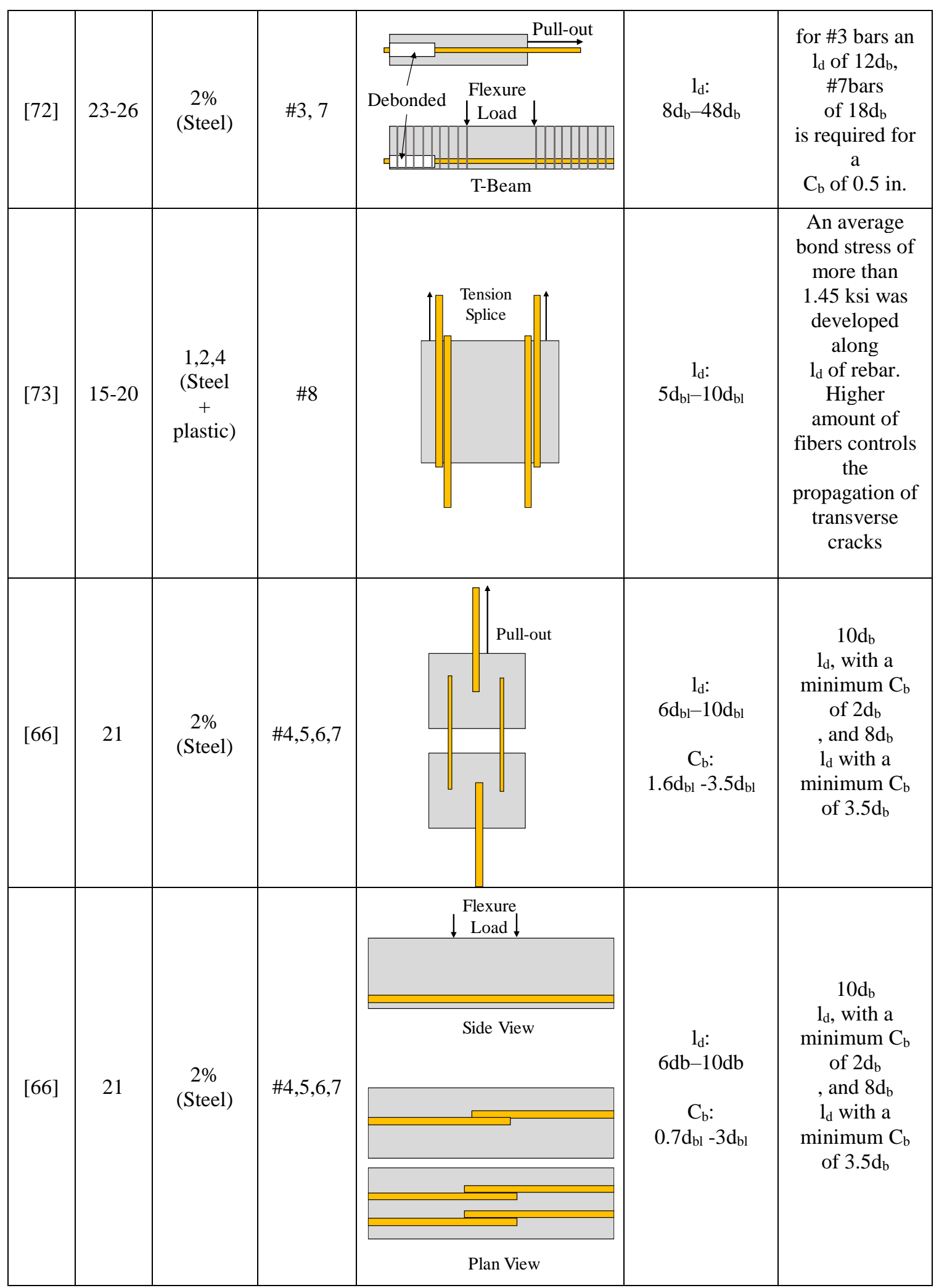




\subsubsection{UHPC to concrete bond behavior}

The distinguishing characteristics of UHPC enable its use in various applications such as toppings when applied as a repair material, joining precast elements, overlay for bridges and thermal bridge breaker [74]-[77]. UHPC is mostly cast alongside the hardened Normal Strength Concrete (NSC); therefore, the interaction between UHPC and the NSC is important in the utilization of UHPC. Also, in the structures with concrete precast elements, bonding between concrete layers could be challenging. The hardening of the added mixture inside the open cavities of the substrate surface, and the physical anchorage resulting from it is responsible for the mechanical adhesion in such composite members [26]. Capillary absorption significantly contributes to the anchorage as it pulls repair paste into cavities of the substrate. The amount of paste towed into the surface count on the size of the cavities and the moisture condition of the existing surface[26].

Concrete-to-concrete bond is known to be influenced by a variety of factors including substrate surface condition, compaction method, curing process, mechanical properties of the material, use of bonding agents, and the age of the chemical bonds [24][26]. Chorinsky [78] stated that applying unmodified cement mortar to dry concrete surface results in sucking a part of the paste water into the substrate concrete before forming reactive components in the cement paste of the fresh concrete. He [78] concluded that the newly added concrete would not adhere firmly to the substrate surface as the penetration of the reactive components into the capillary pores is blocked. He [78] also mentioned that when the fresh mortar is cast over a saturated surface, the capillary holes are shut for penetration of the cement paste hydration products; therefore, the excess water from the capillaries will increase the water-to-cement ratio at the interface layer, and the mechanical 
properties of the overlay concrete will be degraded. He eventually determined that having "a too dry or too wet surface" leads to weakening of the bond strength at the interface.

Pigeon et al.[79] reported that the durability of the bond is not influenced by wetting the substrate surface when the repair material has low water-to-cement $(w / c)$ ratio but is improved for pastes with high w/c. Based on this conclusion, the moisture condition on the substrate before placing UHPC, as a paste with the low w/c ratio, is not expected to influence the interface bond performance significantly.

On the other hand, Monuz et al. [80] observed better bond performance between NSC and UHPC when the concrete substrate was saturated. The results suggested that when sufficient moisture is provided for the substrate, the roughness of the substrate surface does not play a critical role in achieving a strong bond. However, other researches [81]-[83] recommended that the preparation quality of the existing surface before casting UHPC will often determine the quality of the bonding. The results of their pull-off, slant shear, and splitting tensile tests demonstrated that the substrate surface preparation considerably influences the mechanical bond strength between NSC substrate and UHPC. However, it is not always possible to attain the desired surface due to the restrictions on using heavy machinery for structural and environmental safety [84], [85]. In such conditions, the effect of surface wetness on overall joint performance becomes more pronounced [86] and is really necessary for designers to be aware of bond strength between substrate and newly added concrete. 


\subsection{OBJeCtives ANd Methodology}

The enhanced mechanical and low permeability characteristics of UHPC have been widely reported and make UHPC a material of interest for structural applications including rehabilitation of concrete structures. Application of UHPC can potentially result in both technical and economic advantages, including decreased reinforcement corrosion activity and an increase in service life. The scope of this research is to find an accelerated repair solution for reinforced concrete (RC) elements utilizing UHPC. The purposes of this repair method are to:

- $\quad$ improve the structure's function and performance

- $\quad$ rehabilitate and enhance strength and stiffness of the concrete element

- $\quad$ improve concrete surface appearance

- $\quad$ increase water tightness

- $\quad$ prevent penetration of corrosive materials to reinforcing structures

- $\quad$ improve structure's overall durability

This research firstly aims to explore the performance of UHPC as retrofit material for damaged bridge columns. To achieve this goal, an experimental study and numerical analysis were designed to evaluate the mechanical performance of the repaired columns under a combination of static axial and cyclic lateral loads (to simulate operational conditions).

Moreover, this study investigates the use of UHPC to protect or postpone the incipience of corrosion in reinforced concrete elements exposed to aggressive chloride environments. The application of UHPC can potentially result in both technical and economic advantages, including decreased reinforcement corrosion activity and an 
increase in service life. Because it is becoming more common to apply UHPC for rehabilitation to improve strength and ductility, improved protection against corrosion might serve as a complimentary benefit of this treatment. As a part of this study, the extent of macrocell development between the dissimilar concrete materials was monitored to identify the possible beneficial properties of UHPC related to corrosion; and identify the effect of the residual chloride before significant macrocell current. Figure 1- 4 outlines the evaluation program in the following chapters.

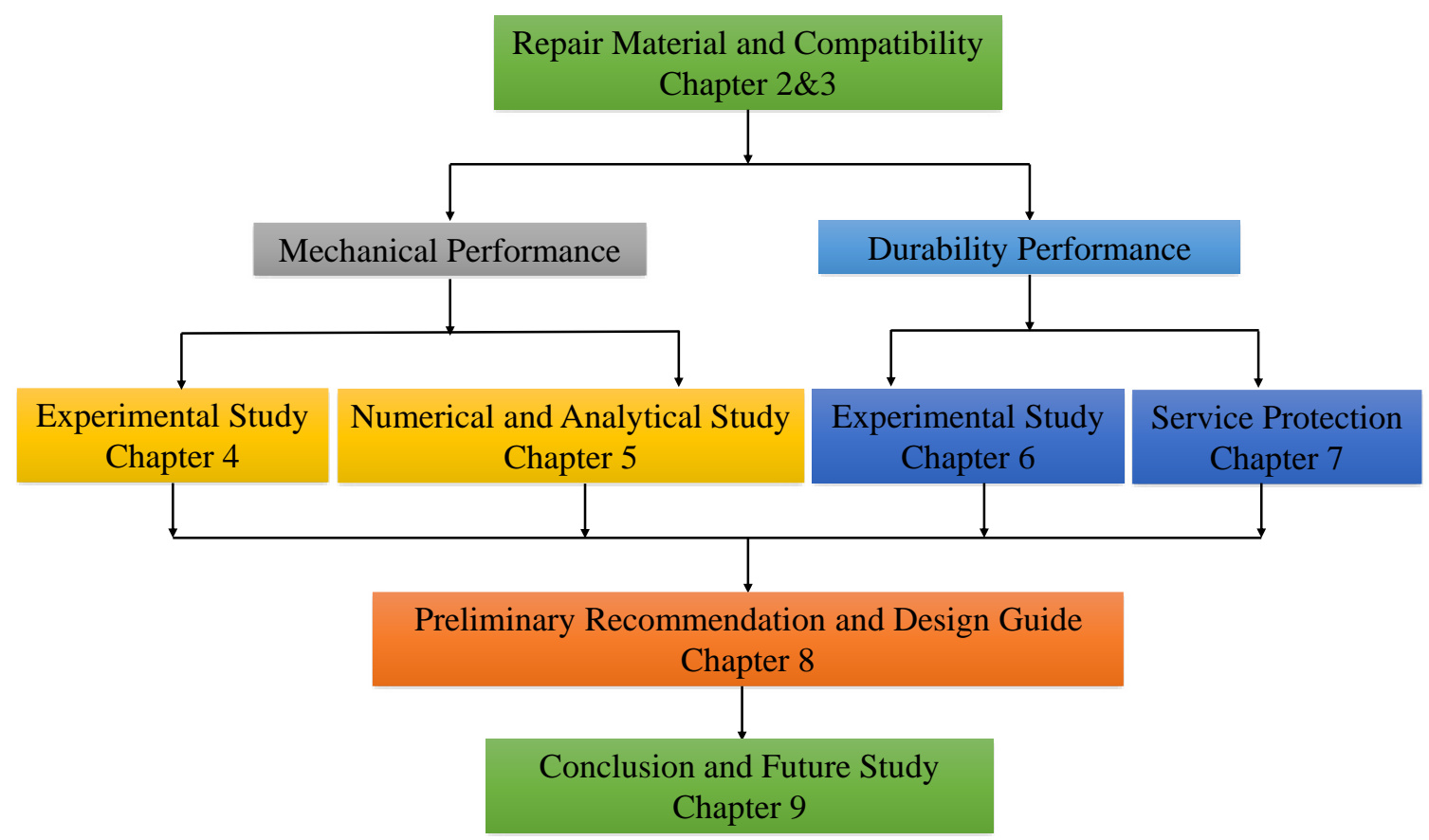

Figure 1- 4 Outline of the Report. 


\section{CHAPTER 2 MATERIAL PROPERTIES OF UHPC}

Ultra High-Performance Concrete (UHPC) is an advanced technology in the concrete industry with superior characteristics such as high strength in compression and tension, and durability. UHPC is a cementitious based material with fine aggregates, silica fume, fibers, superplasticizer, and low water/cement ratio.

Many bridges need rehabilitation and the use of UHPC can increase their durability [87], [88]. The objective of repair is to produce a durable repaired structure with a limited and predictable level of change without deterioration or distress through its intended life and purpose. As shown earlier, the first step in having a durable system is the choice of repair material and system. To do that, the material properties of the selected material should be carefully evaluated to meet the requirements given by the specifications.

The experimental tests were conducted to evaluate the physical properties and durability properties of UHPC as a repair material. The same tests have been conducted on Normal Strength Concrete (NSC), and the corresponding results are compared. The purpose of this part of the research is to quantification of UHPC as repair material per its physical, and durability properties, and to properly assign its repair application.

\subsection{Material Mixing}

Three parts of the UHPC utilized in this research included: premix, fibers, and liquids. The premix (Ductal ${ }^{\circledR}$ JS1000) includes all the cementitious, and filler materials provided by Lafarge ${ }^{\circledR}$. The premix was batched by the manufacturer and delivered to FIU's 
Structural Lab. Figure 2- 1 shows the mix properties and the mix design followed in this research.

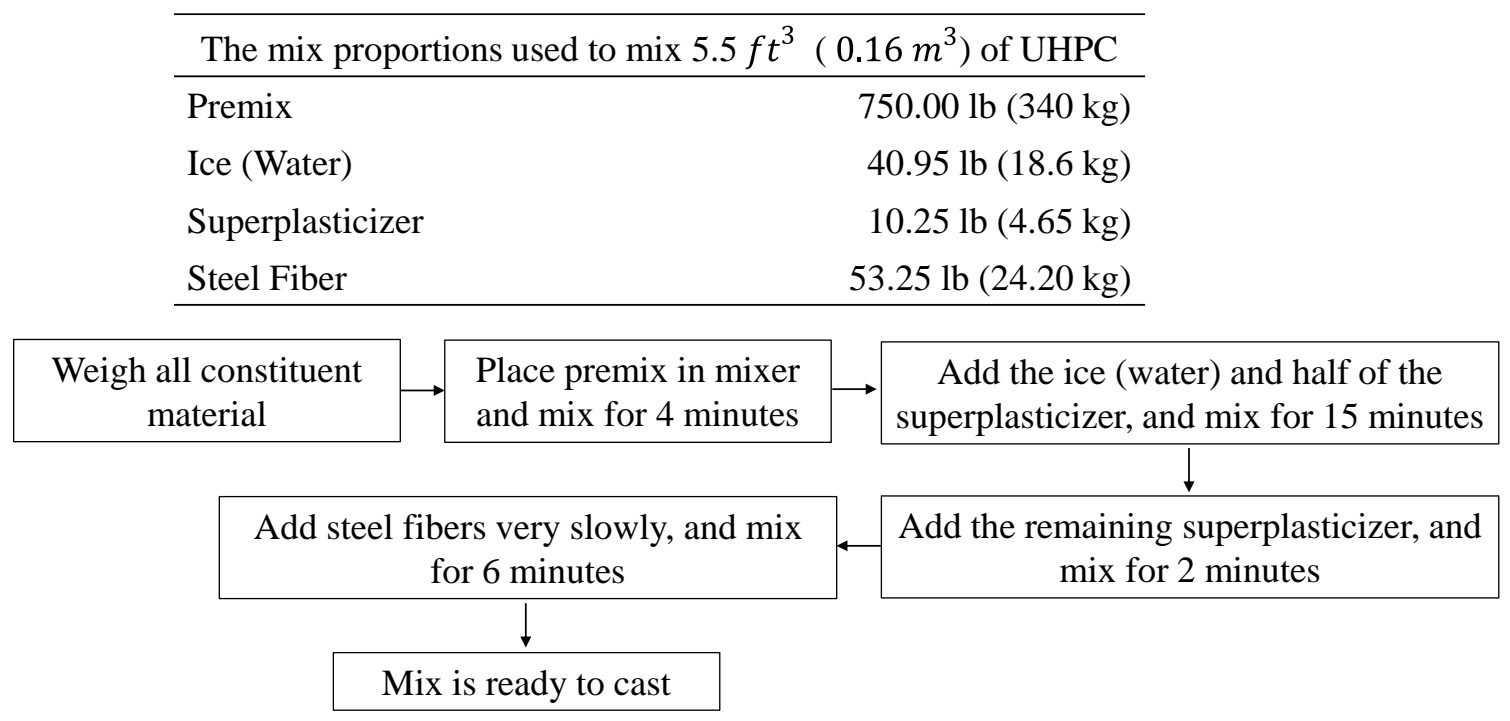

Figure 2- 1 Mix design and proportion of UHPC used in this research.

Immediately after completion of the mix, the casting was started and performed within 15 minutes after completion of mixing. UHPC was scooped into the molds and was not rodded because of the fibers. The exposed surfaces of each sample were then wrapped in plastic to prevent loss of moisture.

The NSC used in the study was provided by a local supplier as a ready-mix with a nominal strength of $5000 \mathrm{psi}$, and a slump of 4 in. (100 mm). The mix comprised of Type II Portland cement, crushed limestone coarse aggregate with a maximum size of 0.8 in (20 $\mathrm{mm}$ ), fine aggregate, and a water-to-cement ratio of 0.43 . The measured slump of the mixed concrete was 5 in. $(127 \mathrm{~mm})$. The compacting procedure for NSC specimens was done according to ASTM specification (ASTM C31-69). The concrete mix proportions are listed in Table 2- 1. 
Table 2- 1 Concrete mix constituents.

\begin{tabular}{|c|c|}
\hline Constituents & Regular Mix \\
\hline Cement (type $\mathrm{II}) \mathrm{lb} / \mathrm{ft}^{3}\left(\mathrm{~kg} / \mathrm{m}^{3}\right)$ & $18.5(297)$ \\
\hline Water $\mathrm{lb} / \mathrm{ft}^{3}\left(\mathrm{~kg} / \mathrm{m}^{3}\right)$ & $8.0(127.5)$ \\
\hline Fine aggregates $\mathrm{lb} / \mathrm{ft}^{3}\left(\mathrm{~kg} / \mathrm{m}^{3}\right)$ & $47.0(757)$ \\
\hline Coarse Aggregates $\mathrm{lb} / \mathrm{ft}^{3}\left(\mathrm{~kg} / \mathrm{m}^{3}\right)$ & $61.0(979)$ \\
\hline Air-entraining agent oz. $(\mathrm{ml})$ & $11.0(325)$ \\
\hline Fly Ash $\mathrm{lb} / \mathrm{ft}^{3}\left(\mathrm{~kg} / \mathrm{m}^{3}\right)$ & $4.6(74)$ \\
\hline Water-to-Cement ratio & 0.43 \\
\hline
\end{tabular}

\subsection{Rheological Properties of UHPC}

Flowability, consolidation, and compaction of the freshly placed material affect its capability to fill open cavities and voids on the surface of the substrate concrete. This directly influences the effective contact area between the new material and substrate. A relatively fluid mixture (made with no excess water) further improves capillary suction in the substrate and consequently increases physical anchorage in substrate surface pores and cavities [89].

The workability of the prepared UHPC mixture is measured in accordance with Precast/Pre-stressed Concrete Institute (PCI) guidelines [90], and ASTM C143 [91] which suggest the following tests:

\subsubsection{Slump flow test (unrestricted flow)}

The slump flow is the mean diameter of the horizontal spread of the concrete mass, after lifting the slump cone, as shown in Figure 2- 2(a). During the slump flow test, there was no restriction offered to the freely flowing mixtures. 


\subsubsection{J-ring test (restricted flow)}

Passing ability of the mixture was tested using a J-ring apparatus as shown in Figure 2- $2 \mathrm{~b}$ with a clear bar spacing of $1.75 \mathrm{in} .(4.5 \mathrm{~cm})$. This test is conducted by lifting the slump cone and allowing UHPC to flow radially outward through the J-ring.

\subsubsection{Static and dynamic flowability}

Flow table test was performed according to ASTM C143 [91], to obtain the rheology of the UHPC. The mini-slump cone (Figure 2- 2c) was filled and then removed to allow the concrete to flow outward. After reaching a steady state, the average diameter was determined to obtain the static flow. The flow table was dropped 20 times in approximately 20 seconds, the average diameter was measured to obtain the dynamic flow.

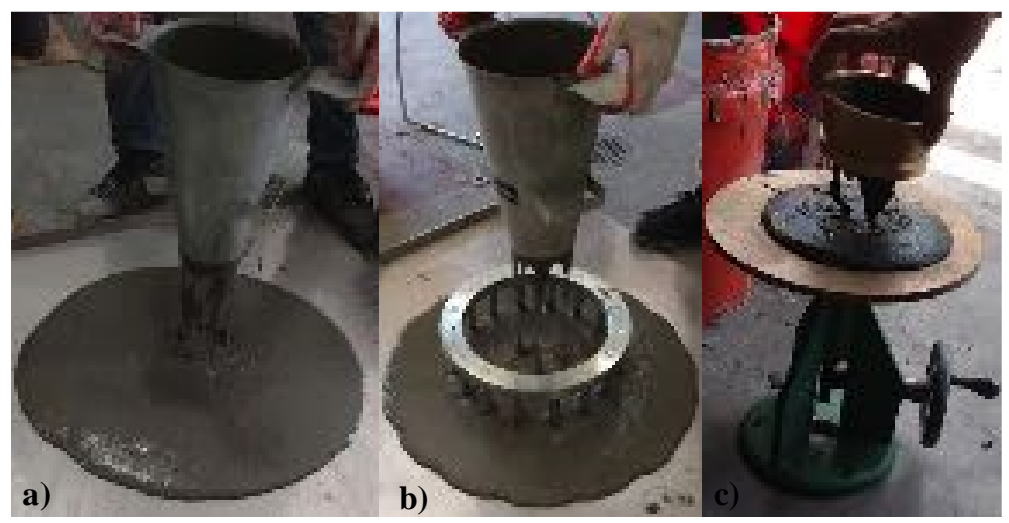

Figure 2- 2 Workability tests of UHPC a) slump flow test, b) J-ring test, c) static and dynamic flowability.

Table 2- 2 Shows the results of the Rheological Properties of UHPC.

Table 2- 2 Workability test parameter

\begin{tabular}{|c|c|c|}
\hline Test & UHPC with $2 \%$ & UHPC with $4 \%$ steel fiber \\
\hline Slump Flow Test PCI [92] & 34.0 in. $(86 \mathrm{~cm})$ & 33.0 in. $(83 \mathrm{~cm})$ \\
\hline J-ring Test PCI [92] & 32.5 in. $(83 \mathrm{~cm})$ & 31.0 in. $(79 \mathrm{~cm})$ \\
\hline $\begin{array}{c}\text { Static Flowability (mini-slump test) } \\
\text { ASTM C1437 [91] }\end{array}$ & 8 in. $(20 \mathrm{~cm})$ & 7.5 in. $(22 \mathrm{~cm})$ \\
\hline $\begin{array}{c}\text { Dynamic Flowability (mini-slump } \\
\text { test) }\end{array}$ & 10 in. $(25 \mathrm{~cm})$ & 9.0 in. $(23 \mathrm{~cm})$ \\
\hline
\end{tabular}




\subsection{Physical Properties}

To ensure a uniform flow of stresses and strains in loaded structures, the overlay material shall have compatible mechanical properties or rather better compressive and tensile strength than that of the base material.

\subsubsection{Compression testing}

One of the most commonly specified and measured properties of concrete is compression strength. The modulus of elasticity, which is similarly measured through standardized compression test methods, is also a regularly engaged parameter in the design of structures. Compressive strength is often used as an indication for other strength properties of concrete such as flexural strength, tensile strength, and shear strength.

Uniaxial compression tests were performed on a total of 5xUHPC and 5xNSC cylindrical specimens of 3 in. $(75 \mathrm{~mm})$ diameter and 6 in. $(150 \mathrm{~mm})$ tall cast in a plastic mold according to the ASTM C39 [93] standard test method.

Prior to each test, all the cylinder specimens were ground to minimize uneven surfaces at each end. The cylinders were measured to determine length, diameter, and density. Density of UHPC and regular concrete were $155 \mathrm{lb} / \mathrm{ft}^{3}\left(2480 \mathrm{~kg} / \mathrm{m}^{3}\right)$ and $150 \mathrm{lb} / \mathrm{ft}^{3}$ $\left(2400 \mathrm{~kg} / \mathrm{m}^{3}\right)$, respectively.

The elastic modulus of the repair material is crucial because it governs the loadsharing capacity [94], [95]. The modulus of elasticity is an indication of rigidity. Under a given load, high modulus materials deform less than those with a lower modulus. Under loading parallel to the bond line, stress is transferred from materials with low modulus 
material to the high modulus material. It leads to stress concentration and failure of the high modulus material [96]. Under loading perpendicular to the bond line, the stiffness distinction between the materials is less problematic if the external load is compressive; nonetheless, if it is tensile, mismatching of the elastic moduli is possible to cause adhesion failure [97]. Therefore, it is mostly recommended that the modulus elasticity of a repair material be close to of the substrate concrete [95], but there are studies reporting strong evidence that effective repairs are accomplished with repair patches with a modulus of elasticity significantly higher than that of the substrate [98]-[100]. The results of these studies have shown that repairs with stiff materials demonstrate efficient structural interaction with the structure. High stiffness repairs efficiently redistribute shrinkage strain to the substrate and attracting external loading in the long term.

The stress-strain curve of 5xUHPC and 5xNSC samples (shown in Figure 2- 3), was obtained based on the load-displacement relationship, and the compressive strength and elastic modulus were calculated. Due to the difference between the stress-strain curve of UHPC and that of conventional concrete, the FHWA [101] suggests calculating the elastic modulus using values that correspond to $10 \%$ and $30 \%$ of the ultimate compressive strength. The average result of the test is listed in Table 2- 3.

Table 2- 3 Compressive cylinder test results.

\begin{tabular}{|c|c|c|}
\hline Test & UHPC & NSC \\
\hline Compressive cylinder test & $22 \mathrm{ksi}(166 \mathrm{MPa})$ & $5.86 \mathrm{ksi}(40.4 \mathrm{MPa})$ \\
\hline Modulus of elasticity & $8700 \mathrm{ksi}(60 \mathrm{GPa})$ & $3200 \mathrm{ksi}(22.06 \mathrm{GPa})$ \\
\hline
\end{tabular}

The NSC specimens behave elastically up to the peak strength followed by a rapid strain softening. After the formation of the first crack, when lateral deformation surpassed 
its tensile capacity, the NSC specimens lost their total strength and failed in a brittle manner. In contrast, UHPC specimens behave elastically until approximately $50 \%$ of their compressive strength, followed by strain hardening behavior up to peak strength. The interaction between the fibers and the matrix resulted in ductile compressive failure where the concrete surface remains intact even at total strength loss. As illustrated in the results, no descending branch in the case of NSC is observed which indicates the brittle behavior of the material, while in UHPC descending branch of the stress-strain curve is observed.
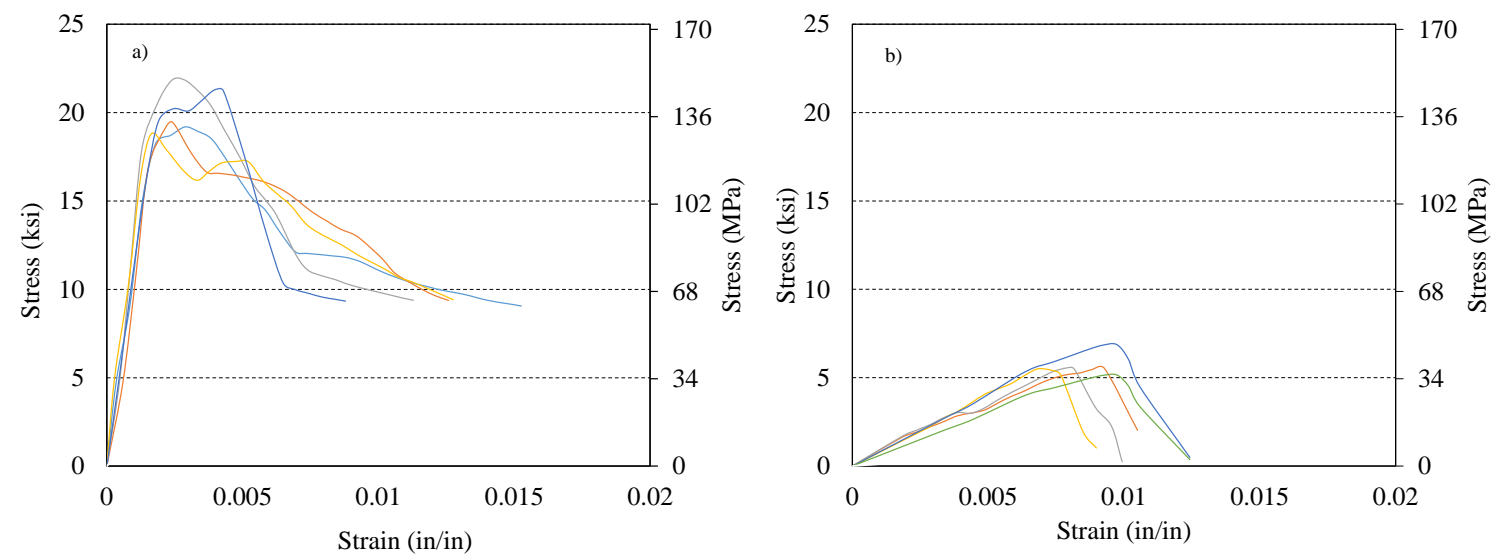

Figure 2- 3 The stress-strain curve based on cylinder test of the specimens: a) UHPC, and b) NSC.

\subsubsection{Tensile behavior}

The localized tensile loading of concrete structures is the most frequent explanation of cracking in structural concrete. Therefore, the tensile strength of concrete is an important strength parameter. Typically, the tensile strength of concrete is neglected in reinforced concrete design and often taken as $6 \sqrt{ } \mathrm{f}^{\prime} \mathrm{c}$ in prestressed concrete girder design [102].

However, UHPC has higher tensile strength than conventional concrete, and it can show sustained tensile strength after first cracking. In this investigation, two test methods 
were used to determine the tensile strength of concrete including flexural test, and direct tensile test.

\subsubsection{FLEXURAL TEST}

Flexural strength of the repair material is an essential property since many repair materials are applied to the substrate in a configuration which experiences high flexural stresses and strains within the repair material.

The ASTM C1018 [103] standard test method for flexural toughness was one test used to determine the tensile properties of UHPC and NSC. Six prisms including 3xNSC, and $3 \times$ UHPC of $20 \times 6 \times 6$ in. $(500 \times 150 \times 150 \mathrm{~mm})$ with a span of $18 \mathrm{in} .(450 \mathrm{~mm})$ were used for this test (see Figure 2- 4). The prisms were placed on the roller supports with the vertical molded faces located at the compression and tension faces. To ensure low horizontal forces due to support friction, the specimens were supported on steel rollers. The load was then applied via the hydraulically controlled constant load rate $(29 \mathrm{lb} / \mathrm{s}$ equal to $13.2 \mathrm{~kg} / \mathrm{s})$ at the middle length until failure.
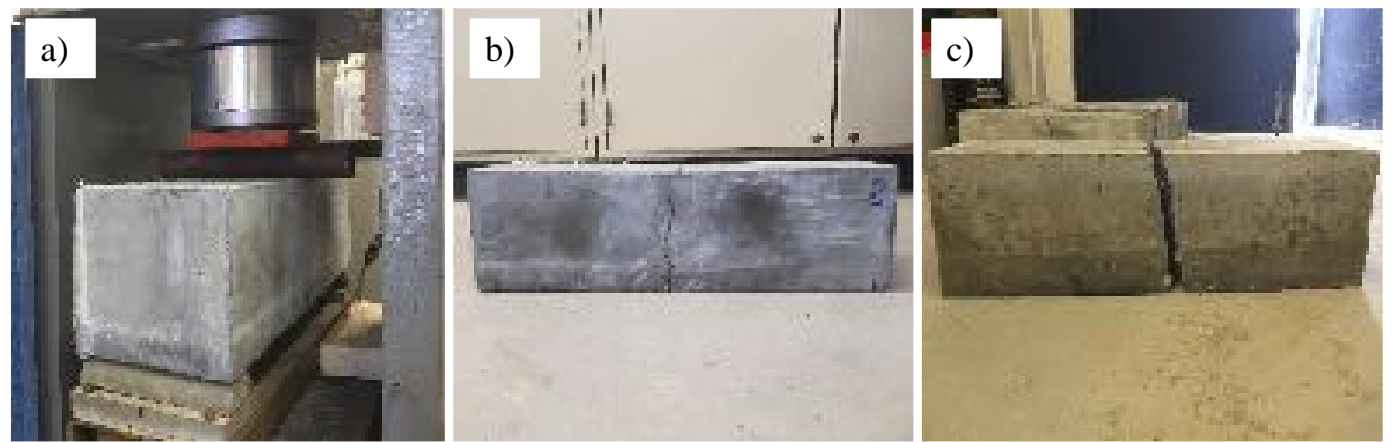

Figure 2- 4 Flexural beams a) before test, b) after test (UHPC), and c) after test (NSC).

This method of testing is based on simple beam bending theory and linear elastic stress-strain behavior up to failure. Due to the nonlinear behavior of concrete, the 
assumption of linear stress distribution is not valid; therefore, results obtained using this method are always greater than the direct tensile strength. Figure 2- 4 also shows pictures of typical UHPC and NSC beams before and after testing. Notice that in the case of UHPC, the beam remains intact due to the presence of the fibers, while NSC prisms failed in brittle behavior. The average result of the tensile strength from the flexural test of UHPC and NSC were $3.17 \mathrm{ksi}(21.9 \mathrm{MPa})$ and $0.7 \mathrm{ksi}$ (4.9 MPa), respectively. The load-displacement curve for all the samples from NSC and UHPC obtained from flexural tests is shown in Figure 2- 5.
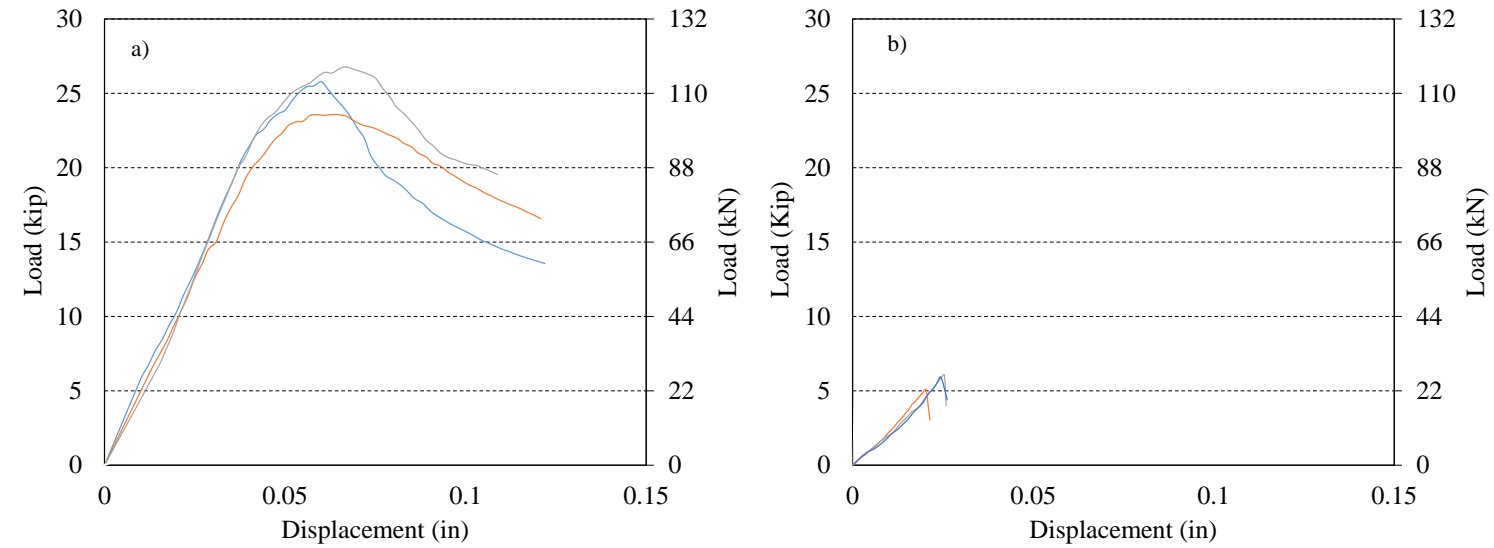

Figure 2- 5 Load-displacement curve for beam test of the specimens: a) UHPC, and b) NSC.

As shown, the UHPC prism's deflection increased linearly until the initiation of the initial crack and was proportional to the load. After the first crack, deflection increased nonlinearly until the ultimate strength was reached. UHPC showed 4.5 times higher flexural strength compared to NSC. The ductile behavior of UHPC compared to NSC also can be seen in the curves. 


\subsubsection{DIRECT TENSILE TEST}

The direct tensile test is a uniaxial test in which the tensile strength of a mortar is determined by pulling the specimen apart. AASHTO T132 [104], describes a test method called briquette tension test method, involving a direct tension testing of a small cement mortar briquette. The dog-bone shaped briquette has a 3-in. (75 mm) length, 1 in. (25 mm) thickness, with a 1 in. $^{2}\left(625 \mathrm{~mm}^{2}\right)$ cross section at mid-length. Since this method is recommended for cement mortar specimens, it cannot be a reliable method for the normal concrete with coarse aggregates. However, due to a comparison of materials behavior in this study, the direct tensile test was done for NSC as well. In addition, in the case of UHPC (as the composition shows) the aggregate size of UHPC will not be an issue; however, due to the small cross-section of the briquette, fibers will not be randomly distributed as is preferred.

In AASHTO T132 [104], the loading rate is recommended at $600 \mathrm{lb} / \mathrm{min}(272$ $\mathrm{kg} / \mathrm{min}$ ). This portion of the test method was modified, and the tests were conducted at a displacement rate of $0.001 \mathrm{in./s}(0.025 \mathrm{~mm} / \mathrm{s})$ suggested by Graybeal [101].

Nine NSC briquettes and nine UHPC briquettes were cast and tested. Figure 2- 6 shows UHPC and NSC briquettes before and after testing. As shown, the steel fibers bridge the crack in the middle. As the fibers pull out of the matrix across the crack, the load capacity decreases until the total strength is lost, while NSC briquettes took apart suddenly after reaching the peak load. The average results of the tensile strength from briquettes for UHPC and regular concrete were $9 \mathrm{MPa}(1.3 \mathrm{ksi})$ and $3.5 \mathrm{MPa}(0.51 \mathrm{ksi})$, respectively. 

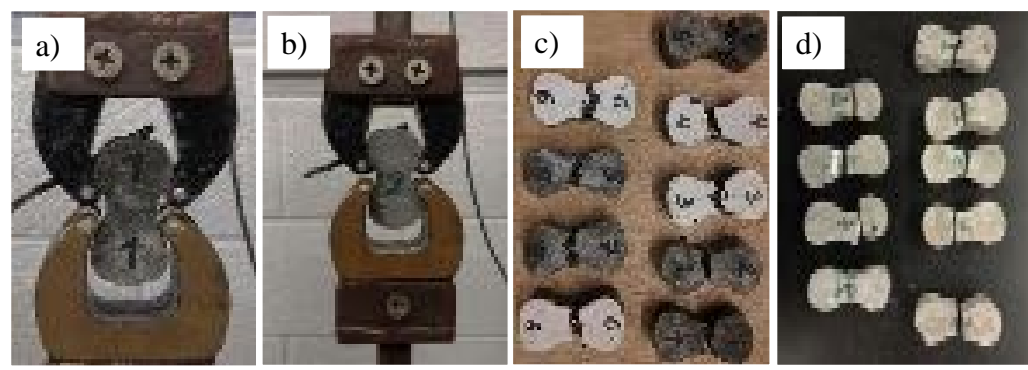

Figure 2- 6 Briquette samples before test a) UHPC, b) NSC, and after test c) UHPC, d) NSC.

Figure 2- 7 presents the load-displacement that resulted for all the nine samples from each concrete type. The results indicated that UHPC behaved linear-elastically up to first cracking, followed by a significant amount of post-cracking load-carrying capacity. This is explained by the presence of the composite action of the fibers that bridge across the cracks. On the contrary, the NSC briquettes failed briskly owning with the localization of the maximum strain in a single crack.
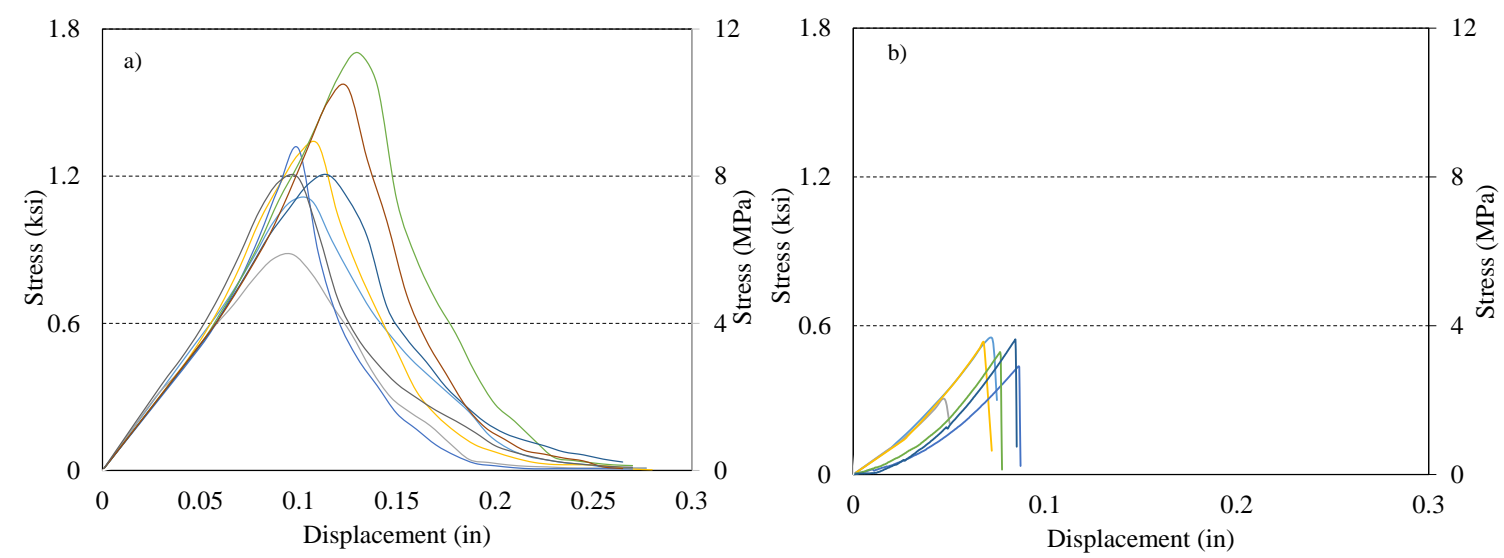

Figure 2- 7 Stress-displacement curves of the briquette specimens: a) UHPC, and b) NSC.

\subsection{Durability Properties}

The development and application of effective repair methods, aimed at extending the lifetime of both existing and new structures, is a critical issue. The repair material 
should have properties required to develop an adequate physical and chemical barrier against the diffusion of deleterious substances, such as chlorides and carbon dioxide.

Experimental research was performed on the corrosion durability of UHPC as a repair material. It was hypothesized that repair of concrete members with a UHPC will decrease or slow reinforcement corrosion by confining the concrete and providing a barrier with reduced permeability. This section investigates corrosion durability properties of UHPC and the objectives are to identify the possible beneficial properties of UHPC related to corrosion.

The small-scale test samples were made to identify UHPC material properties relevant to corrosion durability particularly in various environmental moisture exposure conditions such as immersion conditions, 100\% RH, and 75\% RH. The research was not intended to give direct comparisons to commercially available repair materials but rather give an indication of the performance of UHPC used for repairs on poor quality concretes where corrosion may be prevalent. Sample geometry and dimensions are summarized in Table 2- 4. The small samples were de-molded 7 days after casting and placed in the relevant curing and exposure environments. All small-scale samples were kept in the laboratory where the ambient temperature was typically $77^{\circ} \mathrm{F}\left(25^{\circ} \mathrm{C}\right)$. The small NSC and UHPC samples were used to measure and compare the concrete resistivity, oxygen diffusivity, internal moisture and mass change of the two concrete types for three exposure environments.

Table 2- 4 Dimension of the small samples.

\begin{tabular}{|c|c|}
\hline Type of Test & Dimensions of the Cylinders (Diameter $\times$ Height) \\
\hline Oxygen Diffusion & $3 \times 3$ in. $(76.2 \times 76.2 \mathrm{~mm})$ \\
\hline Resistivity & $3 \times 6$ in. $(76.2 \times 152.5 \mathrm{~mm})$ \\
\hline Internal Humidity & $4 \times 8$ in $(102 \times 204 \mathrm{~mm})$ \\
\hline Mass Change & $3 \times 6$ in. $(76.2 \times 152.5 \mathrm{~mm})$ \\
\hline
\end{tabular}




\subsubsection{Resistivity}

The electrical resistivity of a material is its ability to resist the transfer of ions subjected to an electrical field. This characteristic mostly depends on the microstructure properties of concrete such as pore size and shape of the interconnections [105]. Lower permeability results from a finer pore network with less connectivity and eventually leads to higher electrical resistivity.

Four-point resistance measurements, utilizing a soil resistance meter, were made to calculate the concrete bulk resistivity. The inner reference electrodes were made of activated titanium mesh and the outer counter electrodes were parallel stainless-steel plates. All concrete samples were surface dried with a towel prior to testing. All electrodes were separated by moist sponges in a test array that was confined with a clamp (Figure 2- 8). Excess free moisture was avoided to prevent possible preferential charge through the outer surface of the concrete. The concrete bulk resistivity was calculated by Equation 2- 1.

$$
\rho=R \frac{A}{L}
$$

where $\rho$ is the resistivity of the concrete $(\Omega . \mathrm{m}), \mathrm{R}$ is the resistance $(\Omega), \mathrm{A}$ is the cross-sectional area of the samples ( $7 \mathrm{in}^{2}$ equal to $4600 \mathrm{~mm}^{2}$ ), and $\mathrm{L}$ is the length of the sample (6 in. equal to $152 \mathrm{~mm}$ ). 


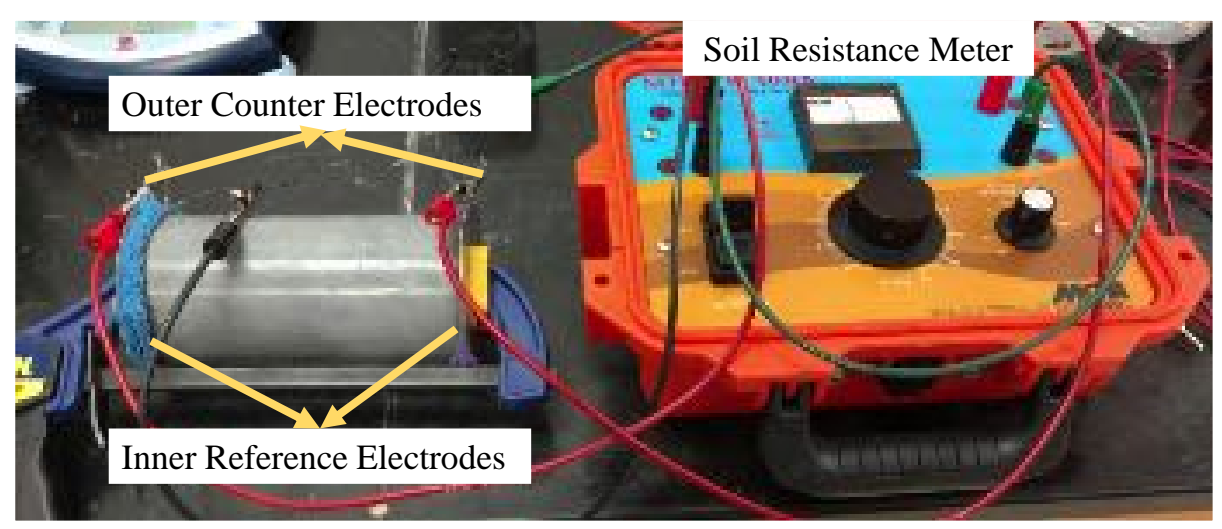

Figure 2- 8 Setup of four-point bulk resistivity test.

Figure 2- 9 shows the calculated bulk resistivity of the concretes in the moisture exposure environments. For conventional concrete and UHPC, the increase in bulk resistivity regardless of expected internal moisture presence (due to the various moisture exposure environments) is indicative of early cement hydration. In the conventional concrete, the lower bulk resistivity developed in the moist exposure conditions is due to filling of pore spaces with excess moisture (as supported by the increase in mass with time in those samples). UHPC showed bulk resistivity up to an order of magnitude larger than the tested conventional concrete, consistent with its higher cement factor and relatively low internal moisture content due to its low permeability.
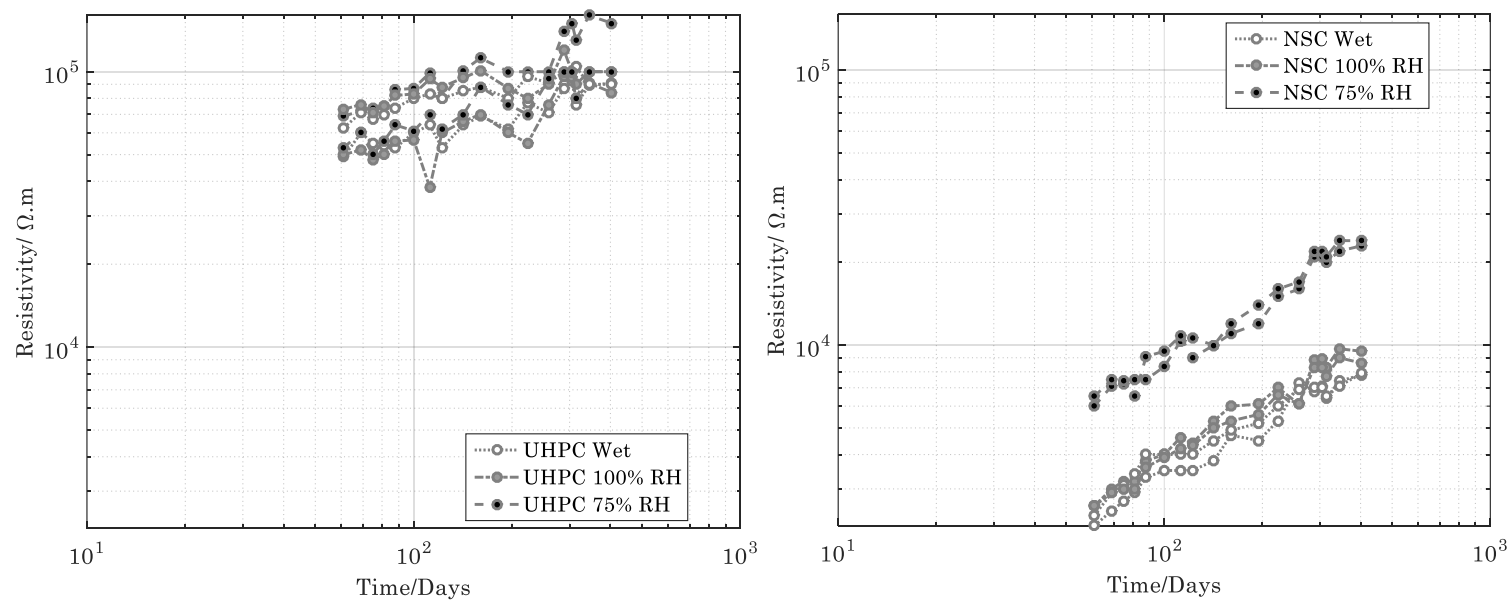

Figure 2- 9 Bulk resistivity for UHPC and NSC in moisture exposure environments. 


\subsubsection{Oxygen diffusivity}

Concrete is a heterogeneous material with a complex structure, containing a distribution of different types and amounts of solid phases, pores, and microcracks [106]. The porosity and pore size distribution in concrete is largely determined by the water to cement ratio. This capillary pore system is responsible for diffusion and permeation processes and, therefore, of importance for corrosion. [107].

Samples used to measure the oxygen diffusivity of the concrete samples had a stainless-steel disk (diameter of 2 in. $(50 \mathrm{~mm})$ ) that was coated with epoxy on the back face and activated titanium rod and mesh embedded inside the concrete to conduct cathodic potentiodynamic polarization scans. Figure 2- 10 shows the stages of sample preparation.

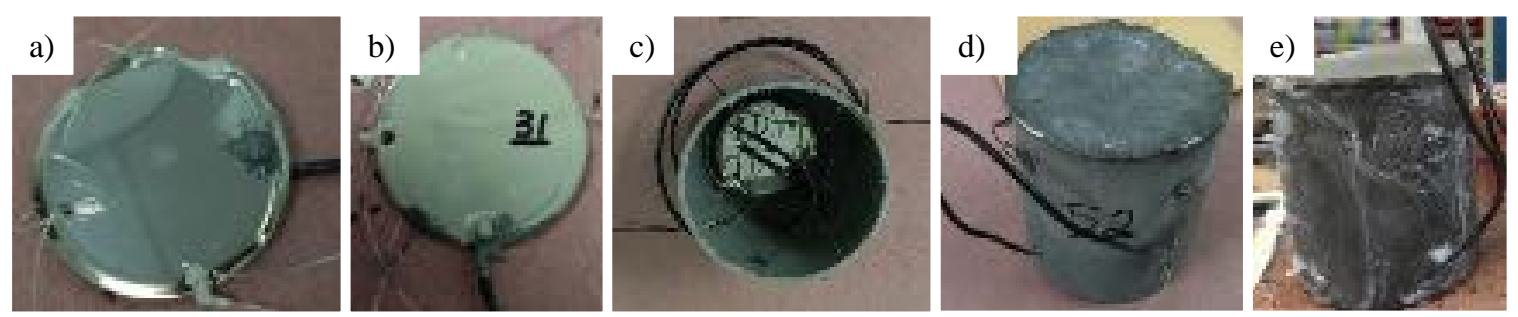

Figure 2- 10 Sample preparation a) stainless steel disk, b) coated side of stainless-steel disk, c) mold to cast the concrete, d) sample after demolding, and e) sample after coating.

The polarization scans were made from the open-circuit potential (OCP) condition to $-1.1 \mathrm{~V}_{\mathrm{SCE}}$ at a scan rate of $0.025 \mathrm{mV} / \mathrm{s}$. The limiting current density was calculated by least-squares fitting using the Butler-Volmer equation including concentration polarization. The stainless-steel disk was used as the working electrode, the activated titanium rod was used as the reference electrode, and the activated titanium mesh was used as the counter electrode. Although the efficiency of oxygen reduction reactions on stainless steel is not the same as for plain carbon steel, the experiments aimed to differentiate oxygen transport parameters in the tested concrete types, mixes, and exposure conditions. For these 
experiments, all concrete surfaces except the top surface were coated with an epoxy. As a first approximation, the oxygen diffusivity $\mathrm{Do}_{2}$ was calculated using Equation 2-2.

$$
i_{L}=\frac{D_{O_{2}} n F C_{B}}{\delta}
$$

where $i_{L}$ is the measured limiting current density, $\mathrm{Do}_{2}$ is oxygen diffusivity, $\mathrm{n}$ is the valence $(n=4), F$ is Faraday's constant $(F=96,500 \mathrm{coul} / \mathrm{mol}), C_{B}$ is the assumed oxygen bulk concentration at the concrete surface (assumed to be $2.5 \times 10^{-7} \mathrm{~mol} / \mathrm{cm}^{3}$ ) [108], and $\delta$ is the diffusion length assumed to be the length of the sample [108] ( $\delta=3$ in equal to 7.6 $\mathrm{cm}$ ). Testing was conducted initially 77 days after casting (71 days after exposure [7 days after coating]) to ideally present early behavior upon cement hydration. Furthermore, testing was conducted after 400 days of casting to compare results with early hydration.

Characterization of oxygen transport through UHPC is important to identify if the concrete may mitigate corrosion. The limiting current was calculated by least square fitting of the cathodic polarization scans. The recorded data and fitted curves are presented in Figure 2- 11 for UHPC and conventional concrete conditioned in different environmental exposures and for early and late hydration.
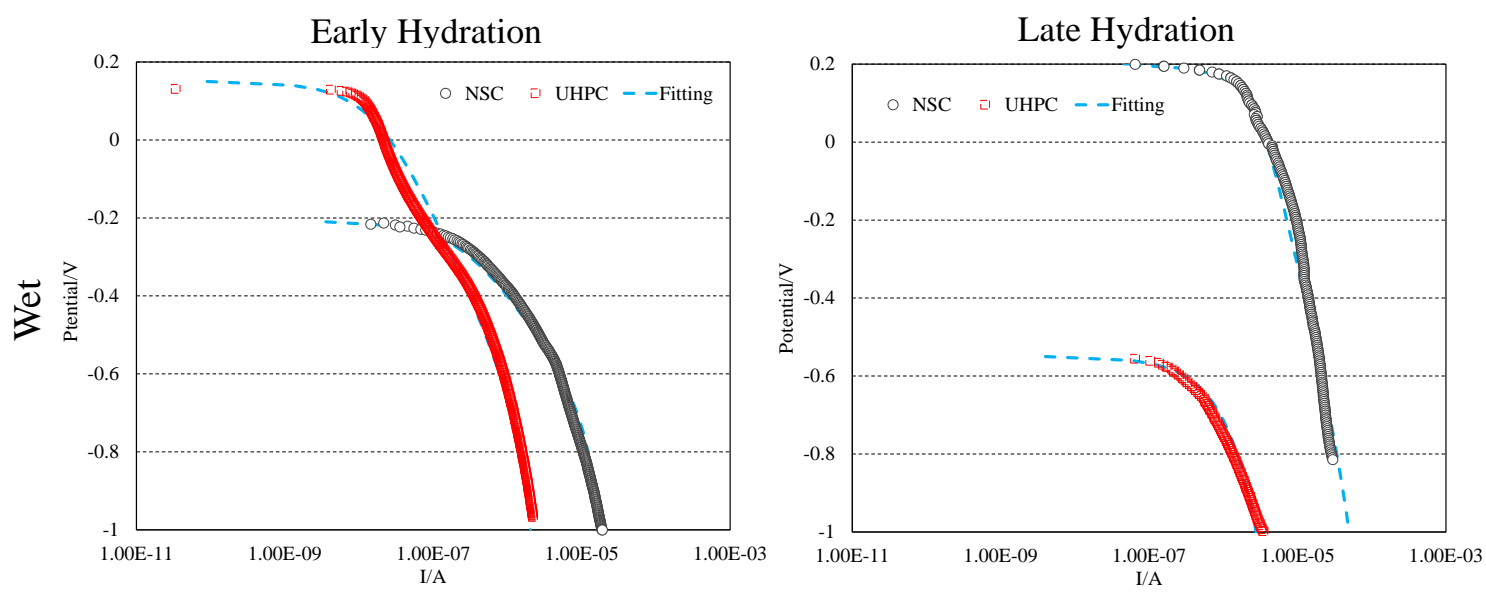

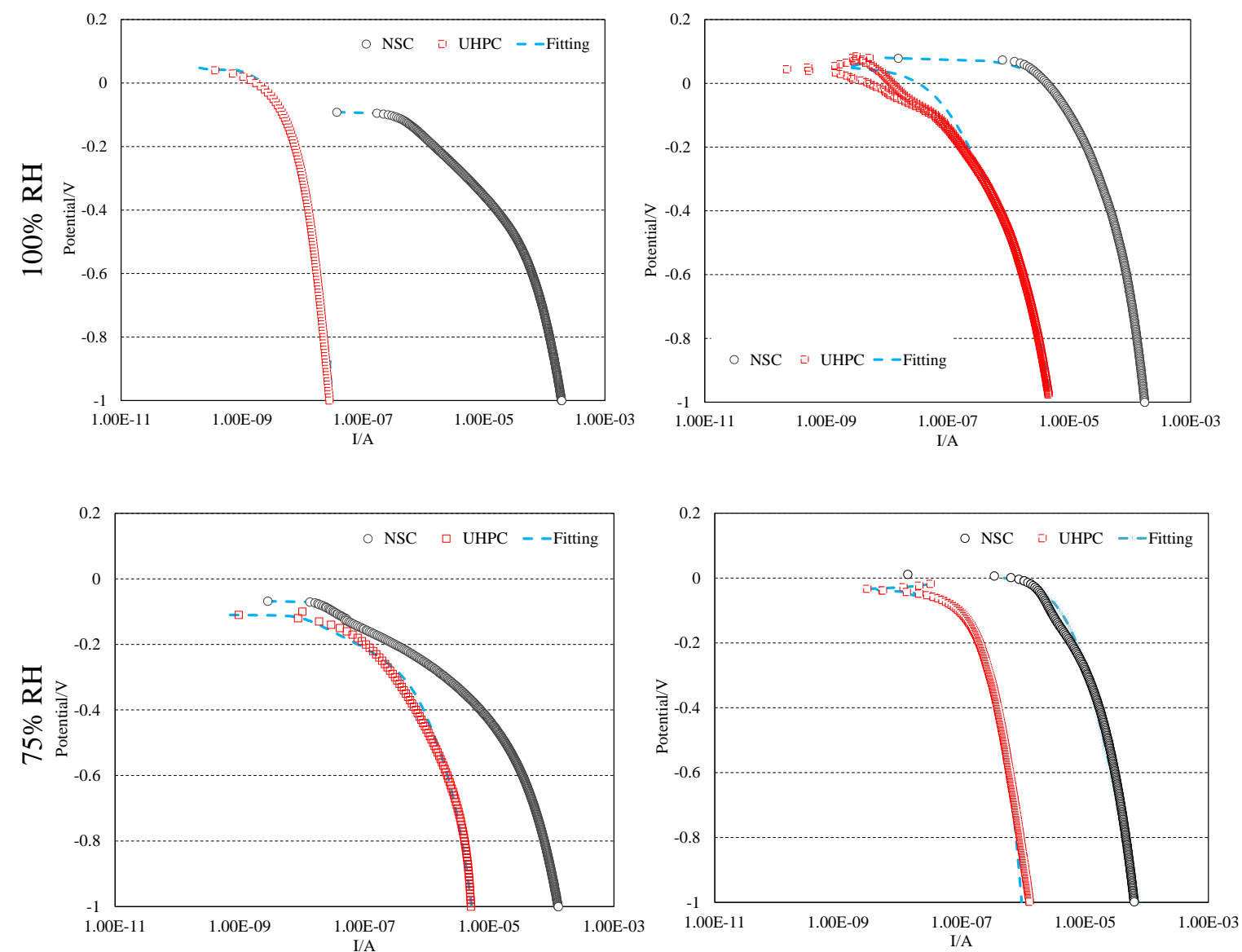

Figure 2- 11 Examples of curve fitting procedure on cathodic polarization scans.

The findings for the small-scale testing indicated low permeability for UHPC in moist exposure conditions. Per earlier discussion, the UHPC would be expected to have low porosity and low internal moisture content where one could pose that the reduced moisture presence may enhance gas transport. However, the larger cement factor in UHPC would provide a denser material. Indeed, the calculated approximate oxygen diffusivity (Figure 2- 12) for UHPC was much lower than the conventional concrete, and lower diffusivity was observed in UHPC exposed in immersed conditions than in ambient humidity conditions. Therefore, the development of corrosion cells is expected to be mitigated due to low gas permeability. 


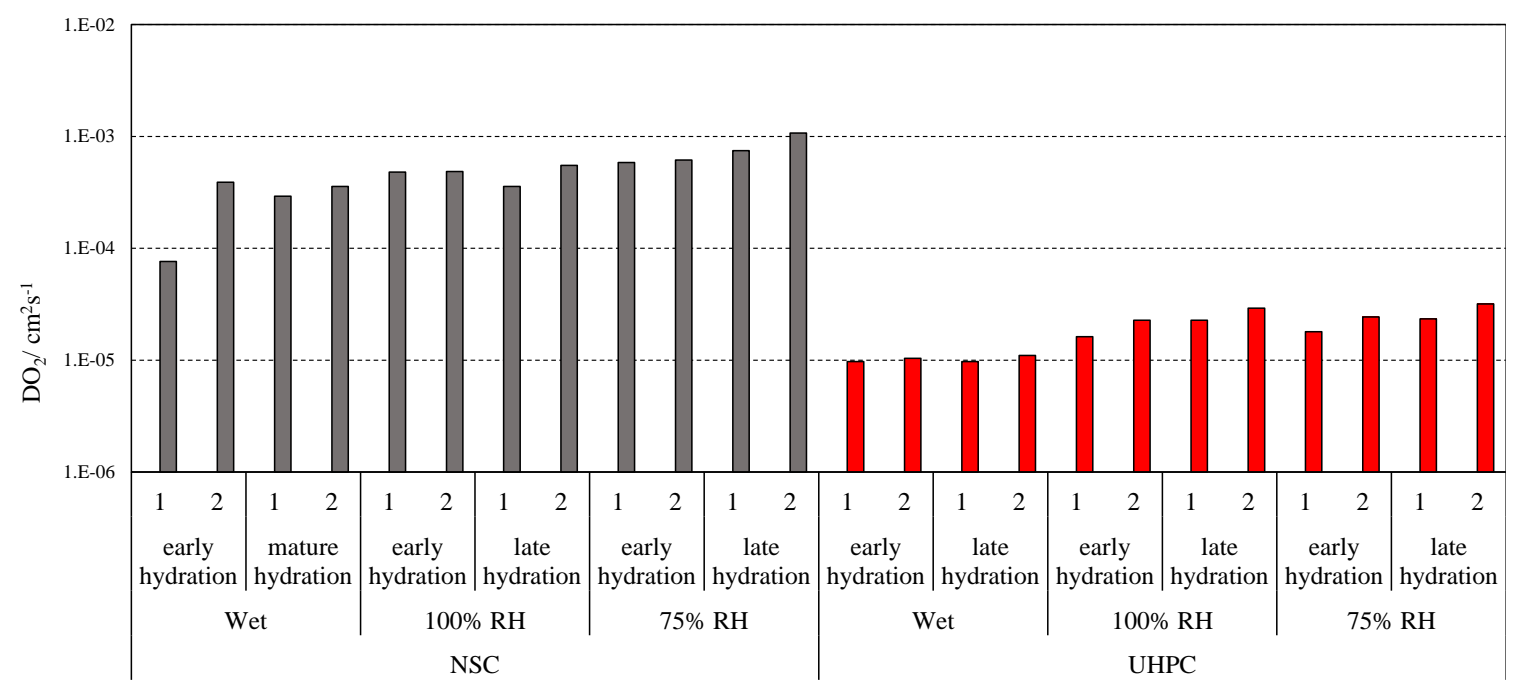

Figure 2- 12 Oxygen diffusivity of NSC and UHPC moisture exposure environments.

\subsubsection{Internal relative humidity}

Samples used to measure the internal relative humidity were prepared after 56 days of exposure (63 days after casting) following ASTM F2170 [109]. A 0.9 in. (22 mm) diameter, 4 in. (102 mm) deep hole was drilled at the top surface where a plastic sleeve was inserted and sealed to expose only the bottom surface of the cavity (see Figure 2- 13). For the testing initiated after 67 days after exposure (74 days after casting), a hygrometer probe was sealed inside the cavity to monitor the temperature and IRH during 3-day intervals for up to $\sim 460$ days of exposure ( 467 days after casting).
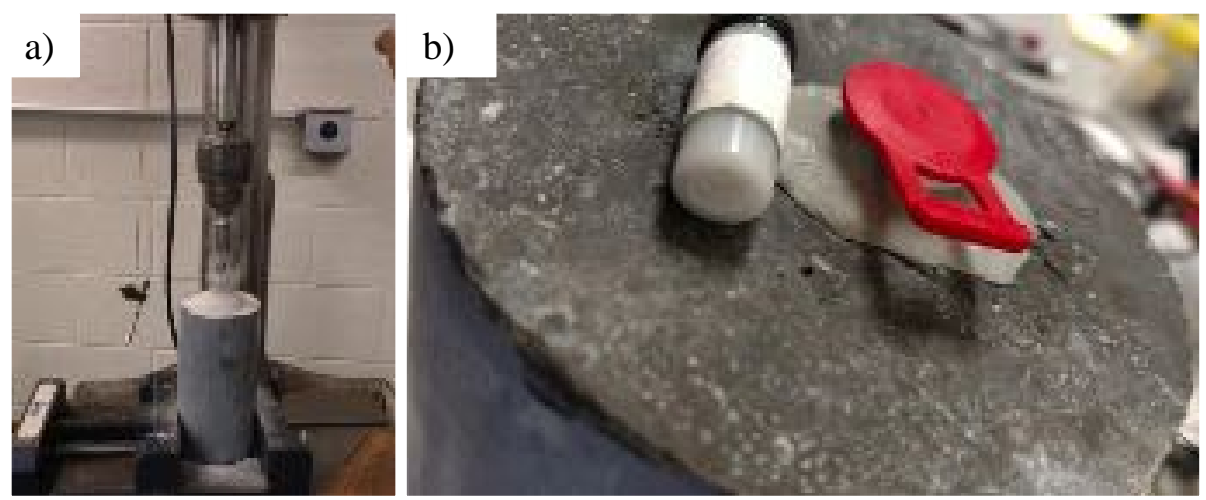

Figure 2- 13 Sample preparation a) hole drilling, b) inserted plastic sleeve with the sealant and the hygrometer probe. 
Figure 2- 14 shows the internal relative humidity (IRH) for conventional concrete and UHPC. As expected, the IRH was higher for the moist exposure conditions than at $75 \%$ RH. Also, UHPC generally showed lower internal relative humidity consistent with a low internal moisture content that was also described by the low mass gain and high bulk resistivity for samples exposed in both $75 \% \mathrm{RH}$ and higher moisture conditions. Therefore, the results verify high quality, low permeability characteristics of UHPC in both ambient and high moisture exposure environments.
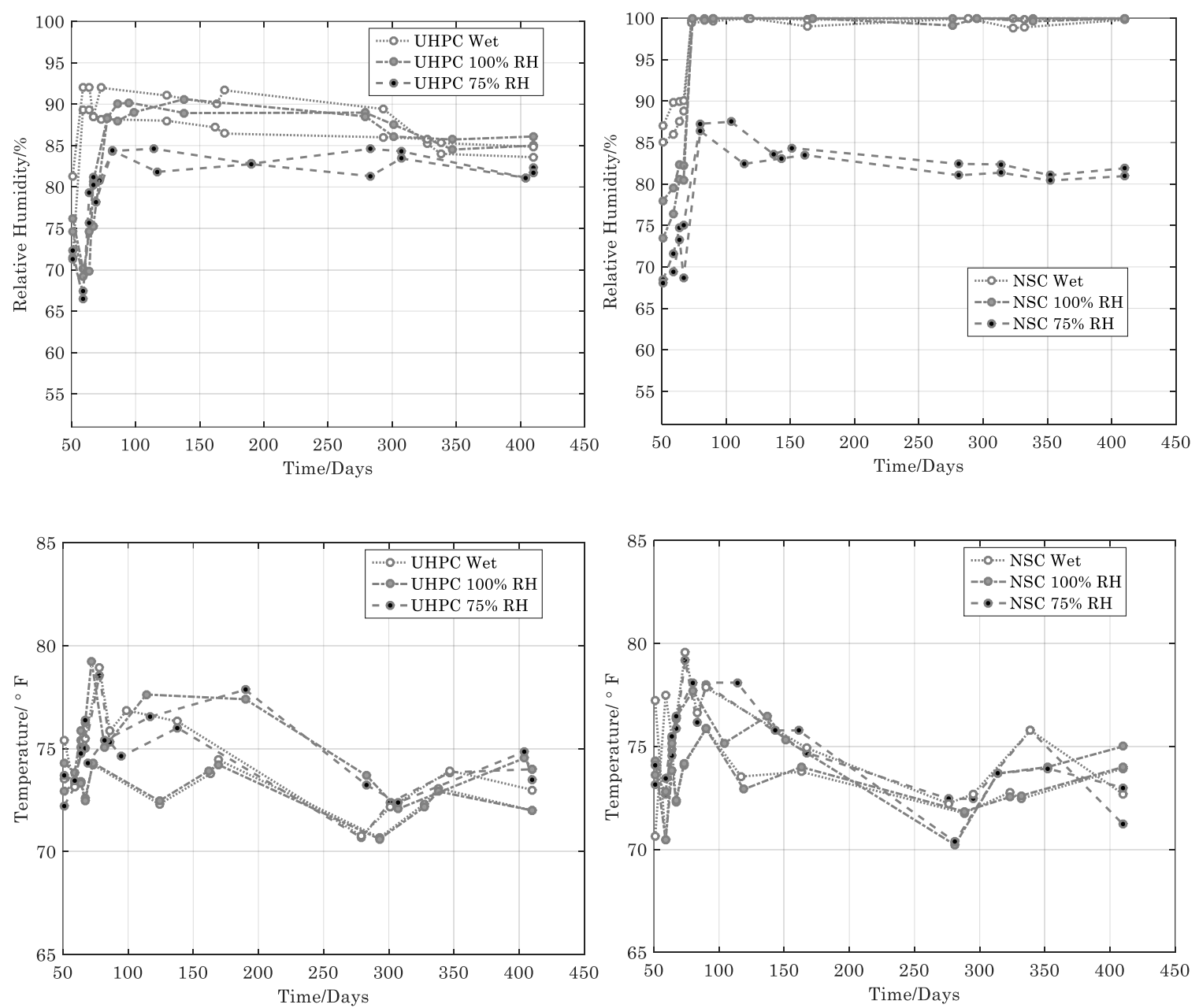

Figure 2- 14 Internal relative humidity and temperature of UHPC and NSC in moisture exposure environments. 


\subsubsection{Mass change}

Figure 2- 15 shows the results of concrete mass change for NSC and UHPC exposed in immersed conditions, $100 \% \mathrm{RH}$, and $75 \% \mathrm{RH}$. As expected, there is a small mass loss during hydration of the conventional concrete in ambient $75 \% \mathrm{RH}$ conditions and some mass increase during hydration when exposed to high moisture conditions such as in immersion or $100 \%$ RH conditions. In the high moisture conditions, excess available moisture is retained in the developed concrete macropores. Only minor to no increase in mass was observed for UHPC in all the tested moisture exposure conditions. This may be due self-desiccation of concrete due to the high cement content and low concrete porosity [110], [111].
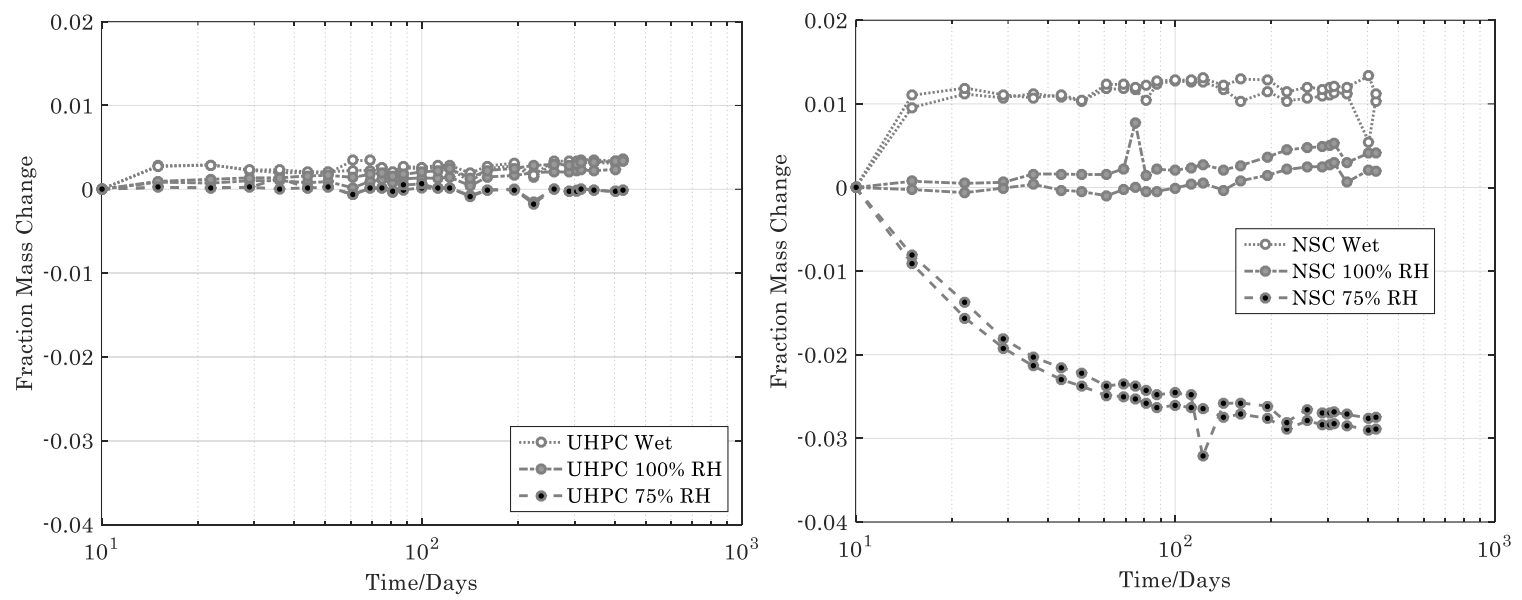

Figure 2- 15 Mass change for UHPC and NSC in moisture exposure environments. 


\subsection{SUMMARY}

Experimental results show that among the two considered material, UHPC had a significantly improved performance compared to normal strength concrete. Based on the results from small scale cast concretes, the following conclusions are drawn for strength and corrosion protection.

- In general, the compressive and tensile strength, ductility and modulus of elasticity of UHPC were notably higher than normal strength concrete.

- $\quad$ The mode of failure and behavior of UHPC test specimen after peak load exhibited the influence of fibers for UHPC.

- $\quad$ Minimal increase in mass was observed for UHPC in all the tested moisture exposure conditions possibly due to self-desiccation of concrete.

- $\quad$ UHPC showed bulk resistivity up to an order of magnitude larger than the tested conventional concrete, consistent with its higher cement factor and relatively low internal moisture content due to its low permeability.

- $\quad$ The calculated approximate oxygen diffusivity for UHPC was much lower than the conventional concrete, and lower diffusivity was observed in UHPC exposed in immersed conditions than in ambient humidity conditions. Therefore, the development of corrosion cells is expected to be mitigated due to low gas permeability.

- UHPC generally showed lower internal relative humidity consistent with low internal moisture content. 


\section{CHAPTER 3 BOND PERFORMANCE BETWEEN UHPC AND SUBSTRATE}

Retrofit and strengthening of concrete reinforced structures are one of the notable challenges nowadays. On this subject, improvements of concrete structures require to be long-lasting. Significant effort is dedicated to enhancing concrete repair durability. One of the crucial perspectives of the durability of concrete repairs is a lasting and adequate bond between a repair material and the existing concrete. A critical element in achieving sufficient bond strength is the moisture condition and surface preparation of the concrete substrate before the application of repair material.

\subsection{Experimental Program}

The bond interaction between the concrete repair material and the substrate is conceivably the most important factor of having successful repair. For the purposes of this investigation, it was decided to employ four different bond tests to assess the bond performance between UHPC and substrate concrete.

The evaluation on the bond strength consists of two sets of experiments. First, the effect of wetness of the substrate as well as the overlay materials was investigated. Second, the bond strength between UHPC and substrate concrete when the substrate is conditioned to various moisture content prior and after UHPC placement was evaluated.

Moreover, the enhanced chloride transport that may occur at the cold joint was examined to evaluate the corrosion durability of steel embedded in dissimilar concretes incorporating UHPC. The effectiveness of the bond at the concrete interface (with various 
levels of moisture availability at the time of UHPC repair) to minimize chloride penetration was examined.

\subsubsection{Bond strength estimation}

The bond strength of a concrete joint is usually evaluated by its performance in tension, shear, and combined shear and compression [112]. In this research, due to simplicity and equipment availability, four types of test were employed to assess the bond strength: third-point flexural, direct shear, slant shear test, and splitting test.

In the first phase, an experimental investigation was performed on a series of 36 composite specimens to characterize the bond performance with different types of stresses applied to the samples (third-point flexural bond test, direct shear, and slant shear test). Besides the composite specimens, nine samples made of full NSC were cast as references. These sets included casting two concrete types NSC and UHPC. The concrete mix proportions are listed in Chapter 2. After casting NSC into the molds, the surface was troweled and screeded without any other surface preparation. The concrete samples remained within the mold for curing for the first day prior to placement in either tap water or open in the ambient laboratory environment where the specimens were cured for an additional 7 days. After curing, the samples were cleaned with compressed air to remove loose surface particles and placement of a UHPC or NSC overlay was made on all samples.

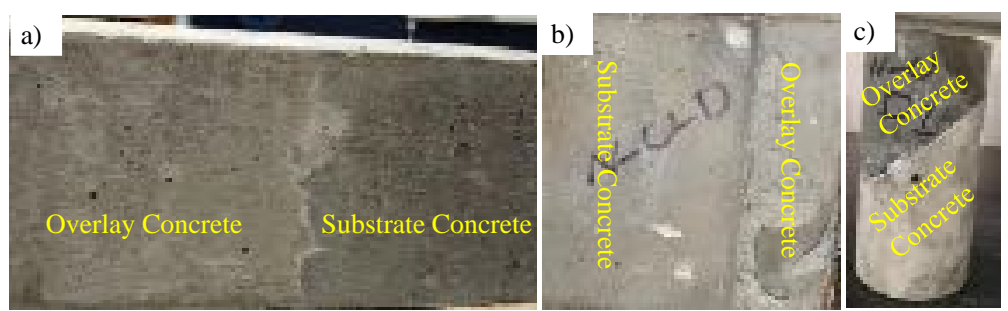

Figure 3- 1 Test specimens a) flexural test b) direct shear and c) cylinder slant-shear composite specimens. 
For each test method, samples were prepared: $3 \times$ NSC-no overlay, $3 \times$ NSC-NSC (dry), $3 \times$ NSC-NSC (wet), $3 \times$ NSC-UHPC (dry), $3 \times$ NSC-UHPC (wet). The specimens for the third-point flexural bond test were $6 \times 6 \times 20$ in. $(15 \times 15 \times 50 \mathrm{~cm})$ beams. The direct shear specimens were $6 \times 6 \times 6$ in. $(15 \times 15 \times 15 \mathrm{~cm})$ prisms, where 4 in. $(10 \mathrm{~cm})$ of the sample comprised the concrete substrate, and the 2 in. $(5 \mathrm{~cm})$ consisted of the overlay material. The slant-shear specimens were $3 \times 6$ in. $(7.5 \times 15 \mathrm{~cm})$ cylinders with an inclination angle ( $\alpha$ ) equal to $42^{\circ}$ from the vertical (see Figure 3-1, and Figure 3-2). Also, three samples of each test were entirely cast of NSC as the reference.

The utilized overlay materials were NSC and UHPC, which were applied over wet and dry substrate surfaces. The dry surface condition is obtained by keeping the substrate in ambient environmental conditions $\left(22{ }^{\circ} \mathrm{C}\right.$ to $25{ }^{\circ} \mathrm{C}$ and $50 \%$ to $\left.60 \% \mathrm{RH}\right)$ from the day after casting to overlay material placement. The wet concrete surface is obtained by keeping the substrate wet for the whole time before overlay casting by sprinkling the interface surface with water. Then it was wiped dry with a damped cloth 10 min before placing the overlay material.

All tests were loaded by a universal testing machine (UTM), and the forces were measured by a calibrated load cell. The load was applied gradually up to the failure point when the maximum force and the mode of failure were recorded. Table 3- 1 shows the number of specimens and the details. 
Table 3- 1 Details of test specimens.

\begin{tabular}{|c|c|c|c|}
\hline & Specimen Size & Substrate/Overlay (Surface wetness) & No. of Samples \\
\hline \multirow{5}{*}{$\begin{array}{l}\text { Third-Point } \\
\text { Flexural }\end{array}$} & \multirow{5}{*}{$\begin{array}{c}6 \times 6 \times 20 \text { in. } \\
(15 \times 15 \times 50 \mathrm{~cm})\end{array}$} & NSC/NSC (Dry) & 3 \\
\hline & & NSC/NSC (Wet) & 3 \\
\hline & & NSC/UHPC (Dry) & 3 \\
\hline & & NSC/UHPC (Wet) & 3 \\
\hline & & Full NSC & 3 \\
\hline \multirow{5}{*}{$\begin{array}{c}\text { Direct- } \\
\text { Shear Test }\end{array}$} & \multirow{5}{*}{$\begin{array}{c}6 \times 6 \times 6 \text { in. } \\
15 \times 15 \times 15 \mathrm{~cm}\end{array}$} & NSC/NSC (Dry) & 3 \\
\hline & & NSC/NSC (Wet) & 3 \\
\hline & & NSC/UHPC (Dry) & 3 \\
\hline & & NSC/UHPC (Wet) & 3 \\
\hline & & Full NSC & 3 \\
\hline \multirow{5}{*}{$\begin{array}{c}\text { Slant-Shear } \\
\text { Test }\end{array}$} & \multirow{5}{*}{$\begin{array}{l}3 \times 6 \text { in. } \\
7.5 \times 15 \mathrm{~cm}\end{array}$} & NSC/NSC (Dry) & 3 \\
\hline & & NSC/NSC (Wet) & 3 \\
\hline & & NSC/UHPC (Dry) & 3 \\
\hline & & NSC/UHPC (Wet) & 3 \\
\hline & & Full NSC & 3 \\
\hline \multirow{6}{*}{$\begin{array}{l}\text { Splitting } \\
\text { Test }\end{array}$} & \multirow{6}{*}{$\begin{array}{c}3 \times 6 \text { in. } \\
7.5 \times 15 \mathrm{~cm}\end{array}$} & NSC/UHPC (0\% RH) & 2 \\
\hline & & NSC/UHPC (75\% RH) & 2 \\
\hline & & NSC/UHPC (100\% RH) & 2 \\
\hline & & NSC/UHPC (Soaked) & 2 \\
\hline & & Full NSC (Soaked) & 2 \\
\hline & & Full UHPC (Soaked) & 2 \\
\hline
\end{tabular}

Figure 3- 2 shows the test setup for the flexural testing with third-point loading, direct shear, and slant shear tests. The flexural test samples were located on two supporting pins with a distance of $18 \mathrm{in} .(45 \mathrm{~cm})$, and two loading pins placed at an equal distance around the center 6 in. $(15 \mathrm{~cm})$. To minimize the effect of friction between the specimen and the supports, the supports were mounted on roller bearings. The test setup of direct shear progressed by setting $2 \times 6 \times 1$ in. $(5 \times 15 \times 2.5 \mathrm{~cm})$ steel plates at the center and each end of the sample. For the slant-shear test, the cylinders were smoothened to achieve two parallel and even loading surfaces and were positioned in direct contact with the loading plates. 


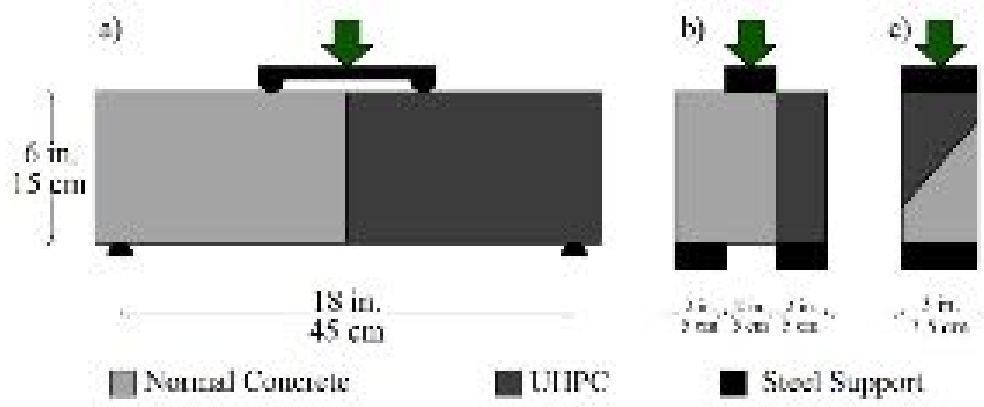

Figure 3- 2 Test setup configuration a) third-point flexural, b) direct shear and c) slant shear test.

\subsubsection{FLEXURAL TEST WITH THIRD-POINT LOADING RESULT}

The behavior of a concrete joint in tension was evaluated by the ASTM C78 thirdpoint flexural test [113]. In this method, when the failure originates in the tension side within the middle third of the span length, the modulus of rupture $(R)$ is calculated as follows:

$$
R=\frac{3 P L}{2 b d^{2}}
$$

Equation 3- 1

where $\mathrm{P}$ is the applied load at failure, $\mathrm{L}$ is the length of the span, $\mathrm{b}$ is the width, and $\mathrm{d}$ represents the height of the beam.

During the third-point flexural bond test, all NSC/NSC samples failed with debonding at the interface regardless of the moisture levels of the concrete substrate during the curing stages (see

Figure 3-3b and c); however, the bond strength was higher when the substrate was wet cured. Similar trends and failure modes occurred for the NSC/UHPC samples, regarding the moisture level of the NSC substrate, but the bond strength was much higher with the presence of the UHPC overlay (as much as 40\%). 

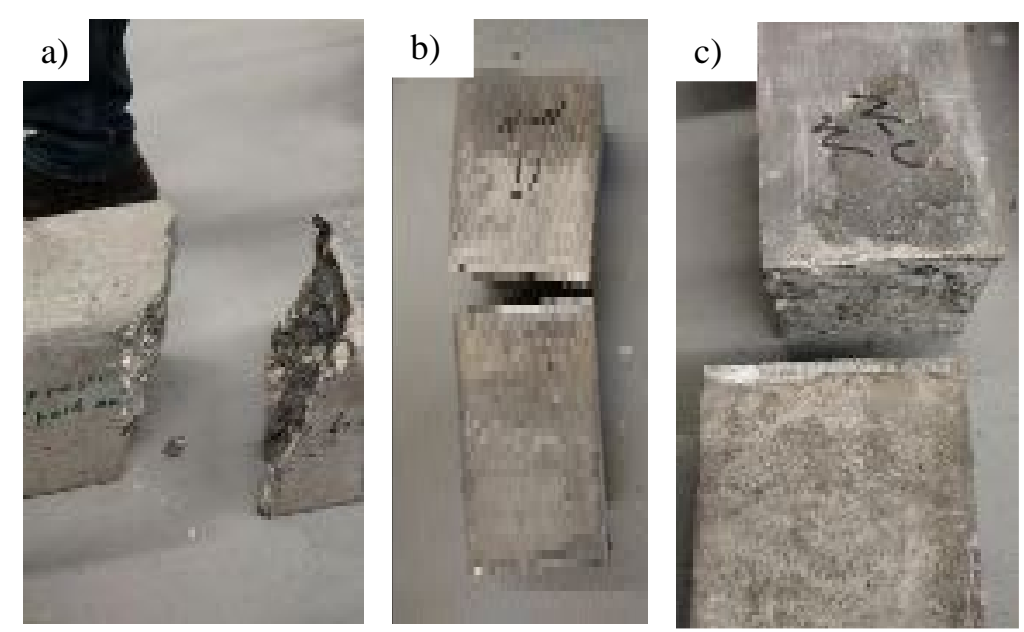

Figure 3- 3 Failure mode observed through third-point flexural test a) FN, b) NND, and c) NUW.

The results showed that the bond strength of the overlay was lower than the rupture strength of the bulk substrate and overlay material. The results would indicate that the smooth interface of the interface plane did not allow for adequate bonding, but the presence of moisture was shown to provide a benefit (Figure 3-4).

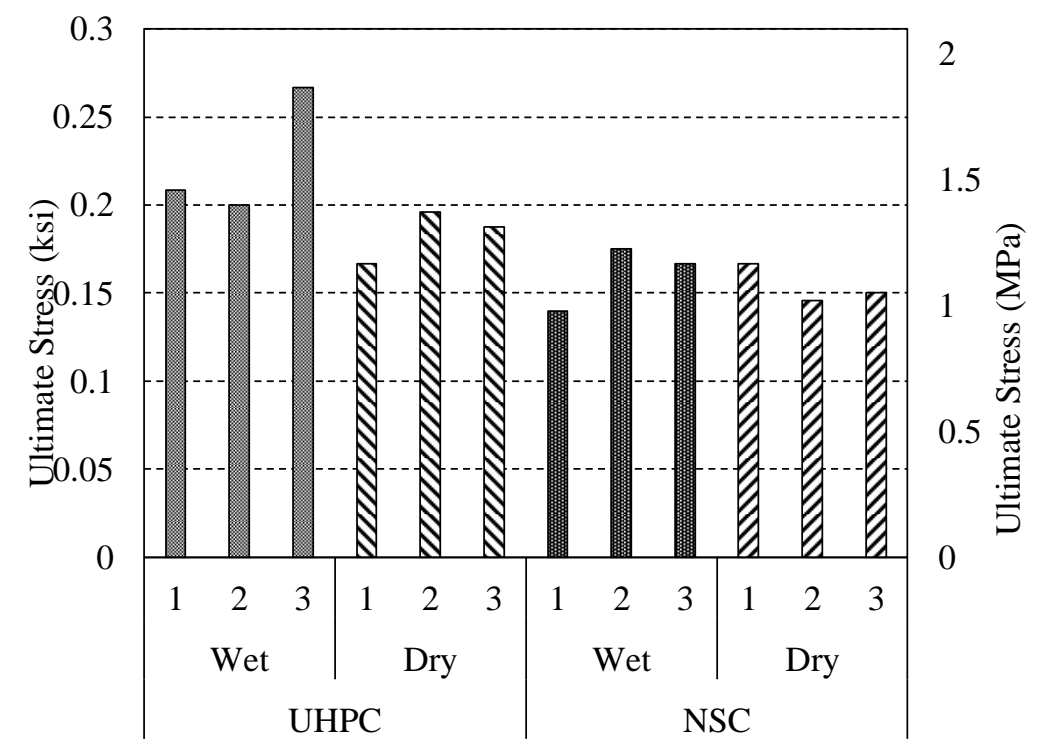

Figure 3- 4 Ultimate flexural strength of composite NSC and UHPC beams.

The same load setup was used to test FN samples. The bonding strength of the composite samples was then normalized to the average results of the FN specimens. The 
reported value was given as the percent reduction of the strength of a composite section compared to a full section of concrete materials with and without the use of UHPC. The average strength value $(0.41 \mathrm{ksi}(2.8 \mathrm{MPa}))$ was adequate for comparison. The standard deviation was $0.02 \mathrm{ksi}(0.14 \mathrm{MPa})$, respectively. The ultimate load of all specimens was noticeably less than that of a full NSC sample (Figure 3- 5), representing the interface bond failure. This reduction for NSC/UHPC samples showed up to 50\%, and for NSC/NSC samples up to $60 \%$ reduction in strength compared to the plain samples.

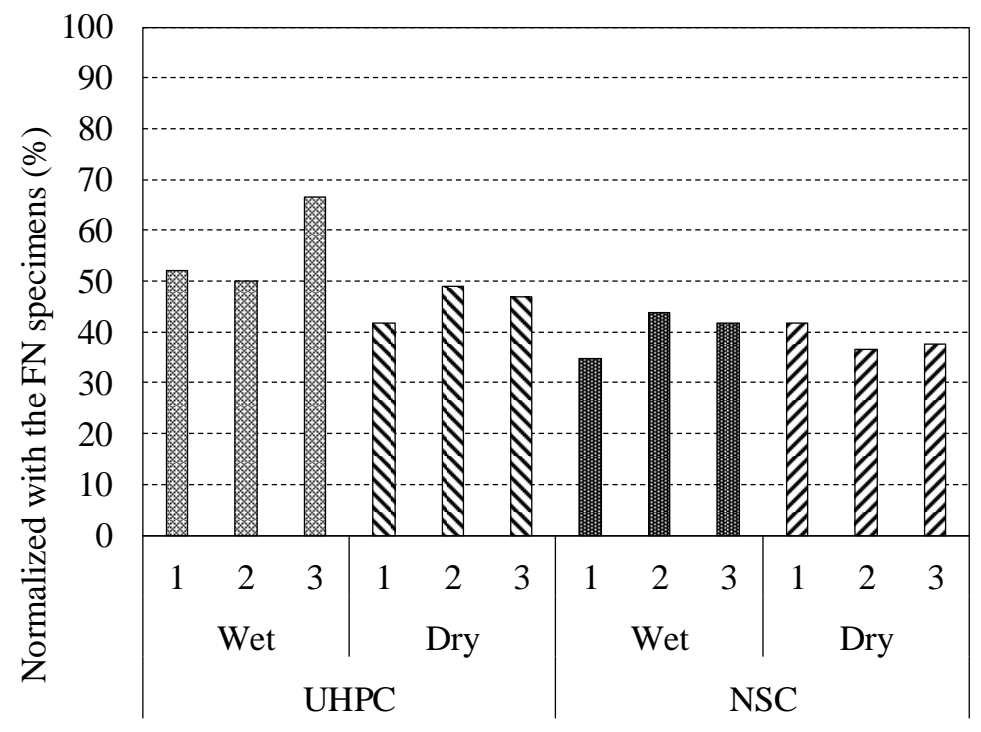

Figure 3- 5 Percent reduction of flexural strength of NSC and UHPC composite sections relative to full NSC sections.

\subsubsection{DIRECT SHEAR TEST}

The direct shear test was used to evaluate the bond strength under shear stress condition. It obtains the shear strength by dividing the maximum load $(P)$ by the surface area [75] (Equation 3- 2):

$$
v_{b}=\frac{P}{2 b d}
$$

Equation 3- 2 
where $v_{b}$ is the shear strength of the bond, $\mathrm{P}$ is the maximum load; $b$ and $d$ are the width and height of the prism, respectively. According to the shear-friction provisions of AASHTO [104], when there is no reinforcement, at the concrete-to-concrete interface, the ultimate longitudinal shear stress $\left(v_{u}\right)$ can be predicted by:

$$
v_{u}=C+\mu \sigma_{n}
$$

Equation 3- 3

where $C$ is the adhesion strength; $\mu$ is the friction coefficient, and $\sigma_{n}$ is the normal external stress acting on the interface, which is zero. Therefore, in the direct shear test, just the adhesion-related part is participating.

Failure of composite prisms by the direct-shear test can result in either shear failure of the bond interface or shear of the bulk concrete materials. Testing with both composite NSC/NSC and NSC/UHPC indicated shear failure at the bond interface. An example of the failure mode observed in direct shear testing is shown in Figure 3- 6.
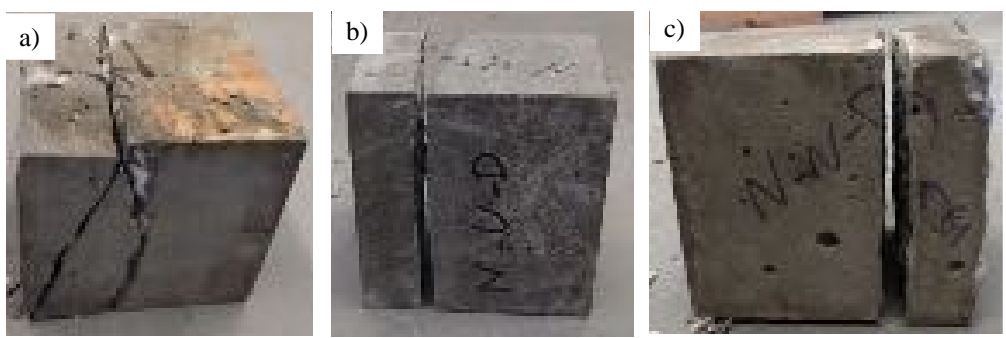

Figure 3- 6 Failure mode observed through direct shear test a) FN block, b) NUD samples (bonding at the interface) and c) NND samples (de-bonding at the interface).

The bond strength was higher when the substrate was wet cured regardless of the overlay material, but the bond strength was much higher with the presence of the UHPC overlay (as much as 50\%). 


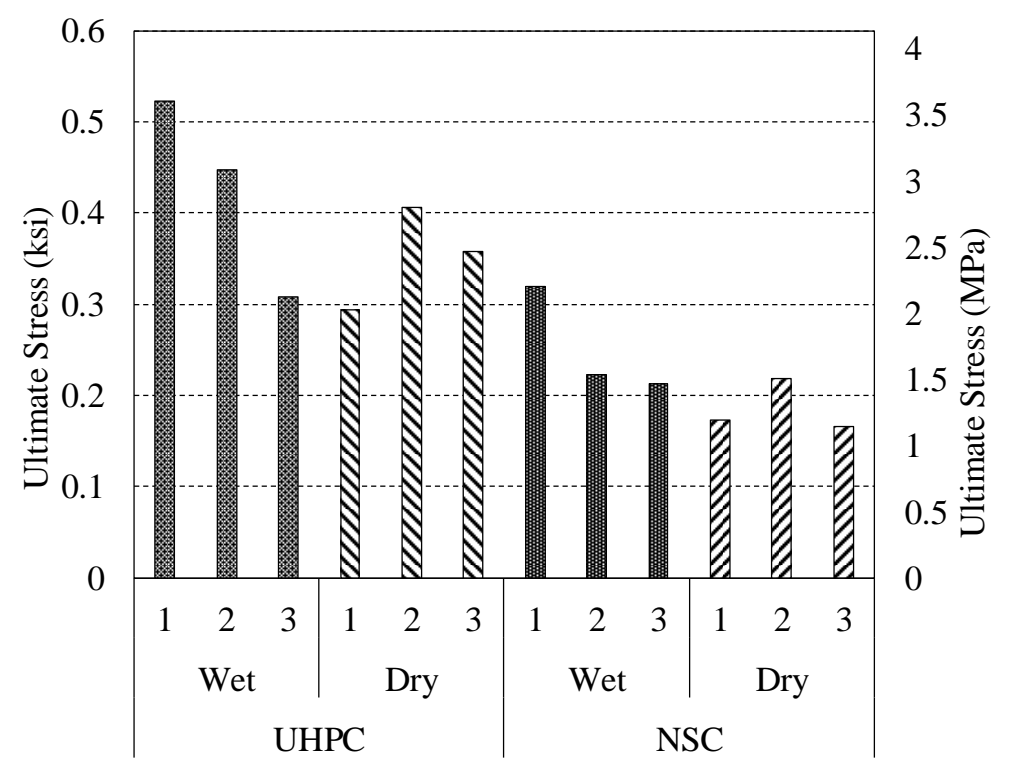

Figure 3- 7 Ultimate shear strength of composite NSC and UHPC prisms.

The same load setup was used to test FN prisms. The bonding strength of the composite samples was then normalized to the average results of the FN specimens. The reported value was given as the percent reduction of the strength of a composite section compared to a full section of concrete materials with and without the use of UHPC. The average strength value $(0.9 \mathrm{ksi}(6.2 \mathrm{MPa}))$ was adequate for comparison. The standard deviation was $0.25 \mathrm{ksi}(1.7 \mathrm{MPa})$, respectively. The ultimate load of all specimens was noticeably less than that of a full NSC sample (Figure 3-8), representing the interface bond failure. This reduction for NSC/UHPC samples showed up to $40 \%$, and for NSC/NSC samples up to $80 \%$ reduction in strength compared to the plain samples. 


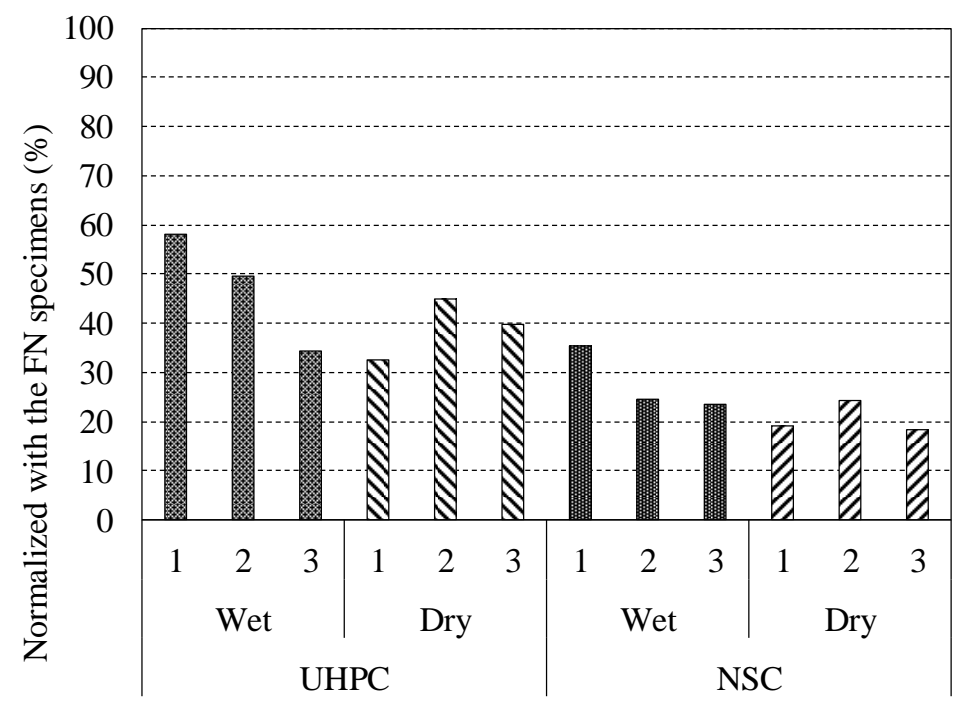

Figure 3- 8 Percent reduction of flexural strength of NSC and UHPC composite sections relative to full NSC sections.

\subsubsection{SLANT SHEAR TEST}

The Slant-Shear test (ASTM C882/C882M) creates a loading state where the bond interface is under combined compression and shear loadings [114]. The normal and shear stresses on the bond surface could be obtained using Equation 3- 4, and Equation 3- 5:

$$
\begin{aligned}
\sigma_{n} & =\frac{P}{A} \cos ^{2} \alpha \\
\tau_{n} & =\frac{P}{A} \sin \alpha \cos \alpha
\end{aligned}
$$

Equation 3- 5

where $\alpha$ is the angle between the bond interface and the longitudinal axis, $\mathrm{P}$ is the applied load, and A shows the cross-section area.

The ultimate stresses on the bond surface were calculated, and the results are presented in Figure 3-10. Moreover, the failure modes are illustrated in Figure 3- 9. One failure mode observed in composite samples was the failure in substrate concrete (Figure 3- 9a). In this mode of failure, the main cracks happened in the substrate concrete portion. 
De-bonding at the interface was another failure mode that formed between substrate concrete and the overlay (Figure 3-9b). The last failure mode that happened was partial failures including mixed-mode failures within both the substrate and the overlay concrete (Figure 3-9c).
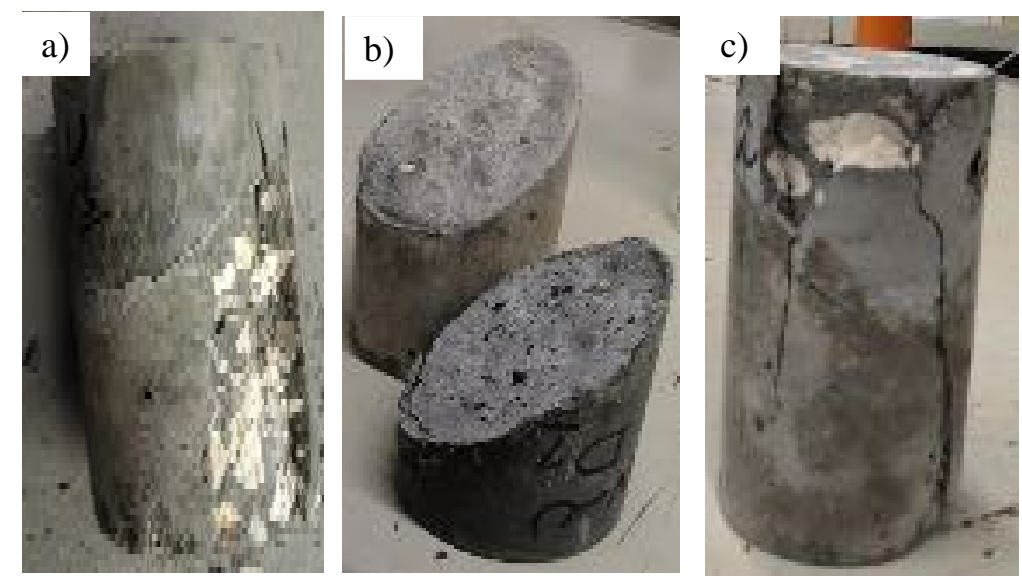

Figure 3- 9 Failure modes observed through slant shear test a) failure within the substrate, b) failure along the bond interface, and c) mixed mode of failure in the overlay and substrate.

The ultimate stress, in wet condition, for the samples when the overlay material is NSC obtained higher value compared to the dry surface. This agrees with the results of third-point flexural and direct shear tests. While the dry substrate offered slightly higher bond strength compared to the wet substrate when UHPC was the overlay material. Similar results were observed by Ref [115] in which pull-off and slant shear tests were conducted. They observed that the wet substrate provides higher bond strength compared to dry in pull-off tests, while the converse was true in slant shear specimens. That might be contributed to the flow of water from overlay to the dry substrate and the casting direction in slant shear test specimens. 


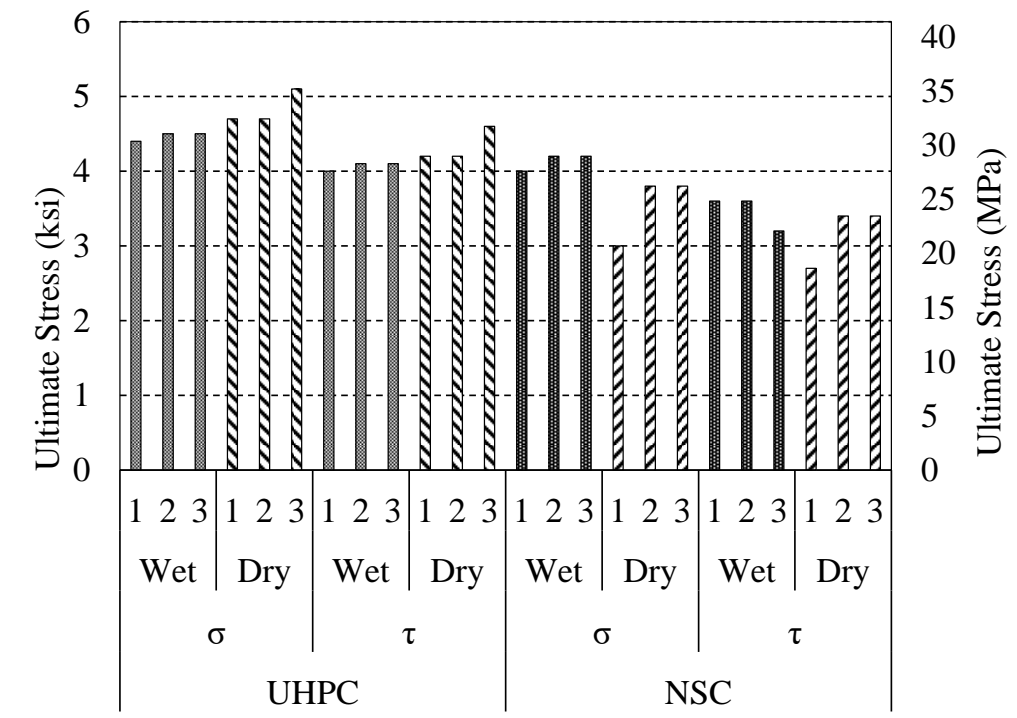

Figure 3-10 Ultimate applied stress on composite NSC and UHPC cylinders.

\subsubsection{SPLITTING TEST}

The ASTM C496 [116] was used to measure the splitting tensile strength bond strength between the substrate and UHPC as of the composite cylinders. This method is simple to perform in which a specimen with square or circular cross-section is positioned under compression. The splitting tensile strength for cylinders is calculated using Equation 3- 6:

$$
T=\frac{2 P}{\pi A r}
$$

Equation 3- 6

where, $\mathrm{T}$ is the splitting tensile strength, $\mathrm{P}$ is the maximum applied load; and $\mathrm{A}$ is the area of the bond plane.

This part includes 12 specimens (with duplicates) tested in splitting cylinders including 8 composite samples plus 2 plain NSC and 2 plain UHPC. It should be noted that plain specimens where soaked in water from demolding to the test day. The same mix design was used for the concrete in substrate portion of all specimens placed in $3 \times 6 \mathrm{in}$. ( $75 \times 150 \mathrm{~mm}$ ) plastic molds. Specimens were removed from the forms 7 days after casting 
and cut in half lengthwise. Afterward, all the specimens were conditioned to moisture content including 5\%,75\%,100\% RH, and immersed in water. After 60 days of conditioning, the interface was roughened by grooving the contact surface of the substrate. The estimated amplitude of roughness was $0.12-0.16$ in. $(3-4 \mathrm{~mm})$ at each $10 \mathrm{~mm}$. The roughened NC substrate specimens were then conditioned up to 3 more days before casting UHPC. Then all the NSC substrate specimens were taken out from the exposure tank and the contact surface of specimens was recleaned using a wire brush and high-pressure air before UHPC plastering. The substrate halves were placed vertically at one side of the cylindrical molds, and the molds were then filled with UHPC. The substrate surface before and after grooving is shown in Figure 3- 11. Seven days after casting UHPC the samples were demolded and again placed in the corresponding condition environment for 190 days then they were prepared for the tests.

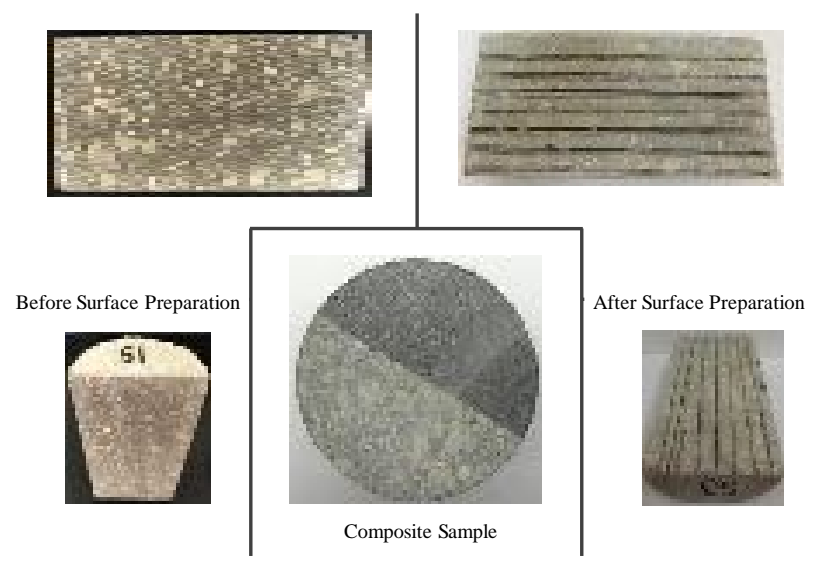

Figure 3- 11 The process of sample preparation.

The values of the splitting cylinder tensile test results are shown in Figure 3-12. The indirect tensile strengths of the different exposures were recorded in ascending order. 


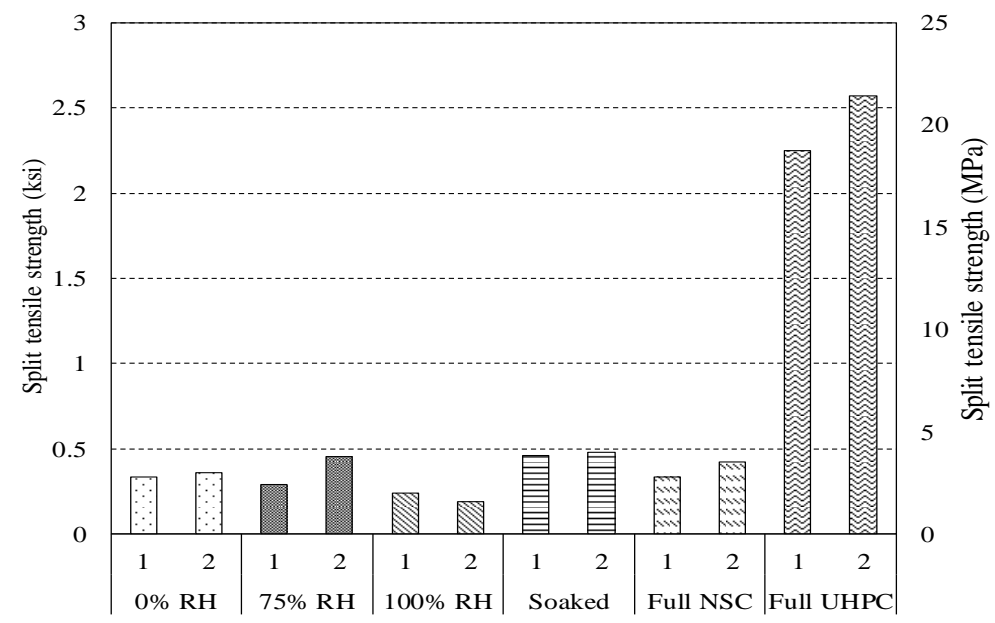

Figure 3- 12 Split tensile strength (T) for each humidity exposures.

The results indicate that strength level achieved by most of the surface moisture content for composite specimens fall under an Excellent bonding category based on the quantitative bond strength quality proposed by Sprinkel and Ozyildirim [117] (Table 3- 2). The only exception was the composite samples with $100 \% \mathrm{RH}$ which attained a strength value that could be classified as Good. It can be attributed to the fact that the coefficient of water diffusion declines by about 10 to 20 times when moving from $90 \%$ to $60 \%$ pore humidity [118]. Diffusion changes the rate of cement hydration as it lowers the water amount available for further hydration process and reduces the reaction rate. Although this may increase the bond strength for many cases [119], for low water-to-cement mixes such as UHPC, there might not be adequate water for further hydration. This may significantly alter the quality of the repair.

In addition, the reported tensile strength of the soaked surface composite cylinders passes the tensile splitting strength of the plain NSC. This approves the general agreement to support the saturated substrate with a dry surface as one of the best compromises for obtaining good surface preparation. 
In term of the samples with dry substrate surface, poor quality of bond was expected, as it was stated in literature [78] that applying cement mortar to dry concrete surface results in sucking a part of the paste water into the substrate concrete before forming reactive components in the cement paste of the fresh concrete. This would result in blocking the capillary pores for penetration of the reactive components. In contrast to the expectations, it was successful which could be contributed to fitting UHPC in the grooves rather than any adhesive mechanism [80].

Table 3- 2 Quantitative bond quality in term of bond strength [117].

\begin{tabular}{cc}
\hline Bond Quality & Bond Strength, ksi (MPa) \\
\hline Excellent & $\geq 0.3(2.1)$ \\
Very Good & $0.25-0.3(1.7-2.1)$ \\
Good & $0.2-0.3(1.4-1.7)$ \\
Fair & $0.1-0.2(0.7-1.4)$ \\
Poor & $0-0.1(0-0.7)$ \\
\hline
\end{tabular}

Three types of failure modes of the splitting cylinder tensile test can be observed in Figure 3-13. These three failure types are represented as, Type A= interface failure, Type $B=$ interface failure with partial substrate failure, and Type $C=$ substrate failure. The results demonstrate that the bonding for the surfaced grooved composite specimens is relatively strong as most of the composite cylinders failed in the NSC substrate. 

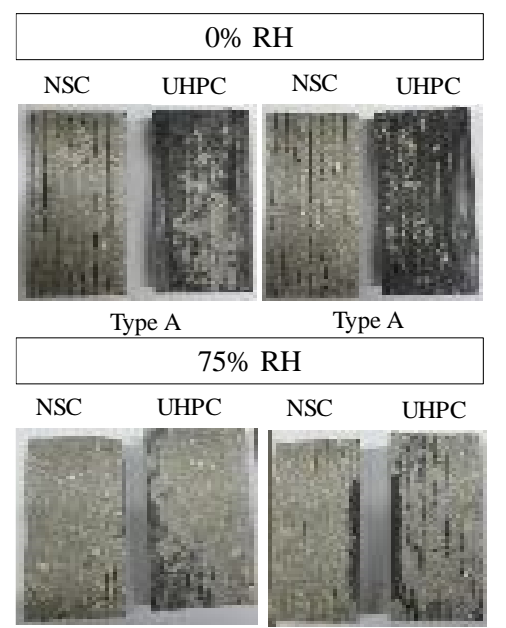

Type B
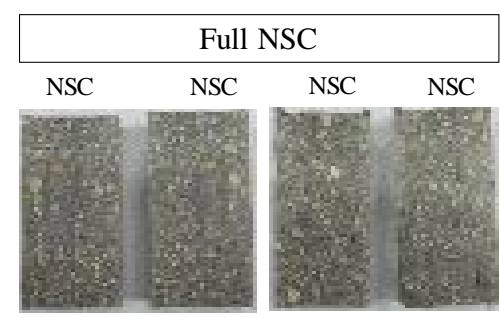

Type C

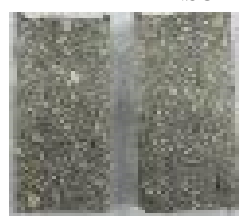

Type C

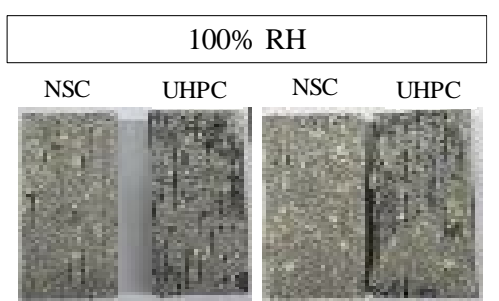

Type A

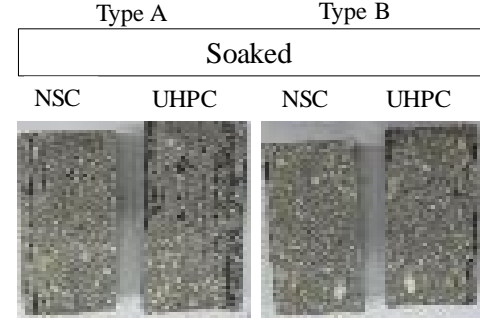

Type C

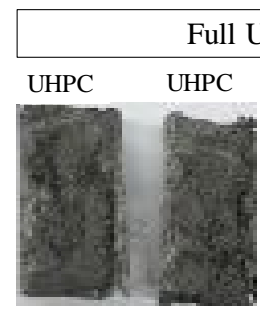

Type C
Type C

UHPC UHPC

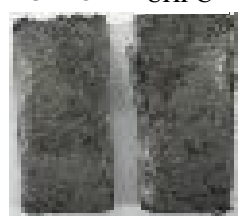

Type C

Figure 3-13 Failure modes of the samples at each exposure condition.

\subsubsection{DISCUSSION}

Generally, samples with wet surface showed better bond behavior as compared to the dry one. The reason could be attributed to the fact that the moisture condition of the substrate determines the water movement rate from the overlay concrete to the substrate [26]. Water movement process includes two parts, first water intrusion from the overlay into the substrate capillaries, and second, cement paste hydration in the overlay or limited rehydration of the substrate [24]. A concrete surface which is dry draws water from the overlay material. If it extracts too much water, the overlay concrete may not hydrate well resulting in a weak interfacial layer [26]. Instead, too wet surface increases the water-tocement ratio of the overlay material at the interface leading to lower strength of the interface, and increase shrinkage [26]. 
Furthermore, the excess water in open cavities may disturb the interlocking effect by preventing the penetration of cement particles into the pores. Therefore, as Chorinsky [78] concluded "too dry or too wet concrete substrate surface" weakens the bond strength. However, it is hard to draw a general conclusion about how much of the moisture content of the concrete substrate helps to improve the bond strength because it depends on the material characteristic of the substrate material.

All specimens exhibited higher bond strength when the overlay material shifted from NSC to UHPC. That indicates the influence of the overlay material on the bond strength. The exceptional workability, compaction, and self-consolidation of UHPC enhance its capability of filling the pores on the substrate surface [26]. This ability improves the capillary suction in the substrate and directly affects enough contact area between UHPC and substrate.

\subsubsection{Chloride penetration at cold joints of structural members with dissimilar concrete incorporating UHPC}

Cold joints are reported to result in strength reduction and increasing corrosion sensitivity [120], [121]. Many investigations on accelerated chloride ingress and carbonation have been published showing that concrete with cold joint allows additional intrusion path of harmful ions [120]-[123].

\subsubsection{TEST SET-UP}

This research examines the extent to which enhanced chloride transport may occur at the cold joint. The effectiveness of the bond at the concrete interface (with various levels of moisture availability at the time of UHPC repair) to minimize chloride penetration was 
examined. To this effect, the substrate concrete was conditioned to moisture content (5\%, $75 \%, 100 \% \mathrm{RH}$, and wet) prior to and after UHPC repair concrete casting. Chloride penetration was accelerated by an impressed current, and chloride content was assessed by silver nitrate solution sprayed on the cold joint. Moreover, the tensile bond strength between substrate concrete and UHPC was measured using the splitting tensile test.

Same specimens used in splitting tensile tests were used for this section. A modified version of the Rapid Migration Test (CTH Test) [124] was used to measure the chloride penetration through the cold joint. In this setup, a migration cell is set up with as shown in Figure 3-14. All the samples were ground at both ends to prepare smooth surfaces (Figure 3- 11). Then a plexiglass cylindrical cup was used to make a pond on one end where the $\mathrm{NaCl}$ solution was poured $(10 \% \mathrm{NaCl}$ by mass in tap water $=100 \mathrm{~g} \mathrm{NaCl}$ in $900 \mathrm{~g}$ water, about $2 \mathrm{~N}$ ). The outside of the cup for one inch down the top was epoxy sealed to limit the chloride penetration in one dimension. Titanium mesh was used in the $\mathrm{NaCl}$ solution as the cathode and in Lime water as an anode $(0.3 \mathrm{~N} \mathrm{NaOH}$ in water $\sim 12 \mathrm{~g} \mathrm{NaOH}$ in 1-liter water), and a voltage of $25 \mathrm{~V}$ was applied to the specimen for 21 days. The current was measured daily to plot the cumulative current vs. time graph.

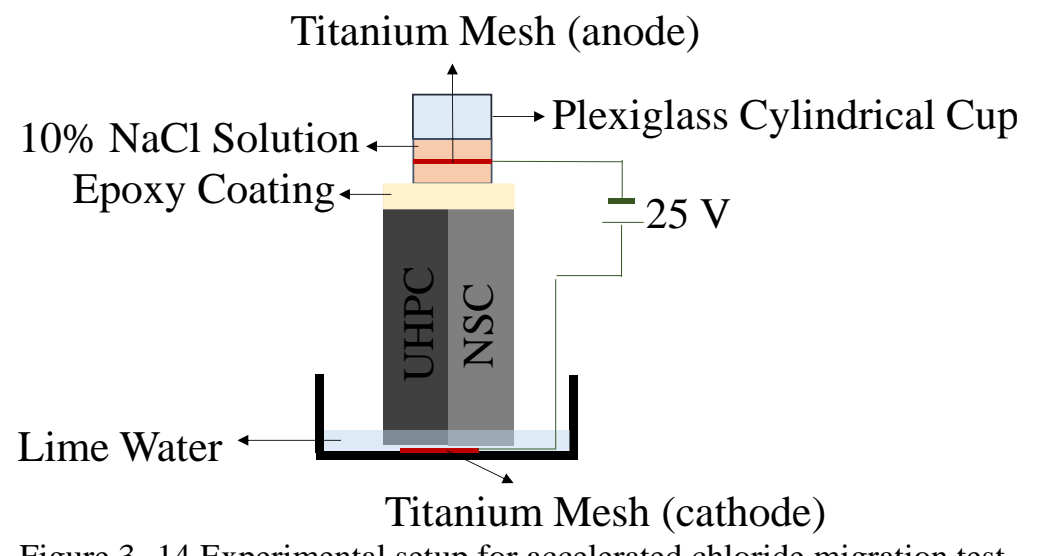


After 21 days the samples were disconnected and prepared to do the splitting test. Tension stresses split the cylinders into two halves. Afterward, a colorimetric technique was employed to determine the depth of chloride penetration in one-half of the specimens. [125][126] In this method, a silver nitrate solution is applied as a colorimetric indicator. When silver nitrate solution is sprayed on a hunk of concrete with chloride ion, a chemical reaction occurs producing silver chloride (a whitish substance). With no chloride in the concrete, the silver alternatively bonds with the hydroxides present in the concrete (a brownish color).

\subsubsection{RESULTS AND DISCUSSION}

Figure 3-15 expresses the results of modified RCPT in term of total charge passed (TCP) in coulombs for the NSC, UHPC, and composite cylinders of NSC/UHPC with different NSC substrate surface moisture content. Hypothetically, the TCP could be associated with the concrete sample resistance against penetration of chloride ion. Higher TCP value means lower resistance to penetration of chloride ion. In other words, the TCP value inversely proportionate to the concrete impermeability. 


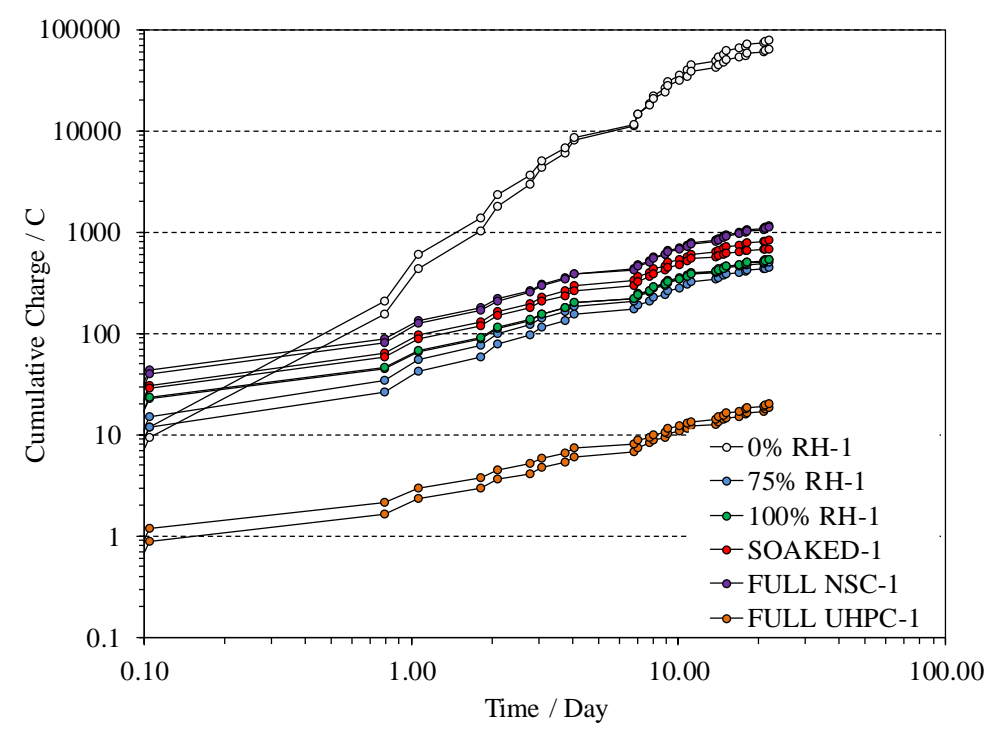

Figure 3-15 Cumulative charge passed through specimens at each different exposure.

Figure 3- 15 shown the RCPT results in term of Total Charge Passed (TCP) in coulombs for the NSC substrate, UHPC, and composite of NSC/UHPC with different substrate surface moisture content. The TCP could be related to the resistance of the concrete sample against chloride ion penetration. Lower TCP value indicates greater resistance to chloride ion penetration.

the plain UHPC specimen had the lowest TCP values (i.e. 21 coulombs at 21 days), while the plain NSC specimen had TCP value more than 4000 coulombs after 21 days. As expected, the low bulk permeability of UHPC resulted in significantly lower chloride ion migration.

All the composite specimens, except the composite samples where substrate had 0\% RH before UHPC placement, exhibited TCP values of less than 750 coulombs after 21 days. This also seemed to signify that the conditioning environments for the NSC substrate $(75 \%, 100 \% \mathrm{RH}$, and soaked) did not have a major influence on chloride permeability during the testing. Adequate surface preparation with sufficient moisture levels apparently 
provided good bonding for all composite samples and similar performance to resist chloride ion penetration.

The high value of the recorded TCP for of the composite samples where substrate had 0\% RH before UHPC placement (70000 coulombs) can be contributed to the capillary absorption of the concrete substrate leading to quick absorption of chloride solution. Capillary absorption is very rapid and strong transport mechanisms compared to the other transport mechanisms.

Assuming that the flux of chloride transport is proportional to the surface area of the NSC (and little current passes through UHPC component), the total ionic current passing composite concrete specimens would ideally result in a 1:2 ratio compared to the plain NSC sample. However, in the composite samples with $100 \%$ RH the TCP values were larger. This could be an indication of preferential chloride penetration through the joint.

To assess the chloride penetration path through the joint interface, after splitting the samples under load, the substrate surfaces were sprayed with $1 \mathrm{M} \mathrm{AgNO3}$ solutions. The specimens were allowed to dry naturally at room temperature for 30 minutes. When a silver nitrate solution is sprayed on concrete containing chloride ion, a photochemical reaction occurs. The chlorides bind with the silver to produce silver chloride (white precipitation). In the absence of chlorides, the silver instead bonds with the hydroxides present in the concrete and formed a brown precipitate of silver oxide [23]. Representative photos after spraying AgNO3 indicator are shown in Figure 3- 16.

Chloride penetration could be readily observed by the differentiation in surface coloration on the NSC portion of the specimen, and bulk chloride penetration was generally 
seen at the upper portion of the specimen. No chloride penetration could be captured for UHPC samples mainly due to its remarkable impermeability. A generally uniform chloride penetration front through the joint developed in the composite concrete specimens conditioned in $0 \%, 75 \% \mathrm{RH}$ and soaked in water.

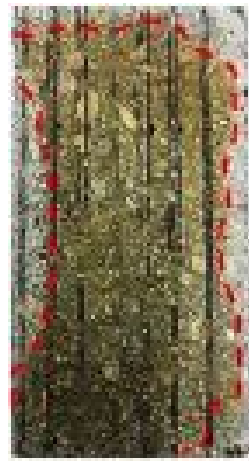

Q936 RH

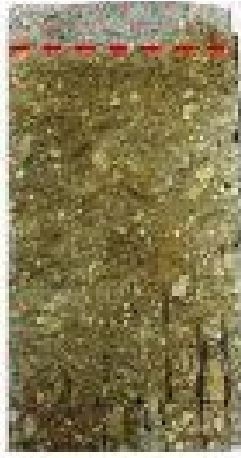

$75 \% \mathrm{RH}$

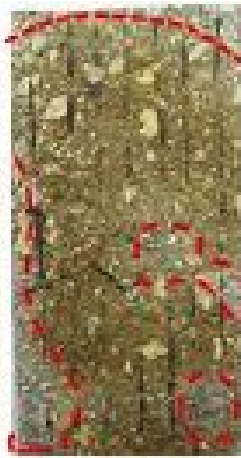

$100 \%$ RH

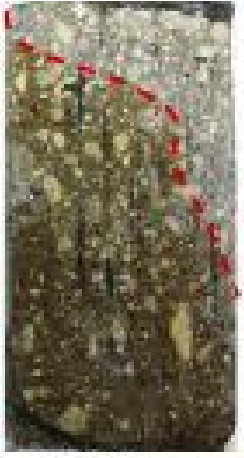

SOATID

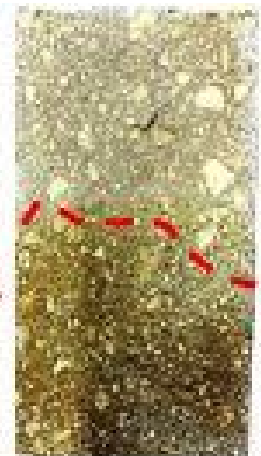

FLL NSC $5 O A K T D$

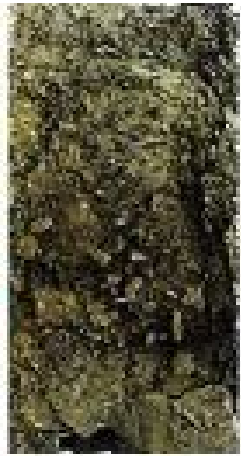

VIL LHPC

Figure 3- 16 Chloride penetration depth for each sample.

As expected, the apparent bulk chloride penetration depth through the joint was higher with the presence of excess moisture levels. The highest chloride penetration depth (up to $76 \mathrm{~mm}$ ) was measured for samples soaked in water. Generally lower chloride penetration depths (up to $16 \mathrm{~mm}$ ) were measured for the other cases.

However, it was apparent that chloride ions can also penetrate along the surface of the joint interface. For the specimens conditioned at $0 \% \mathrm{RH}$, the high measured TCP values evidently occurred along the edge of the specimen. The specimens conditioned at $100 \% \mathrm{RH}$ also showed indication of non-uniform chloride penetration along the surface of the cold joint as evidenced by localized regions of silver chloride penetrations throughout the joint surface. In part to address the possible means for non-uniform chloride penetration, the bulk chloride transport was compared to the bond of the cold joint. 
The specimens soaked in water showed both the largest bulk chloride penetration and the highest split tensile strength which would indicate that bulk diffusion was prominent here. The specimens conditioned at $100 \% \mathrm{RH}$ showed the lowest bulk chloride penetration and also the lowest split tensile strength indicating that the joint environment there did not provide strong resistance to chloride penetration and non-Fickian transport can occur. Similar behavior would be expected for the other samples.

\subsection{SUMMARY}

The evaluation of the bond strength consists of two sets of experiments. First, the effect of wetness of the substrate as well as the overlay materials was investigated. Second, the bond strength between UHPC and substrate concrete when the substrate is conditioned to various moisture content prior and after UHPC placement was evaluated.

Moreover, the enhanced chloride transport that may occur at the cold joint was examined to evaluate the corrosion durability of steel embedded in dissimilar concretes incorporating UHPC. The effectiveness of the bond at the concrete interface (with various levels of moisture availability at the time of UHPC repair) to minimize chloride penetration was examined.

- $\quad$ Samples with wet surface showed better bond behavior as compared to the dry one. The reason could be attributed to the fact that the moisture condition of the substrate determines the water movement rate from the overlay concrete to the substrate. 
- All specimens exhibited higher bond strength when the overlay material shifted from NSC to UHPC. That indicates the influence of the overlay material on the bond strength.

- The maximum value of the standard variation of each group of tests was calculated and compared. The calculation results show that the flexural test with a maximum standard deviation of $0.03 \mathrm{ksi}(0.2 \mathrm{MPa})$ has the best consistency and slant shear test with $0.5 \mathrm{ksi}(3.5 \mathrm{MPa})$ has the most inconsistent results.

- $\quad$ According to Sprinkel and Ozyildirim categorization, the strength level obtained for most surface moisture content of the substrate falls under an 'Excellent' bonding category, except the composite samples with $100 \% \mathrm{RH}$ which had a strength value classified as "Good".

- The attained tensile strength of the soaked surface composite cylinders exceeds the tensile splitting strength of the plain NSC cylinders.

- $\quad$ Plain UHPC specimen exhibited significantly lower chloride penetration compared to NSC.

- $\quad$ Chloride penetration was generally observed as bulk transport but there was an indication that non-Fickian chloride transport can occur along the surface of the joint. There was a general indication that moisture transport through the cold joint depends on moisture levels. 


\section{CHAPTER 4 MECHANICAL PERFORMANCE OF UHPC REPAIR IN AXIALY LOADED BRIDGE ELEMNENTS}

This section investigates the performance of the proposed retrofit method through a series of experimental studies. A total of eleven columns were cast and intentionally damaged to simulate a deficient column. Three columns with different transverse reinforcement ratios were considered as the baseline, and seven of the columns were repaired using UHPC, and one with Normal Strength Concrete (NSC) for comparison. The retrofitted columns were subjected to a constant axial and a cyclic lateral load. The obtained experimental results revealed that the UHPC shell increased the strength of the damaged elements, without increasing the size.

\subsection{RESEARCH APPROACH}

To evaluate the performance of UHPC as repair material, column prototypes were designed and built to represent a bridge pier or a building column. The columns were then artificially damaged and repaired with UHPC. The specimens were scaled as $1 / 4$ of a bridge column with a height to diameter ratio of 5 , and their stubs represented a connection, such as a beam-column joint or a footing. The dimensions of the test columns are presented in Figure 4- 1. 

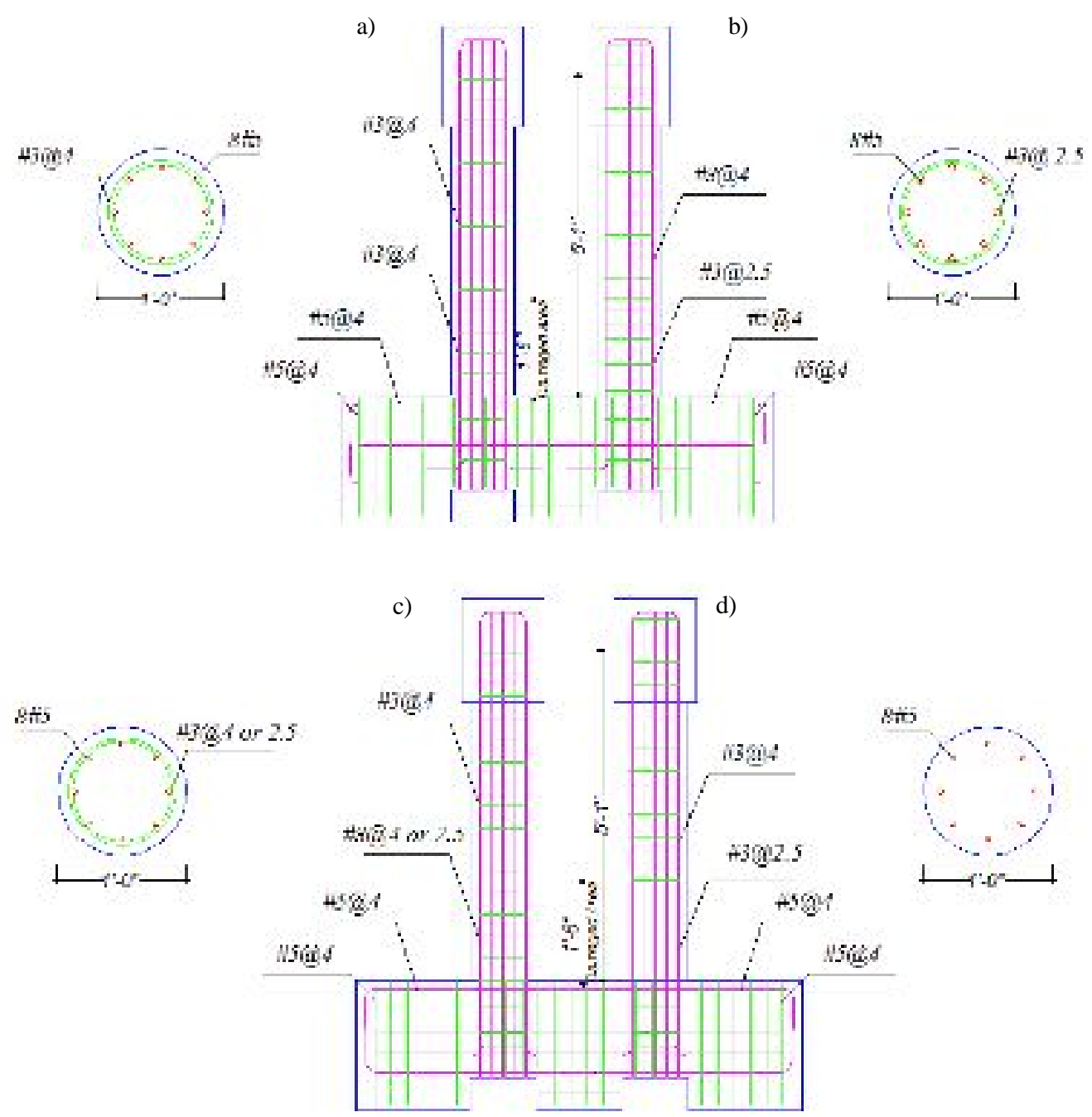

Figure 4- 1 Test specimen dimensions a) Unit 1 through 3 and, b) Unit 7 through 11 c) Unit 5 and 6, and d) Unit 4.

The first phase of the repair procedure is the material removal of the damaged concrete cover and cleaning the substrate from residue particles and creation of an exposed aggregate interface which is necessary to have a good bond between UHPC and existing concrete in repaired areas. Then the lost, corroded, or extremely deformed reinforcement is cut and replaced. Before casting UHPC, the substrate concrete surface was sprayed with water. At the end, all the cavities were filled with UHPC using proper forming. 
The flowability of UHPC makes it possible to fill different shapes of cavities, and its low permeability acts as a barrier to the intrusion of deleterious agents. UHPC has a relatively early strength gain, which reduces the traffic interruptions, and its durability decreases the life-cycle cost of the repair [130].

\subsection{EXPERIMENT DESIGN}

In this research, $11 \mathrm{RC}$ columns were cast and artificially damaged with spalling cover. Seven of the damaged columns were repaired with UHPC, one repaired with NSC, and one column with no repair was used as the test baseline. Moreover, two intact columns were cast with the substrate concrete as the test reference columns. The test specimens were embedded in a reinforced base, which supports the columns during the test. The test matrix is listed in Table 4- 1.

Table 4- 1 Test matrix.

\begin{tabular}{|c|c|c|c|c|c|c|c|}
\hline UNIT & $\begin{array}{c}\text { Damage } \\
\text { Geometry }\end{array}$ & $\begin{array}{c}\text { Shell } \\
\text { Thickness }\end{array}$ & $\begin{array}{c}\text { Damage } \\
\text { Length }\end{array}$ & $\begin{array}{c}\text { Repair } \\
\text { Material }\end{array}$ & $\begin{array}{c}\text { Fiber } \\
\text { Content }\end{array}$ & $\begin{array}{c}\text { Hoops Spacing } \\
\text { in repair area }\end{array}$ & $\begin{array}{c}\text { Footing } \\
\text { Repair }\end{array}$ \\
\hline 1 & Asymmetric & $0.5-2$ in & 18 in. & UHPC & $2 \%$ & No Hoops & Yes \\
\hline 2 & Asymmetric & $0.5-2$ in & 18 in. & UHPC & $2 \%$ & 4 in. & Yes \\
\hline 3 & Symmetric & 0.75 in. & 45 in. & UHPC & $2 \%$ & 4 in. & Yes \\
\hline 4 & Asymmetric & - & 18 in. & No Repair & - & No Hoops & No \\
\hline 5 & - & - & - & Reference 1 & - & 4 in. & No \\
\hline 6 & - & - & - & Reference 2 & - & 2.5 in. & No \\
\hline 7 & Symmetric & 2 in. & 18 in. & NSC & $0 \%$ & 2.5 in. & No \\
\hline 8 & Symmetric & 2 in. & 18 in. & UHPC & $2 \%$ & 2.5 in. & No \\
\hline 9 & Symmetric & 2 in. & 18 in. & UHPC & $2 \%$ & 2.5 in. & No \\
\hline 10 & Symmetric & 2 in. & 18 in. & UHPC & $4 \%$ & 2.5 in. & Yes \\
\hline 11 & Symmetric & 2 in. & 18 in. & UHPC & $4 \%$ & 2.5 in. & Yes \\
\hline
\end{tabular}

\subsection{Test SPECIMEn CONSTRUCTION}

The columns were longitudinally reinforced with eight Grade $60 \mathrm{ksi}(414 \mathrm{MPa})$, \#5 (16mm) steel bars, resulting in $2.2 \%$ longitudinal steel reinforcement ratios $(\rho=2.2 \%)$. All columns were initially equipped with 0.375 in. $(10 \mathrm{~mm})$ diameter steel hoops with 4 in. 
(100 mm) spacing, in accordance with AASHTO specification for the non-seismic area [131]. The construction process of a typical specimen forming, caging and casting is shown in Figure 4- 2.
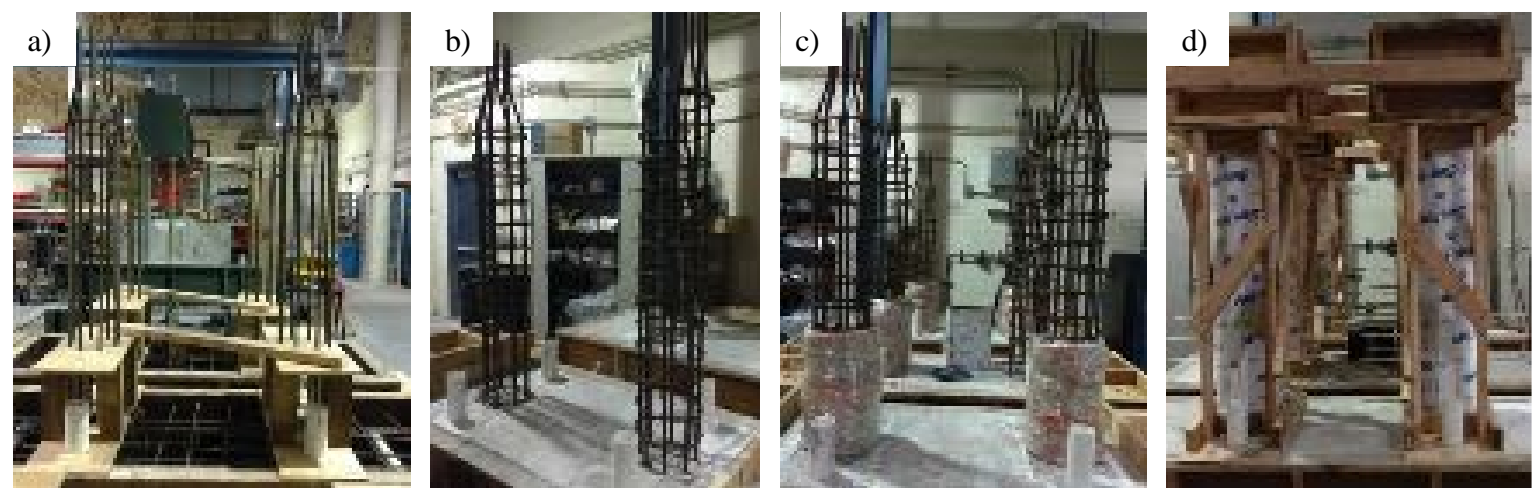

Figure 4- 2 The construction process of a typical specimen: a) formwork and caging, b) casting the footing, c) simulating the damage, and d) erecting the columns, and casting the concrete substrate.

The simulated damages were created similar to partial concrete spalling, and they were made in the lower portion of the columns to achieve flexural enhancement. To create typical damage, the bottom $18 \mathrm{in.}(460 \mathrm{~mm})$ of each column was filled with insulation roll (see Figure 4- 2c) according to the section view presented in Figure 4- 3.

Specimens were cast and stripped after seven days. The curing regime used for this study was moist curing using plastic sheets for seven more days and air-dried allowing the specimens to remain in an ambient laboratory environment until repair. 

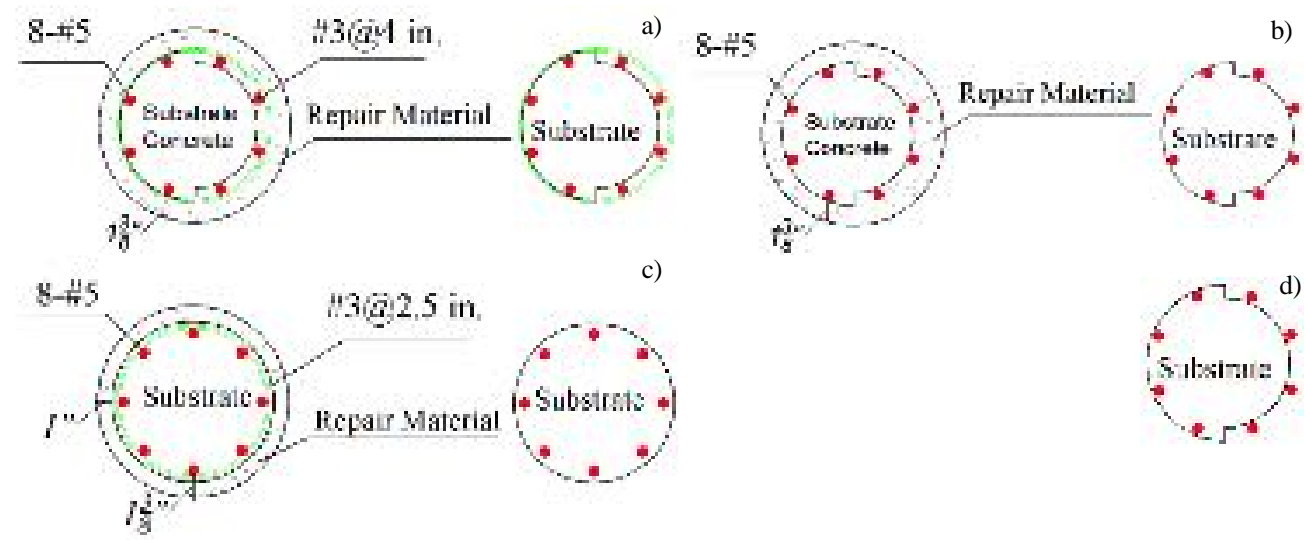

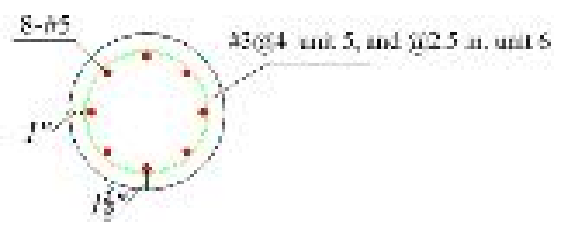

Repaired Section

Damage Section

)

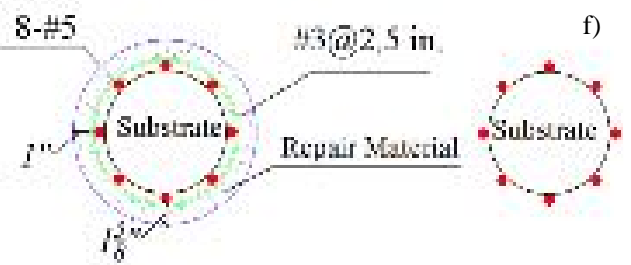

Repaired Section

Damage Section

Figure 4- 3 Damage geometry before and after repair a) Unit 1 b) Unit 2, c) Unit 3, d) Unit 4, e) Unit 5 \& 6, f) Unit 7, through 11 .

\subsection{RePair Procedure}

The damaged areas of the test specimens were sandblasted to expose the aggregate and clean the substrate from residue particles. As listed in Table 4- 1, the footing of some specimens was also sandblasted to consider for repairing with UHPC. The cleaned surface was sprayed with water and allowed to dry to reach the dry-surface condition. The damaged area was then cast with UHPC.

The UHPC used in this study was an available commercial product, Ductal®, provided by Lafarge, and composed of premix powder, water, superplasticizer. According to Table 1 , two different percentage of steel fiber $(2 \%$ or $4 \%)$ by volume were used. The fibers were $0.4 \mathrm{in} .(10 \mathrm{~mm})$ long, with a tensile strength of $406 \mathrm{ksi}$ (2800 MPa). The specimens after sandblasting are presented in Figure 4- 4. 

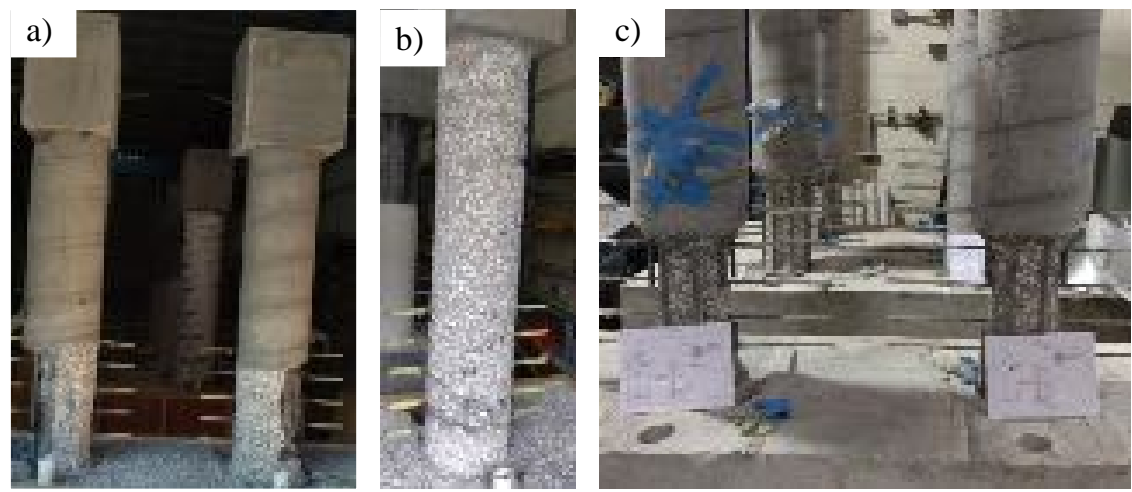

Figure 4- 4 Damaged specimens after sandblasting: a) Unit 1 and 2, b) Unit 3, and c) Unit 7 through 11.

The transfer reinforcement was added to the system using welding two half circular hoops with overlap length equal to $8 \mathrm{~d}_{\mathrm{bt}}$, where $\mathrm{d}_{\mathrm{bt}}$ is the diameter of the transverse reinforcement. To upgrade the specimen for seismic events Unit 6 through 11 had 2.5 in. spacing within the repair area according to AASHTO specification for the seismic area [131]. In case of Unit 10 and 11 four rebars, two at the tension and compression side were cut and lap spliced for a length of $8 \mathrm{~d}_{b l}$, where $\mathrm{d}_{\mathrm{bl}}$ is the diameter of the longitudinal reinforcement (Figure 4- 5).
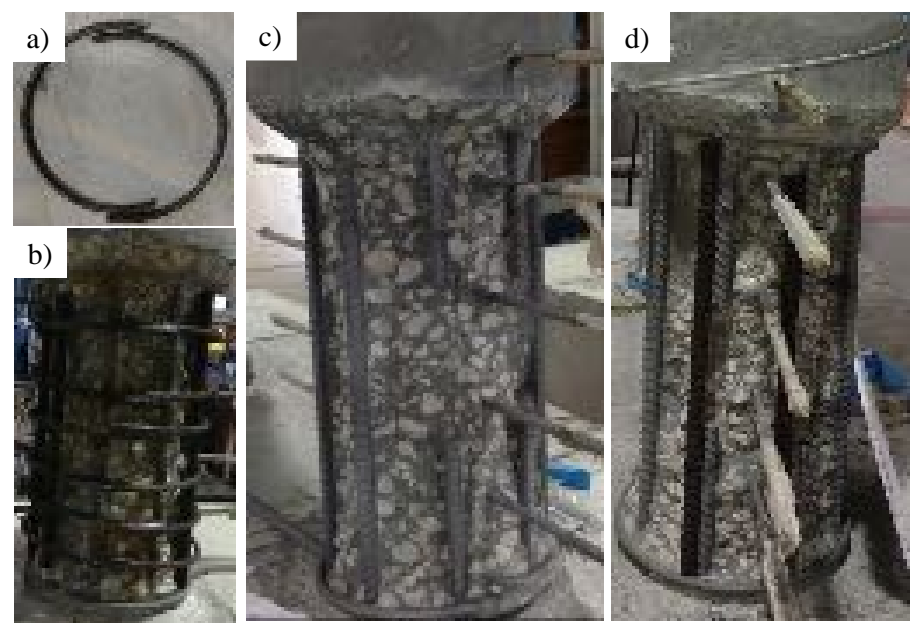

Figure 4- 5 Substrate preparation a) Transfer reinforcement before placing, b) transfer reinforcement after placement, c) Unit 10 and 11 after cutting the rebar, and d) Unit 10 and 11 after placing the spliced rebar. 
In this study, three different forming were employed to place UHPC, as shown in Figure 4- 6. The first forming (Figure 4- 6a) was built using Quikrete concrete Quik-Tube Form cut in half giving two half-circular cross section. The UHPC was cast through a 3in. diameter pipe inserted into the top of the form. Although the flowability of UHPC filled all the cavities, and the casting procedure was hard, causing fibers at the end of the pipe to obstruct the free flow of UHPC. The second form used in this study as presented in Figure 4- $6 \mathrm{~b}$ comprises of two parts bolted together at corner. The cross-section of the formwork started widening at two inches below the end of the damaged area, streamlining the casting process. In this way monitoring the UHPC streaming was possible, although the excess UHPC at the widened cross-section had to be ground the next day. The other difficulty pertaining to the second form was leveling the form to have equal cover at the perimeter. To solve the issues of the second form, the last formwork was proposed (Figure 4- 6c). This worming similar to the second one came into two parts bolting together. In this forming, the height was 6 inches above the damaged area. This helped to have a level form with equal cover. The UHPC was placed through the widened sections at the sides acting as a funnel. That minimized the subsequent grinding to reach the flush surface.
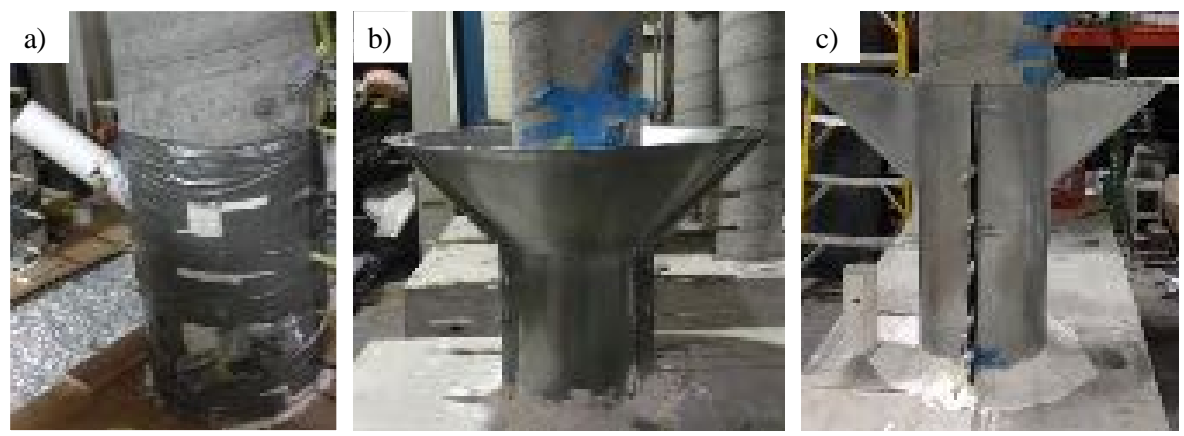

Figure 4- 6 Different forming used in this study to place UHPC. 
All the repaired specimens were de-molded after 24 hours. Each specimen was then covered in plastic to prevent drying shrinkage and kept at laboratory temperature for seven days. Then, they were kept in a standard laboratory environment until testing.

\subsection{TEST SETUP AND INSTRUMENTATION}

Specimens were set up and aligned in a vertical position, and the footings were tied down to avoid any movement or rotation. The dead load was simulated by applying an external post-tensioning force equal to $0.1 \mathrm{f}^{\prime}{ }_{\mathrm{c}} \mathrm{A}_{\mathrm{g}}$, where $\mathrm{f}_{\mathrm{c}}$ is the compressive strength of the 28-day-old concrete substrate, and $\mathrm{A}_{\mathrm{g}}$ is the gross cross-sectional area of the column. Test specimens were first subjected to constant axial load and then cyclic lateral loads at increasing displacement levels were applied. A typical test specimen, with loading devices attached, is shown in Figure 4- 7.
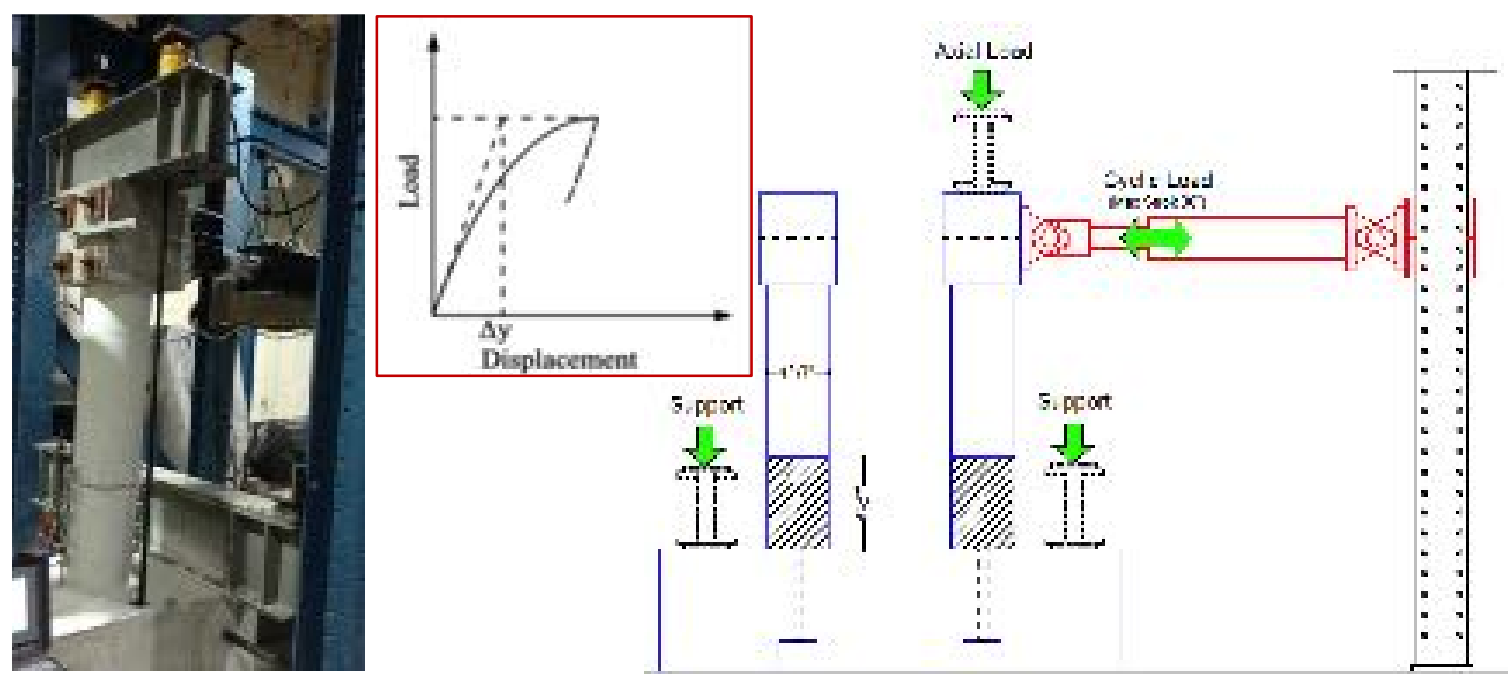

Figure 4- 7 Test setup, and the experimental definition of first yield displacement.

Each column was laterally loaded for three cycles at each displacement ductility ratio. The displacement ductility ratio $\mu_{\Delta}$ is defined as the ratio of peak lateral displacement to the first yield displacement. The first yield displacement, $\Delta_{\mathrm{y}}$, is determined during the 
first loading cycle of each test. Its value was defined as the displacement corresponding to the point where initial and final tangents to the load-deflection curve meet, as shown in Figure 4- 7.

Test specimens were instrumented to measure curvature distribution along the height of the column, and lateral load vs. lateral displacement responses. The column and footing surfaces were painted white to facilitate monitoring the crack pattern formation. The combined cyclic lateral load and constant axial load were applied up to the point of failure. Deflections and applied loads were monitored continuously, and the developed cracks were traced and recorded at the peak of each displacement ductility ratio.

Four strain gauges at each side were installed along the longitudinal reinforcement at the extreme tensile face. Moreover, to measure the curvature profile, ten linear potentiometers were mounted on steel rods placed in the column, prior to cast (8 potentiometers in the damaged zone, and two outside of it).

\subsection{TeSt OBSERVATIONS}

All test specimens failed by buckling and fracture of longitudinal steels, coinciding with a sharp drop in lateral load carrying capacity of the columns. Figure 4- 8 through Figure 4- 18 shows the condition of the test specimens at different displacement ductility ratios.

During testing Unit 1, flexural cracks first appeared at approximately $1 \%$ drift. At $3.7 \%$ drift, the cracks in the repaired zone significantly widened, the concrete cover started to spall off, followed by buckling of a couple of longitudinal reinforcements. Finally, at 
5.4\% drift, a fracture developed at one of the buckled reinforcements at the side with a thinner shell, as shown in Figure 4- 8 at which stage the test was stopped.
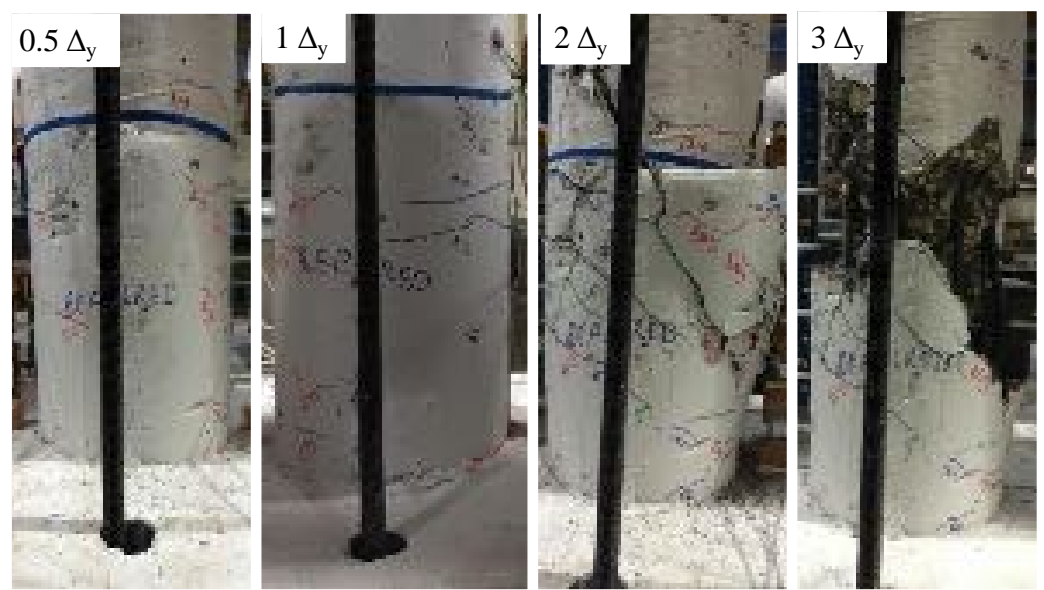

Figure 4- 8 Test specimen at the end of each loading cycle (Unit 1).

At the initial loading stage, the response of Unit 2 was similar to Unit 1 . The first sign of concrete crush and diagonal crack happened at 3.7\% drift, followed by an extensive plateau in the load-displacement response of the specimen. The concrete cover started to spall off at $5.4 \%$ drift, and the diagonal crack got wider but was still narrower than the ones in Unit 1. Eventually, the specimen fractured at 9\% drift, as shown in Figure 4- 9.
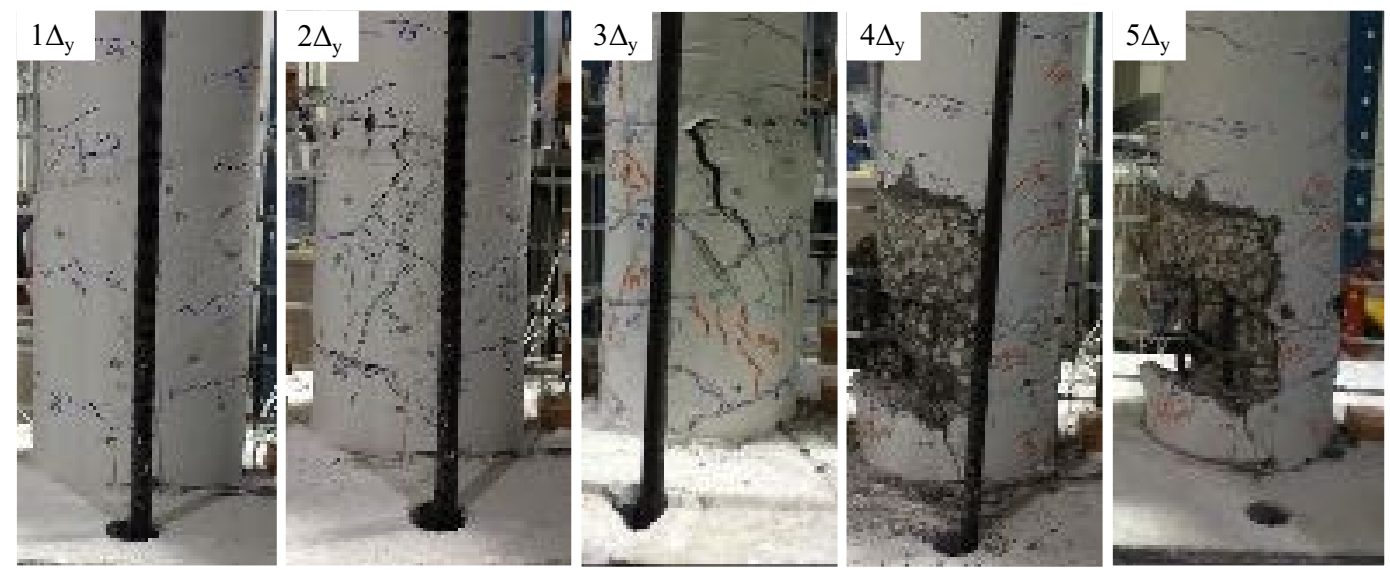

Figure 4- 9 Test specimen at the end of each loading cycle (Unit 2). 
Flexural cracks on Unit 3 first appeared at approximately $1.8 \%$ drift. At the second cycle of $5.4 \%$ drift, the cracks at the bottom of the column widened, and the concrete cover started to spall off, followed by buckling of a couple of longitudinal reinforcements. Finally, at 9\% drift, one of the longitudinal rebars buckled, as shown in Figure 4- 10, and then the test was stopped.
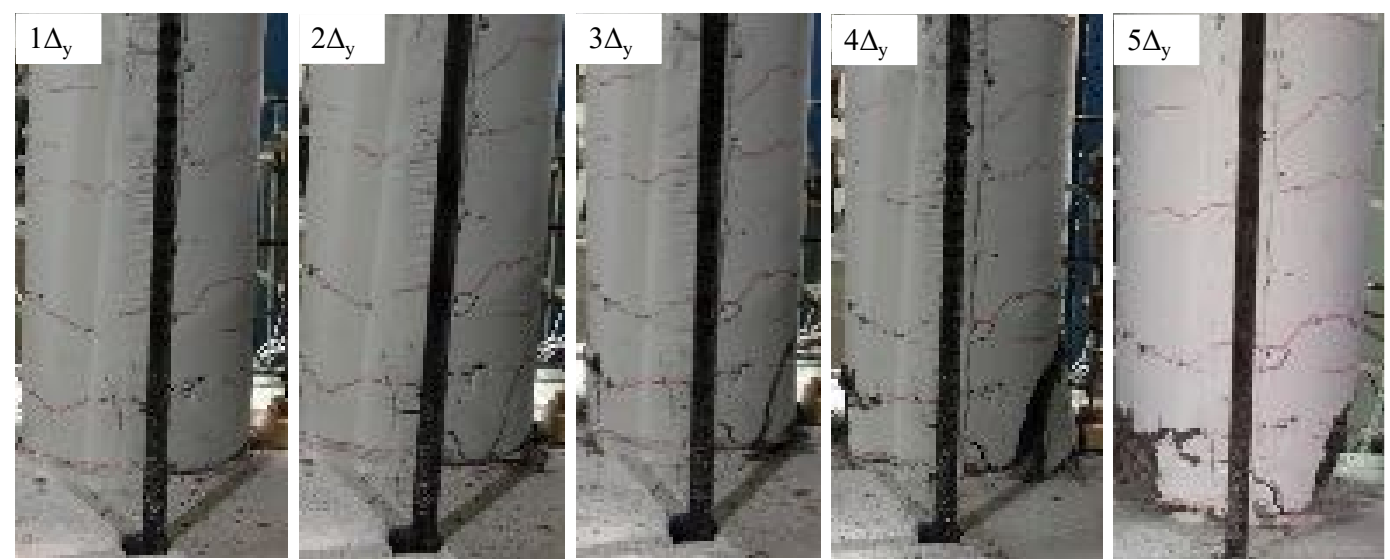

Figure 4- 10 Test specimen at the end of each loading cycle (Unit 3).

Flexural cracks on Unit 4 first appeared at approximately $1.8 \%$ drift. At the second cycle of $1.8 \%$ drift, the cracks significantly widened, the concrete cover started to spall off, followed by buckling of a couple of longitudinal reinforcements. Finally, at $5.4 \%$ drift, all the longitudinal reinforcements buckled, as shown in Figure 4- 11, and then the test was stopped. 


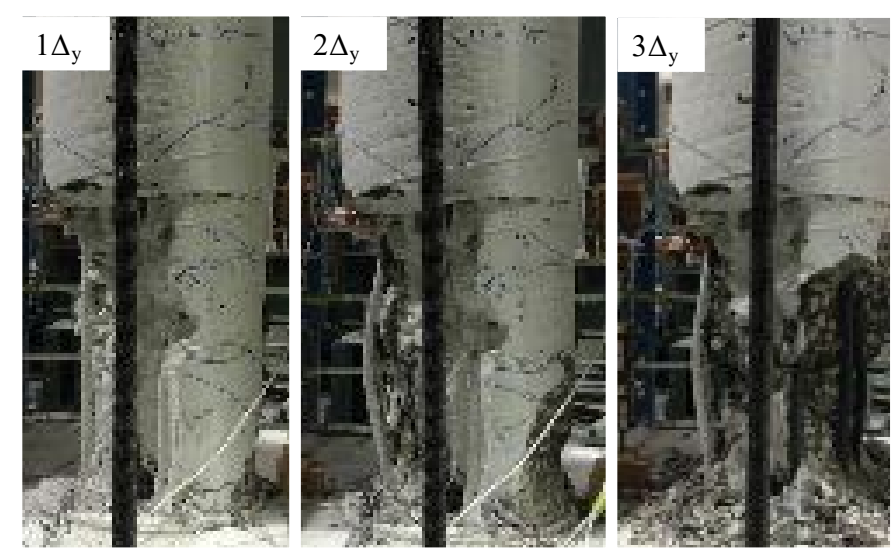

Figure 4- 11 Test specimen at the end of each loading cycle (Unit 4).

During testing Unit 5 flexural cracks first appeared at approximately $1.6 \%$ drift. At $3.2 \%$ drift, the concrete cover started to spall off, followed by buckling of a couple of longitudinal reinforcements at 5\% drift ratio. Finally, at $8.2 \%$ drift, a fracture developed at one of the longitudinal reinforcements, and then the test was stopped (Figure 4-12).
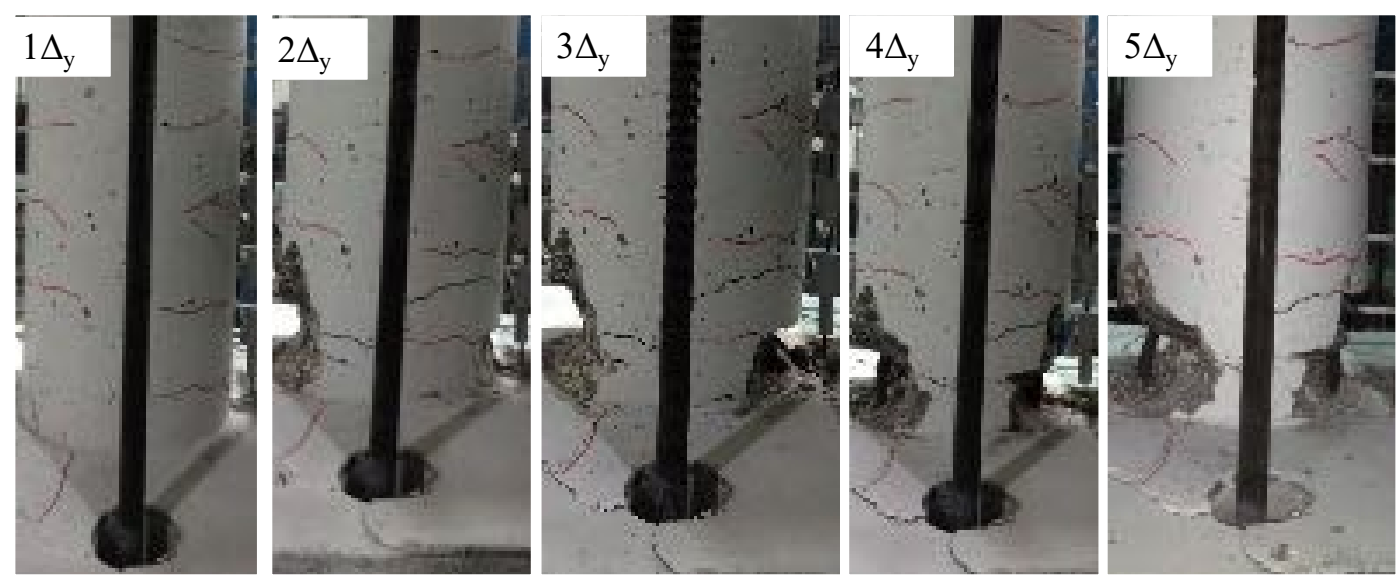

Figure 4- 12 Test specimen at the end of each loading cycle (Unit 5).

Flexural cracks of Unit 6 first appeared at approximately $1.7 \%$ drift. At $3.3 \%$ drift, the concrete cover started to spall off, followed by buckling of a couple of longitudinal reinforcements at 5\% drift ratio. Finally, at $8.2 \%$ drift, a fracture developed at one of the longitudinal reinforcements and then the test was stopped (Figure 4- 13). 

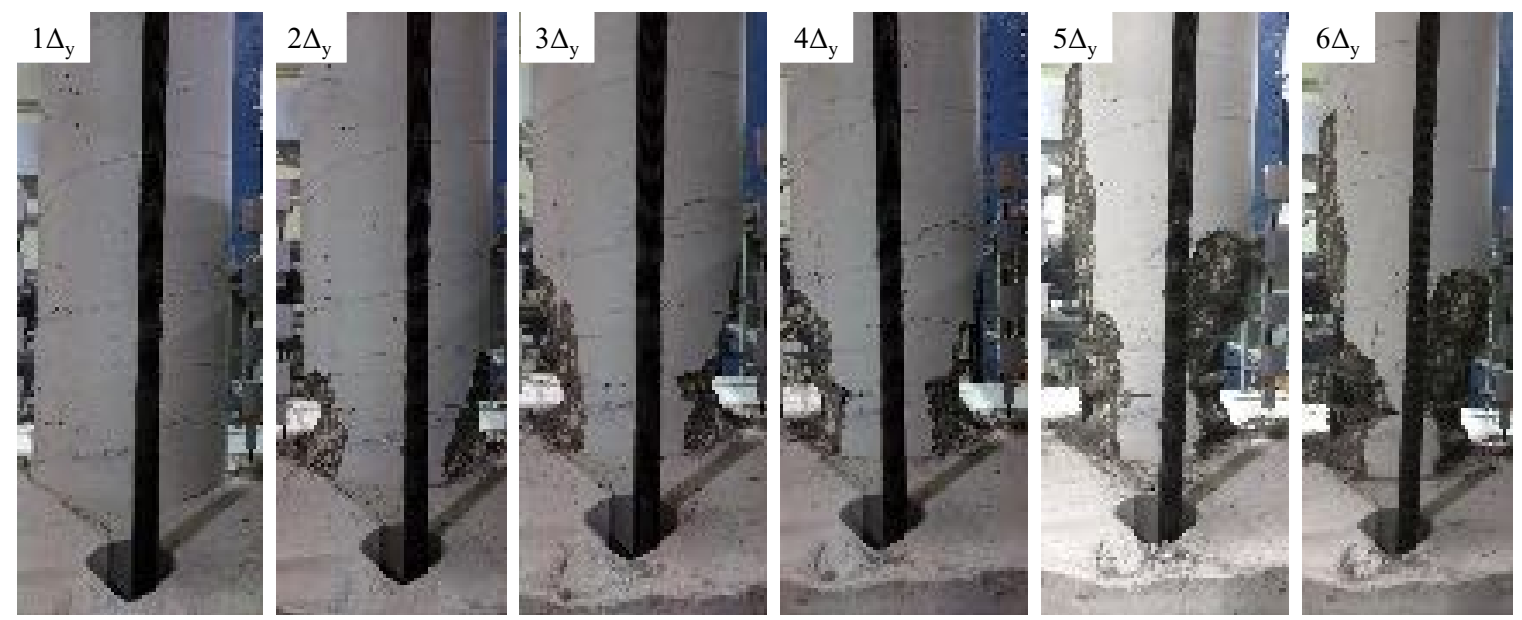

Figure 4- 13 Test specimen at the end of each loading cycle (Unit 6).

During testing Unit 7, thin flexural cracks first appeared at approximately $1.7 \%$ drift ratio. At 3.3\% drift, the concrete cover started to crush, followed by spalling off at 5\% drift ratio. Finally, at a drift of $6.5 \%$, a couple of longitudinal rebars buckled and at a drift ratio of $10 \%$, a fracture developed at one of the buckled longitudinal reinforcements and then the test was stopped (Figure 4- 14).
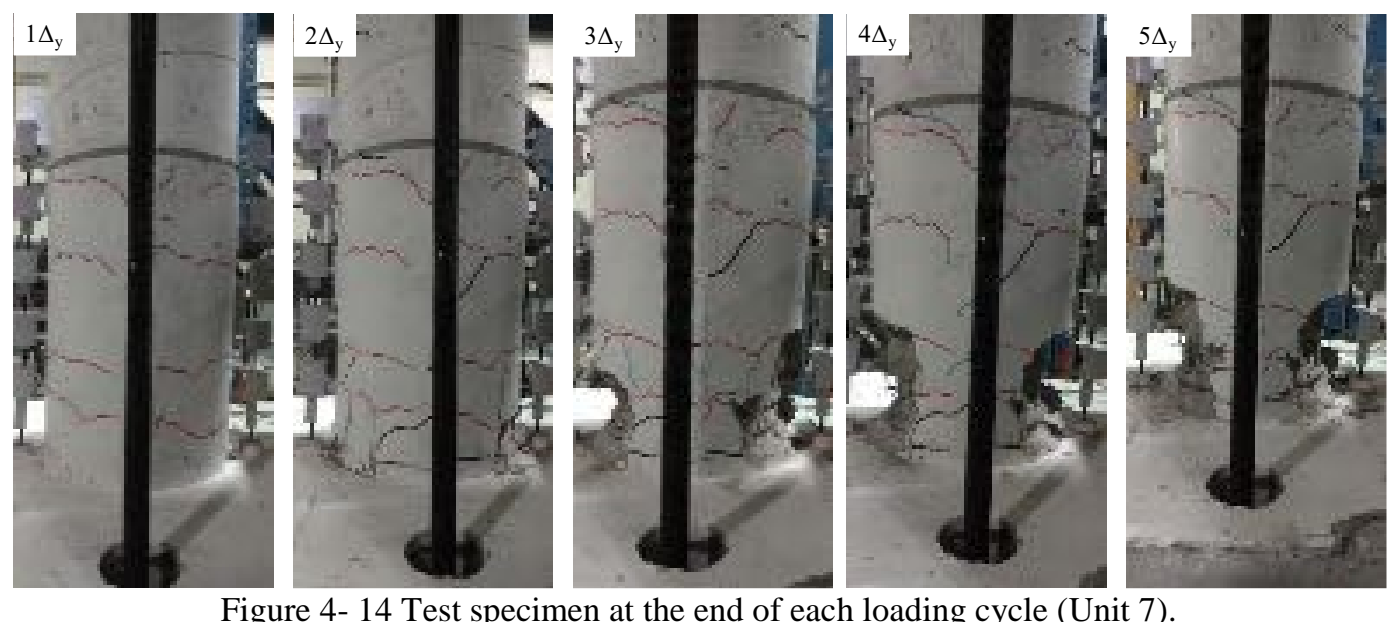

Figure 4- 14 Test specimen at the end of each loading cycle (Unit 7).

Flexural cracks on the footing of Unit 8 first appeared at approximately 5\% drift. At the second cycle of 5\% drift, the cover of the footing spalled off, followed by buckling of a couple of longitudinal reinforcements inside the footing. Finally, at $10 \%$ drift, a 
fracture developed at one of the buckled rebar one inches below the footing surface (Figure 4- 15), and then the test was stopped.

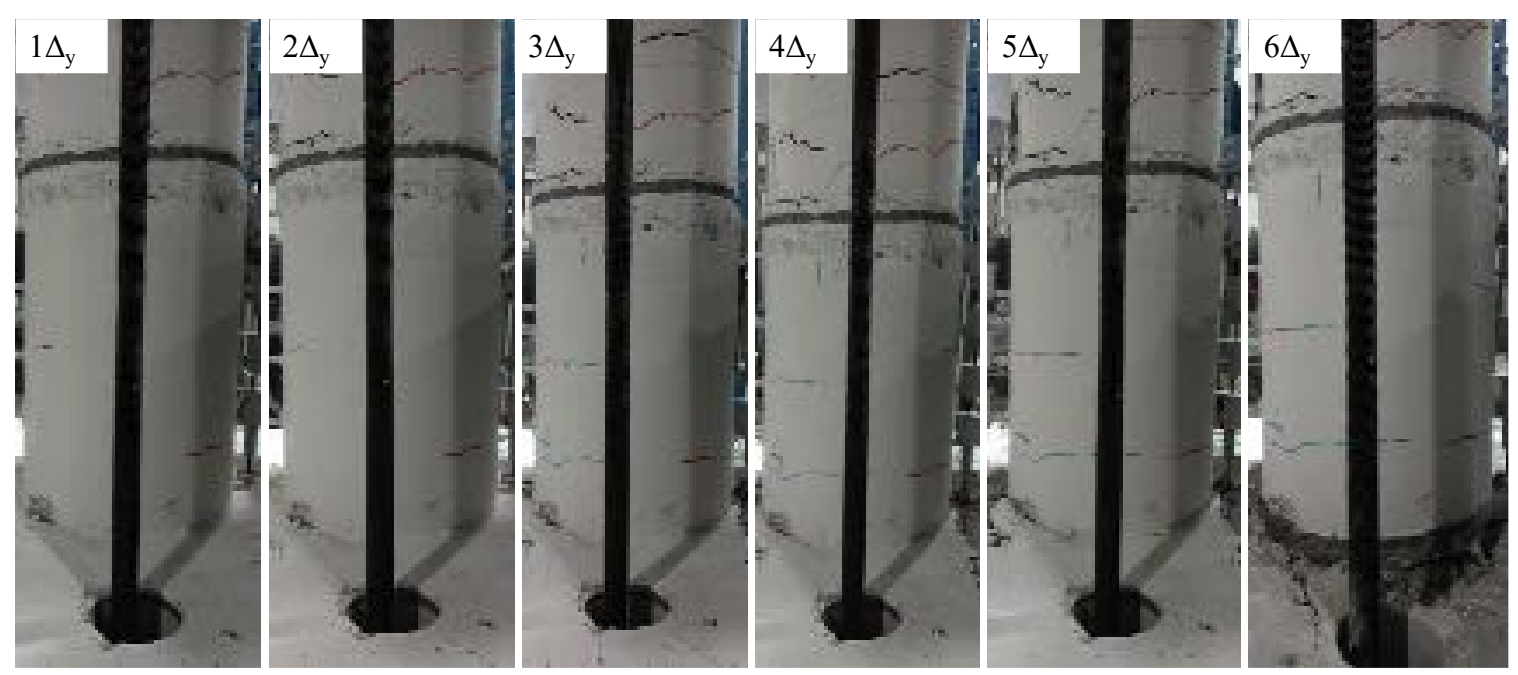

Figure 4- 15 Test specimen at the end of each loading cycle (Unit 8).

Flexural cracks on the footing of Unit 9 first appeared at approximately $6.6 \%$ drift. At the third cycle of $6.6 \%$ drift, the cover of the footing spalled off, followed by buckling of a longitudinal reinforcement inside the footing. Finally, at $11.5 \%$ drift, a fracture developed at the buckled rebar half-inch below the footing surface (Figure 4- 16), and then the test was stopped.

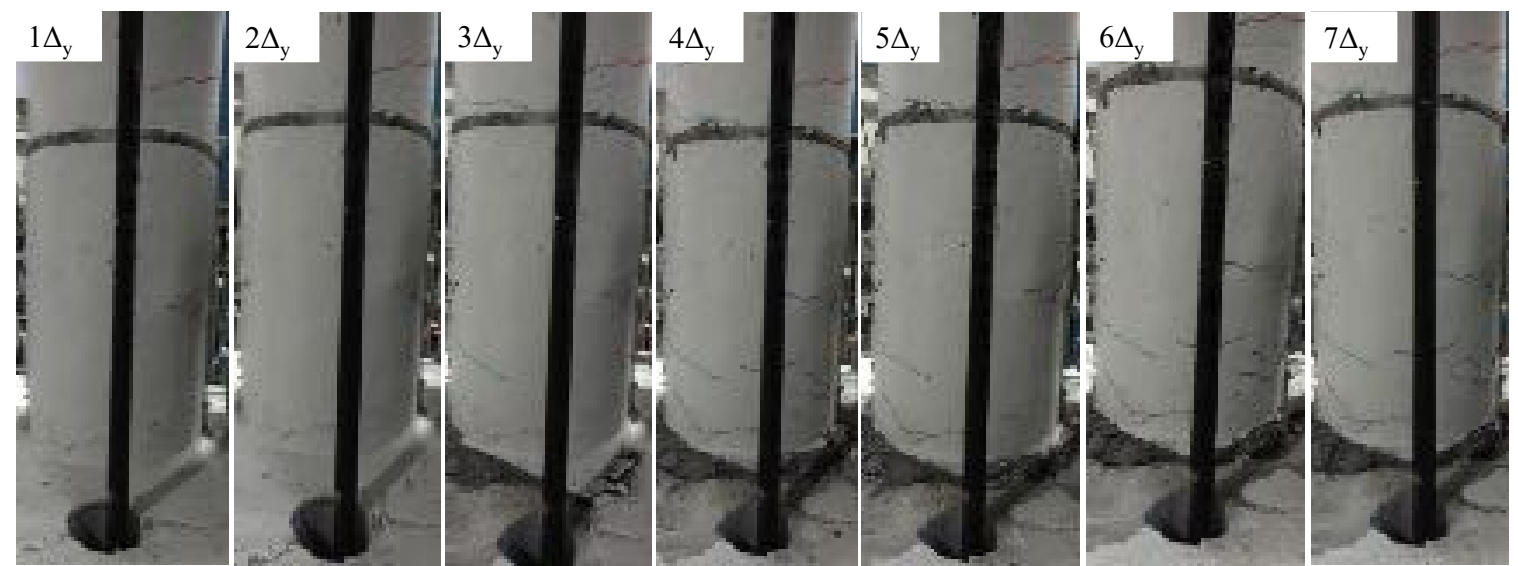

Figure 4- 16 Test specimen at the end of each loading cycle (Unit 9). 
During testing, the Unit 10 flexural cracks first appeared at approximately $1.7 \%$ drift. At $3.3 \%$ drift, the concrete cover started to crush, then at the ratio of $5 \%$ the cover spalled off, followed by buckling of a couple of longitudinal reinforcements at $6.6 \%$ drift ratio. Finally, at $8.2 \%$ drift, a fracture developed at one of the longitudinal reinforcements, and then the test was stopped (Figure 4- 17).
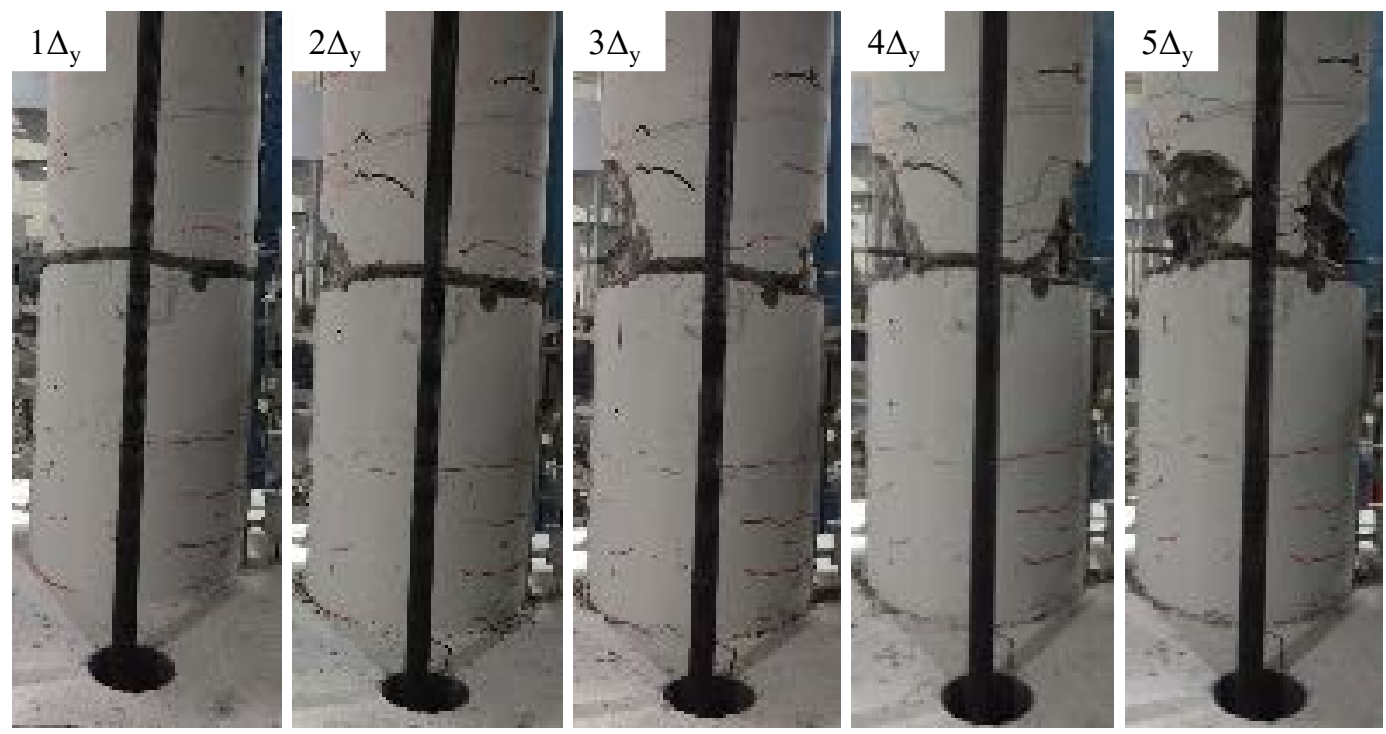

Figure 4- 17 Test specimen at the end of each loading cycle (Unit 10).

During the testing the Unit 11 flexural cracks first appeared at approximately $1.7 \%$ drift. At $3.3 \%$ drift, the concrete cover started to crush, then at the ratio of $5 \%$ the cover spalled off, followed by buckling and fracturing of longitudinal reinforcements at $6.6 \%$ drift ratio (Figure 4- 18). 

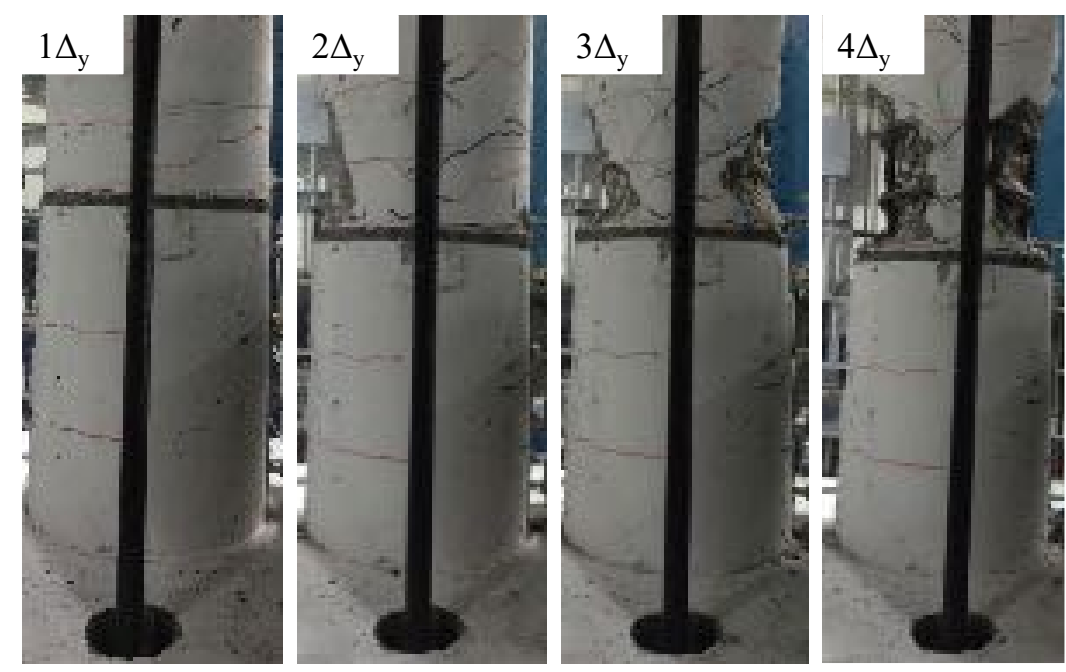

Figure 4- 18 Test specimen at the end of each loading cycle (Unit 11).

Good bonding between substrate concrete and UHPC was observed during the tests, as failure surface was always located outside of interface between two concrete layers and in the normal strength concrete. Lack of any delamination across the circumferential shell of UHPC shows the effectiveness of the surface preparation, which is a prerequisite for a successful restoration.

Table 4- 2 presents a summary of test observations. It contains the significant events during the test (crack initiation, crack appearance in the repaired zone, cover spalling, and fracture) and the corresponding drift ratios. 
Table 4- 2 Summary of test observations.

\begin{tabular}{|c|c|c|c|c|c|c|}
\hline Unit & $\begin{array}{c}\text { Crack } \\
\text { initiation }\end{array}$ & $\begin{array}{l}\text { Cracks in the } \\
\text { repaired zone }\end{array}$ & $\begin{array}{c}\text { Cover } \\
\text { spalling }\end{array}$ & $\begin{array}{c}\text { Reinforcement } \\
\text { buckling }\end{array}$ & $\begin{array}{l}\text { Fracture } \\
\text { (test end) }\end{array}$ & Failure location \\
\hline 1 & $\begin{array}{c}1 \% \\
\text { (flexural) }\end{array}$ & $\begin{array}{c}3.7 \% \\
\text { (diagonal) }\end{array}$ & $\begin{array}{l}3.7 \% \\
\text { repaired area }\end{array}$ & $\begin{array}{c}5.0 \% \\
\text { repaired area }\end{array}$ & $5.4 \%$ & repaired area \\
\hline 2 & $1 \%$ (flexural) & $\begin{array}{c}3.7 \% \\
\text { (diagonal) }\end{array}$ & $\begin{array}{c}5.0 \% \\
\text { repaired area }\end{array}$ & $\begin{array}{c}8.0 \% \\
\text { repaired area }\end{array}$ & $9 \%$ & repaired area \\
\hline 3 & $\begin{array}{c}1.7 \% \\
\text { (flexural) }\end{array}$ & $\begin{array}{c}5.0 \% \\
\text { (flexural) }\end{array}$ & $\begin{array}{c}5.0 \% \\
\text { repaired area }\end{array}$ & $\begin{array}{l}8.0 \% \\
\text { repaired area }\end{array}$ & $9 \%$ & repaired area \\
\hline 4 & $\begin{array}{c}1.7 \% \\
\text { (flexural) }\end{array}$ & - & $\begin{array}{c}5.0 \% \\
\text { column end } \\
\end{array}$ & $\begin{array}{c}5.0 \% \\
\text { column end } \\
\end{array}$ & $5.4 \%$ & column end \\
\hline 5 & $\begin{array}{c}1.7 \% \\
\text { (flexural) }\end{array}$ & - & $\begin{array}{c}3.3 \% \\
\text { column end }\end{array}$ & $\begin{array}{c}3.3 \% \\
\text { column end }\end{array}$ & $5 \%$ & column end \\
\hline 6 & $\begin{array}{c}1.7 \% \\
\text { (flexural) }\end{array}$ & - & $\begin{array}{c}3.3 \% \\
\text { column end }\end{array}$ & $\begin{array}{c}5.0 \% \\
\text { column end }\end{array}$ & $8.0 \%$ & column end \\
\hline 7 & $\begin{array}{c}1.7 \% \\
\text { (flexural) }\end{array}$ & $\begin{array}{c}3.3 \% \\
\text { (flexural) }\end{array}$ & $\begin{array}{c}5.0 \% \\
\text { repaired area }\end{array}$ & $\begin{array}{c}6.6 \% \\
\text { repaired area }\end{array}$ & $10 \%$ & repaired area \\
\hline 8 & $\begin{array}{c}5.0 \% \\
\text { (flexural) }\end{array}$ & - & $\begin{array}{l}5.0 \% \\
\text { footing }\end{array}$ & $\begin{array}{c}8.0 \% \\
\text { footing }\end{array}$ & $10 \%$ & footing \\
\hline 9 & $\begin{array}{c}6.6 \% \\
\text { (flexural) } \\
\end{array}$ & - & $\begin{array}{c}6.6 \% \\
\text { footing } \\
\end{array}$ & $\begin{array}{c}8.0 \% \\
\text { footing } \\
\end{array}$ & $11.5 \%$ & footing \\
\hline 10 & $\begin{array}{c}1.7 \% \\
\text { (flexural) }\end{array}$ & - & $\begin{array}{c}5.0 \% \\
\text { above repair }\end{array}$ & $\begin{array}{c}6.6 \% \\
\text { above repair }\end{array}$ & $8.2 \%$ & above repair \\
\hline 11 & $\begin{array}{c}1.7 \% \\
\text { (flexural) }\end{array}$ & - & $\begin{array}{c}5.0 \% \\
\text { above repair }\end{array}$ & $\begin{array}{c}6.6 \% \\
\text { above repair }\end{array}$ & $6.6 \%$ & above repair \\
\hline
\end{tabular}

As mentioned earlier, Unit 10 and 11 had splices with a length of $8 \mathrm{~d}_{\mathrm{bl}}$ for 4 of the longitudinal reinforcements. No vertical cracks were observed in these units, which indicates the splice length was enough to prevent debonding between steel reinforcement and UHPC.

The test observations indicate that the changes in the thickness of the UHPC shell could shift the failure location to above or below the repaired section. Comparing Units 8 and 9 to Units 10 and 11 shows when the footing was not strengthened, all the damage happened inside the footing while the whole column remained intact. This can be an issue in seismic areas where it is preferable for damage to be away from the footing or the cap beam. On the other hand, strengthening the footing along with the column shifted the 
damage above the repaired area resulting in a short column. Therefore, the increased capacity of the section after repair should be evaluated as a design consideration.
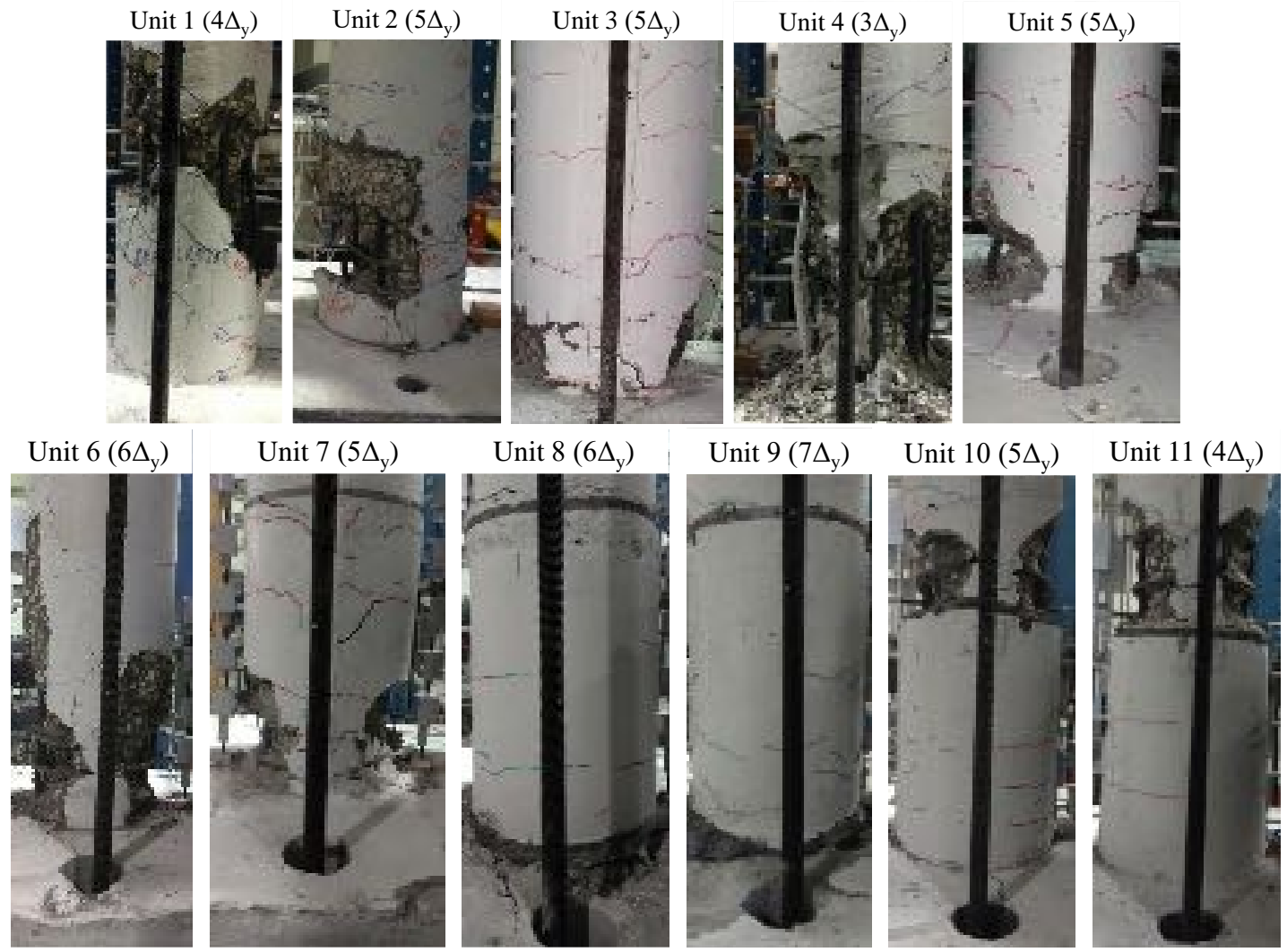

Figure 4- 19 Test specimens at the end of the test.

\subsection{RESULTS AND DISCUSSION}

In order to evaluate the lateral strength and ductility of the repaired columns, the monitored force, displacement, strain, and curvature data were used to generate forcedisplacement, moment-displacement, and curvature distributions along the height of the column, and calculate energy dissipation, and stiffness.

Figure 4- 20 shows the moment-displacement plots for all specimens and their corresponding references. The shape of hysteretic loops indicates an approximately linear response at the initial loading stage for all specimens. 

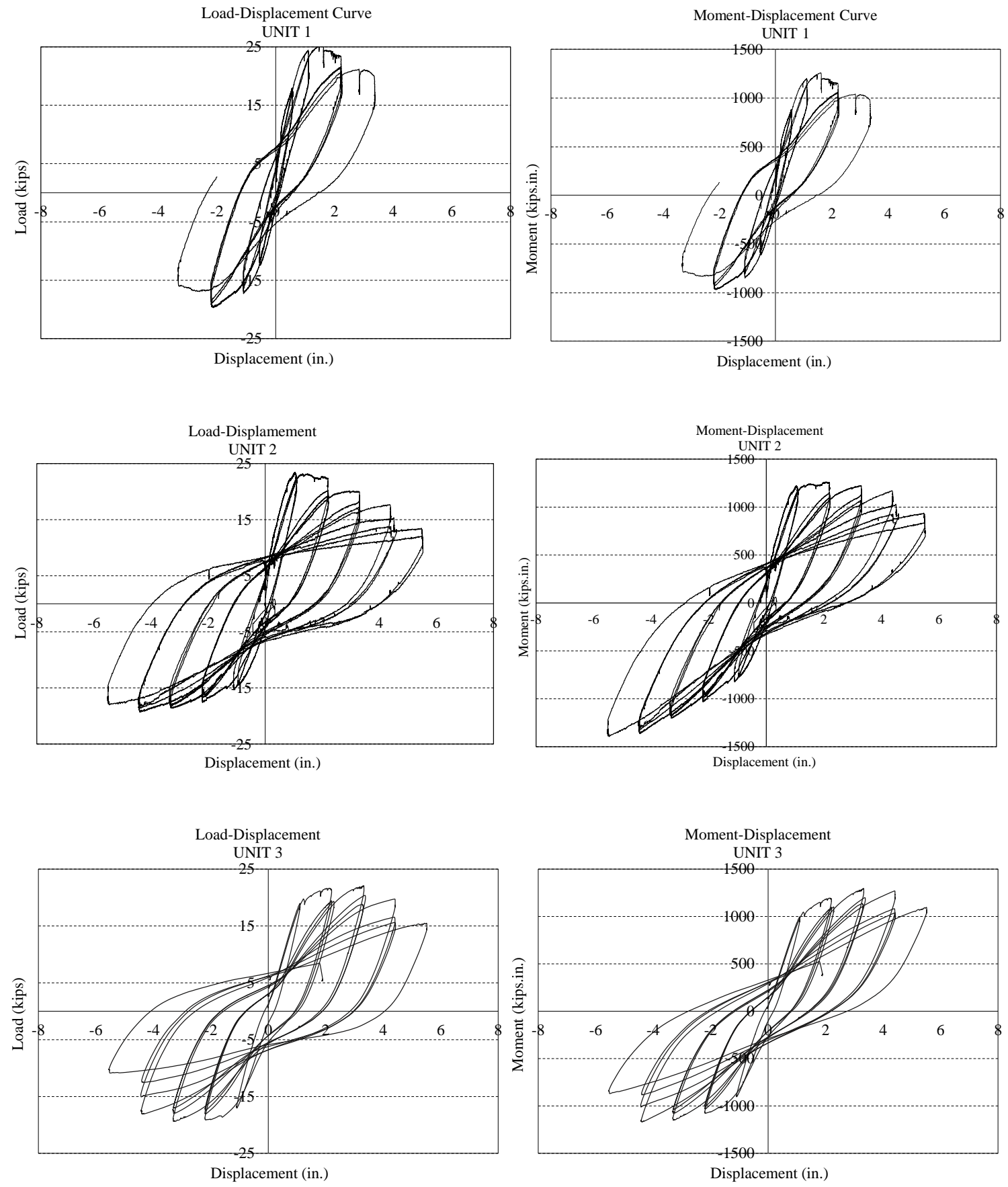

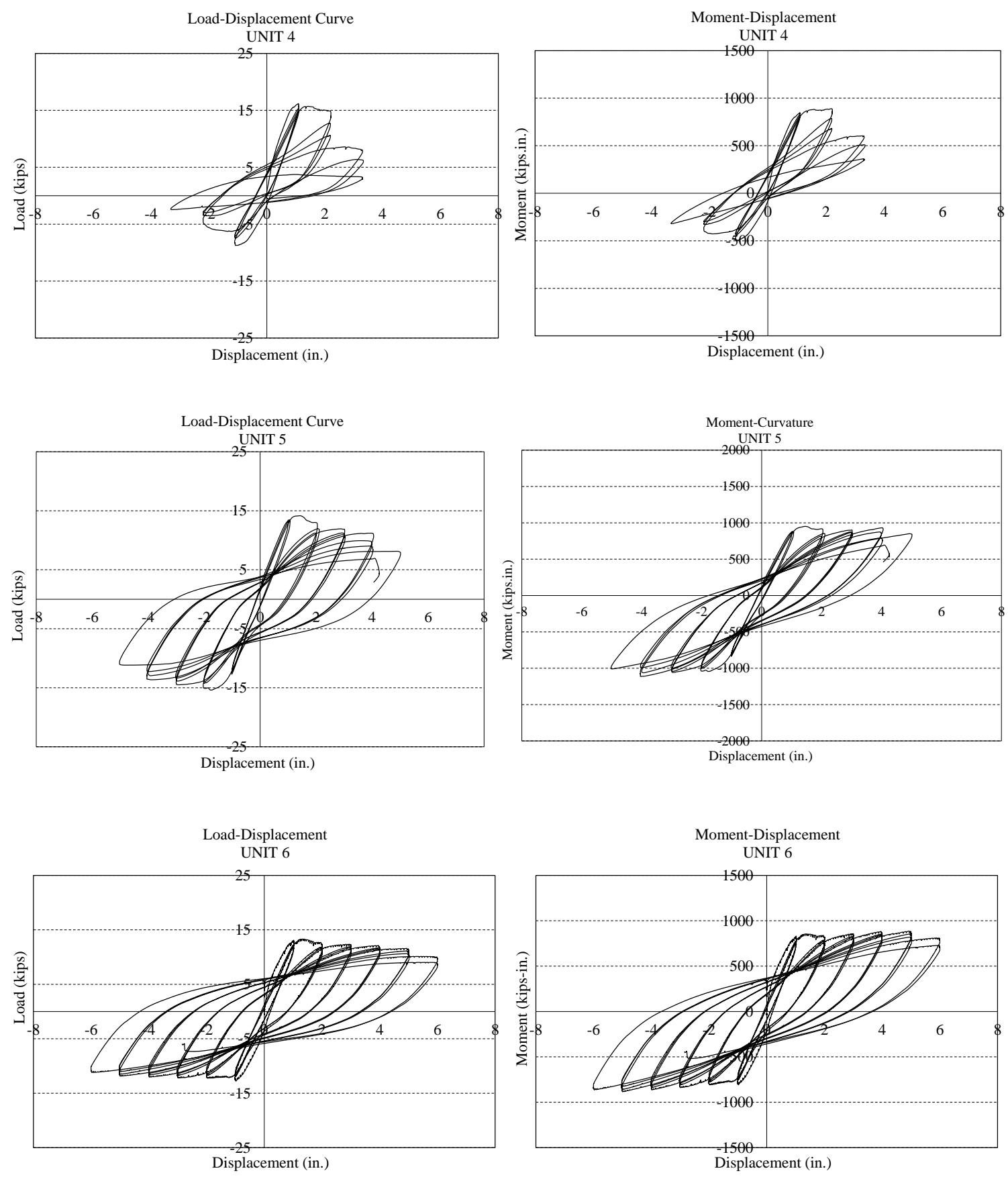

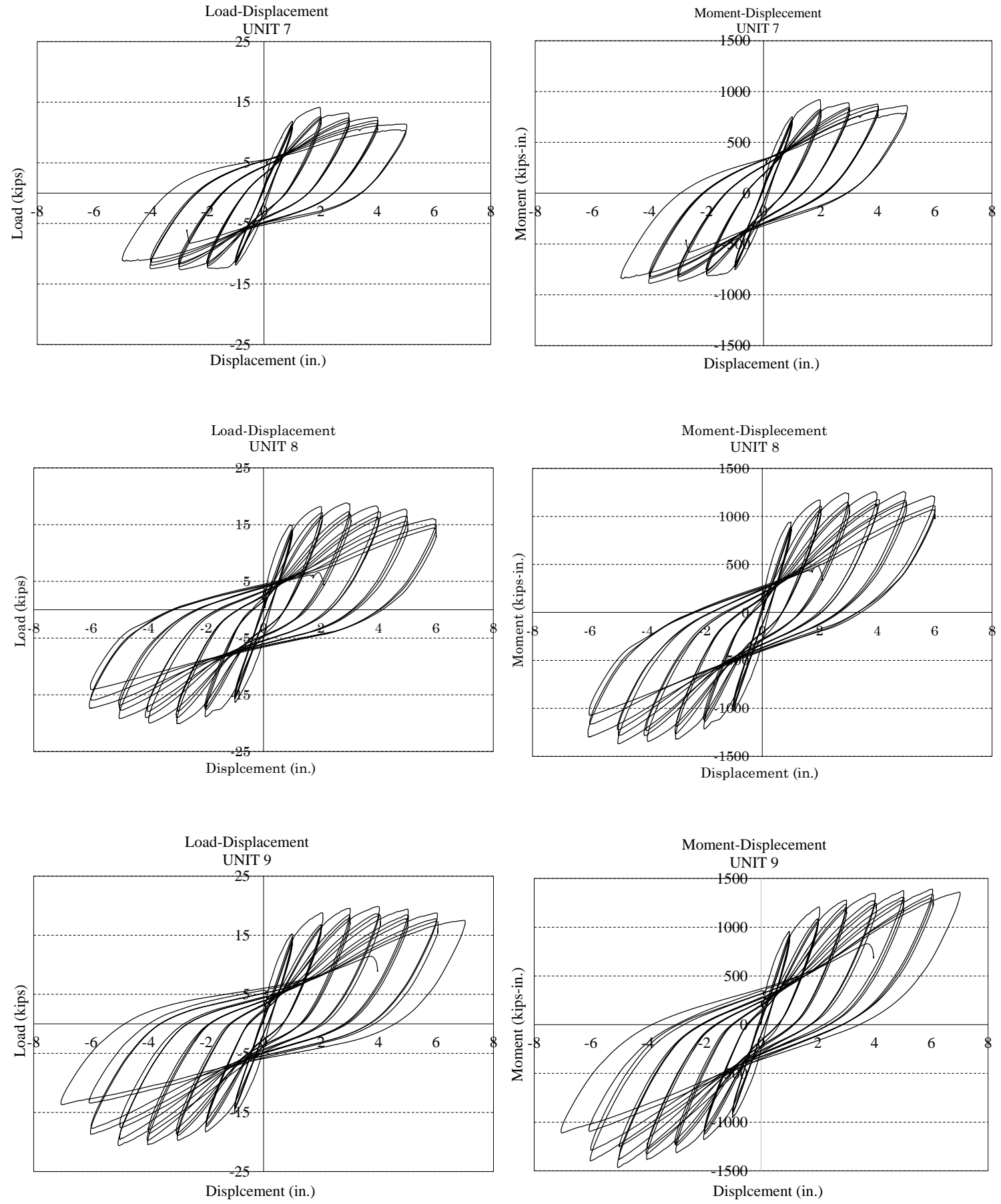

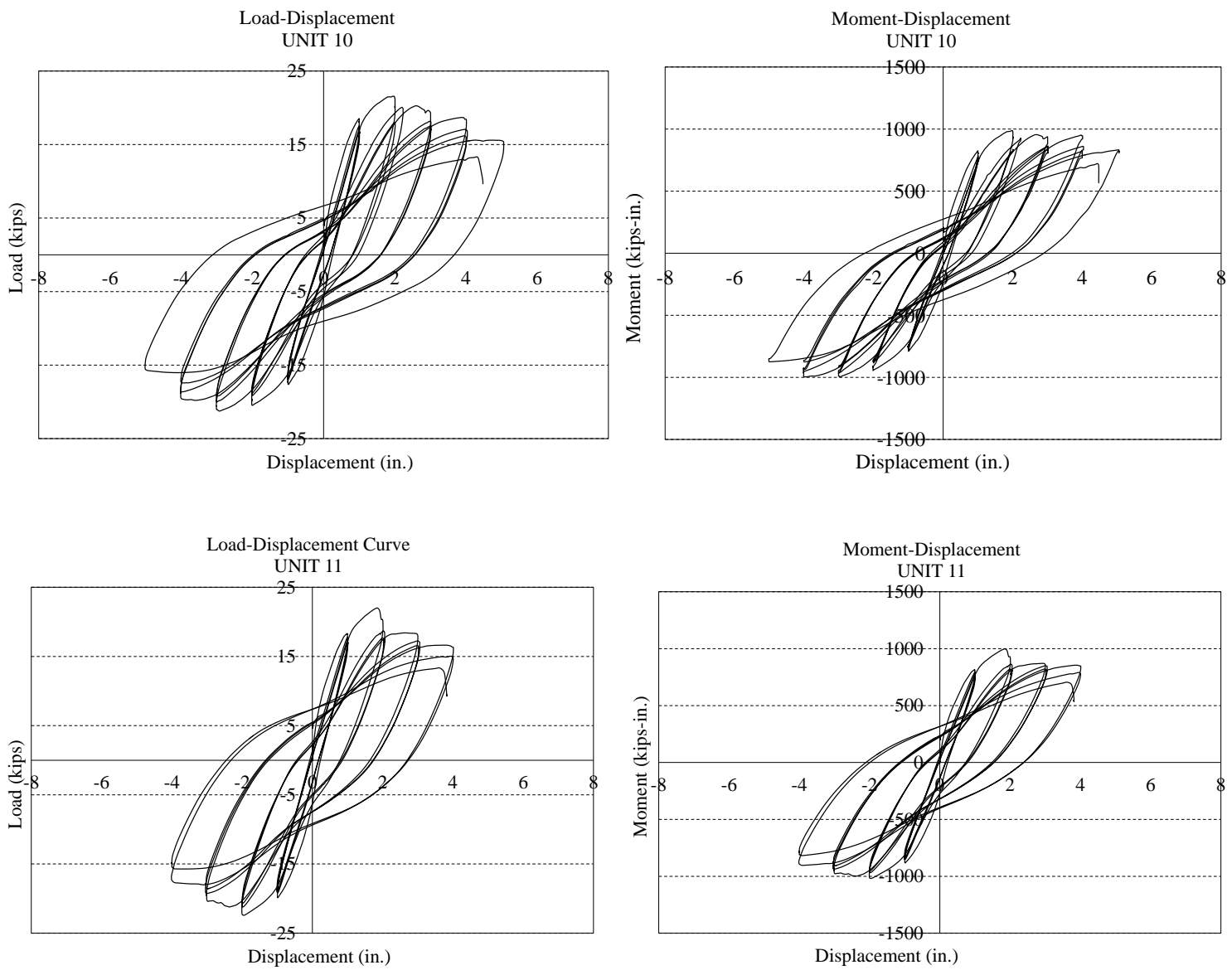

Figure 4- 20 Force-displacement, and moment-displacement hysteretic responses of the specimens.

Figure 4- 21 shows the moment-displacement plots for all specimens and their corresponding references. The shape of hysteretic loops indicates an approximately linear response at the initial loading stage for all specimens. 

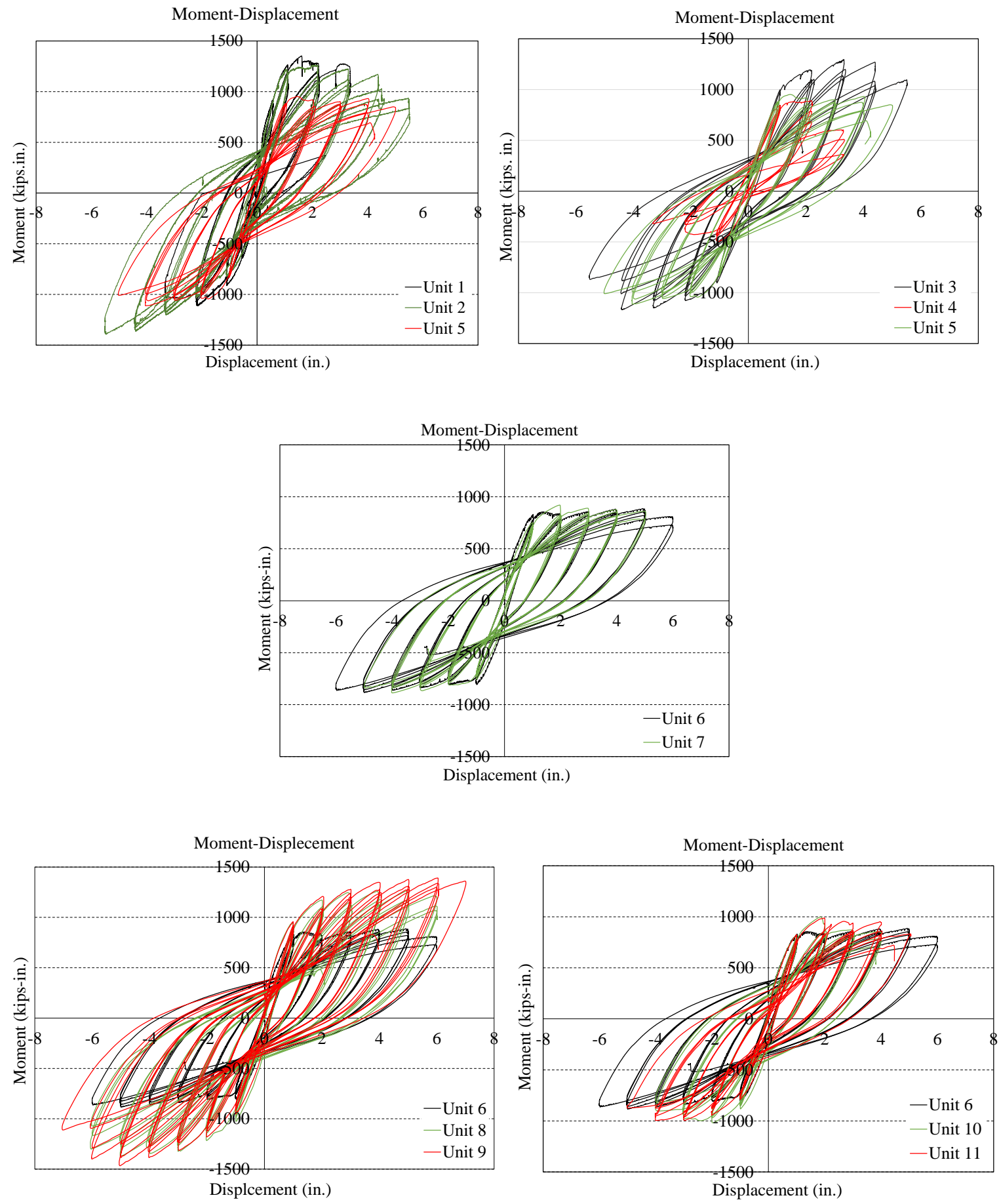

Figure 4- 21 Moment-displacement hysteretic responses of Unit 1 through 11.

As indicated in Figure 4- 21, UHPC shell increased the lateral strength of the repaired specimens compared to their references. Units 1 and 2 showed $80 \%$ and $75 \%$ increase in capacity, respectively. The ductility of Unit 2 was the same as the intact column 
indicating that the confinement is mostly on the transverse reinforcement rather than UHPC shell. This improvement for Units 8 and 9 in comparison to their reference (Unit 6) was around 55\%. The specimen repaired by NSC (Unit 7) did not show any considerable increase, which highlights the improved mechanical properties provided by UHPC.

The experimental peak curvatures measured within the repaired region and 4 in. $(10 \mathrm{~cm})$ above that are shown in Figure 4- 22.
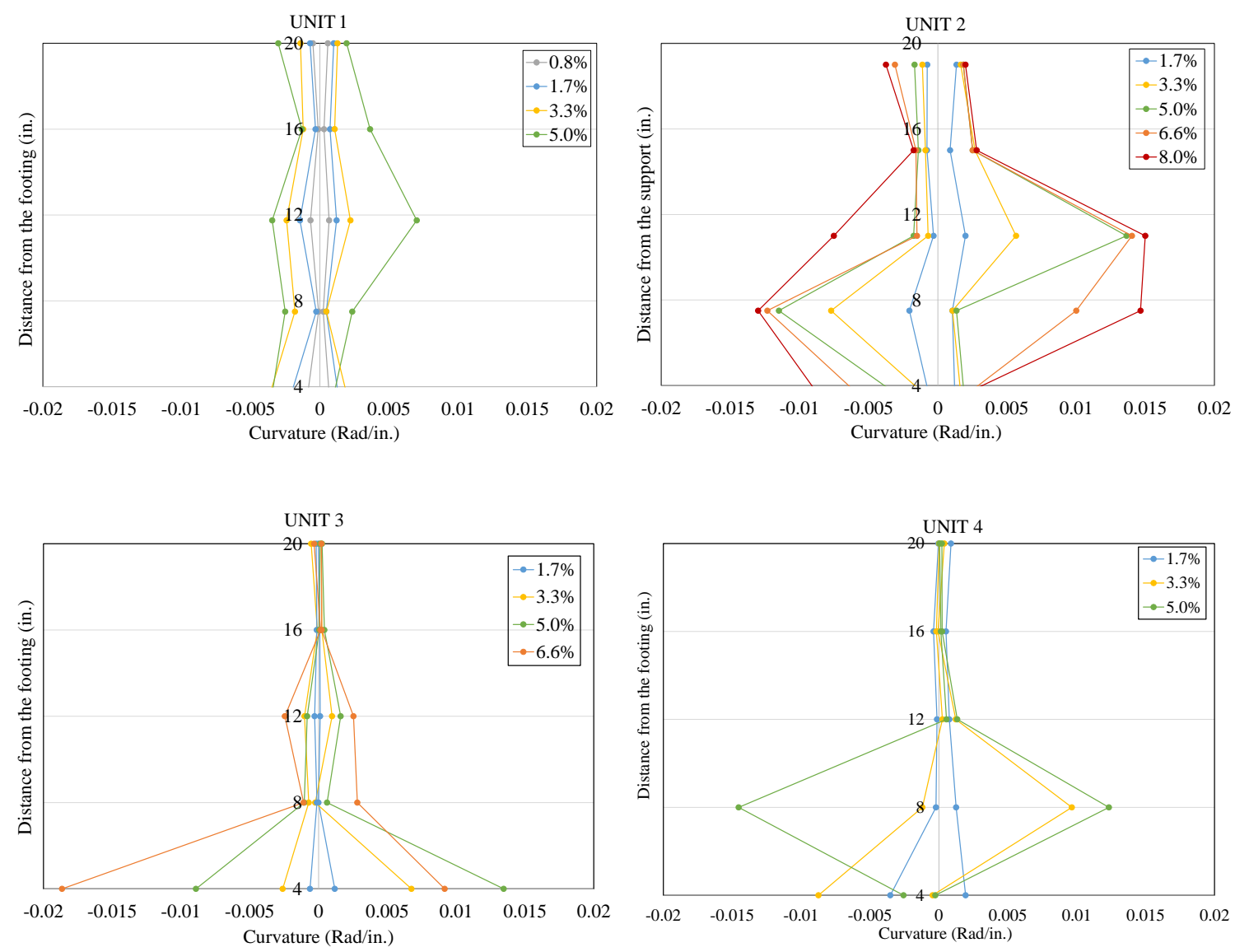

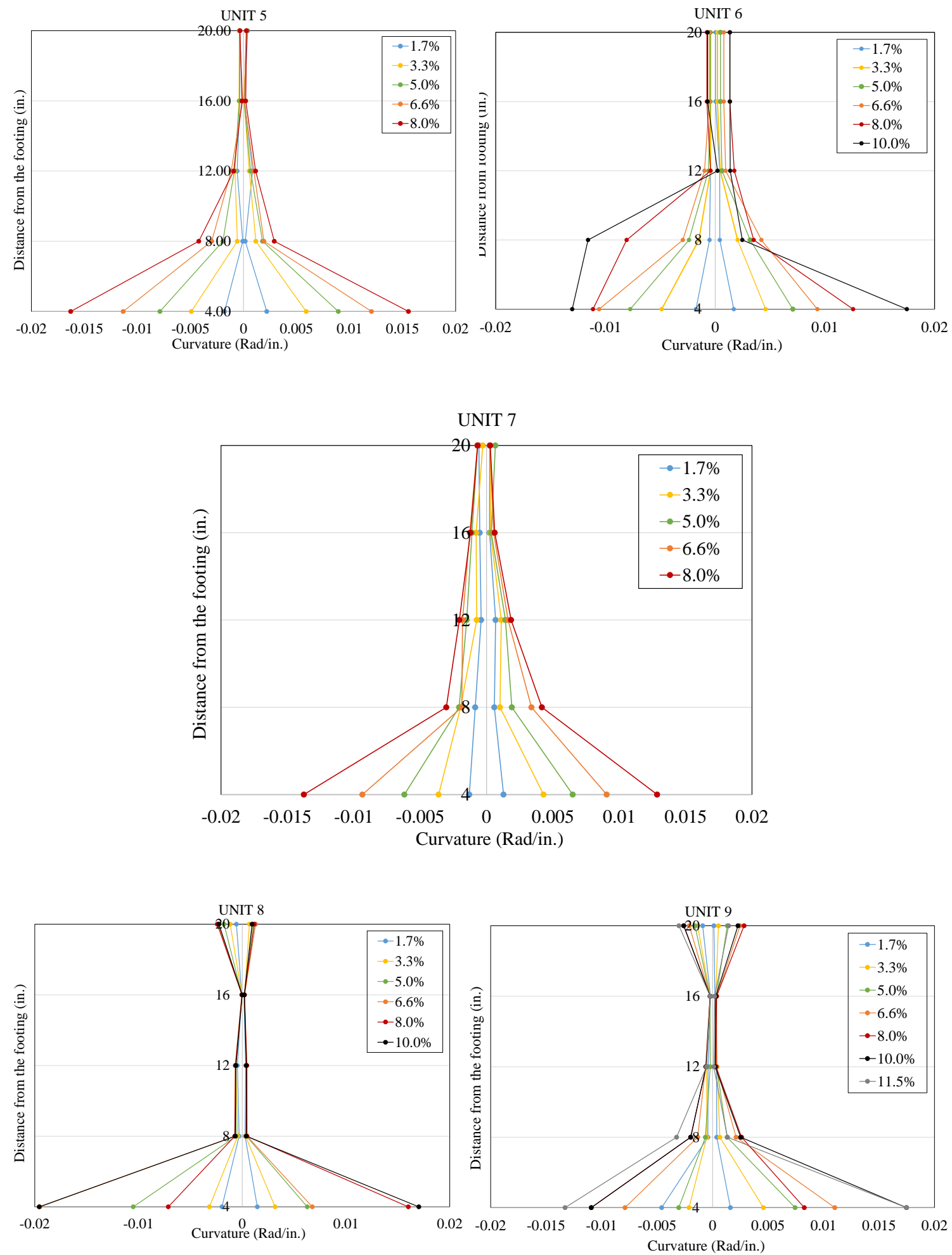

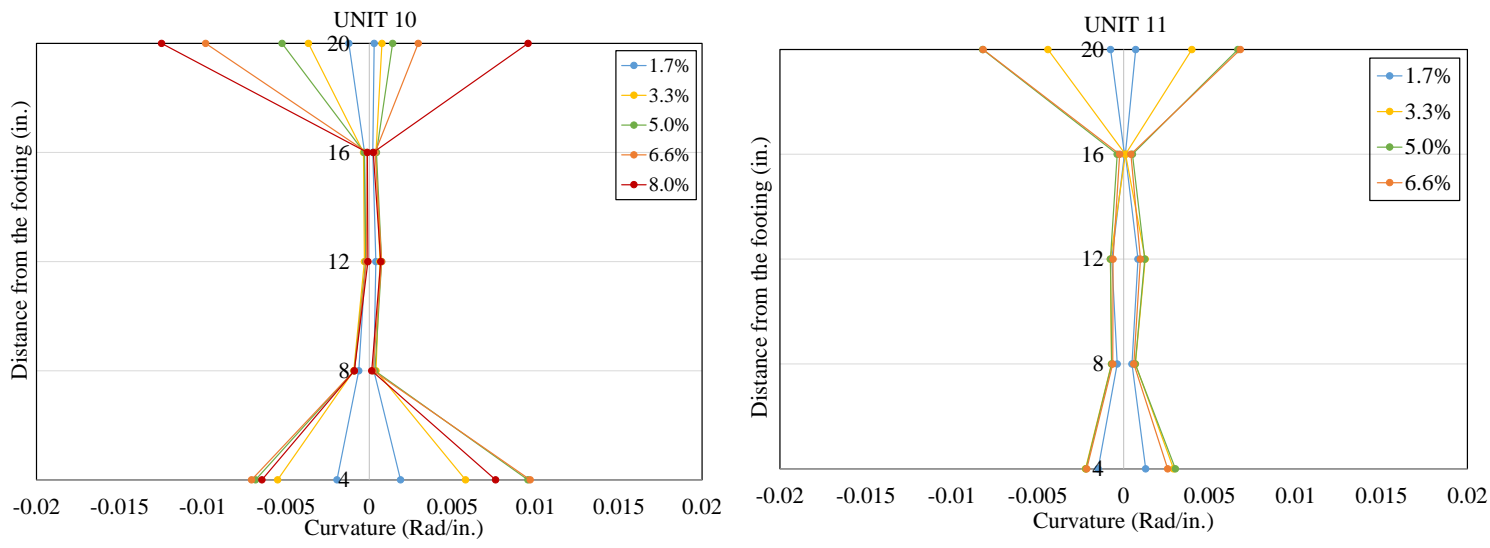

Figure 4- 22 Curvatures measured along the columns Unit 1 through Unit 11.

As mentioned earlier, strengthening of the footing can help to shift the damage away from the footing. Comparing the strain gage data of units with (Units 10 and 11) and without (Units 8 and 9) footing strengthening shows that applying UHPC to the footing could significantly decrease the strain in the footing area (up to 80\%). On the other hand, units with footing strengthening (Units 10 and 11) show 1.5 times larger strains in the steel reinforcements above the repaired area, (see Figure 4- 23).
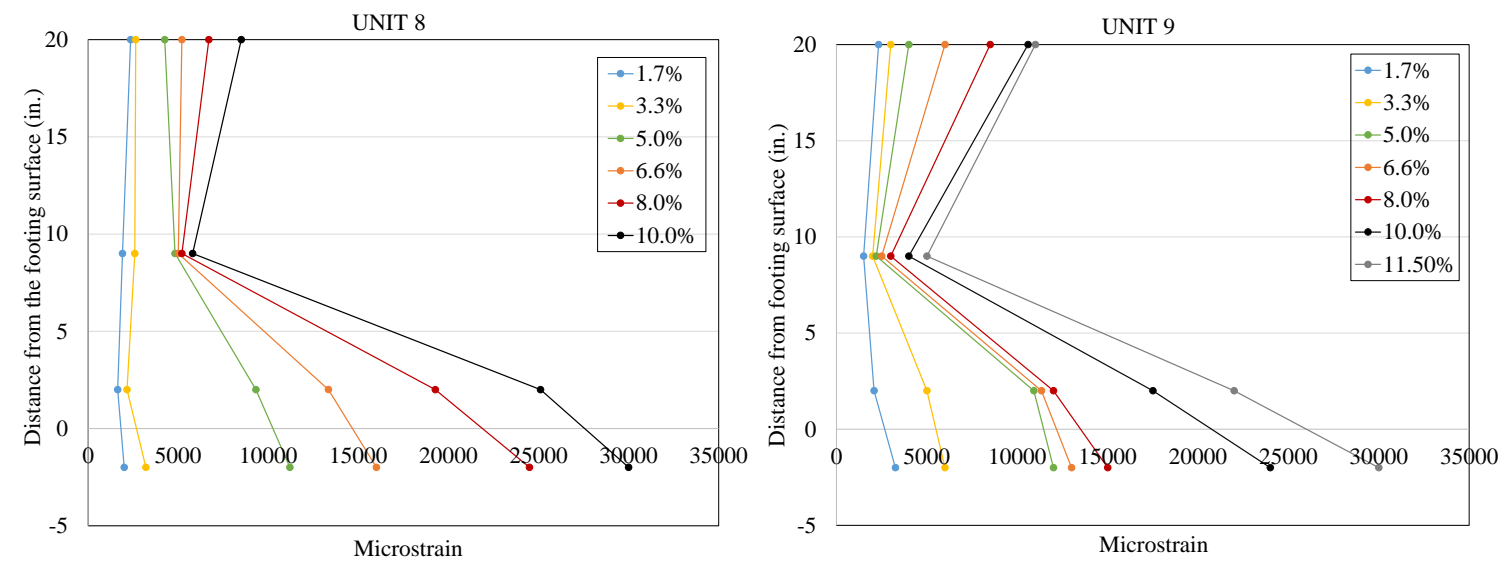

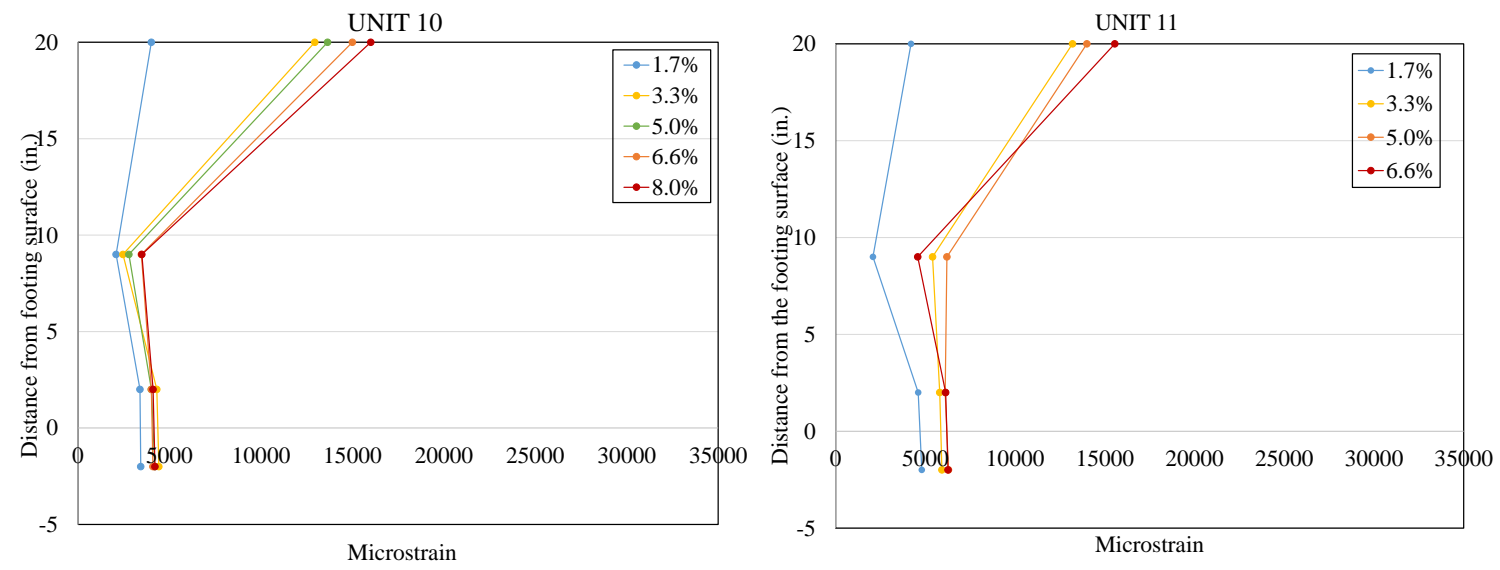

Figure 4- 23 Strain measured along the columns Unit 8 through Unit 11.

The stiffness of the test specimens, defined as the slope of the load-displacement curves, during each cycle of each displacement ductility ratio is compared in Figure 4- 24. Figure 4- 24 also shows stiffness degradation plotted against the applied cycle number.
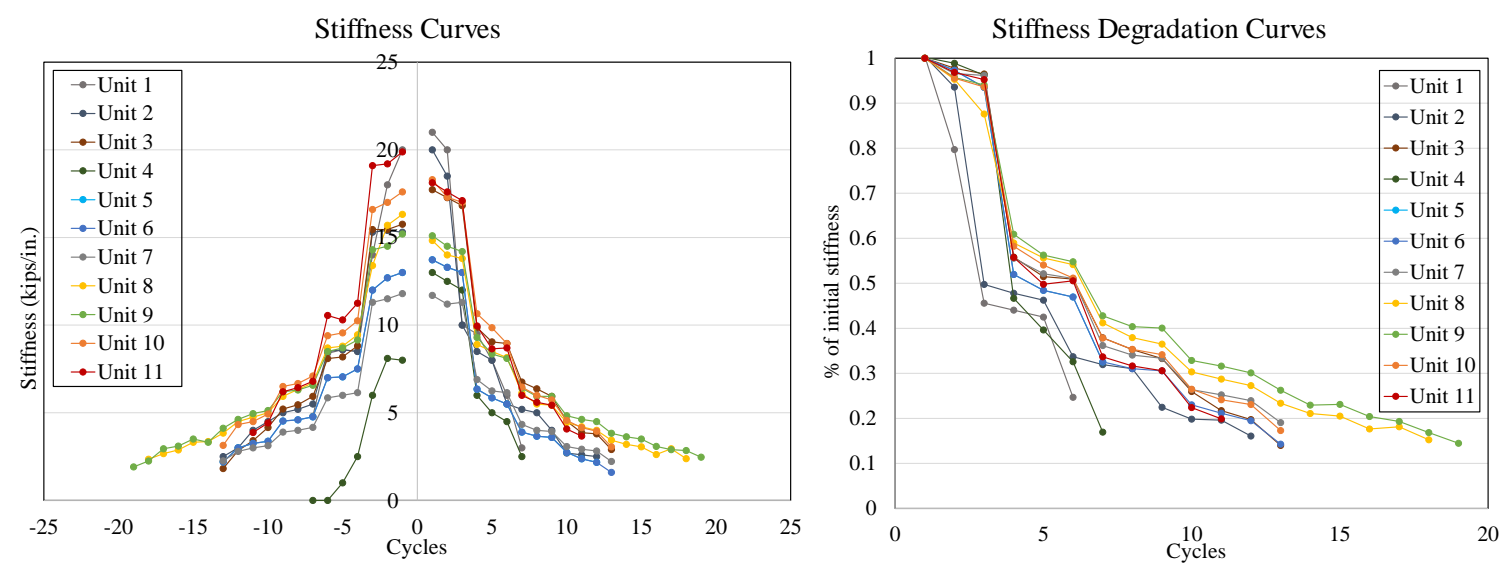

Figure 4- 24 Stiffness of the specimens during the test.

Figure 4- 25 shows dissipated energy per each cycle and the cumulative dissipated energy for each specimen, calculated based on the enclosed area within the hysteresis loops. Results indicate that using UHPC and adding transverse steel reinforcement improves the energy dissipation of the column. 

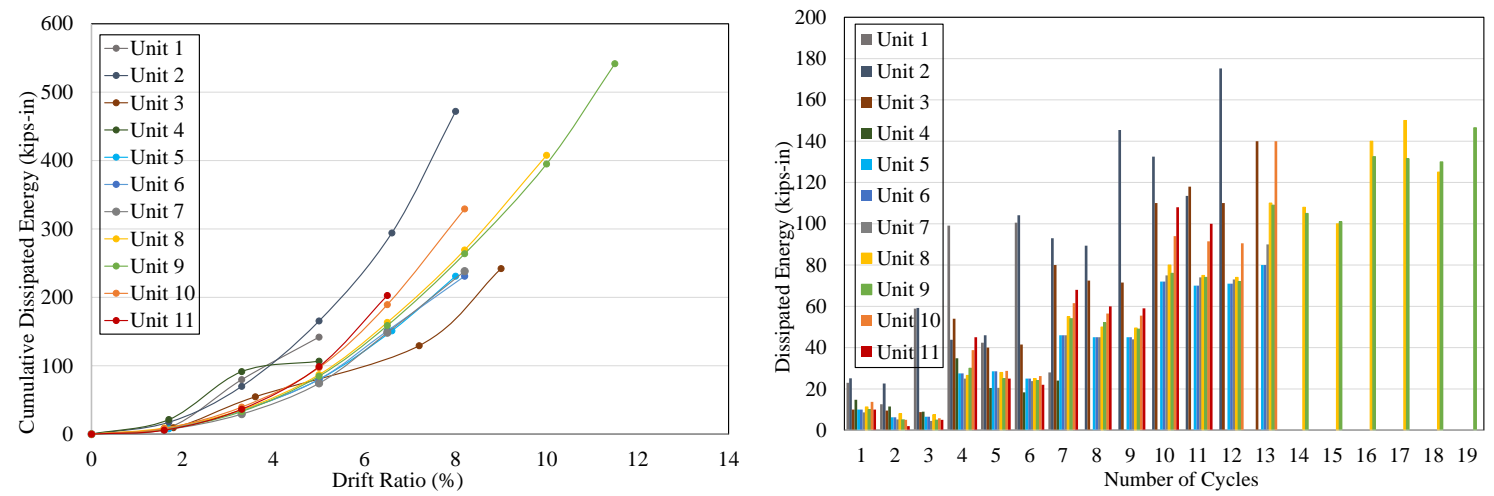

Figure 4- 25 Energy dissipation vs. number of cycles.

\subsection{SUMMARY}

In this section, the mechanical and durability performance the proposed repair method was experimentally investigated. First, a total of eleven 1/4-scale columns were cast, and typical damages were simulated in them. Eight of the damaged columns were repaired with UHPC, one repaired with NSC, and one column, with no repair, was used as the test baseline. Moreover, two intact columns were cast with the substrate concrete as the references. The obtained experimental results reveal that the UHPC shell increases the strength of the damaged elements, without increasing its size.

- $\quad$ Firstly, the repair scheme using the UHPC is rather efficient regarding lateral strength, deformation, energy dissipation capacity, and stiffness degradation. Furthermore, lack of any delamination across the circumferential shell shows the effectiveness of the surface preparation, which is a prerequisite for a successful restoration.

- UHPC shell transforms the sudden cover spalling to a gradual mechanism.

This enhancement is due to the ability of the fibers to limit the progression of cracks in the concrete, thereby resulting in greater material integrity at large strains. 
Regarding the confinement effect of UHPC shell, experimental findings indicate that a slight increase of lateral reinforcement significantly improves the cyclic behavior of the specimen, energy dissipation capacity, deformability, and ductility. - The test results of the units with lap splice in longitudinal reinforcements indicates that with proper design, UHPC is capable of developing bars in repair area with short splice length $\left(8 \mathrm{~d}_{\mathrm{bl}}\right)$. Moreover, from strength stand point UHPC with $2 \%$ or $4 \%$ fiber content resulted in similar behavior.

- $\quad$ More importantly, depending on the UHPC shell thickness, this method may cause shifting the damage above or below the repair section and that should be a design consideration. 


\section{CHAPTER 5 NUMERICAL AND ANALYTICAL APPROACH}

The circular cross-section is the common geometry used for reinforced concrete columns in bridge construction. The circular shape of the cross-section and uniform distribution of reinforcement along the perimeter of cross-section generate some difficulties in calculation of load carrying capacity of such members. The cross section would become more complicated with UHPC shell. Therefore, for such complicated cross sections, integration methods using analytical and numerical algorithms are mostly implemented, and a quick hand calculation may seem impossible. The objective of this chapter is to present a simplified method to analyze an RC circular section with UHPC shell. The results are then validated with the results from MATLAB program presented in the following section.

\subsection{Numerical Modeling}

Numerical modeling was used to evaluate the effect of different parameters such as the thickness of the UHPC shell, the diameter of the column, steel reinforcement ratio on the moment capacity of the repaired columns. To that aim, moment-curvature analysis was derived based on the validated models.

A set of MATLAB codes were developed to calculate monotonic momentcurvature analysis and force-displacement response of reinforced concrete members of circular sections. The section analysis is achieved by tabulating moment from equilibrium for increasing levels of curvature. The response of the member has obtained from the 
section moment-curvature results along with an equivalent critical section length, as presented by Priestley et al [132].

This program uses the constitutive model proposed by Mander et al. [133] for the confined and unconfined concrete, and Simple and Park [134] constitutive model for the steel reinforcement. UHPC properties were defined based on the experiments discussed in Chapter 2, and the Refs. [28], [135]. The code also allows the analysis of members subjected to axial load (tension or compression).

\subsubsection{Material models}

The following constitutive models for the concrete (confined and unconfined), UHPC and reinforcing steel were used. The following parameters define the parametric stress-strain curve for the concrete and rebars:

$\varepsilon_{c}:$ longitudinal compressive concrete strain

$\varepsilon_{c o}:$ unconfined concrete strain

$f^{\prime}{ }^{\prime}$ : unconfined concrete stress

$f_{y h}$ : yielding stress of transverse steel

$A_{s p}$ : cross section area of spiral or hoop

$d_{s}$ : diameter of the core (center to center of spirals)

$s^{\prime}$ : clear distance between spirals or hoops

$\rho_{c c}$ : ratio of area of longitudinal reinforcement to area of core section

\subsubsection{CONCRETE}

A stress-strain model for confined and unconfined concrete was employed in the analysis to determine the local capacity of the columns. For both the confined and 
unconfined model, the initial ascending curve was expressed by the same equation as the confining steel has no effect in this range of strains. When the curve equals the compressive strength of the unconfined concrete, the unconfined stress starts to decline to an unconfined strain level before rapidly degrading to zero at the spalling strain $\left(\varepsilon_{s p} \approx 0.005\right)$. The confined concrete model continues to soar until the confined compressive strength $f_{c c}^{\prime}$ is reached. The descending part of the confined concrete model depends on the confining steel parameters. The ultimate strain $\left(\varepsilon_{c u}\right)$ is the point where strain energy equilibrium is reached between the confinement steel and the concrete. Mander's stress-strain model for confined concrete is the commonly used model as shown in Figure 5- 1 [133].

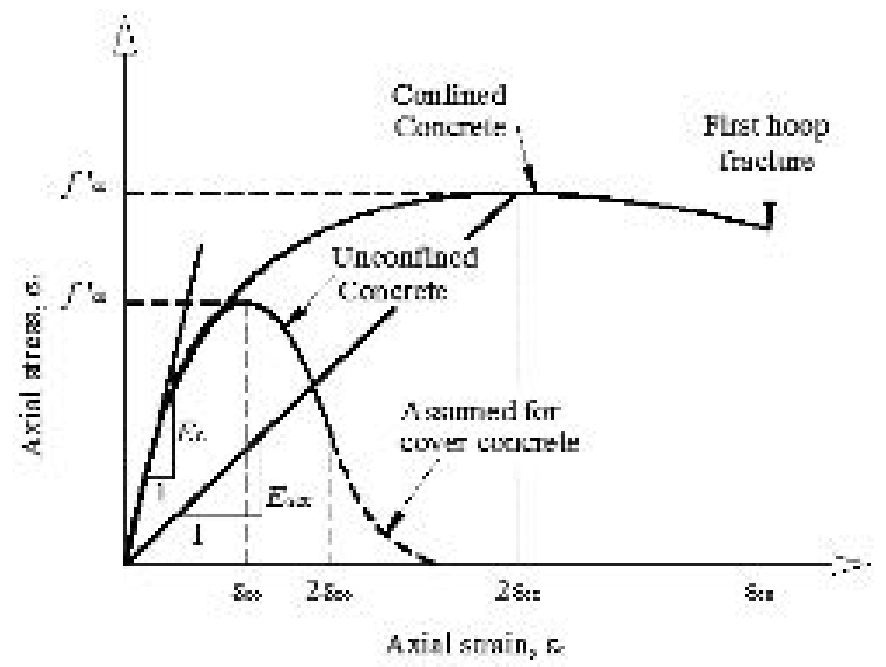

Figure 5- 1 Mander's concrete stress-strain model [133].

The longitudinal compressive stress $f_{c}$ is given by:

$$
\begin{aligned}
& f_{c}=\frac{f_{c c}^{\prime} x r}{r-1+x^{r}} \\
& x=\frac{\varepsilon_{c}}{\varepsilon_{c c}} \\
& \varepsilon_{c c}=\varepsilon_{c o}\left[1+5\left(\frac{f_{c c}^{\prime}}{f_{c o}^{\prime}}-1\right)\right]
\end{aligned}
$$

Equation 5- 1

Equation 5- 2

Equation 5- 3 


$$
\begin{aligned}
& r=\frac{E_{c}}{E_{c}-E_{s e c}} \\
& f_{c c}^{\prime}=f_{c o}^{\prime}\left(-1.254+2.254 \sqrt{\left.1+\frac{7.94 f_{l}^{\prime}}{f_{c o}^{\prime}}-2 \frac{f_{l}^{\prime}}{f_{c o}^{\prime}}\right)}\right. \\
& f_{l}^{\prime}=\frac{1}{2} k_{e} \rho_{s} f_{y h} \\
& \rho_{s}=\frac{4 A_{s p}}{d_{s} s}
\end{aligned}
$$

for circular hoops:

$$
k_{e}=\frac{\left(1-\frac{s^{\prime}}{2 d_{s}}\right)^{2}}{1-\rho_{c c}}
$$

Equation 5- 8

for circular spirals

$$
k_{e}=\frac{\left(1-\frac{s^{\prime}}{2 d_{s}}\right)}{1-\rho_{c c}}
$$

The unconfined concrete follows the same curve that the confined concrete Equation 5- 1 with a lateral confined stress $f_{l}^{\prime}=0$. The part of the dropping branch for strains greater than $2 \varepsilon_{o}$ is assumed to be a straight line which reaches zero at $\varepsilon_{s p}$ [133].

The stress-strain curve of UHPC in compression and tension was defined based on the experiments discussed in Chapter 2, and [28], [50], [135]. Australian and Japanese design recommendations for UHPC recommended the stress-strain curve shown in Figure 5- 2 for design. The important values in this figure are also compatible with the design guidelines proposed by Graybeal [27]. In this model, the stress-strain behavior of UHPC in compression is taken as a trilinear curve in which the maximum compressive strain is limited to $0.0032[50]$.

The tension behavior of UHPC for different curing conditions and steel fiber contents was characterized by Graybeal and Baby using dog-bone shaped test specimens 
of different sizes. This study categorized the tensile behavior of UHPC to four phases including elastic behavior, inelastic cracking, straining in discrete cracks, and single crack localization [27]. The results of their study also verified that the tensile behavior of UHPC can be described with an elastic-perfectly plastic response for design purposes as suggested in Ref. [50].
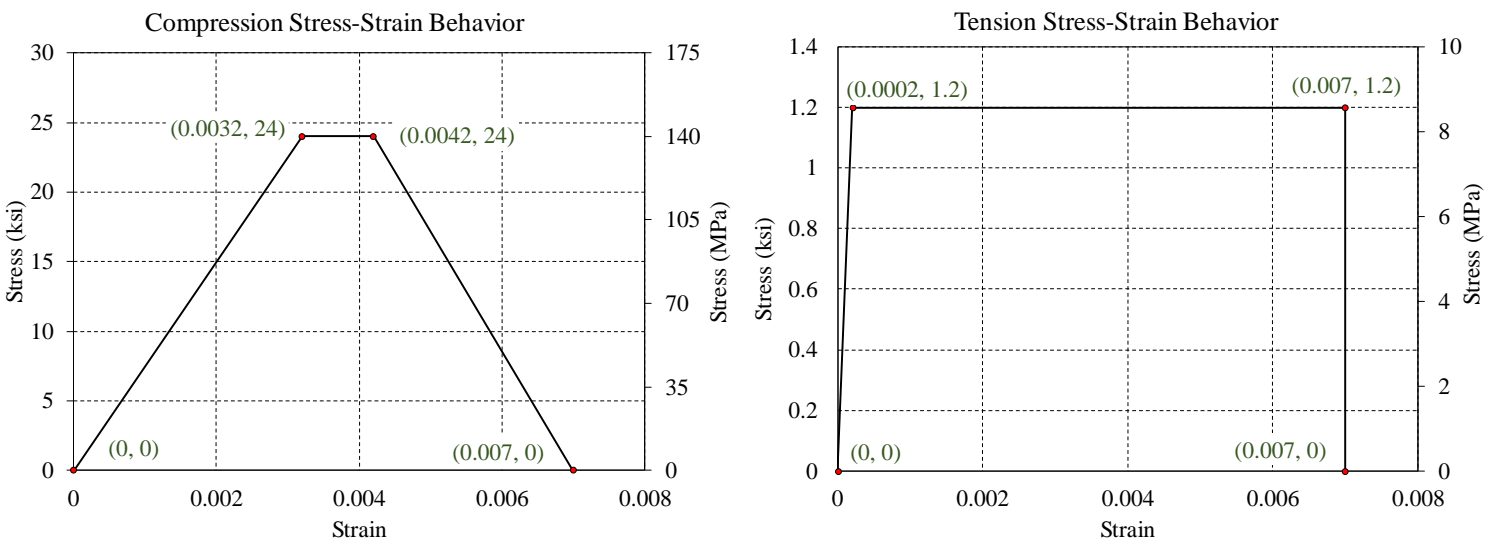

Figure 5- 2 Design stress-strain behavior of UHPC [50].

\subsubsection{STEEL}

The stress-strain relation for the reinforcing steel (Figure 5-3) is the same used by park et al. [134]:

$$
\begin{array}{lcc}
f_{s}=E_{s} \varepsilon_{s} & \varepsilon_{s} \leq \varepsilon_{y} & \text { Equation 5- 10 } \\
f_{s}=f_{y} & \varepsilon_{y} \leq \varepsilon_{s} \leq \varepsilon_{s h} & \text { Equation 5- 11 } \\
f_{s}=f_{u}\left[\frac{m\left(\varepsilon_{s}-\varepsilon_{s h}\right)+2}{60\left(\varepsilon_{s}-\varepsilon_{s h}\right)+2}+\frac{\left(\varepsilon_{s u}-\varepsilon_{s}\right)(60-m)}{2(30 r+1)^{2}}\right] & \varepsilon_{s h} \leq \varepsilon_{s} \leq \varepsilon_{s u} & \text { Equation 5- 12 }
\end{array}
$$

where:

$$
\begin{aligned}
& m=\frac{\left(f_{s u} / f_{y}\right)(30 r+1)^{2}-60 r-1}{15 r^{2}} \\
& r=\left(\varepsilon_{s u}-\varepsilon_{s h}\right)
\end{aligned}
$$

Equation 5- 14 


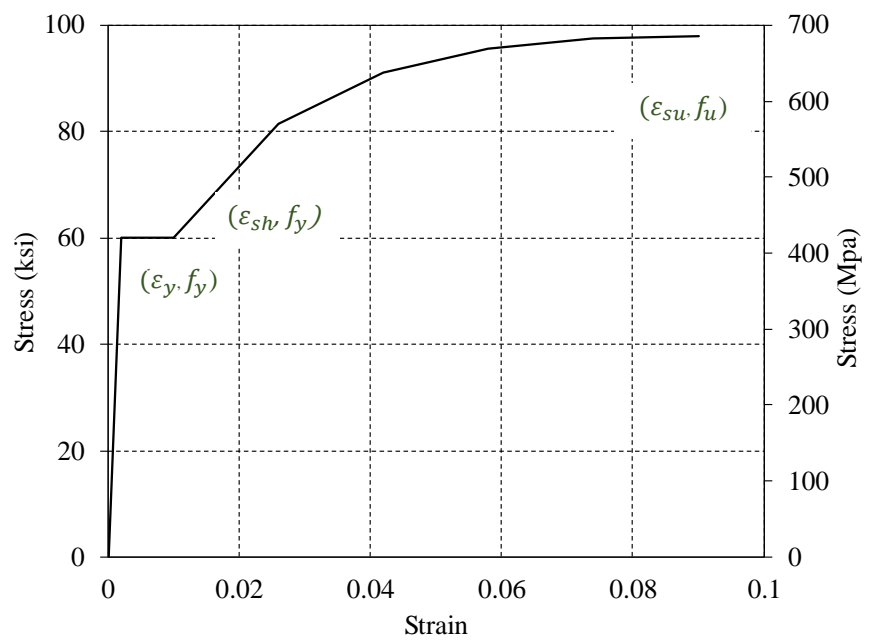

Figure 5- 3 Park model for steel reinforcing.

The sectional analysis is performed by finding the moment of the member section for increasing levels of curvature, an iterative procedure is used to determine the neutral axis depth so that the equilibrium at each level of curvature is satisfied. The program stops when the concrete strain in the core exceeds the maximum concrete compressive strain, or the tensile strain in the steel bars surpasses the maximum steel strain. The idealized plastic moment capacity is then determined by balancing the areas between the actual and the idealized $\mathrm{M}-\varphi$ curves beyond the first reinforcing bar yield point, see Figure 5- 4 [136].

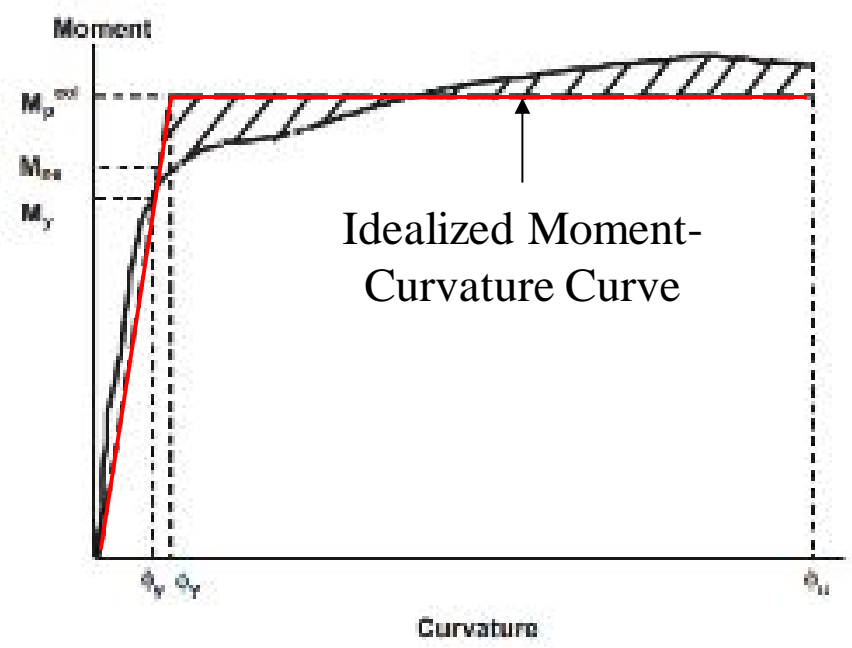

Figure 5- 4 Moment Curvature Curve [136]. 


\subsubsection{Model validation}

The moment-displacement responses obtained for the tested columns are compared to the measured average response envelopes established from the push and pull direction responses in Figure 5- 5. This comparison demonstrations that the analytical model satisfactorily captured the overall lateral load response of tested columns. Therefore, the model is validated to match the moment capacity of the tested specimens.
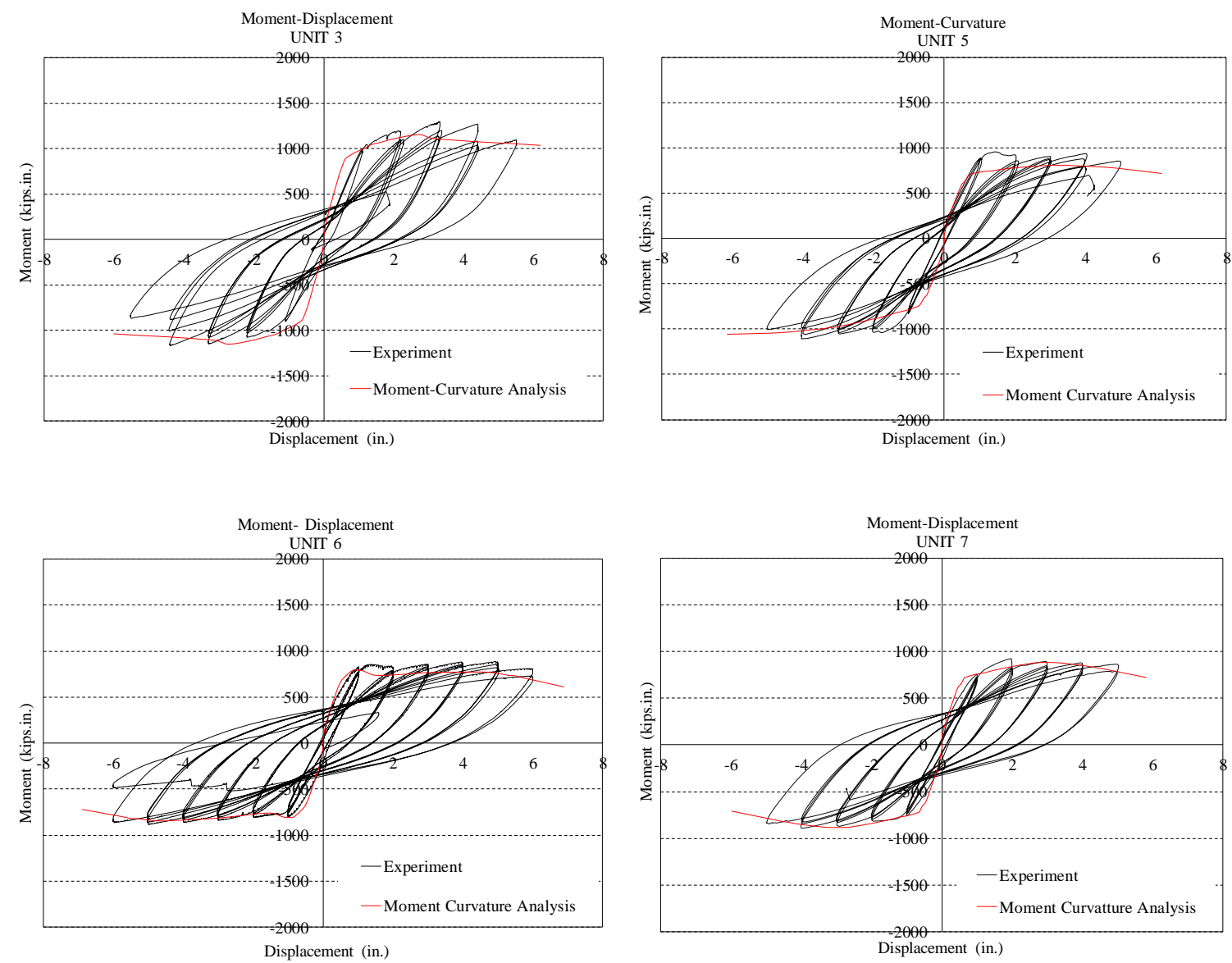

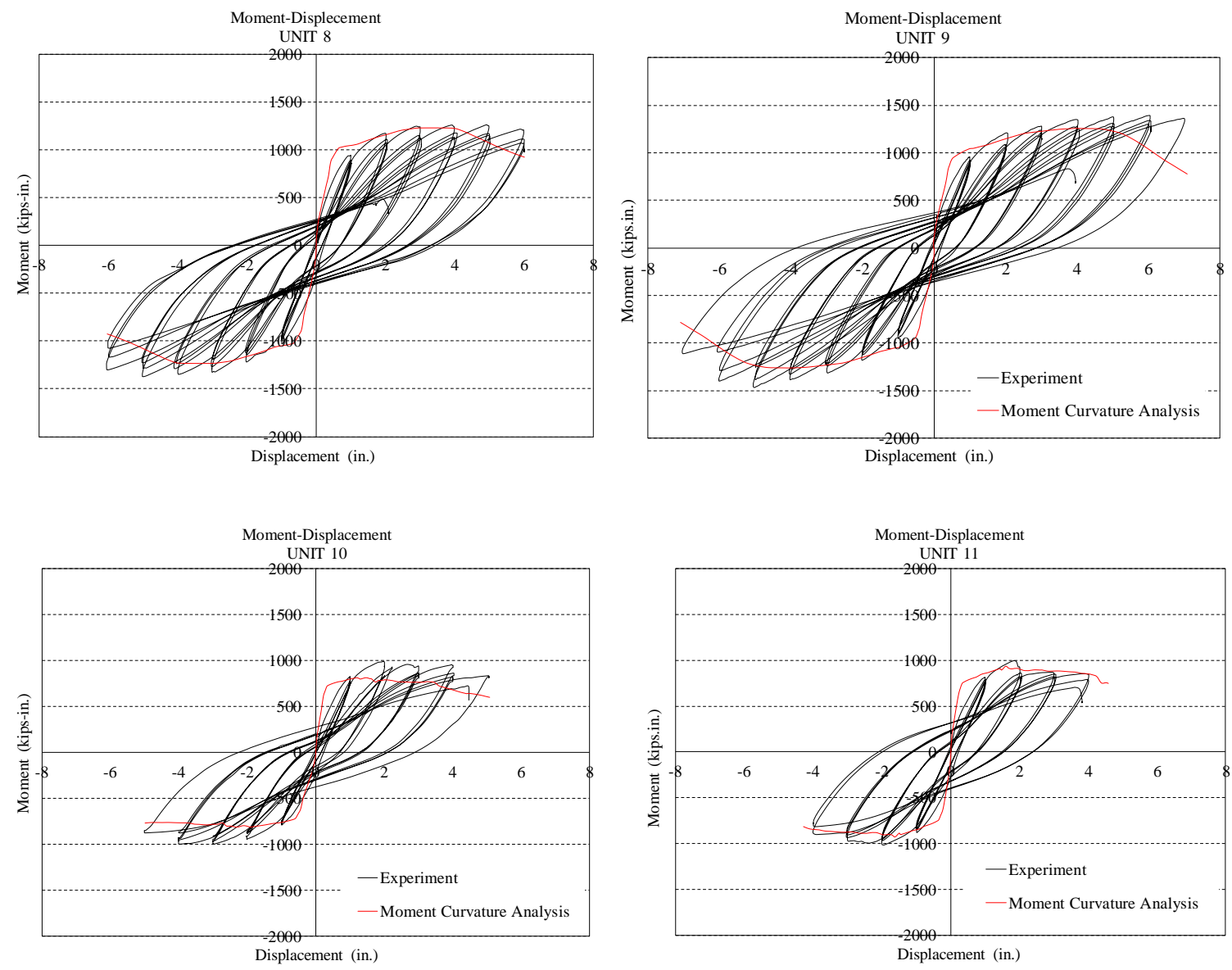

Figure 5- 5 Comparison of the measured and calculated force-displacement response envelopes of the column-foundation systems.

To capture the damage location in the columns three critical sections were analyzed; namely, column section (upper repaired section), repaired section, and support section, and the section having the lowest load (moment) capacity to applied load (moment) ratio was considered as the main critical section where the damage occurred. The critical section was then used to produce the moment displacement diagram of the column. To do that, the relations explained in section 3 of Caltrans [136] were used to calculate the displacement based on the curvature obtained by $M-\phi$ analysis of the critical section. For comparison purposes, Table 5- 1 provides the response of the tested specimens and the analytically calculated strengths. 
Table 5- 1 Experimental vs. analytical

\begin{tabular}{|c|c|c|c|c|c|c|c|}
\hline Unit & Critical Section & $\begin{array}{c}\text { Push Experiment } \\
\text { kips-in. }\end{array}$ & $\begin{array}{c}\text { Push } \\
\text { kips-in. }\end{array}$ & $\begin{array}{c}\text { Error } \\
\%\end{array}$ & $\begin{array}{c}\text { Pullical } \\
\text { kipseriment }\end{array}$ & $\begin{array}{c}\text { Pull } \\
\text { kipalytical }\end{array}$ & $\begin{array}{c}\text { Error } \\
\%\end{array}$ \\
\hline 3 & Repair & 1210 & 1140 & 5.8 & 1160 & 1153 & 0.6 \\
\hline 5 & End column & 920 & 810 & 12 & 1100 & 1018 & 7.5 \\
\hline 6 & End column & 901 & 890 & 1.2 & 860 & 880 & 2.3 \\
\hline 7 & Repair & 1235 & 1230 & 0.4 & 1340 & 1240 & 7.5 \\
\hline 8 & Support & 1235 & 1230 & 0.4 & 1300 & 1230 & 5.4 \\
\hline 9 & Support & 1340 & 1260 & 6 & 1470 & 1260 & 14 \\
\hline 10 & Upper repair & 920 & 780 & 15 & 925 & 780 & 16 \\
\hline 11 & Upper repair & 1000 & 860 & 14 & 1000 & 860 & 14 \\
\hline
\end{tabular}

\subsubsection{Effects of UHPC repair thickness}

The validated column model was used to identify the effect of UHPC shell thickness on the repaired sectional capacity of typical bridge columns. To accomplish that five Prototype bridge columns were chosen based on studies conducted by Refs. [137][139]. The geometry and the reinforcement characteristics of the bridge columns are given in Table 5- 2, where $D$ is the column diameter, $\rho_{l}$ is the ratio of the longitudinal reinforcement, $\rho_{t}$ is the volumetric ratio of the transverse reinforcement, and $C$ is the clear cover.

Table 5- 2 Basic dimensions and reinforcement of prototypes.

\begin{tabular}{|c|c|c|c|c|}
\hline Reference & $\begin{array}{c}\text { D } \\
\text { in. }(\mathrm{m})\end{array}$ & $\begin{array}{c}\rho_{\mathrm{l}} \\
\%\end{array}$ & $\begin{array}{c}\rho_{\mathrm{t}} \\
\%\end{array}$ & $\begin{array}{c}\mathrm{C} \\
\text { in. }(\mathrm{mm})\end{array}$ \\
\hline Adapted from [137] & $24(0.61)$ & 2 & 0.78 & $2(48)$ \\
\hline Adapted from [139] & $30(0.76)$ & 1.9 & 0.12 & $1(25)$ \\
\hline Adapted from [138] & $54(1.4)$ & 1.3 & 0.3 & $1.6(41)$ \\
\hline Adapted from [138] & $72(1.8)$ & 1.3 & 1.5 & $2(48)$ \\
\hline Adapted from [138] & $84(2.1)$ & 1.1 & 0.7 & $2(48)$ \\
\hline
\end{tabular}

Different shell thickness varying from 1 in. $(25 \mathrm{~mm})$ to the whole section was considered and the moment capacity of the section after repair versus the original crosssection (of the intact column) was calculated. It should be noted that the compressive strength of the substrate and UHPC were considered $6 \mathrm{ksi}(41 \mathrm{MPa})$ and $24 \mathrm{ksi}(165 \mathrm{MPa})$, 
respectively. The desired outcome of this part was to provide a rule of thumb to calculate the increase in the section's moment capacity which is not only important for the design procedure but also defines the failure location under loading. Figure 5- 6 shows the trend lines of the increased moment capacity of the prototype column sections repaired with UHPC shell under different axial load levels. Using this graph and choosing the best match of the column properties listed in Table 5- 2 the increased capacity of the section can be estimated for each repair thickness.
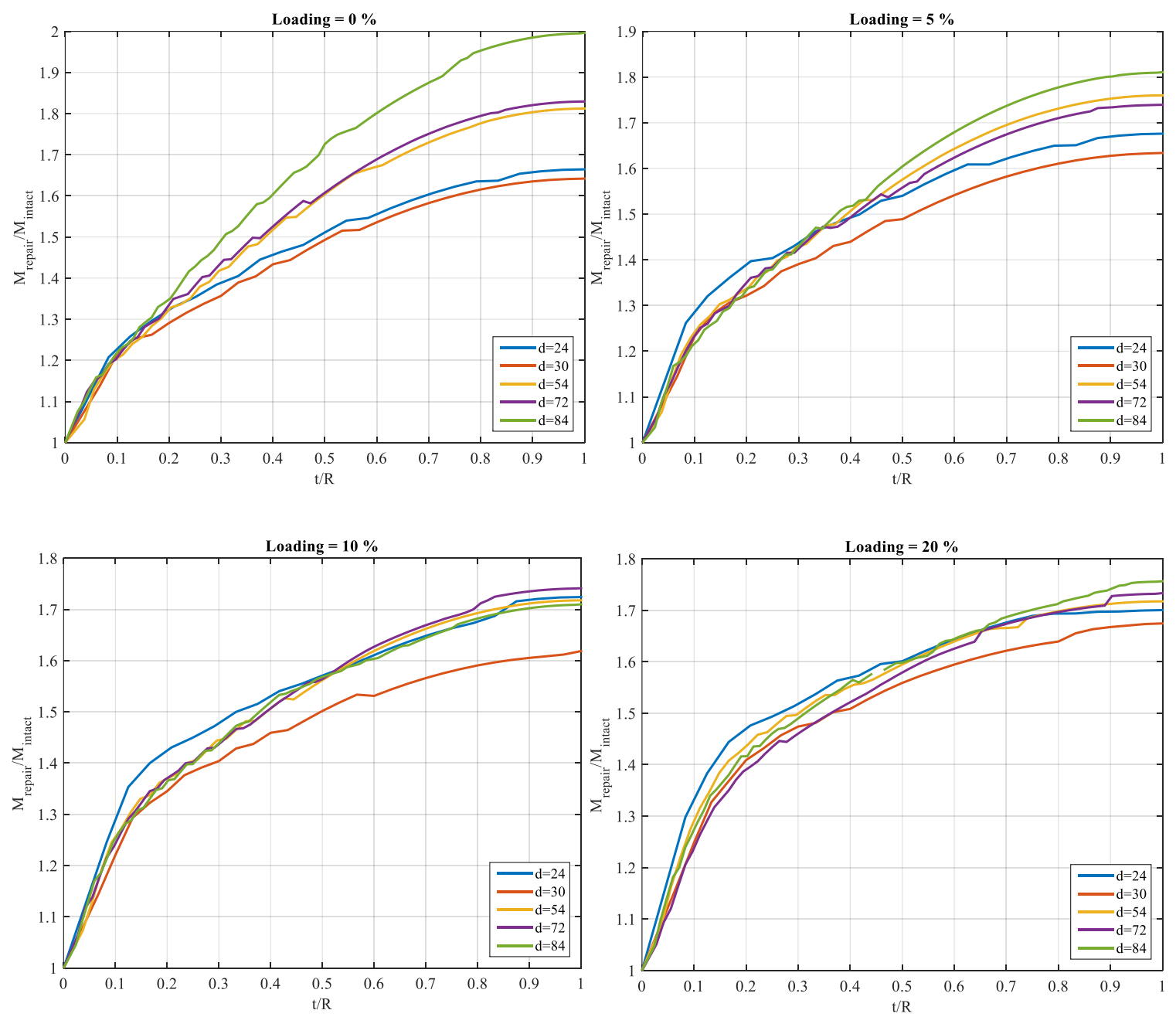

Figure 5- 6 Trend lines of the increased moment capacity of the prototype column sections repaired with UHPC shell under various axial load level. 
Moreover, to have a single trend line for each axial load level to calculate the increased capacity of the UHPC repaired sections all the data has been put together, and the increased capacity of the UHPC repaired section can be calculated using Equation Equation 5- 15 through Equation 5- 18.

Pure Bending
5\% Axial Load
10\% Axial Load
20\% Axial Load

$$
\begin{aligned}
& M_{\text {repaired }} / M_{\text {intact }}=1.8(t / R)^{0.16} \\
& M_{\text {repaired }} / M_{\text {intact }}=1.7(t / R)^{0.14} \\
& M_{\text {repaired }} / M_{\text {intact }}=1.7(t / R)^{0.12} \\
& M_{\text {repaired }} / M_{\text {intact }}=1.7(t / R)^{0.10}
\end{aligned}
$$

Equation 5- 15

Equation 5- 16

Equation 5- 17

Equation 5- 18

This will help the designers to have a rough estimate of the increased capacity of the repaired section which is important to predict the critical section. For instance, Caltrans [136] and AASHTO LRFD [131] recommend 20\%-30\% over strength magnifier for protected concrete components such as footings, bent cap beams, superstructure, joints, and shafts, to remain basically elastic when the column reaches its overstrength capacity. Therefore, when the strengthening of the repaired section is calculated to be greater than $30 \%$ of the original section the damage may take place in the footing, and design considerations should be made.

\subsection{Bending Moment CaPacity for Circular RC Columns with UHPC Shell REPAIR}

According to the conclusions obtained through the experimental studies on repaired columns, it was recommended to have an accurate estimation of the capacity of the repaired, upper repaired and lower repaired sections. The reason is, by using strong repair material such as UHPC the capacity of the repair region can increase so that the critical section be relocated. Depending on the desired relocation for the critical section, the 
geometry and length of the repair section may change. Therefore, the first step for the engineer to start the repair process with UHPC is to design the geometry of the repair. To do so, doing sectional analysis comes handy and helpful.

\subsubsection{Simplified approach}

In this section, equations to calculate the flexural capacity of circular cross-section with a symmetric longitudinal steel bar arrangement and UHPC shell (Figure 5- 7) are presented. When assuming a simplified elastic-ideal plastic stress-strain diagram for reinforcing steel, the flexural failure occurs due to concrete crushing. Any strain diagram conforming to such mode of failure has its fixed point at the limit value of maximum concrete compressive strain $\left(\varepsilon_{c u}\right)$ with a linear distribution of strain over the depth of the section [140].

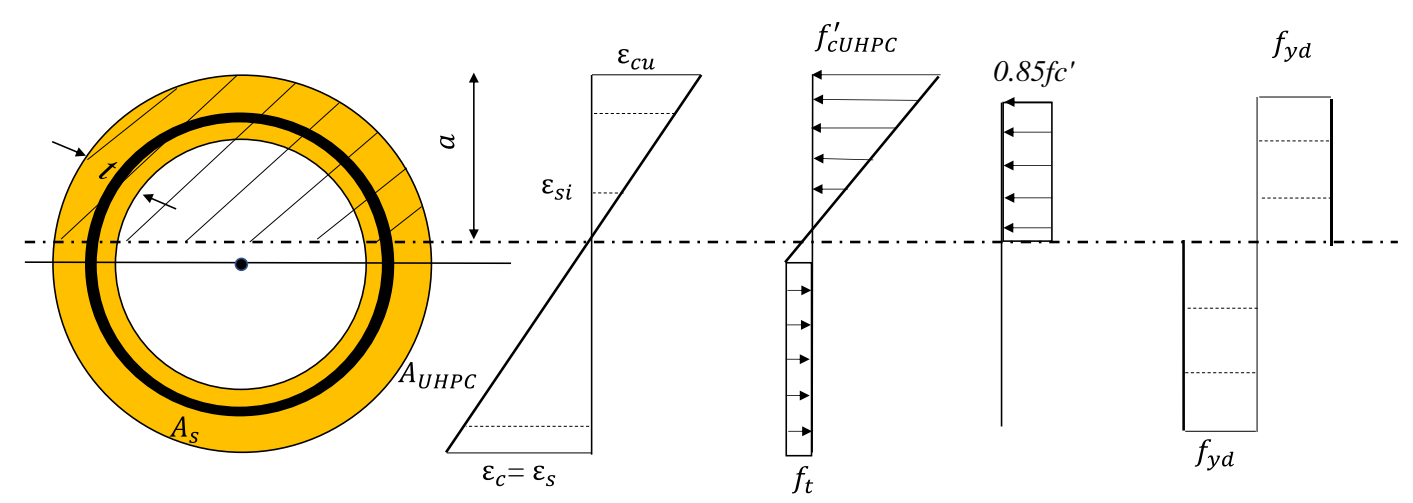

Figure 5- 7 Diagrams for analysis of circular cross-section with UHPC repair.

In this part for simplicity, the flexural behavior of normal strength concrete (substrate) is simplified using rectangular stress block parameters [141]. It was also assumed that normal strength concrete cannot transfer the tensile stress [141]. The compressive force in substrate concrete can then be calculated multiplying the area of the circular segment to the compressive stress (Figure 5- 8). In Figure 5- 8, $r$ is the radius of 
the column, $t$ is the thickness of UHPC, $\beta$ is one half of the angle subtended at the center of the cross-section by the concrete compression stress block, $f_{c d}$ is the design value of concrete compressive strength $\left(0.85 f^{\prime}\right)$, and $a$ is the distance of the neutral axis from the top of the section.

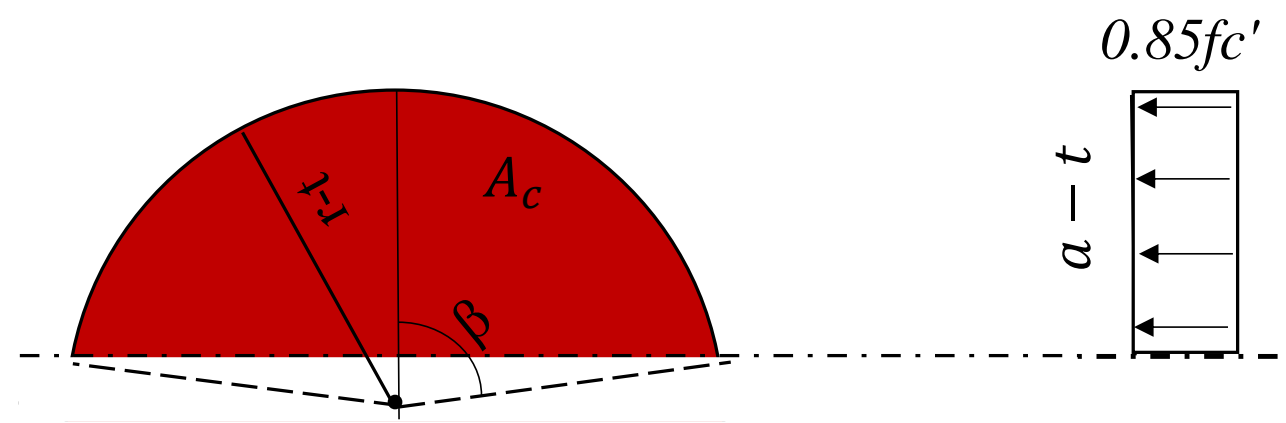

Figure 5- 8 Diagrams for calculation of compressive force in substrate concrete.

The area of the circular segment can be computed by subtracting the area of the triangle from the area of the sector (Figure 5- 9). The area of a sector (PQR in Figure 5- 9) is equal to the area of the circle $\left(\pi r^{2}\right)$ times the fraction of the circle represented by the sector (Equation 5- 19).

$$
\begin{aligned}
& \text { Area }_{\text {Sector } P Q R}=\left[\frac{\theta}{2 \pi}\right]\left(\pi r^{2}\right)=\frac{\theta}{2}\left(r^{2}\right) \\
& \text { Area }_{\text {TriangleYXZ }}=\frac{r^{2}}{2}\left(\sin \frac{\theta}{2} \cos \frac{\theta}{2}\right)=\frac{r^{2}}{2}(\sin \theta) \\
& \text { Area }_{\text {Segment }}=\text { Area }_{\text {Sector } P Q R}-\text { Area }_{\text {TriangleYXZ }}=\frac{r^{2}}{2}(\theta-\sin \theta)
\end{aligned}
$$

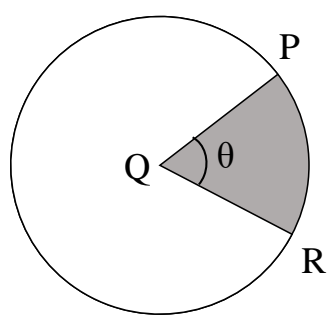

Sector

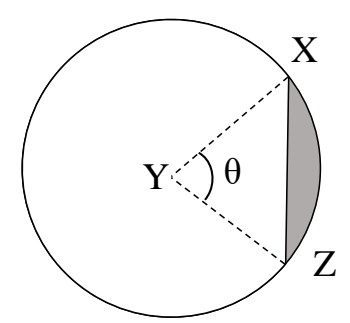

Segment

Figure 5- 9 Computation of the area of a circular segment. 
The compressive force in substrate is the calculated by Equation 5- 22 using the formula of area for a circular segment (Equation 5- 21), see Figure 5- 8.

$$
N_{\text {csubstrate }}=\frac{(r-t)^{2}}{2}(2 \beta-\sin 2 \beta) f_{c d}
$$

However, the same assumptions as considered for substrate concrete cannot be applied to flexural strength calculation of UHPC. UHPC has much higher compressive strength than normal strength concrete. That converts the shape of stress distribution in compression side to triangle [51], [135], [142], [143].

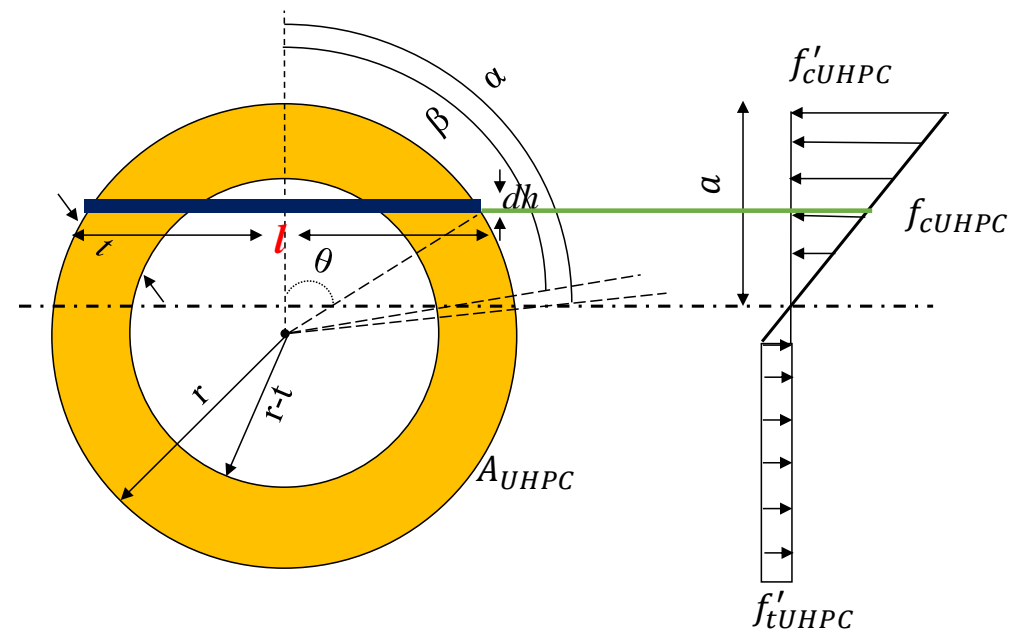

Figure 5- 10 Diagrams for calculation of compressive and tensile force of UHPC shell.

The compressive force of UHPC shell is then calculated by integration of the forces (compressive stress $x$ area) over the shell length on the compression side (Equation 5- 26).

Where:

$$
d A=l d h=(2 r \sin \theta)(r \sin \theta) d \theta
$$

Equation 5- 23

The compressive stress of UHPC at each height $\left(f_{c U H P C}\right)$ is computed using trigonometric functions: 


$$
f_{U H P C}=f_{c U H P C}^{\prime} \frac{\cos \theta-\cos \alpha}{1-\cos \alpha}
$$

In Figure 5-10, $f^{\prime}{ }_{C U H P C}$ is the nominal 28-day compressive strength of UHPC, $\alpha$ is one half of the angle subtended at the center of the cross-section by the UHPC compression stress block, $f_{t U H P C}^{\prime}$ is the tensile strength of UHPC, and $A_{U H P C}$ is the total area of the shell.In to calculate the compressive force in UHPC, the sector containing substrate (angle $=2 \beta)$ is subtracted from the whole sector in compression (angle $=2 \alpha$ ), see Figure 5-

11. Where:

$$
\frac{(r-t)}{r} \cos \beta=\cos \alpha
$$

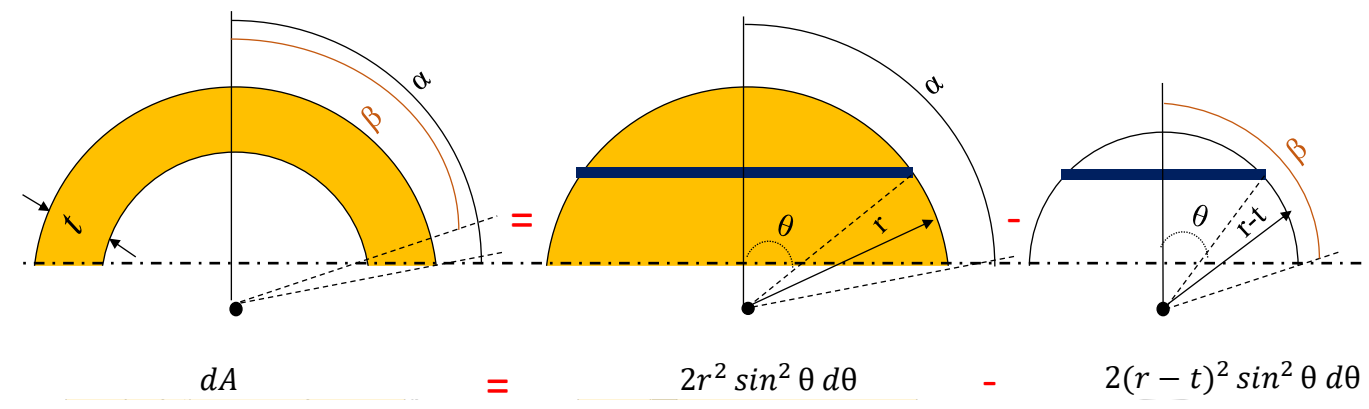

Figure 5- 11 Computation of the area of the UHPC shell.

$$
\begin{aligned}
& N_{C U H P C}=\int_{0}^{\alpha} f_{C U H P C} d A=\int_{0}^{\alpha}\left(\frac{2 r^{2} f_{C U H P C}^{\prime}}{1-\cos \alpha}\right) \sin ^{2} \theta(\cos \theta-\cos \alpha) d \theta- \\
& \int_{0}^{\beta}\left(\frac{2(r-t)^{2} f_{C U H P C}^{\prime}}{1-\cos \beta}\right) \sin ^{2} \theta(\cos \theta-\cos \beta) d \theta=\left(\frac{2 r^{2} f_{C U H P C}^{\prime}}{1-\cos \alpha}\right)\left(\frac{1}{3} \sin ^{3} \alpha-\right. \\
& \left.\frac{\alpha}{2} \cos \alpha+\frac{1}{4} \cos \alpha \sin 2 \alpha\right)-\left(\frac{2(r-t)^{2} f_{C U H P C}^{\prime}}{1-\cos \alpha}\right)\left(\frac{1}{3} \sin ^{3} \beta-\frac{\alpha}{2} \cos \beta+\right. \\
& \left.\frac{1}{4} \cos \beta \sin 2 \beta\right)
\end{aligned}
$$

The ductility and tensile strength of UHPC that mainly result from the fibers is a characteristic material behavior that cannot be ignored. Therefore, the tensile stress distribution in tension side should be considered to calculate the flexural strength of section 
[50], [55], [56], [144]. The tensile stress distribution is conservatively considered constant for the post-cracking tensile behavior [50], [55], [56], [144]. The tensile force of UHPC can be approximated by Equation 5- 27, where $\left(\frac{\pi-\alpha}{\pi}\right) A_{U H P C}$ is the cross-sectional areas of UHPC shell in tension.

$$
N_{\text {tUUPC }}=\left(\frac{\pi-\alpha}{\pi}\right) A_{U H P C} f_{t U H P C}^{\prime}
$$

One difficulty pertaining to the circular cross-section with a symmetric arrangement of steel reinforcement along the perimeter is calculating the compressive and tensile forces in each individual reinforcement based on its generated stress. This calculation should be done based on the assumption the linear strain distribution along the cross-section. Therefore, when the maximum concrete compressive strain, $\varepsilon_{c u}$ is reached, the strain in any row of reinforcing bars $\varepsilon_{s t}$ can be calculated using Equation 5- 28, where $y_{i}$ is the vertical distance between the $i$-th row of reinforcing bars and the neutral axis.

$$
\varepsilon_{s, i}=\varepsilon_{c u} \frac{y_{i}}{x}
$$

However, the developed equations in this section assume that the entire steel area is merged into an equivalent steel ring. This assumption was introduced by Cosenza et al [145] to calculate the ultimate moment capacity of circular RC cross-sections subjected to axial loads combined with uniaxial bending. In this method, the longitudinal bar arrangements are substituted with a thin steel ring equivalent to steel total area $\left(A_{s}\right)$, (Figure 5- 12). This approximation does not consider the vertical location of the longitudinal reinforcements with respect to the neutral axis changing the results of the analysis. The results obtained through the proposed simplified method was then verified with a wide 
range of design cases exhibiting a good similarity with the values calculated by more rigorous methods [145].

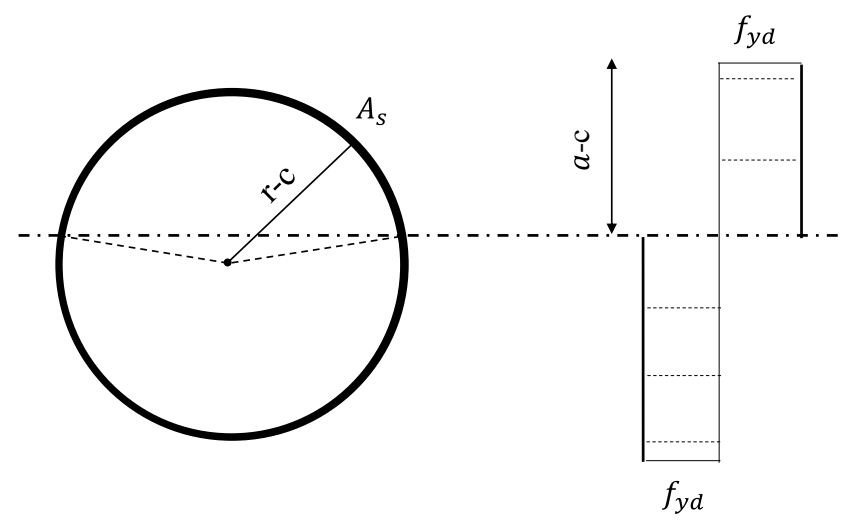

Figure 5- 12 Diagrams for calculation of compressive and tensile force of equivalent steel ring.

$$
\left(\frac{\alpha}{\pi}\right) A_{s} \text { and }\left(\frac{\pi-\alpha}{\pi}\right) A_{s} \text { are approximately cross-sectional areas of longitudinal }
$$

reinforcement in compression and tension, respectively. The compressive and tensile force of steel ring are then calculated by multiplying the designed yield stress to the corresponding area.

For a given section, the position of the neutral axis (from the extreme compression fiber) is calculated based on the force equilibrium as in Equation 5- 29.

$$
N_{\text {csubstrate }}+N_{c U H P C}+N_{s}^{\prime}-N_{s}-N_{c U H P C}=P
$$

$\mathrm{N}_{\text {csubstrate, }} \mathrm{N}_{\mathrm{cUHPC}}$, and $N_{S}^{\prime}$ denote compressive forces in substrate concrete, UHPC and steel reinforcement of the compression zone, respectively. $\mathrm{N}_{\mathrm{s}}$, and $\mathrm{N}_{\mathrm{tUHPC}}$ denotes the tensile force in reinforcement and UHPC shell of the tension zone; $\mathrm{P}$ is the value of the applied axial force (compression).

The value of " $a$ " denoting the compressive portion of the cross-section may be calculated through the condition of equilibrium that the total internal and external forces are equal to zero, Equation 5- 30. 
$\frac{(r-t)^{2}}{2}(2 \beta-\sin 2 \beta) f_{c d}+\left(\frac{2 r^{2} f_{c U H P C}^{\prime}}{1-\cos \alpha}\right)\left(\frac{1}{3} \sin ^{3} \alpha-\frac{\alpha}{2} \cos \alpha+\frac{1}{4} \cos \alpha \sin 2 \alpha\right)-$

$\left(\frac{2(r-t)^{2} f_{C U H P C}^{\prime}}{1-\cos \alpha}\right)\left(\frac{1}{3} \sin ^{3} \beta-\frac{\alpha}{2} \cos \beta+\frac{1}{4} \cos \beta \sin 2 \beta\right)+\left(\frac{2 \alpha-\pi}{\pi}\right) A_{s} f_{y d}-$

Equation 5- 30

$\left(\frac{\pi-\alpha}{\pi}\right) A_{U H P C} f_{t U H P C}^{\prime}=P$

The determination of location of the neutral axis (i.e. $a$ or, equivalently, $\alpha$ and $\beta$ ) is carried out by iteration methods. Newton's method is reasonably the best-known method to obtain successively better approximations to the roots (or zeroes) of a real-valued function. It can often converge remarkably quickly. In this method, given a function $f(\mathrm{x})$ and its derivative $f^{\prime}(\mathrm{x})$, a first guess is considered (such as $\pi / 6$ ). A better approximation $\mathrm{x}_{1}$ is:

$$
x_{1}=x_{0}-\frac{f(x)}{f^{\prime}(x)}
$$

It should be noted that in the above equations to calculate the location of neutral axis, the initial assumption is $a>t$. If the calculated $a$ is less than the UHPC thickness the whole substrate would be in tension, and as mentioned earlier the contribution of substrate is ignored. In that condition the value of $a$ is determined from Equation 5- 32.

$$
\begin{aligned}
& \left(\frac{2 r^{2} f_{c U H P C}^{\prime}}{1-\cos \alpha}\right)\left(\frac{1}{3} \sin ^{3} \alpha-\frac{\alpha}{2} \cos \alpha+\frac{1}{4} \cos \alpha \sin 2 \alpha\right)+\left(\frac{2 \alpha-\pi}{\pi}\right) A_{s} f_{y d}- \\
& \left(\frac{\pi-\alpha}{\pi}\right) A_{U H P C} f_{t U H P C}^{\prime}=P
\end{aligned}
$$

The flexural capacity of the member $\left(M_{R d}\right)$ can be calculated by adding the moment due to internal and external forces about the axis through the cross-section's center of the member, as in Equation 5- 33.

$$
M_{R d}=M_{C U H P C}+M_{\text {CSubstrate }}+M_{C s t e e l}+M_{t S t e e l}+M_{t U H P C}
$$

Where, $\mathrm{M}_{\mathrm{CUHPC}}$, and $\mathrm{M}_{\mathrm{CS} u b s t r a t e}$, are the moment due the compressive forces in UHPC, substrate and steel, respectively. $\mathrm{M}_{\mathrm{tUHPC}}$ is the moment caused by the forces in 
UHPC in tension zone, and $\mathrm{M}_{\text {Steel }}$ is the moment due the compressive and tensile forces in steel. Equation 5- 34 through Equation 5- 37 show the relations to calculate each of the corresponding moments for the initial assumption $(a>t)$.

$$
\begin{aligned}
& M_{C U H P C}=\left(\frac{2 f_{C U H P C}^{\prime} r^{3}}{1-\cos \alpha}\left(\frac{\alpha}{8}-\frac{1}{3} \cos \alpha \sin ^{3} \alpha-\frac{1}{32} \sin 4 \alpha\right)\right)- \\
& \left(\frac{2 f_{C U H P C}^{\prime}(r-t)^{3}}{1-\cos \alpha}\right)\left(\frac{\beta}{8}-\frac{1}{3} \cos \beta \sin ^{3} \beta-\frac{1}{32} \sin 4 \beta\right) \\
& M_{\text {CSubstrate }}=\frac{2}{3}(r-t)^{3} \sin ^{3} \beta f_{c d} \\
& M_{\text {steel }}=2(r-c)\left(\frac{\sin \alpha}{\pi}\right) A_{s} f_{y d} \\
& M_{\text {tUHPC }}=\frac{2}{3} f_{t} \sin ^{3} \alpha\left(r^{3}-(r-t)^{3}\right)
\end{aligned}
$$

Equation 5- 37

If the calculated " $a$ " is less than the UHPC thickness, there would be no McSubstrate, and the moment corresponding to the UHPC in compression is determined from Equation 5- 38.

$$
M_{C U H P C}=\left(\frac{2 f_{C U H P C}^{\prime} r^{3}}{1-\cos \alpha}\right)\left(\frac{\alpha}{8}-\frac{1}{3} \cos \alpha \sin ^{3} \alpha-\frac{1}{32} \sin 4 \alpha\right)
$$

To make the equation more simplified, the same process was performed except rectangular stress distribution was considered instead of the triangular one for UHPC. In Figure 5-13" $\kappa "$ is the reduction factor of the compressive strength of UHPC.

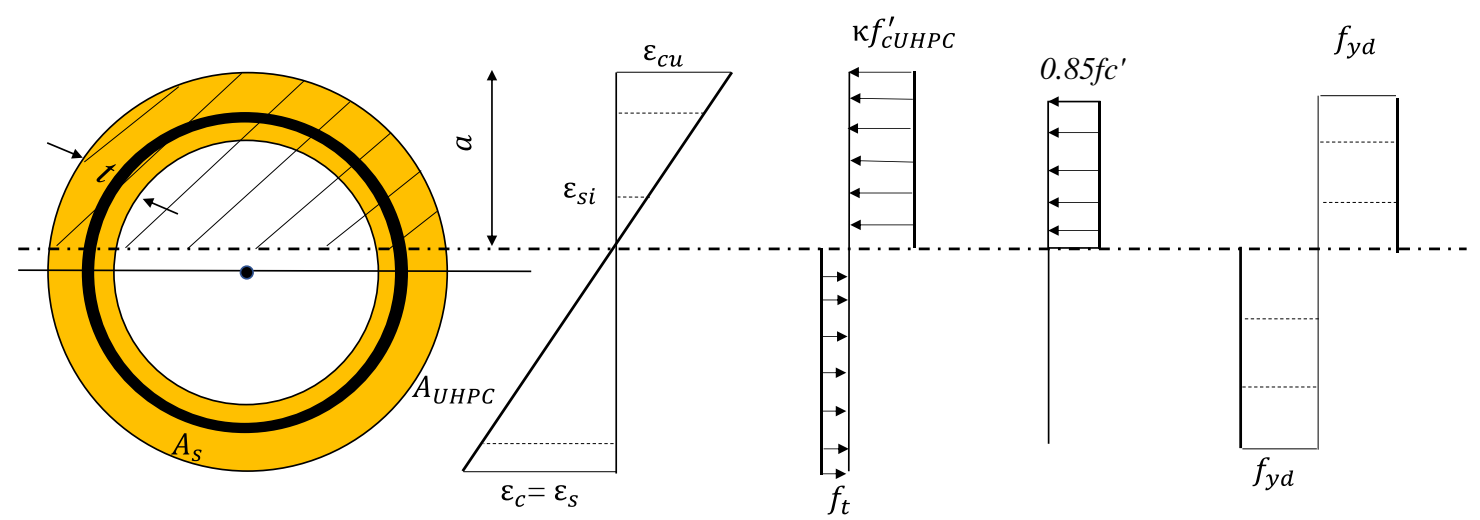

Figure 5- 13 Diagrams for analysis of circular cross-section with UHPC repair (rectangular stress distribution for UHPC in compression). 
The compressive force of UHPC shell is then calculated by integration over the shell length on the compression side (Equation 5- 39).

$$
\left.N_{c U H P C}=0.5 t(2 r-t) \kappa f_{c U H P C}^{\prime}(2(\alpha-\beta)-\sin 2 \alpha+\sin 2 \beta)\right)
$$

The force component of the remaining sections follows the previous equations. The determination of location of the neutral axis is again carried out by iteration methods with the initial assumption of $a>t$ (Equation 5-40).

$$
\begin{aligned}
& \frac{(r-t)^{2}}{2}(2 \beta-\sin 2 \beta) f_{c d}+0.5 t(2 r-t) \kappa f_{c U H P C}^{\prime}(2(\alpha-\beta)-\sin 2 \alpha+ \\
& \sin 2 \beta))+\left(\frac{2 \alpha-\pi}{\pi}\right) A_{s} f_{y d}-\left(\frac{\pi-\alpha}{\pi}\right) A_{U H P C} f_{t U H P C}^{\prime}=P
\end{aligned}
$$

If the calculated " $a$ " does not meet the initial assumption, it should be calculated using Equation 5- 41

$$
0.5 r^{2} \kappa f_{c U H P C}^{\prime}(2 \alpha-\sin 2 \alpha)+\left(\frac{2 \alpha-\pi}{\pi}\right) A_{s} f_{y d}-\left(\frac{\pi-\alpha}{\pi}\right) A_{U H P C} f_{t U H P C}^{\prime}=P
$$

The member flexural capacity of the UHPC in compression $\left(\mathrm{M}_{\mathrm{CUHPC}}\right)$ is then determined by Equation 5- 42 for the initial assumption of $a>t$.

$$
M_{C U H P C}=\left(\frac{2 \kappa f_{C U H P C}^{\prime}}{3}\right)\left(r^{3} \sin ^{3} \alpha-(r-t)^{3} \sin ^{3} \beta\right)
$$

and if $a \leq t, \mathrm{M}_{\mathrm{CUHPC}}$ is calculated by Equation 5- 43 .

$$
M_{C U H P C}=\left(\frac{2 \kappa f_{C U H P C}^{\prime} r^{3}}{3}\right) \sin ^{3} \alpha
$$

The reduction factor for the compressive strength of UHPC was determined by equating the results calculated through both stress distributions. It was observed the $\kappa$ varies when $t / R$ varies. This relationship is formulated in Equation 5- 44.

$$
\kappa=0.43\left(\frac{t}{R}\right)^{-0.172}
$$




\subsubsection{Illustrative example}

The values of ultimate bending moment capacity of the five prototype circular cross-section columns presented in Table 5- 2 for different axial load level are given in Table 5- 3 using the presented approaches; concrete and steel are characterized by $\mathrm{f}_{c}{ }_{c}=6$ ksi (41 MPa) and $f_{y}=65 \mathrm{ksi}(450 \mathrm{MPa})$, respectively. In Table 5- 3, $\mathrm{M}_{\mathrm{M}}$ is the value of the flexural capacity of cross-section computed by MATLAB program. $\mathrm{M}_{\mathrm{T}}$ and $\mathrm{M}_{\mathrm{R}}$ are the value of the flexural capacity of cross-section calculated by the proposed method when the stress distribution for UHPC in compression is triangular, and rectangular, respectively.

Table 5- 3 reveals that the design value of load carrying capacity of eccentrically compressed RC members of circular cross-section determined by the proposed method for both triangular and rectangular stress distribution for UHPC in compression is very close to that determined using more refined methods of analysis.

The comparison shows that the average ratio between design load carrying capacity of eccentrically compressed RC members of circular cross-section determined by the proposed method with triangular stress distribution of UHPC in compression $\left(\mathrm{M}_{\mathrm{T}}\right)$, and the Moment-Curvature ones $\left(\mathrm{M}_{\mathrm{M}}\right)$ is 0.98 with a maximum value of $\mathrm{M}_{\mathrm{M}} / \mathrm{M}_{\mathrm{T}}$ for 1.05. These value for the rectangular stress distribution of UHPC in compression are 0.99 for the average value and the maximum value of $\mathrm{M}_{\mathrm{M}} / \mathrm{M}_{\mathrm{R}}$ equal to 1.07 . 
Table 5- 3 Results of simplified method vs. MATLAB program.

\begin{tabular}{|c|c|c|c|c|c|c|c|c|c|c|}
\hline Ref & $\begin{array}{l}\mathrm{R} \\
\text { in. } \\
(\mathrm{mm})\end{array}$ & $\begin{array}{c}\text { Cover } \\
\text { in. } \\
(\mathrm{mm})\end{array}$ & $\begin{array}{c}\mathrm{A}_{\mathrm{s}} \\
\mathrm{in}^{2} \\
\left(\mathrm{~cm}^{2}\right)\end{array}$ & $\begin{array}{c}\text { Axial } \\
\%\end{array}$ & $\mathrm{t} / \mathrm{R}$ & $\begin{array}{c}\mathrm{M}_{\mathrm{M}} \\
\text { kips.in }\end{array}$ & $\begin{array}{c}\mathrm{M}_{\mathrm{T}} \\
\text { kips.in }\end{array}$ & $\mathrm{M}_{\mathrm{T}} / \mathrm{M}_{\mathrm{M}}$ & $\begin{array}{c}\mathrm{M}_{\mathrm{R}} \\
\text { kips.in }\end{array}$ & $\mathrm{M}_{\mathrm{R}} / \mathrm{M}_{\mathrm{M}}$ \\
\hline \multirow{20}{*}{ [137] } & \multirow{20}{*}{$\begin{array}{c}12 \\
(305)\end{array}$} & \multirow{20}{*}{$\begin{array}{c}1.5 \\
(38)\end{array}$} & \multirow{20}{*}{$\begin{array}{c}8.8 \\
(57)\end{array}$} & \multirow{5}{*}{0} & 0 & 5853 & 5700 & 0.97 & 5700 & 0.97 \\
\hline & & & & & 0.1 & 7548 & 7160 & 0.95 & 7000 & 0.93 \\
\hline & & & & & 0.2 & 7978 & 8000 & 1.00 & 7900 & 0.99 \\
\hline & & & & & 0.5 & 9067 & 8890 & 0.98 & 9073 & 1.00 \\
\hline & & & & & 1 & 9987 & 9870 & 0.99 & 9924 & 0.99 \\
\hline & & & & \multirow{5}{*}{5} & 0 & 6490 & 6400 & 1.00 & 6400 & 1.00 \\
\hline & & & & & 0.1 & 8570 & 8120 & 0.95 & 8200 & 0.96 \\
\hline & & & & & 0.2 & 9067 & 9016 & 0.99 & 9000 & 0.99 \\
\hline & & & & & 0.5 & 9996 & 9871 & 0.99 & 9900 & 0.99 \\
\hline & & & & & 1 & 10878 & 10811 & 0.99 & 10700 & 0.98 \\
\hline & & & & \multirow{5}{*}{10} & 0 & 7200 & 7200 & 1.00 & 7200 & 1.00 \\
\hline & & & & & 0.1 & 9744 & 8990 & 0.92 & 9200 & 0.94 \\
\hline & & & & & 0.2 & 10299 & 9920 & 0.96 & 10000 & 0.97 \\
\hline & & & & & 0.5 & 11310 & 10800 & 0.95 & 10700 & 0.95 \\
\hline & & & & & 1 & 12414 & 11750 & 0.95 & 11400 & 0.92 \\
\hline & & & & \multirow{5}{*}{20} & 0 & 7970 & 8400 & 0.99 & 8400 & 1.05 \\
\hline & & & & & 0.1 & 11022 & 10500 & 0.95 & 10900 & 0.99 \\
\hline & & & & & 0.2 & 11765 & 11540 & 0.98 & 11800 & 1.02 \\
\hline & & & & & 0.5 & 12760 & 13000 & 1.01 & 12100 & 0.95 \\
\hline & & & & & 1 & 13552 & 13400 & 0.99 & 12700 & 0.94 \\
\hline \multirow{20}{*}{ [139] } & \multirow{20}{*}{$\begin{array}{c}15 \\
(380)\end{array}$} & \multirow{20}{*}{$\begin{array}{c}1.0 \\
(25)\end{array}$} & \multirow{20}{*}{$\begin{array}{l}13.2 \\
(85)\end{array}$} & \multirow{5}{*}{0} & 0 & 11876 & 11000 & 0.93 & 11000 & 0.93 \\
\hline & & & & & 0.1 & 14441 & 13200 & 0.91 & 13900 & 0.98 \\
\hline & & & & & 0.2 & 15331 & 15400 & 1.00 & 15700 & 1.03 \\
\hline & & & & & 0.5 & 17731 & 17400 & 0.98 & 17700 & 1.00 \\
\hline & & & & & 1 & 19500 & 19300 & 0.99 & 19400 & 1.00 \\
\hline & & & & \multirow{5}{*}{5} & 0 & 13373 & 12900 & 0.88 & 12900 & 0.96 \\
\hline & & & & & 0.1 & 16484 & 15500 & 0.94 & 16350 & 0.99 \\
\hline & & & & & 0.2 & 17677 & 17700 & 1.00 & 17800 & 1.00 \\
\hline & & & & & 0.5 & 19912 & 19730 & 0.99 & 19700 & 0.99 \\
\hline & & & & & 1 & 21850 & 21500 & 0.98 & 21200 & 0.97 \\
\hline & & & & \multirow{5}{*}{10} & 0 & 14827 & 14650 & 0.99 & 14650 & 0.99 \\
\hline & & & & & 0.1 & 18095 & 17500 & 0.97 & 18600 & 1.03 \\
\hline & & & & & 0.2 & 19943 & 19900 & 0.99 & 20170 & 1.01 \\
\hline & & & & & 0.5 & 22266 & 21900 & 0.98 & 21500 & 0.96 \\
\hline & & & & & 1 & 24000 & 23550 & 0.92 & 23000 & 0.96 \\
\hline & & & & \multirow{5}{*}{20} & 0 & 17092 & 17300 & 1.01 & 17300 & 1.01 \\
\hline & & & & & 0.1 & 21339 & 20720 & 0.99 & 22600 & 1.06 \\
\hline & & & & & 0.2 & 24081 & 23500 & 0.98 & 24300 & 1.00 \\
\hline & & & & & 0.5 & 26644 & 26800 & 1.00 & 24700 & 0.93 \\
\hline & & & & & 1 & 28620 & 27400 & 0.96 & 26000 & 0.91 \\
\hline \multirow{7}{*}{ [138] } & \multirow{7}{*}{$\begin{array}{c}27 \\
(686)\end{array}$} & \multirow{7}{*}{$\begin{array}{c}2.0 \\
(50)\end{array}$} & \multirow{7}{*}{$\begin{array}{c}28.1 \\
(181)\end{array}$} & & 0 & 48921 & 43353 & 0.89 & 43353 & 0.89 \\
\hline & & & & & 0.1 & 58646 & 57000 & 0.97 & 58600 & 1.00 \\
\hline & & & & 0 & 0.2 & 65000 & 67000 & 1.03 & 67800 & 1.04 \\
\hline & & & & & 0.5 & 78482 & 80000 & 1.02 & 83100 & 1.06 \\
\hline & & & & & 1 & 88657 & 92000 & 1.04 & 93400 & 1.05 \\
\hline & & & & 5 & 0 & 58541 & 56000 & 0.96 & 56000 & 0.96 \\
\hline & & & & 5 & 0.1 & 71988 & 70000 & 0.97 & 73300 & 1.02 \\
\hline
\end{tabular}




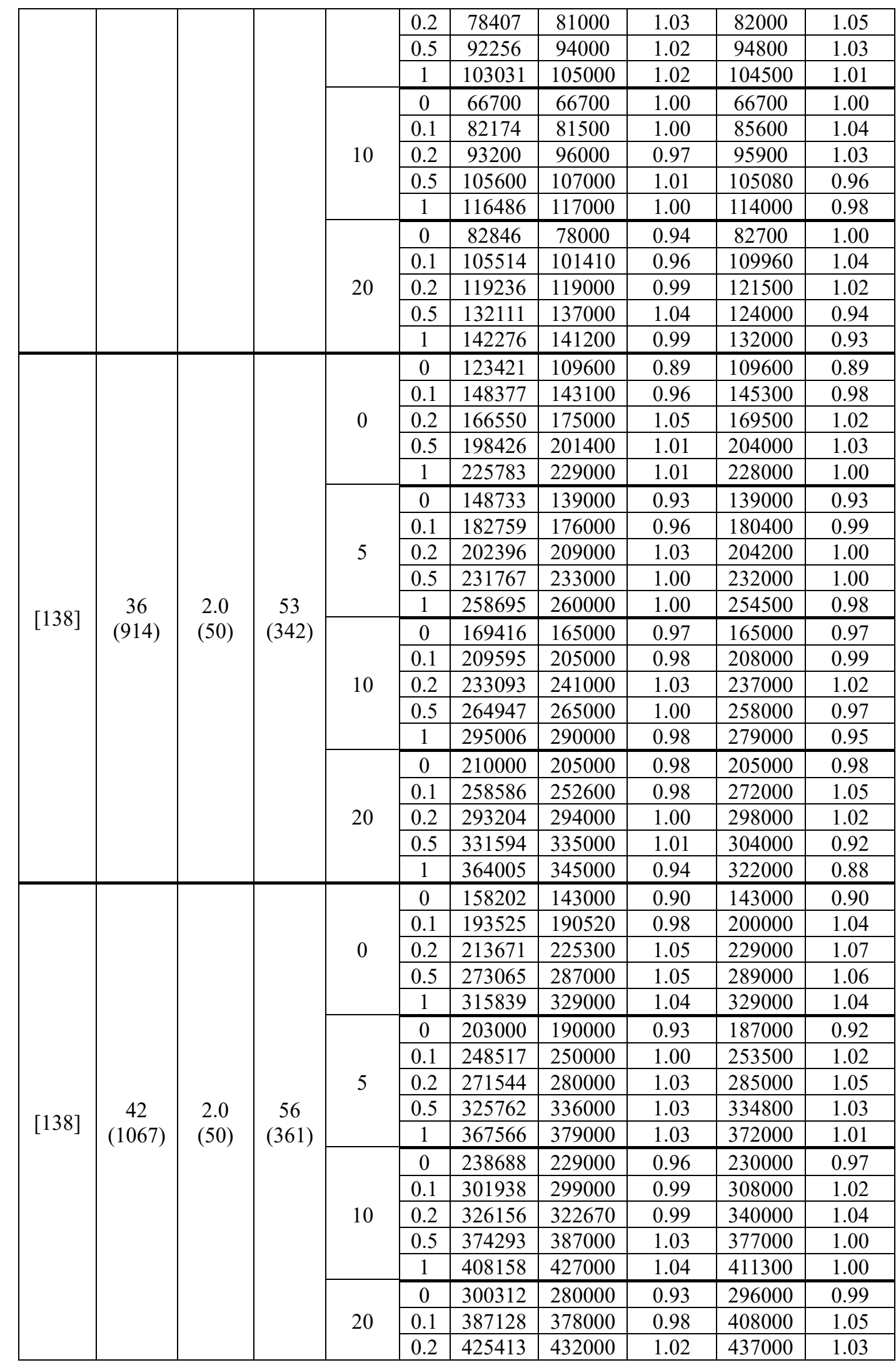




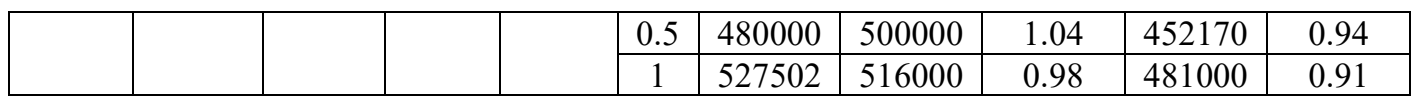

*note: 1 kips.in $=0.113$ kN.m

\subsection{SUMMARY}

Generally, the columns of RC bridges are under axial load and uniaxial or biaxial bending moments because of their geometry, the shape of the cross-section and the type of external loads (e.g. wind and seismic forces). For this type of structures, the cross-section is typically rectangular or circular.

The structural analysis (and design) for RC columns with a circular cross-section, is more complicated than for rectangular cross-section members. The circular shape and uniform reinforcement distribution around the perimeter create some complications for a simple assessment of bending moment capacity.

In this study, simple formulae were proposed to analyze the ultimate capacity of circular cross-section subjected to axial loads combined with uniaxial bending. A thorough example has been performed to determine the level of precision of the proposed design formulae. The results obtained for a wide range of design case (corresponding to the most commonly employed in practice) have shown a very good resemblance of the values computed by MATLAB program. 


\section{CHAPTER 6 DURABILITY OF UHPC REPAIR OF MARIN SUBSTRUCTURE}

This chapter investigates the corrosion durability of UHPC repair and its possible use to mitigate macrocell corrosion caused by the presence of incipient anodes in concrete repairs with dissimilar concrete materials. The objectives of the research presented here were to identify if concrete wetness will increase macrocell current and how much repair with UHPC may provide extended repair service life.

\subsection{RESEARCH APPROACH}

Experimental research on the corrosion durability was conducted on concrete prisms with a ladder rebar array to measure corrosion macrocell development. It had been suggested that repair of concrete members with a UHPC shell will decrease or slow reinforcement corrosion by confining the concrete and providing a barrier layer with reduced permeability; however, it has been observed that corrosion cells may redevelop in steel encapsulated in the repair materials. This section investigates corrosion durability properties of UHPC and its possible use to mitigate macrocell corrosion caused by the presence of incipient anodes in concrete repairs with dissimilar concrete materials. The objectives of the preliminary research were to:

- Identify the possible beneficial properties of UHPC related to corrosion;

- Investigate the extent of local macrocell coupling between incipient anodes and local cathodes in the UHPC repair material; and

- Identify the effect of the incipient chloride content. 


\subsection{EXPERIMENTAL DESIGN}

Sixteen RC specimens were cast and divided into two groups according to the repair material (NSC or UHPC). All testing was conducted on duplicate samples. Each specimen contained a concrete portion of the Chloride Mix to represent the substrate and a portion of either the Regular Mix or UHPC to represent repair concrete. The interior side of the initial concrete cast was roughened with a mechanical grinder; and prior to final casting section, the interface surface was kept moist to facilitate bond at the cold joint. The details of the test specimen are shown in Figure 6- 1.

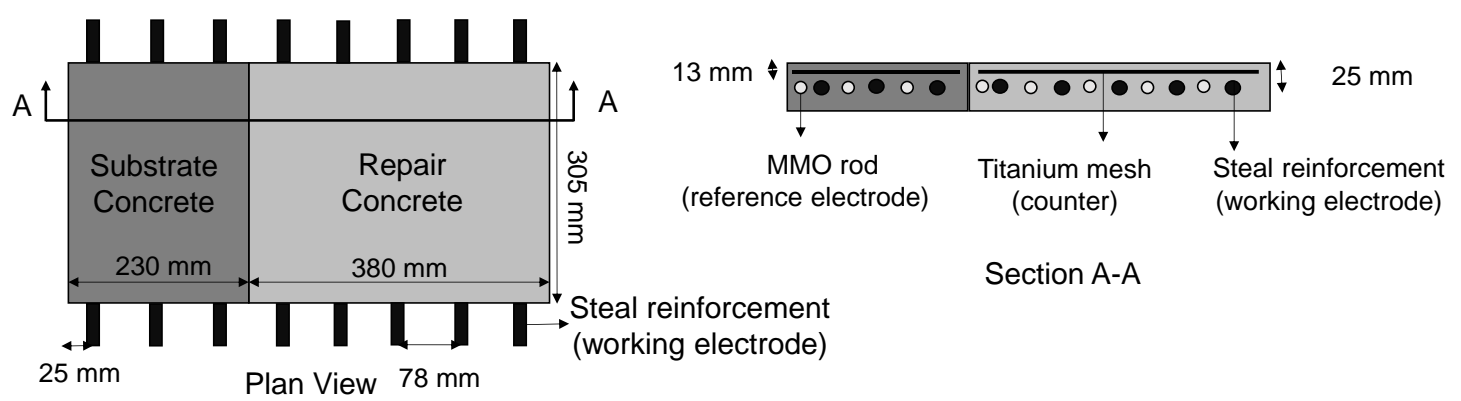

Figure 6- 1 Test sample geometry.

Each concrete sample had geometry $24 \times 12 \times 3$ in. $(610 \times 305 \times 76 \mathrm{~mm})$ and contained eight equidistant $0.375 \mathrm{in}$. $(9.5 \mathrm{~mm})$ diameter deformed steel rebar with $1 \mathrm{in}$. (25 $\mathrm{mm}$ ) clear cover from the top, bottom and side surfaces. Three of these bars were placed in the substrate concrete and five bars were placed in the repair concrete. To eliminate steel corrosion on the bar sections extending out of the concrete, the outer 2 in. $(51 \mathrm{~mm})$ sections of the rebar were coated with epoxy. Activated titanium rod as reference electrodes were placed between each bar and two discrete activated titanium mesh was embedded on the near surface of the prism. Each bar was electrically coupled via electrical switches to allow macrocell current measurements from steel electrodes in the substrate concrete and repair 
concrete. The electrical switches also allowed for changes in sample configuration cathode and anode size. Cathode-to-anode ratio (5:3, 5:2, 5:2, 5:1, 4:3, 4:2, 4:1, 3:3, 3:2, 3:1, 2:3, 2:2, 2:1, 1:3, 1:2, 1:3) were varied by systematically decoupling rebar electrodes.

All concrete samples were kept in the laboratory where the ambient temperature was typically $25^{\circ} \mathrm{C}$. The first phase of measurements [33] was made for $\sim 250$ days after casting and the second phase of measurements was made for an additional $\sim 250$ days. In the second phase, a pond was made from acrylic molding attached along the periphery of the top surface of the concrete test prisms. Tap water was periodically added so that the top surface of the sample remained wet.

\subsection{TEST SETUP AND INSTRUMENTATION}

The open-circuit potential (OCP) of the individual bars was periodically measured by decoupling the rebar via the external electrical switch. A copper/copper sulfate reference electrode (CSE) was centered on the concrete surface immediately above the rebar. The concrete test samples contained 5 bars in the repair concrete and 3 bars in the substrate concrete. OCP was made for individual bars. The OCP was measured after 2-3 hours decoupling. Although the measured potentials may not necessarily reflect terminal rest potentials, the measured values did differentiate relative passive and active conditions.

Linear polarization resistance (LPR) measurements were periodically made after approximately 24-hour depolarization of the coupled electrodes. The corrosion current density was calculated from Equation 6- 1.

$$
i_{\text {corr }}=\frac{B}{R_{p} A}
$$

Equation 6- 1 
where $B$ was assumed to be $26 \mathrm{mV}, R_{p}$ was the measured polarization resistance and $A$ is the surface area of rebar. Although $i_{c o r r}$ was calculated for individual bars, the replicate readings are shown as the average of group measurements within the repair or substrate concrete sections.

Similar macrocell measurements, as in the first phase, were made [33] where the current measurement was made between the electrodes by a temporary opening at the electrical switches connecting these electrodes. Moreover, the resistance between every two working electrodes was measured using two-point resistance measurements prior to and after ponding the samples to see the effect of concrete wetness on the resistivity. The measurements were made for five configurations as shown in Figure 6- 2 including resistance measurements in the substrate concrete, repair concrete, and the interface.

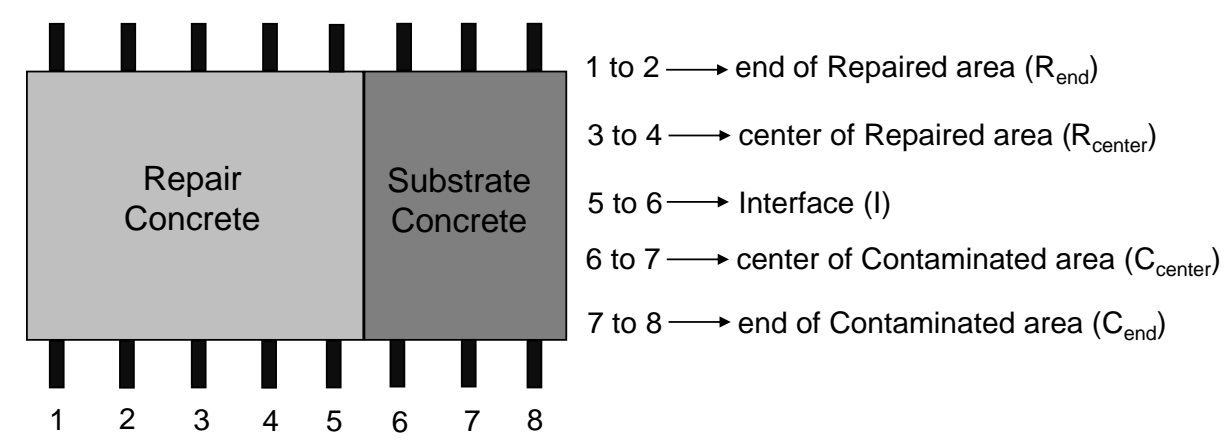

Figure 6- 2 Resistivity configuration.

\subsection{RESULTS AND DISCUSSION}

The repair NSC and UHPC were chloride free, and the OCP generally reflected passive corrosion conditions before and after wetting although some measurements were more electronegative. For the test samples, the substrate NSC concrete contained different levels of chlorides. For those samples that were admixed with low $(0.4 \%)$ or no chloride contamination, the $\mathrm{OCP}$ also reflected passive conditions prior to wetting. It was noted that 
after wetting, OCP values for the 0 and $0.4 \%$ chloride case were between -263 and -538 $\mathrm{mV}_{\mathrm{CSE}}$. This may be related to possible concrete pore water carbonation of the pore quality NSC that may have occurred prior to wetting. As expected, with chloride contamination (4\% and $8 \%$ ), the active potential was observed before and after wetting (Table 6- 1 ).

Table 6- 1 OCP (mVCSE)

\begin{tabular}{|c|c|c|c|c|c|c|c|c|}
\hline Sample & \multicolumn{2}{|c|}{ Repair (Dry) } & \multicolumn{2}{c|}{ Substrate (Dry) } & \multicolumn{2}{c|}{ Repair (Wet) } & \multicolumn{2}{c|}{ Substrate (Wet) } \\
\hline NSC-0\% & -115 & -108 & -108 & -105 & -97 & -120 & -431 & -263 \\
\hline NSC-0.4\% & -106 & -116 & -142 & -135 & -113 & -145 & -472 & -430 \\
\hline NSC-4\% & -116 & -114 & -475 & -396 & -142 & -135 & -576 & -632 \\
\hline NSC-8\% & -129 & -115 & -690 & -509 & -246 & -173 & -690 & -670 \\
\hline UHPC-0\% & -101 & -76 & -103 & -113 & -217 & -217 & -439 & -538 \\
\hline UHPC-0.4\% & -111 & -82 & -144 & -148 & -330 & -240 & -351 & -475 \\
\hline UHPC-4\% & -40 & -138 & -458 & -480 & -221 & -380 & -717 & -715 \\
\hline UHPC-8\% & -122 & -49 & -489 & -513 & -221 & -252 & -684 & -706 \\
\hline
\end{tabular}

Consistent with OCP measurements, low corrosion currents were measured in the chloride-free repair UHPC and NSC concrete before and after wetting (see Figure 6- 3). As expected, high corrosion current densities were measured for the substrate NSC concrete contaminated with 4 and $8 \%$ chlorides; these corrosion current densities showed further increase after concrete wetting due to the expected lower solution resistance of wet concrete. The unexpected activation after wetting of the substrate NSC concrete with 0 and $0.4 \%$ chloride in all test samples showed a minor increase in corrosion current density relative to corrosion current densities measured for those electrodes when passive in the dry condition. 

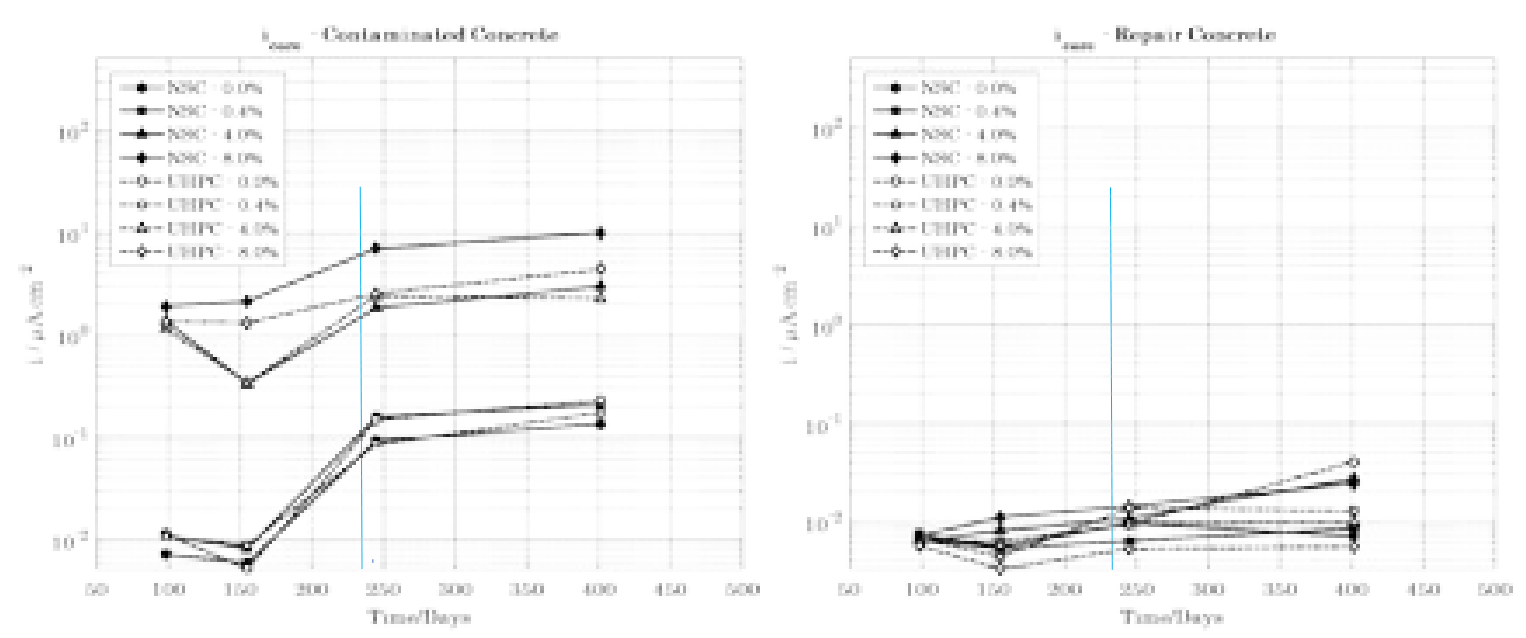

Figure 6- 3 Corrosion current density

(*Vertical line represents the time of initial ponding).

After coupling all rebar electrodes together, the macrocell current between the electrodes in the repair and substrate concrete was measured. Low macrocell currents were measured for NSC in the dry condition where passive corrosion conditions were present for rebar in both substrate and repair concrete ( 0 and $0.4 \%$ wt $\mathrm{Cl}$ in substrate concrete). After wetting, the OCP values showed unexpected activation of the rebar in the substrate concrete for these test samples. The developed macrocell current, correspondingly, showed an increase. When rebar in the substrate concrete in the presence of higher chloride content (4 and $8 \%$ wt $\mathrm{Cl}^{-}$) had active corrosion, large macrocells developed. These values showed a significant increase (as much as 5 times greater) after wetting (see Figure 6- 4). As will be described later, macrocell current can be enhanced with larger cathode-to-anode ratios. In contrast, low macrocell current developed between the rebar electrodes embedded in the UHPC repair and substrate concrete regardless of the level of anodic activity in any of the chloride content in the substrate concrete. Wetting of the concrete did indicate overall increase but current levels remained significantly smaller than comparative samples cast 
with repair NSC. The results indicate that regardless of corrosion activity, there is a mitigating effect due to the placement of UHPC. Galvanic coupling of rebar electrodes between the repair and substrate concrete is reduced due to the high electrical resistivity provided by the UHPC and enhancement due to moisture is mitigated by the low permeability characteristics of the material.
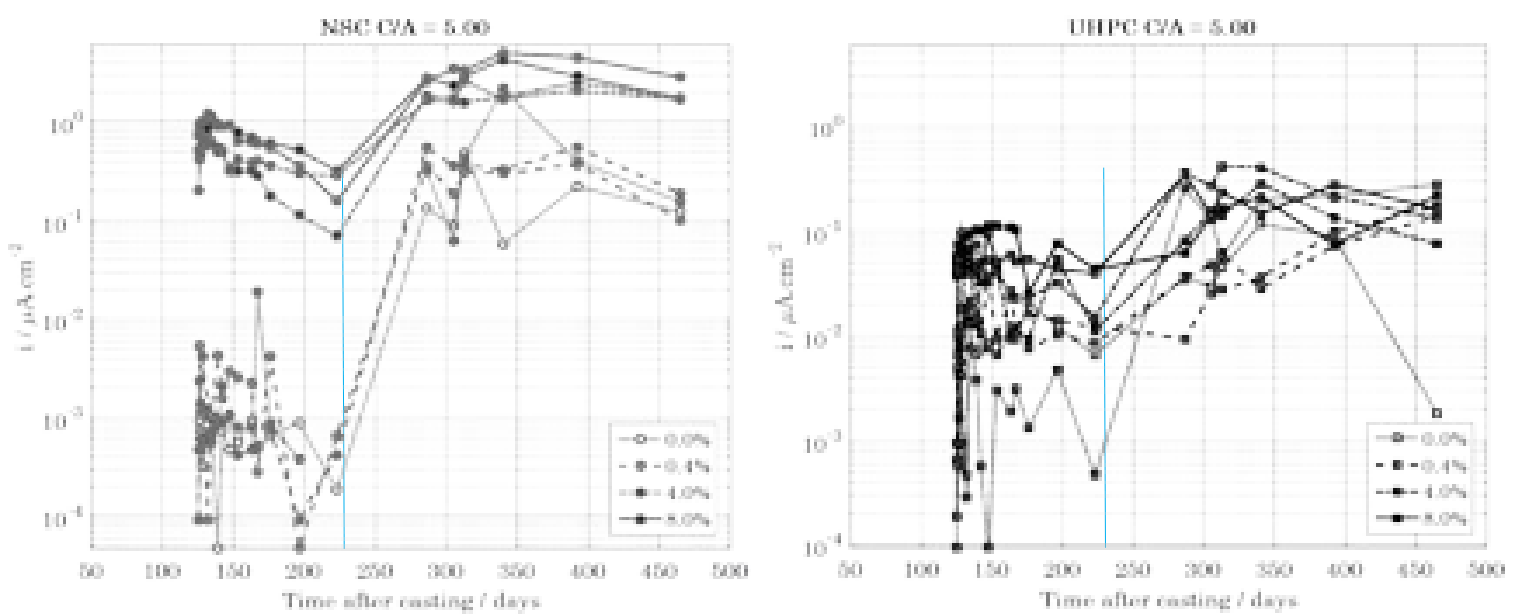

Figure 6- 4 Macrocell current of steel rebar embedded in repair and substrate concrete.

(*Vertical line represents the time of initial ponding).

In part to address the area effect on macrocell coupling in wet concrete, the test setup was configured to allow for various cathode-to-anode (C/A) ratio following similar methodology as in Ref [33]. Figure 6- 5 shows a compilation of test results of C/A ratio for rebar embedded in UHPC or conventional concrete with substrate concrete containing $0,0.4,4$, and $8 \%$ wt chlorides after concrete wetting.

Similar trends in the wet concrete were observed as in the dry concrete described in Ref [33]; however, as described earlier, macrocell currents were overall higher for all conditions including with the use of UHPC as the repair material. Low macrocell currents developed in samples with conventional and UHPC repair concrete when the vestigial 
chloride content in the substrate concrete was low. For both NSC and UHPC the macrocell currents increased with higher $\mathrm{C} / \mathrm{A}$. As mentioned before, larger macrocell current was measured for samples repaired with NSC when the substrate concrete contained more than 0.4\% chloride content and low macrocell developed for samples repaired with UHPC even with the higher chloride levels. In comparison to results for concrete in dry condition [33], the macrocells were elevated for all concentrations.
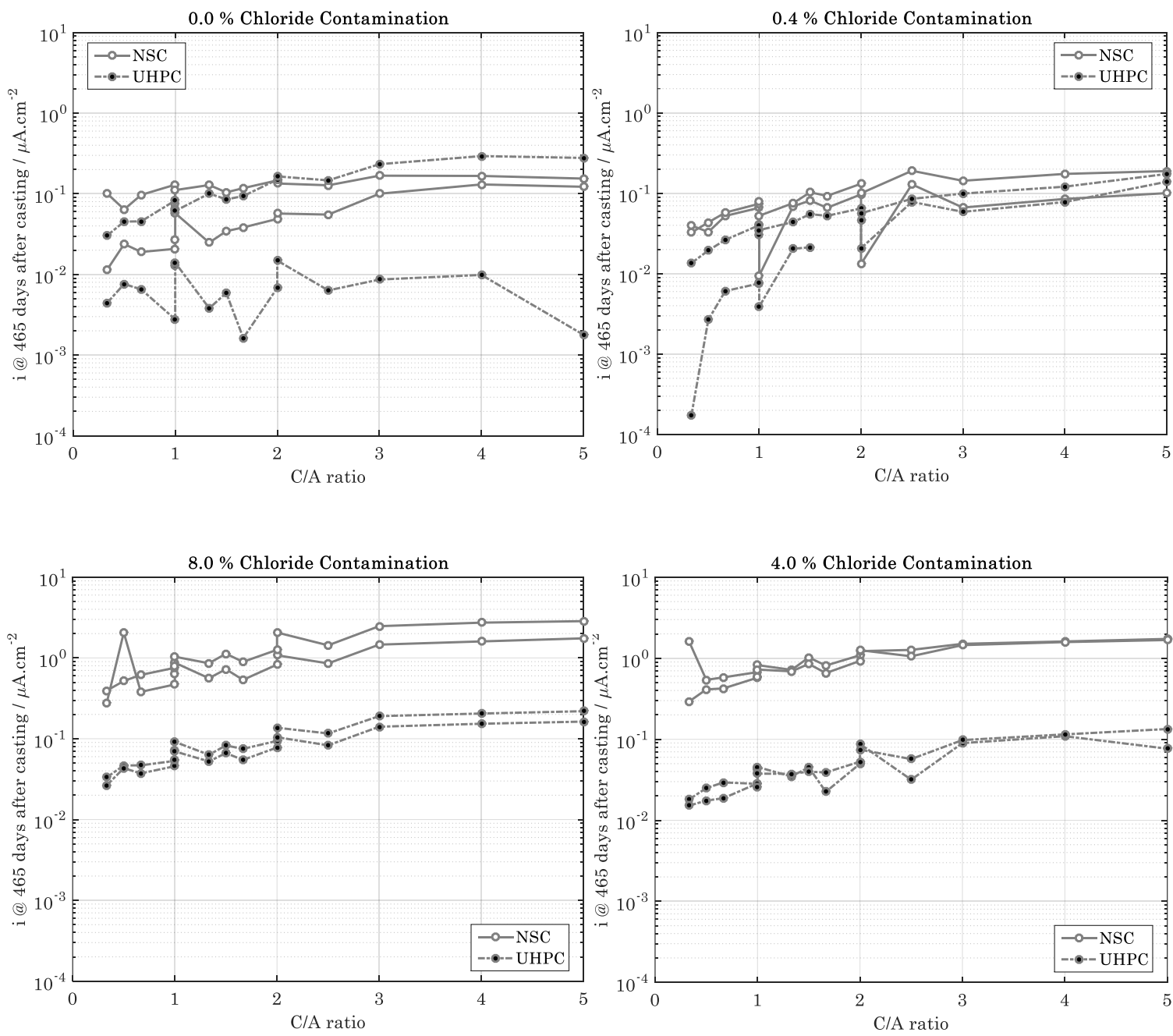

Figure 6- 5 Effect of cathode-to-anode (c/a) ratio for rebar embedded in UHPC or NSC repair concrete with vestigial chlorides in substrate concrete in wet condition. 
The results of measured two-point resistance of the samples are shown in Figure 66. The resistance of the samples regardless of the location on the concrete samples decreased after wetting; however, this reduction was significantly less in UHPC consistent with the low permeability of the material. The changes in the concrete bulk resistance were consistent with the trends observed in the macrocell measurements and further illustrate the positive use of UHPC.
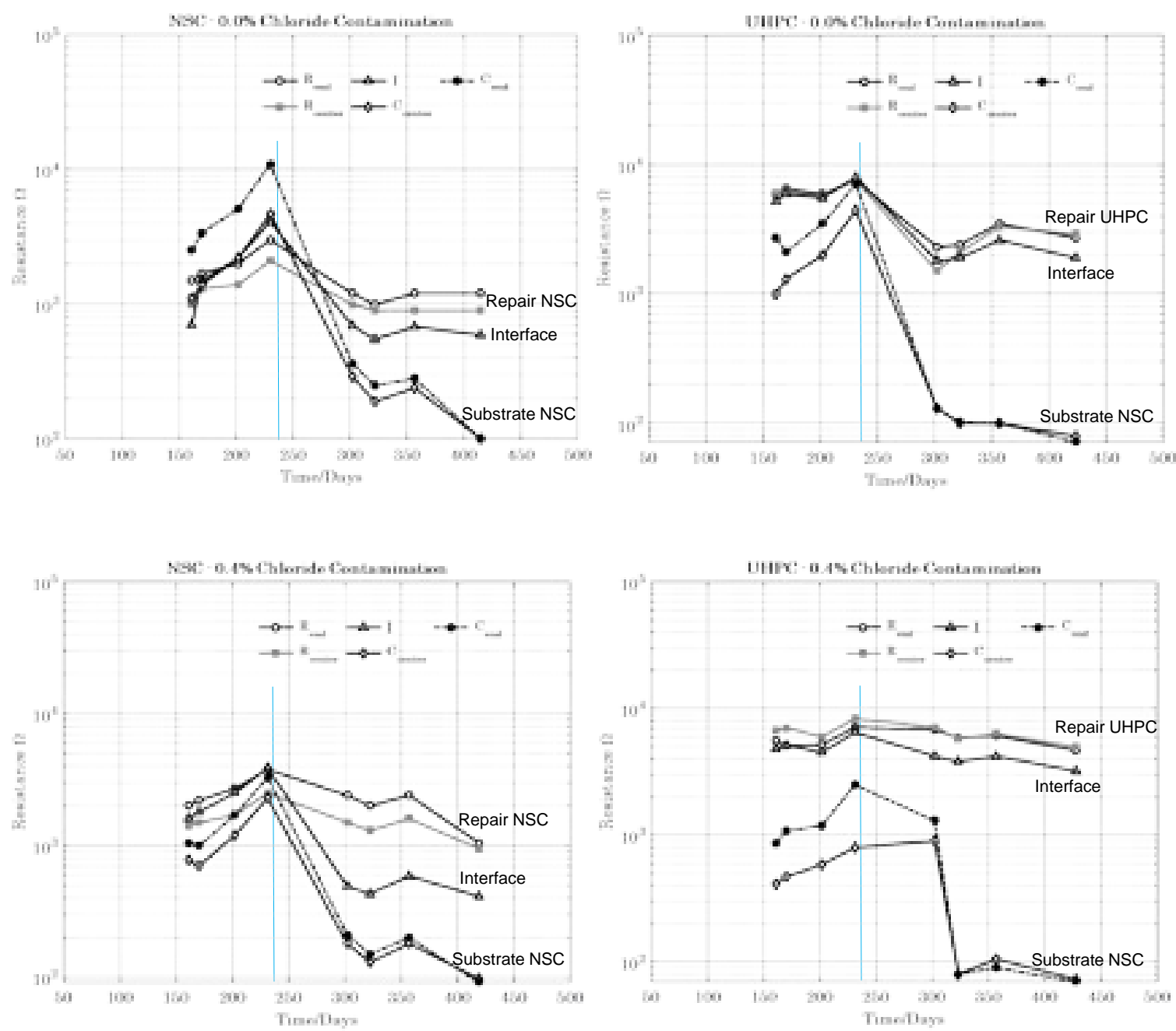

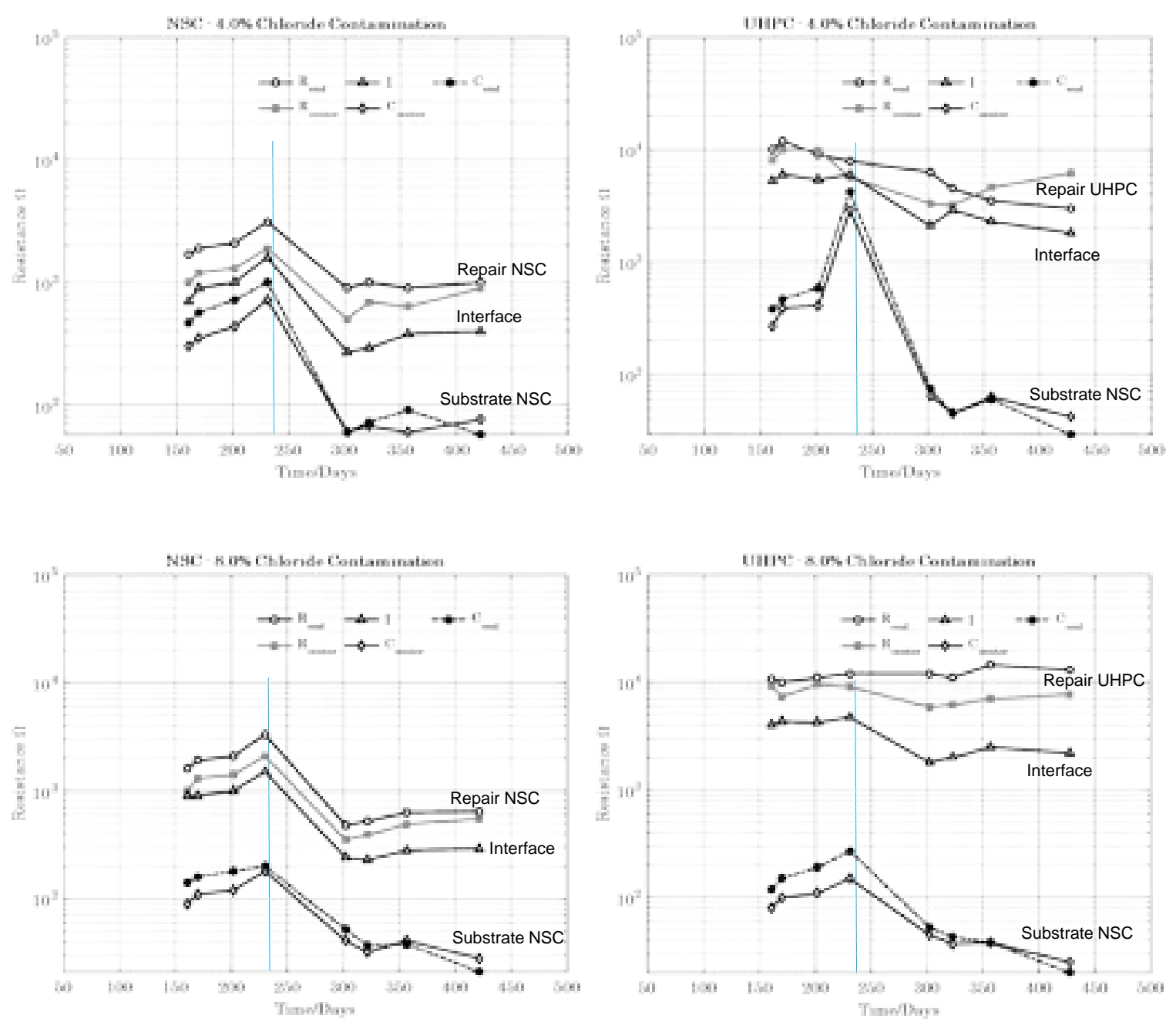

Figure 6- 6 Bulk concrete resistivity.

(*Vertical line represents the time of initial ponding)

Comparison of the potentials for steel in the substrate and repair concrete from, for dry and wet concretes, show that there is generally low driving voltage when chloride level is low (0 and $\left.0.4 \% \mathrm{CL}^{-}\right)$for either repair application of NSC and UHPC. Therefore, low macrocells were expected and indeed measured regardless of the resistance of the concrete materials. In presence of high chloride content (4 and $8 \% \mathrm{CL}^{-}$), the driving voltage regardless of repair concrete material was high (as much as $\sim 500 \mathrm{mV}$ ). High macrocell currents developed for NSC due to this driving voltage and the relatively low concrete 
resistance (Figure 6- 6). On the other hand, despite similar driving voltage, low macrocell current developed with UHPC repair due to its high concrete resistance.

\subsection{SUMMARY}

The macrocell development between the dissimilar concrete materials was examined to identify possible benefits and challenges of utilizing UHPC as a repair material for reinforced concrete marine bridges. The following conclusions were drawn based on the results from testing repair columns and durability study.

- Low macrocell currents developed in samples with conventional and UHPC repair concrete when the chloride content in the substrate concrete was low. Even though the higher current was observed in wet condition compared to the dry condition, the increase in samples repaired with UHPC, this value was significantly lower than the comparative one with NSC.

- At higher chloride contents in the substrate concrete, the macrocell current was enhanced at higher C/A for samples utilizing conventional concrete for the repair concrete and this trend was more highlighted after wetting.

- In context to the local coupling of local anodes to cathodes in repair material, the measured macrocell current was much reduced in samples repaired with UHPC even with higher chloride present in the substrate concrete than the conventional concrete even after wetting the samples. 


\section{CHAPTER 7 DURABILITY ASSESSMENT}

\subsection{ChLORIDE Diffusion Through UHPC SHELL}

A substantial increase in research on the durability assessment of concrete has been reported in recent years. In a marine environment, the service life of reinforced concrete structures principally depends on the deterioration generated from chloride-induced corrosion of steel reinforcement. Therefore, corrosion management of the aging infrastructure assets of the U.S. is becoming increasingly necessary to keep these structures operational throughout their design life.

The advanced mechanical properties and durability of UHPC make it possible to reconsider the conventional design methods for many common bridge components. This corrosion-resistant concrete has a longer lifespan and can withstand many of the harsh conditions and elements that contribute to the deterioration of traditional concrete [146]. UHPC is moisture-resistant due to its higher density [130], [146]. which makes it practically impossible for ordinary or salt water to penetrate to the surface The longer life and lower lifetime cost of UHPC make it the fitting way to restore and replace existing bridges, so they will last longer [147], [148]. The U.S. Federal and many state governments are strongly recommending that UHPC be used in all future bridge construction projects, including the repair of existing bridges [44], [101].

It is the purpose of this section to examine the influence of UHPC shell thickness on the rate of penetration of chloride ions into concrete marine substructure and to provide means for estimating the extent of chloride contamination of reinforcing steel in bridge substructure as a function of shell thickness, substrate quality, exposure zone, and time. 


\subsubsection{Methodology}

The highly alkaline pore solution of concrete $(\mathrm{pH} \sim 12.5-13.5)$ forms a passive oxide film on the steel protecting it from corrosion. This protective film is destroyed when enough chloride ions penetrate the concrete cover and reache to the steel surface and cause initiation of reinforcement corrosion. Chloride-induced reinforcement corrosion can occur within a relatively short period of time depending on the concrete properties, concrete cover thickness, and exposure conditions.

The chloride transport is mostly governed by the coefficient of chloride diffusion and surface chloride concentration. The chloride diffusion coefficient is a concrete parameter that describes resistance to chloride penetration. Low values indicate that the concrete has a high resistance to chloride penetration.

Using impermeable material such as UHPC as a protective shell around the marine substrates, exposed to high chloride concentration, can postpone the $\mathrm{Cl}^{-}$transport, which increases the service life of the existing structure and decreases the requirement for unplanned maintenance (Figure 7- 1 (1)). Moreover, for conventional concrete repair, damaged concrete elements are patched, overlaid, or encased in new repair materials; but, there can be concrete with some level of chloride-contamination left in place in regions beyond the repair. Thus, degradation of the repair in time can occur due to chloride migration from the substrate through the repair to the steel reinforcements (Figure 7- 1 (2)).

When chloride levels exceed the critical threshold concentrations, $\mathrm{C}_{\mathrm{T}}$, corrosion cells can form. $\mathrm{C}_{\mathrm{T}}$ value depends on numerous factors including water-to-cement ratio, $\mathrm{pH}$ of concrete, the additional cementitious material, pozzolanic reaction, steel reinforcement type, exposure conditions, etc. [149], [150]. The binder types such as fly ash, and silica 
fume, and low water content used in UHPC may affect the $C_{T}$ values [151]. Due to the variety of factors affecting $\mathrm{C}_{\mathrm{T}}$ value of concrete, different investigations have reported different values for this parameter, depending on which factors were considered and examined. In particular the lack of data on $\mathrm{C}_{\mathrm{T}}$ value for UHPC is more evident. Also, the type of reinforcing steel can have effect (e.g. corrosion resistant rebar such as galvanized and stainless steel will have high $\mathrm{C}_{\mathrm{T}}$ ) [150], [152]-[155]. For carbon steel, a suggested chloride threshold level to initiate corrosion has been cited at $1.2 \mathrm{~kg} / \mathrm{m}^{3}$ of acid-soluble chloride [156]-[159].

To calculate the extended service life offered by UHPC as a protective layer or repair material, analytical solutions of the diffusion equation were expressed for two cases as shown in Figure 7- 1 These cases were defined based on the common scenarios of a concrete pier in a marine environment. Case 1 describes an idealized condition where a protective layer of UHPC is used with varying thickness $\left(\mathrm{L}_{1}\right)$. Case 2 describes an idealized condition where UHPC is fully encapsulating the reinforcing steel with varying $\mathrm{L}_{3}$. Here, the diffusion of chloride ion from the substrate was considered.

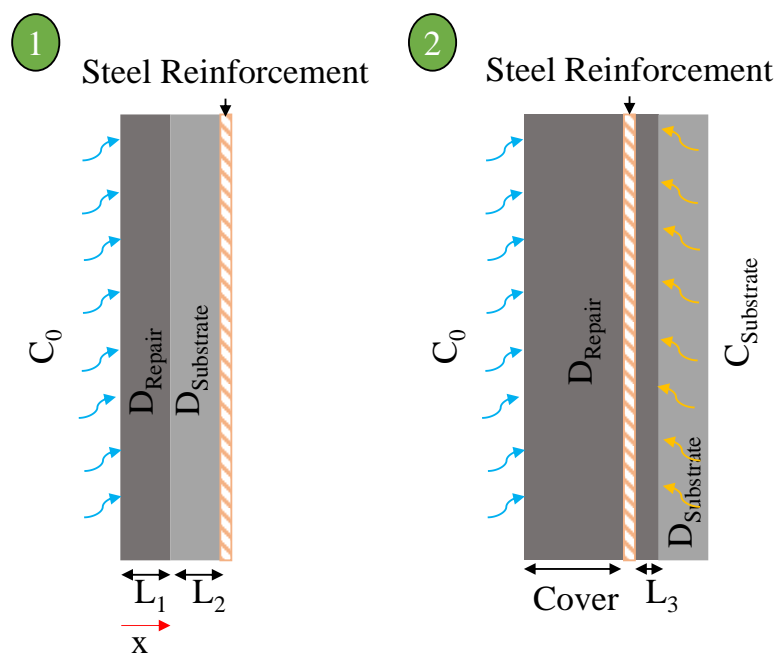

Figure 7- 1 Problem concept of (1) a protection layer of UHPC, and (2) UHPC repair. 
Estimation of chloride diffusion coefficient (D) and surface chloride concentration (Cs) from data sets of Florida bridges [158], [160] was used to calculate the service life of marine structure protected by UHPC shell. The service life of the structure $\left(t_{\text {critical }}\right)$ is defined as the time for chloride concentration at the rebar surface to reach the critical threshold $\left(\mathrm{C}_{\mathrm{T}}\right)$. The chloride diffusion coefficient of UHPC was considered as $1.3 \times 10-13$ based on Ref. [161]. In the following calculations a one-dimensional horizontal diffusion normal to the cover is considered. The cover thickness was so that $\mathrm{L}_{1}+\mathrm{L}_{2}=7 \mathrm{~cm}$.

\subsubsection{CASE 1: Protective LaYer OF UHPC}

In case 1 the concrete cover is composed of two sublayers. Layer 1 is the repair concrete and 2 is the substrate concrete. Both layers are assumed to be individually homogeneous with specific diffusion coefficients $\left(\mathrm{D}_{1}\right.$ and $\left.\mathrm{D}_{2}\right)$. The 1-D (normal to the concrete cover) diffusion equations, in the two layers, are:

$$
\begin{array}{llll}
\frac{\partial C_{1}}{\partial t}=D_{1} \frac{\partial^{2} C_{1}}{\partial x^{2}} & 0<x<L_{1} & t>0 & \text { Equation 7- 1 } \\
\frac{\partial C_{2}}{\partial t}=D_{2} \frac{\partial^{2} C_{2}}{\partial x^{2}} & L_{1}<x<L_{2} & t>0 & \text { Equation 7- 2 }
\end{array}
$$

where $C_{1}$ and $C_{2}$ are the chloride concentrations in the liquid phase in the first and second layer, respectively, $\mathrm{x}$ is the distance from the top of the first layer, $t$ is time, and $L_{1}$ and $L_{2}$ are the thicknesses of the layers. The boundary concentration at the surface of the concrete cover (first scenario of Figure 7- 1) is set and assumed to be a known constant concentration $C_{0}$.

$C_{1}(x=0, t)=C_{0}$ Equation 7- 3

At the interface between the two layers, concentration and mass flux continuity is imposed. 
$C_{1}\left(x=L_{1}, t\right)=C_{2}\left(x=L_{1}, t\right)$

$\left.D_{1} \frac{\partial C_{1}}{\partial x}\right|_{x=L_{1}}=\left.D_{2} \frac{\partial C_{2}}{\partial x}\right|_{x=L_{1}}$

Equation 7- 5

The boundary concentration at the end of the second layer is set and assumed to be initially zero. This is a common boundary condition in diffusion subjugated problems [162].

$C_{2}\left(x=L_{1}+L_{2}\right)=0$

Equation 7- 6

The initial concentrations of the contaminant in layers 1 and 2 are assumed to be zero.

$$
\begin{aligned}
& C_{1}(x, t=0)=0 \\
& C_{2}(x, t=0)=0
\end{aligned}
$$

It was assumed that the inner layer is semi-infinite. The solution for $C(x, t)$ could be obtained using the Laplace transform on Equation 7- 1, and Equation 7- 2 [163].

$$
\begin{aligned}
& C_{1}(x, t) \\
& =\sqrt{\frac{1}{D_{1}}} \sum_{n=0}^{\infty} \alpha^{n} \int_{0}^{t} d \tau f(\tau) \frac{(2 n l+x)}{2 \sqrt{\pi(t-\tau)^{3}}} \exp \left(-\frac{(2 n l+x)^{2}}{4 D_{1}(t-\tau)}\right) \\
& -\sqrt{\frac{1}{D_{1}}} \sum_{n=0}^{\infty} \alpha^{n+1} \int_{0}^{t} d \tau f(\tau) \frac{((2 n+2) l-x)}{2 \sqrt{\pi(t-\tau)^{3}}} \exp \left(-\frac{(2 n+2) l-x)^{2}}{4 D_{1}(t-\tau)}\right) \\
& C_{2}(x, t)=(1-\alpha)\left[\sum_{n=0}^{\infty} \alpha^{n} \int_{0}^{t} d \tau \frac{k}{2 \sqrt{D_{1} \pi(t-\tau)^{3}}} f(\tau) \exp \left(-\frac{k^{2}}{4 D_{1}(t-\tau)}\right)\right]
\end{aligned}
$$

Considering that inverse Laplace transfer of $\frac{\exp (-q x)}{P}$ is equal to $\operatorname{erfc}\left(\frac{x}{2 \sqrt{k t}}\right)$, above formulation could be rewritten as the following [164]:

$$
C_{1}(x, t)=C_{0} \sum_{n=0}^{+\infty} \alpha^{n}\left[\operatorname{erfc}\left(\frac{(2 n+1) L_{1}+x}{2 \sqrt{D_{1} t}}\right)-\alpha \operatorname{erfc}\left(\frac{(2 k+1) L_{1}-x}{2 \sqrt{D_{1} t}}\right)\right]
$$


$C_{2}(x, t)=\frac{2 k C_{0}}{k+1} \sum_{n=0}^{+\infty} \alpha^{n} \operatorname{erf} c\left(\frac{(2 n+1) L_{1}+k x}{2 \sqrt{D_{1} t}}\right.$

Equation 7- 12

where

$$
\begin{aligned}
& k=\left(\frac{D_{1}}{D_{2}}\right)^{\frac{1}{2}} \\
& \alpha=\frac{1-k}{1+k}
\end{aligned}
$$

Equation 7- 13

Equation 7- 14

\subsubsection{CASE 2: FULL UHPC REPAIR}

Modifying the solution obtained for two layers (Equation 7- 11 and Equation 7- 12) to consider only one layer $(\mathrm{k}=0$ ), leads to the well-known one-layer solution (Fick's second law), which was used to calculate the effect of UHPC thickness beyond the rebar ( $L_{3}$ in Figure 7- $1(2)$ ), and the vestigial chloride in the substrate concrete $\left(\mathrm{C}_{\text {Substrate }}\right.$ in Figure 7- 1(2)) on the service life of the repaired pier.

$$
c(x, t)=C_{0} \sqrt{\frac{x^{2}}{4 D}} \int_{0}^{t} \frac{1}{\sqrt{(t-\tau)^{3}}} \exp \left(-\frac{x^{2}}{4 D(t-\tau)}\right) d \tau=C_{0}\left[1-\operatorname{erf}\left(\frac{x}{2 \sqrt{D t}}\right)\right] \quad \text { Equation 7- 15 }
$$

\subsubsection{Setup}

In case 1, the performance of UHPC and NSC protective layers were compared for various operating conditions. Calculations were made to identify the effect of protective layer thickness, and environmental conditions on service life for the UHPC and NSC repairs. The chloride ion diffusivity was $1 \times 10^{-11} \mathrm{~m}^{2} / \mathrm{s}$ for the substrate, $1 \times 10^{-12} \mathrm{~m}^{2} / \mathrm{s}$ for the NSC repair [158]. Five different chloride exposure levels $\left(35,25,20,15,10 \mathrm{~kg} / \mathrm{m}^{3}\right)$ were assumed to simulate exposure to different natural water bodies or different elevations.

In case 2, the performance of UHPC and NSC were compared for various operating conditions. Calculations were made to identify the effect of repair thickness beyond the 
rebar on the diffusion of vestigial chloride in the existing concrete through the repair material. Five different chloride levels $\left(2,4,6,8\right.$, and $\left.10 \mathrm{~kg} / \mathrm{m}^{3}\right)$ of the base concrete was considered in these calculations.

\subsubsection{Computational results}

\subsubsection{CASE 1: COMPARISON OF PROTECTIVE LAYER SERVICE TIME}

Figure 7- 2 shows the result of calculated $t_{\text {critical }}$ for the original case when no protective layer is employed at different environmental exposures. It is evident that for the concrete piers with a coefficient of diffusivity of $1 \times 10^{-11} \mathrm{~m}^{2} / \mathrm{s}$ in less than 5 years the chloride concentration at the rebar surface will reach the critical threshold value.

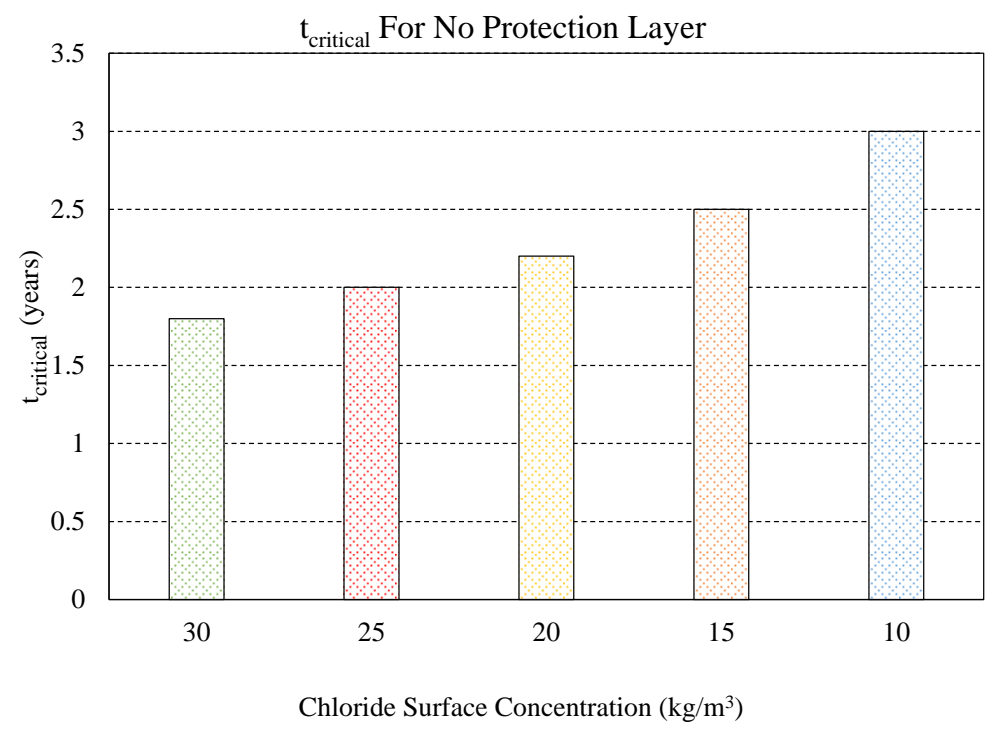

Figure 7-2. Calculated $t_{\text {critical }}$ for pier with no protective layer

Figure 7- 3 illustrates the calculation results for cases presented in case 1, where a conjectural protective layer was made by replacing a portion of concrete cover either with UHPC or with NSC. 
To obtain the service life of the rehabilitated piers, Equation 7- 11, and Equation 712 were solved to calculate $t_{\text {critical }}$. These equations were studied for 5 different chloride concentrations $\left(\mathrm{C}_{0}\right)$.
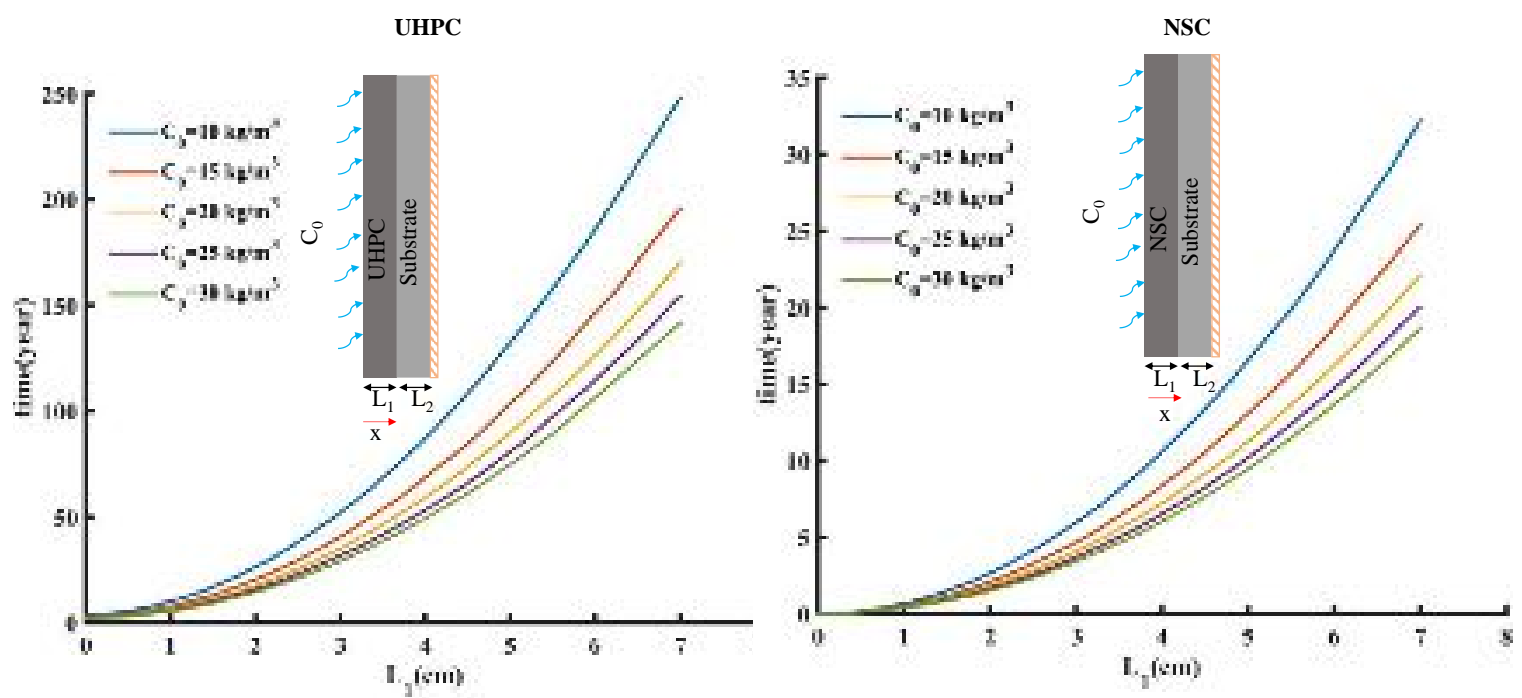

Figure 7- $3 t_{\text {critical }} v s$. the thickness of protective layer

Figure 7-3, and Table 7- 4 show the time ( $\left.\mathrm{t}_{\text {critical }}\right)$ required for chloride concentration to reach the critical value when different thicknesses of the protective layer are applied. The influence of the protective layer with both UHPC and NSC is evident compared to the one with no protection layer (Figure 7-2). Furthermore, the effect of the protective layer material on the increased service life is clearly demonstrated in the calculations, so that $t_{\text {critical }}$ is longer for the UHPC than to NSC. 
Table 7- 1 Comparison of the offered service life by UHPC and NSC protective layers

\begin{tabular}{|c|c|c|c|}
\hline Chloride Concentration $\left(\mathrm{C}_{0}\right)$ & $\begin{array}{c}\text { Material of Protective } \\
\text { Layer }\end{array}$ & $\begin{array}{c}\text { Thickness of Protective } \\
\text { Layer }\end{array}$ & $\begin{array}{c}\mathrm{t}_{\text {critical }} \\
\text { (years) }\end{array}$ \\
\hline \multirow{6}{*}{$10 \mathrm{~kg} / \mathrm{m}^{3}$} & \multirow{3}{*}{ UHPC } & $1 \mathrm{~cm}$ & 11 \\
\hline & & $2 \mathrm{~cm}$ & 31 \\
\hline & & $5 \mathrm{~cm}$ & 140 \\
\hline & \multirow{3}{*}{ NSC } & $1 \mathrm{~cm}$ & 4 \\
\hline & & $2 \mathrm{~cm}$ & 6 \\
\hline & & $5 \mathrm{~cm}$ & 19 \\
\hline \multirow{6}{*}{$20 \mathrm{~kg} / \mathrm{m}^{3}$} & \multirow{3}{*}{ UHPC } & $1 \mathrm{~cm}$ & 7 \\
\hline & & $2 \mathrm{~cm}$ & 21 \\
\hline & & $5 \mathrm{~cm}$ & 95 \\
\hline & \multirow{3}{*}{ NSC } & $1 \mathrm{~cm}$ & 3 \\
\hline & & $2 \mathrm{~cm}$ & 4 \\
\hline & & $5 \mathrm{~cm}$ & 13 \\
\hline \multirow{6}{*}{$30 \mathrm{~kg} / \mathrm{m}^{3}$} & \multirow{3}{*}{ UHPC } & $1 \mathrm{~cm}$ & 6 \\
\hline & & $2 \mathrm{~cm}$ & 17 \\
\hline & & $5 \mathrm{~cm}$ & 80 \\
\hline & \multirow{3}{*}{ NSC } & $1 \mathrm{~cm}$ & 2 \\
\hline & & $2 \mathrm{~cm}$ & 3 \\
\hline & & $5 \mathrm{~cm}$ & 11 \\
\hline
\end{tabular}

The extended service life was defined as the difference in the $t_{\text {critical }}$ between the cases when a protective repair concrete (UHPC or NSC) was added and the base case with only substrate concrete. As calculations show in Figure 7- 4, the extended service life by UHPC cover repair is at least 5 times greater than the one by NSC. 


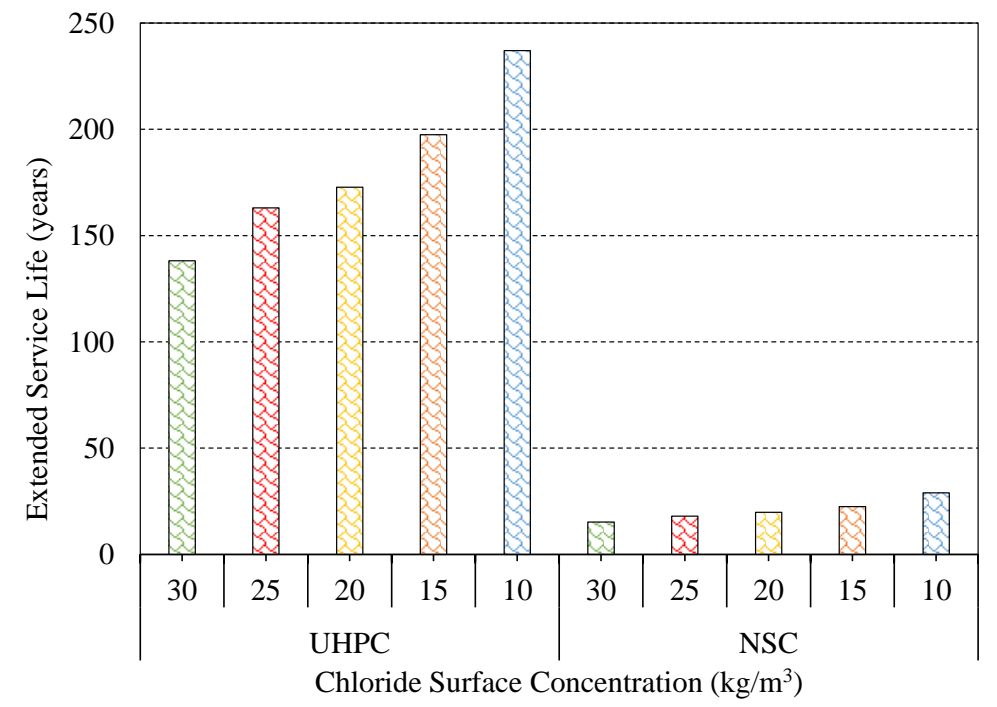

Figure 7- 4 Extended service life for full cover repair with UHPC or NSC.

\subsubsection{CASE 2: COMPARISON OF REPAIR SERVICE TIME}

To investigate the corrosion characteristics of Case 2, Equation 7- 15 was solved and the $t_{\text {critical }}$ was obtained. Figure 7- 5 shows the service life for 6 different levels of chloride contamination in the substrate concrete. The influence of different diffusion coefficient between UHPC compared to NSC repair is readily apparent in the calculation results. Much longer tcritical was calculated for the UHPC repair than NSC concrete repair, for varying $L_{3}$.
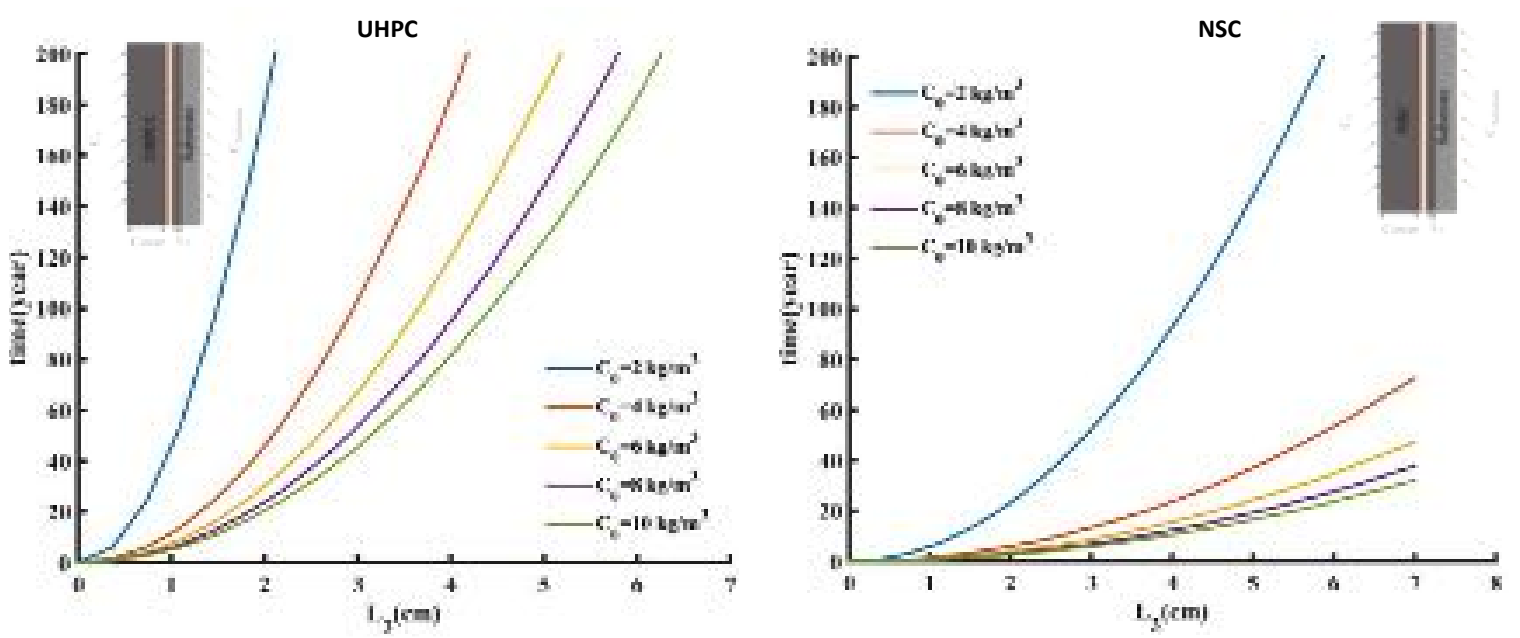

Figure 7- 5 Output results for hypothetical cases with varying repair thickness beyond the rebar. 
Table 7- 2 Comparison of service life of UHPC and NSC repaired piers with varying $\mathrm{L}_{3}$

\begin{tabular}{|c|c|c|c|}
\hline $\begin{array}{c}\text { Chloride Concentration } \\
\left(\mathrm{C}_{\text {Substrate }}\right)\end{array}$ & Material of Protective Layer & $\mathrm{L}_{3}$ & $\begin{array}{c}\mathrm{t}_{\text {critical }} \\
\text { (years) }\end{array}$ \\
\hline \multirow{6}{*}{$2 \mathrm{~kg} / \mathrm{m}^{3}$} & \multirow{3}{*}{ UHPC } & $1 \mathrm{~cm}$ & 70 \\
\hline & & $2 \mathrm{~cm}$ & 281 \\
\hline & & $4 \mathrm{~cm}$ & 950 \\
\hline & \multirow{3}{*}{ NSC } & $1 \mathrm{~cm}$ & 7 \\
\hline & & $2 \mathrm{~cm}$ & 28 \\
\hline & & $4 \mathrm{~cm}$ & 95 \\
\hline \multirow{6}{*}{$4 \mathrm{~kg} / \mathrm{m}^{3}$} & \multirow{3}{*}{ UHPC } & $1 \mathrm{~cm}$ & 18 \\
\hline & & $2 \mathrm{~cm}$ & 72 \\
\hline & & $4 \mathrm{~cm}$ & 243 \\
\hline & \multirow{3}{*}{ NSC } & $1 \mathrm{~cm}$ & 2 \\
\hline & & $2 \mathrm{~cm}$ & 7 \\
\hline & & $4 \mathrm{~cm}$ & 24 \\
\hline \multirow{6}{*}{$6 \mathrm{~kg} / \mathrm{m}^{3}$} & \multirow{3}{*}{ UHPC } & $1 \mathrm{~cm}$ & 12 \\
\hline & & $2 \mathrm{~cm}$ & 47 \\
\hline & & $4 \mathrm{~cm}$ & 160 \\
\hline & \multirow{3}{*}{ NSC } & $1 \mathrm{~cm}$ & 1.2 \\
\hline & & $2 \mathrm{~cm}$ & 5 \\
\hline & & $4 \mathrm{~cm}$ & 16 \\
\hline
\end{tabular}

\subsubsection{Cost analysis}

UHPC is not a mass-produced concrete, therefore it is more expensive than the regular concrete. The high cost of UHPC is mainly associated with the increased raw materials used in the mix. Moreover, UHPC is not widely used, hence it is typically mixed with a special order. Proprietary and Commercial UHPC mixes cost higher than $\$ 2,500$ per cubic yard, which is $\sim 20$ times more expensive than conventional concrete. Although the high prices of UHPC might be a disadvantage, applying UHPC can significantly improve the durability and service life of bridges [165]. The relatively high initial cost of UHPC has restricted its wider use in the construction industry. However, ongoing research and investigations are filling knowledge gaps to commence innovative UHPC having reduced initial cost. As an example, ABC-UTC is now focusing on the production of nonproprietary UHPC that would cost $\$ 1000$ per cubic yard [166]. 
Table 7- 3 is considering examples of a protective layer around a pier with a 36 in $(92 \mathrm{~cm})$ diameter for 36 in $(92 \mathrm{~cm})$ in height. The required volume of material (NSC or UHPC) are calculated and the initial cost, as well as cost per cycle, are compared. The cost of a repair process for a pier is estimated from the bridge repair cost estimate worksheet provided by Michigan (www.michigan.gov).

Table 7- 3 Examples of cost analysis

\begin{tabular}{|c|c|c|c|c|c|c|c|}
\hline $\begin{array}{r}\left(\mathrm{C}_{0}\right) \\
\mathrm{kg} / \mathrm{m}^{3}\end{array}$ & $\begin{array}{l}\text { Material of } \\
\text { Protective } \\
\text { Layer }\end{array}$ & $\begin{array}{c}\text { Thickness } \\
\text { of } \\
\text { Protective } \\
\text { Layer }\end{array}$ & $\begin{array}{c}t_{\text {critical }} \\
\text { (years) }\end{array}$ & $\begin{array}{c}\text { Initial } \\
\text { material } \\
\text { cost }\end{array}$ & $\begin{array}{c}\text { Pier } \\
\text { Repair } \\
\text { Cost } \\
(6750 / \mathrm{cy})\end{array}$ & $\begin{array}{c}\text { Total } \\
\text { Initial } \\
\text { Cost }\end{array}$ & $\begin{array}{c}\text { Total } \\
\text { Cost in } \\
100 \\
\text { years }\end{array}$ \\
\hline \multirow{9}{*}{10} & \multirow{3}{*}{$\begin{array}{c}\text { UHPC } \\
\text { (proprietary) }\end{array}$} & $1 \mathrm{~cm}$ & 11 & $\$ 90$ & $\$ 230$ & $\$ 320$ & $\$ 2900$ \\
\hline & & $2 \mathrm{~cm}$ & 31 & $\$ 170$ & $\$ 460$ & $\$ 630$ & $\$ 2000$ \\
\hline & & $5 \mathrm{~cm}$ & 140 & $\$ 410$ & $\$ 1115$ & $\$ 1500$ & $\$ 1100$ \\
\hline & \multirow{3}{*}{$\begin{array}{c}\text { UHPC } \\
\text { (nonproprietary) }\end{array}$} & $1 \mathrm{~cm}$ & 11 & $\$ 35$ & $\$ 230$ & $\$ 270$ & $\$ 2400$ \\
\hline & & $2 \mathrm{~cm}$ & 31 & $\$ 70$ & $\$ 460$ & $\$ 530$ & $\$ 1700$ \\
\hline & & $5 \mathrm{~cm}$ & 140 & $\$ 165$ & $\$ 1115$ & $\$ 1300$ & $\$ 900$ \\
\hline & \multirow{3}{*}{ NSC } & $1 \mathrm{~cm}$ & 4 & $\$ 3.5$ & $\$ 230$ & $\$ 240$ & $\$ 6000$ \\
\hline & & $2 \mathrm{~cm}$ & 6 & $\$ 7$ & $\$ 460$ & $\$ 500$ & $\$ 7800$ \\
\hline & & $5 \mathrm{~cm}$ & 19 & $\$ 17$ & $\$ 1115$ & $\$ 1200$ & $\$ 6000$ \\
\hline \multirow{9}{*}{20} & \multirow{3}{*}{$\begin{array}{c}\text { UHPC } \\
\text { (proprietary) }\end{array}$} & $1 \mathrm{~cm}$ & 7 & $\$ 90$ & $\$ 230$ & $\$ 320$ & $\$ 4600$ \\
\hline & & $2 \mathrm{~cm}$ & 21 & $\$ 170$ & $\$ 460$ & $\$ 630$ & $\$ 3000$ \\
\hline & & $5 \mathrm{~cm}$ & 95 & $\$ 410$ & $\$ 1115$ & $\$ 1500$ & $\$ 1600$ \\
\hline & \multirow{3}{*}{$\begin{array}{c}\text { UHPC } \\
\text { (nonproprietary) }\end{array}$} & $1 \mathrm{~cm}$ & 7 & $\$ 35$ & $\$ 230$ & $\$ 270$ & $\$ 3800$ \\
\hline & & $2 \mathrm{~cm}$ & 21 & $\$ 70$ & $\$ 460$ & $\$ 530$ & $\$ 2500$ \\
\hline & & $5 \mathrm{~cm}$ & 95 & $\$ 165$ & $\$ 1115$ & $\$ 1300$ & $\$ 1400$ \\
\hline & \multirow{3}{*}{ NSC } & $1 \mathrm{~cm}$ & 3 & $\$ 3.5$ & $\$ 230$ & $\$ 240$ & $\$ 7900$ \\
\hline & & $2 \mathrm{~cm}$ & 4 & $\$ 7$ & $\$ 460$ & $\$ 500$ & $\$ 12000$ \\
\hline & & $5 \mathrm{~cm}$ & 13 & $\$ 17$ & $\$ 1115$ & $\$ 1200$ & $\$ 9000$ \\
\hline \multirow{9}{*}{30} & \multirow{3}{*}{$\begin{array}{c}\text { UHPC } \\
\text { (proprietary) }\end{array}$} & $1 \mathrm{~cm}$ & $\overline{6}$ & $\$ \$ 90$ & $\$ \$ 230$ & $\$ 320$ & $\$ \$ 5300$ \\
\hline & & $2 \mathrm{~cm}$ & 17 & $\$ 170$ & $\$ 460$ & $\$ 630$ & $\$ 3700$ \\
\hline & & $5 \mathrm{~cm}$ & 80 & $\$ 410$ & $\$ 1115$ & $\$ 1500$ & $\$ 2000$ \\
\hline & \multirow{3}{*}{$\begin{array}{c}\text { UHPC } \\
\text { (nonproprietary) }\end{array}$} & $1 \mathrm{~cm}$ & 6 & $\$ 35$ & $\$ 230$ & $\$ 270$ & $\$ 4500$ \\
\hline & & $2 \mathrm{~cm}$ & 17 & $\$ 70$ & $\$ 460$ & $\$ 530$ & $\$ 3100$ \\
\hline & & $5 \mathrm{~cm}$ & 80 & $\$ 165$ & $\$ 1115$ & $\$ 1300$ & $\$ 1600$ \\
\hline & \multirow{3}{*}{ NSC } & $1 \mathrm{~cm}$ & 2 & $\$ 3.5$ & $\$ 230$ & $\$ 240$ & $\$ 11800$ \\
\hline & & $2 \mathrm{~cm}$ & 3 & $\$ 7$ & $\$ 460$ & $\$ 500$ & $\$ 16000$ \\
\hline & & $5 \mathrm{~cm}$ & 11 & $\$ 17$ & $\$ 1115$ & $\$ 1200$ & $\$ 10300$ \\
\hline
\end{tabular}

The service life calculation for a pier in different environments demonstrated that UHPC layer would postpone the second generation of repair for at least a decade. While 
NSC would experience several times of replacements during this duration. Therefore, for the above cases, the total cost of NSC during 100 years of service life would way exceed the initial cost of UHPC repair.

\subsection{Durability Projections}

Durability projections were made for idealized test cases to identify the applicability of UHPC for repair of damaged concrete and compare relative service lives of UHPC repair to conventional concrete repair applied to concrete bridge piers for marine environments. To that aim, a simple approach was used to calculate service life, based on chloride ion diffusivity, corrosion initiation, and macrocell currents quantified by the experimental work.

\subsubsection{Methodology}

In the practical application of repair concrete in marine concrete substructures, the placement and geometry of the repair patch can significantly affect the durability of the structural element.

Macrocell behavior can be completed due to numerous material and environmental conditions that can include concrete resistivity, oxygen availability, spatial geometric nonhomogeneity, etc. Modeling efforts of macrocell development can be complex requiring many system variables. The work here does not pose to account for the many variables and instead seeks to provide a rough estimation of macrocell behavior with the application of UHPC relative to NSC based on information obtained from comparative laboratory testing of those materials. In part to assess the application of UHPC repair, a simplified approach to calculate service projections was followed based on chloride diffusion and macrocell 
coupling. Estimation of chloride diffusion coefficient $(D)$ and surface chloride concentration $\left(C_{s}\right)$ from data sets of Florida bridges [158], [160] was used for simple damage projection calculations.

For the calculations, simplifying assumptions and definitions were made. Corrosion of the steel was accounted only by macrocell currents which would underestimate actual corrosion rates. As such, the calculations output can only be used qualitatively in its comparison of the repair materials. The macrocell currents were obtained from the experimental work described above with the material and geometric constraints of the small-scale test samples. Acceleration of corrosion rates due to macrocell coupling was only accounted for the experimental data for a cathode-to-anode ratio of 5:1. However, this may not necessarily reflect larger extended geometries and conditions where cathodic regions may also be extended in the substrate concrete. Also, the calculations only account for development of a small anodic region at the regions adjoining the repair patch (as these locations would have the highest chloride levels and loss of cathodic prevention (i.e. halo effect) due to repair). Corrosion at other locations including within the repair concrete was discounted. For simplicity, the chloride ion diffusivities were discretized and assumed to be only related to the quality of the concrete mix and did not account for internal moisture content.

For these calculations, a discrete anode length was assumed to develop. For simplicity, this length was assumed to be 0.4 in. $(1 \mathrm{~cm})$. The bar diameter used in the calculation was 0.5 in. $(1.2 \mathrm{~cm})$ with a clear cover of 3 in. $(7.6 \mathrm{~cm})$.

From the experimental work described in Chapter 6, macrocell currents developed between local anodes in the substrate concrete and the steel in the repair material. These 
macrocell currents were greater at higher chloride concentrations in the substrate concrete and furthermore enhanced in wet conditions. For the simple damage projection calculations, the macrocell current magnitudes were discretized based on the chloride levels used for testing $\left(0,0.4,4\right.$, and $\left.8 \% \mathrm{wt} \mathrm{Cl}^{-}\right)$as shown in Figure 7- 6. Based on the chloride levels calculated by simple diffusion transport at time $t$, the macrocell current corresponding to the next higher discretized chloride step was selected. This was thought to be a conservative approach given the rather coarse level discretization. The cumulative mass loss (based on Faradays Law) was calculated using the given macrocell current for the time period required for chlorides to diffuse to the next higher chloride level step. The process was repeated (summing up the total mass loss) with each successive step of chloride level concentration (and the corresponding macrocell current). If the chloride concentration at the bar cover depth already exceeded lower steps, the next higher macrocell level was assumed. If chloride levels exceed $8 \%$, the macrocell current at $8 \%$ was retained.

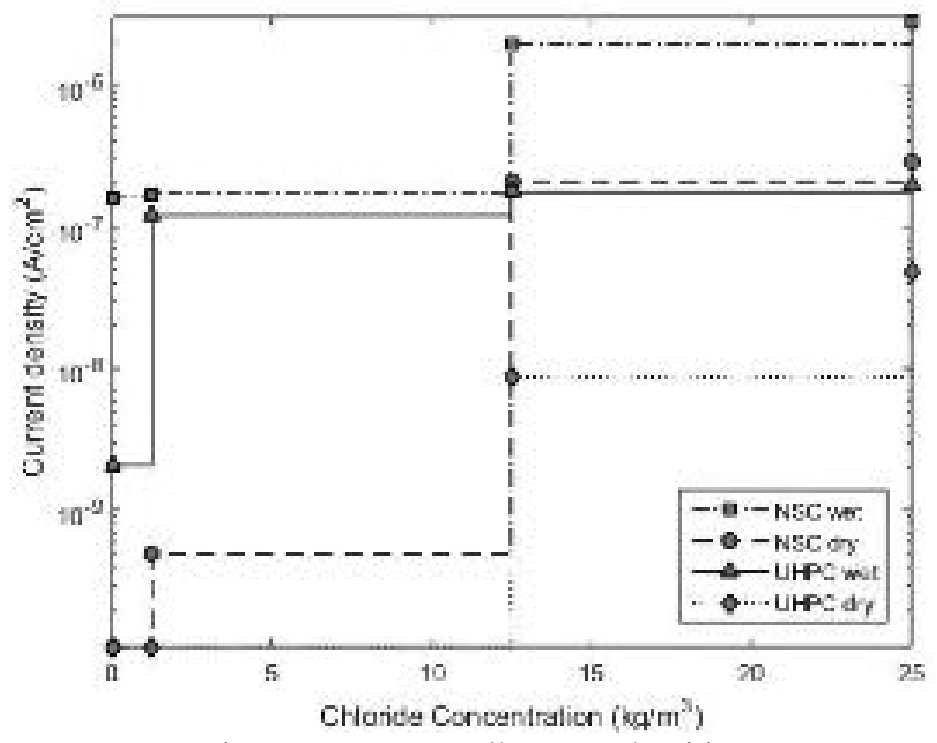

Figure 7- 6 Macrocell current densities 
In the first set, the comparative performance of repair with UHPC and NSC was made for various cases shown in Table 7 - 4 for this set, three exposure zones were defined; Damage zone, Tidal zone, and Upper splash zones.

Table 7- 4 lists the defined diffusion parameters approximated from data for Florida bridges [158], [160]. Chloride ion diffusivity was in the order of $108 \times 10^{-11}-130 \times 10^{-11} \mathrm{ft}^{2} / \mathrm{s}$ $\left(10^{-12}\right.$ or $\left.10^{-11} \mathrm{~m}^{2} / \mathrm{s}\right)$. The damage zone refers to a section that had initial spalling and delamination due to chloride-induced corrosion. Moreover, durability projections were made for cases with partial concrete repair and complete concrete repair. Assumptions for a partial repair were that after removal of degraded concrete, there was some level of sound base concrete that maintained elevated chloride levels based on concentrations calculated from Equation 7- 16 for the time for initial corrosion initiation given the parameters for the respective exposure zones.

$$
C(x, t)=C_{s}\left(1-\operatorname{erf}\left(\frac{x}{2 \sqrt{D t}}\right)\right)
$$

where $C_{s}=$ surface chloride concentration $\left(\mathrm{kg} / \mathrm{m}^{3}\right), t=$ time of exposure to $C_{s}(s), D$ $=$ chloride diffusion coefficient $\left(\mathrm{m}^{2} / \mathrm{s}\right)$.

It was assumed that the partial repair was made with adjoining concrete with diffusion characteristics of the tidal zone. Likewise, assumptions for a complete repair were that concrete in the tidal regions was fully removed and adjoining concrete had diffusion characteristics of the upper splash zone.

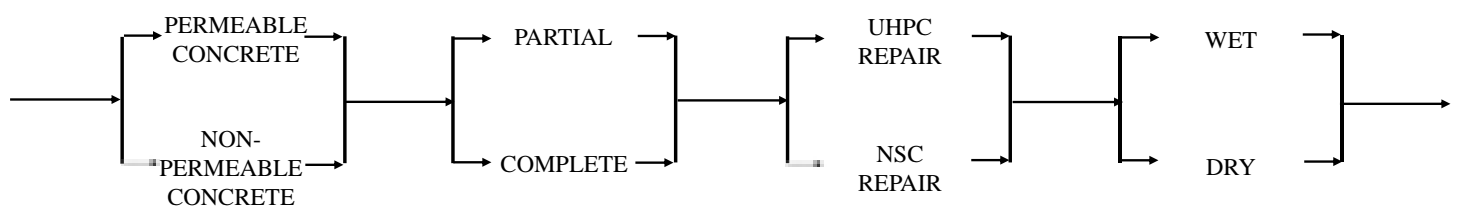

Figure 7-7 Calculation approach to compare repair service time. 
Table 7- 4 Exposure zones.

\begin{tabular}{ccccc}
\hline \multirow{2}{*}{ Zones } & \multicolumn{2}{c}{ Base Concrete $1(\mathrm{C} 1)$} & \multicolumn{2}{c}{ Base Concrete 2 $(\mathrm{C} 2)$} \\
\cline { 2 - 5 } & $\mathrm{D}\left(\mathrm{m}^{2} / \mathrm{s}\right)$ & $\mathrm{Cs}\left(\mathrm{kg} / \mathrm{m}^{3}\right)$ & $\mathrm{D}\left(\mathrm{m}^{2} / \mathrm{s}\right)$ & $\mathrm{Cs}\left(\mathrm{kg} / \mathrm{m}^{3}\right)$ \\
\hline Damage & $1 \times 10^{-12}$ & 25 & $1 \times 10^{-11}$ & 25 \\
Tidal & $1 \times 10^{-12}$ & 25 & $1 \times 10^{-11}$ & 25 \\
Upper Splash & $1 \times 10^{-12}$ & 15 & $1 \times 10^{-11}$ & 15 \\
\hline
\end{tabular}

In the second set, calculations were made to identify concrete and environmental conditions that can provide extended repair service life for the UHPC and NSC repairs. The base concrete quality was considered in these calculations quantitatively by chloride ion diffusivity (Figure 7- 8 and Table 7- 5).

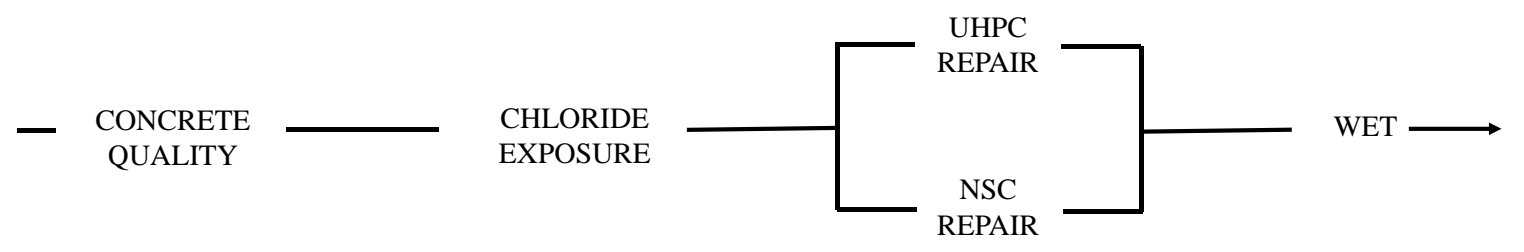

Figure 7- 8 Calculation approach to assess repair application

Five conditions were considered and are shown in Table 7- 5 Chloride exposure levels (for example in different natural water bodies or by elevation) were considered with discrete chloride surface concentrations also listed in the table.

Table 7- 5.Concrete and environmental conditions

\begin{tabular}{l}
\hline Base Concrete Quality (Chloride Diffusivity $\left.\mathrm{m}^{2} / \mathrm{s}\right)$ \\
\hline $1 \times 10^{-12}$ \\
$5.5 \times 10^{-12}$ \\
$1 \times 10^{-11}$ \\
$5 \times 10^{-11}$ \\
$8 \times 10^{-11}$ \\
\hline Chloride Surface Concentrations $\left(\mathrm{kg} / \mathrm{m}^{3}\right)$ \\
\hline 35 \\
25 \\
15 \\
10 \\
\hline Repair Material \\
\hline UHPC \\
NSC
\end{tabular}




\subsubsection{Computational results}

\subsubsection{COMPARISON OF REPAIR SERVICE TIME}

Figure 7-9 shows the calculation output results for conjectural cases for 2 concrete mixes (Base Concrete 1 and 2) characterized by its chloride ion diffusivity: $1.1 \times 10^{-11}$ and $1.1 \times 10^{-10}\left(1 \times 10^{-12} \mathrm{~m}^{2} / \mathrm{s}\right.$ and $\left.1 \times 10^{-11} \mathrm{~m}^{2} / \mathrm{s}\right)$, respectively. For those concretes, a hypothetical repair was made by replacing damaged concrete either within the tidal zone (partial repair) or in the upper splash zone (complete repair) with UHPC or with NSC.

Generally, the influence of the substrate concrete quality was readily evident. For the conjectural cases, the calculated chloride levels in the zones adjacent to the repair concrete at the time of repair already exceeded $0.4 \%$. Therefore, following the calculation protocol, the time for diffusion of chlorides to $4 \%$ was used for initial calculations for initial macrocell corrosion. Base Concrete 2 with $\mathrm{D}=1 \times 10^{-11} \mathrm{~m}^{2} / \mathrm{s}$ reached that initial chloride step 10 times faster than Base Concrete 1 with $\mathrm{D}=10 \times 10^{-12} \mathrm{~m}^{2} / \mathrm{s}$. In a similar way, the extent of the repair material (i.e. partial or complete repair) was evident by the diffusion of chlorides where longer service time to reach $4 \%$ chloride was evident for the complete repair compared to the partial repair. Mass loss was faster for the calculation conditions assuming the concrete was in wet condition due to the enhanced macrocell currents there. 

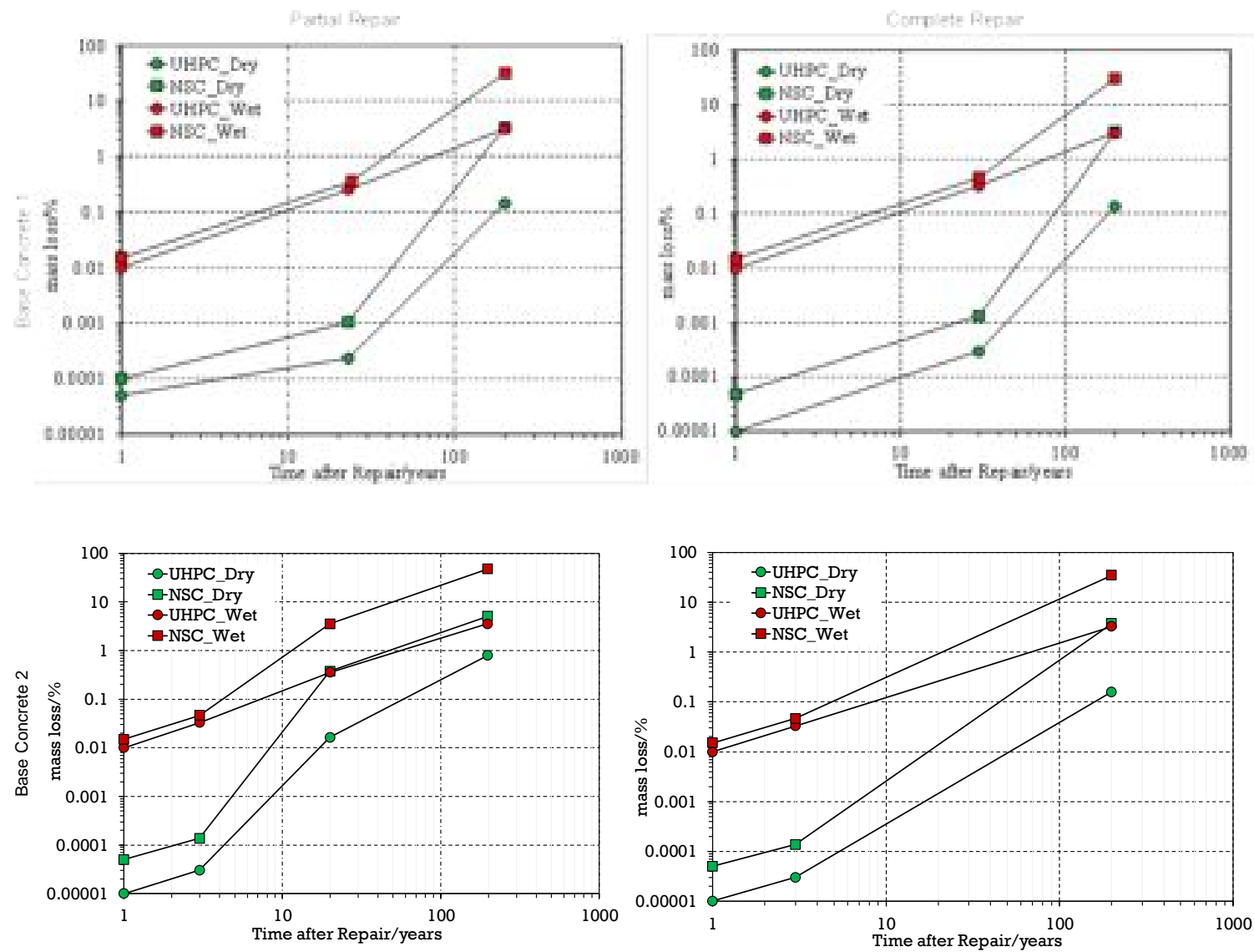

Figure 7- 9 Calculation results for repair service time.

Figure 7- 10 shows a compilation of calculations for repair service time for $1 \%$ corrosion damage. It was evident that extended service time in comparison to conventional patch repairs can be afforded by the application of UHPC repair based on the assumptions of the calculation approach. The effect of substrate concrete quality, moisture level, and repair placement can also be summarized in the figure. 


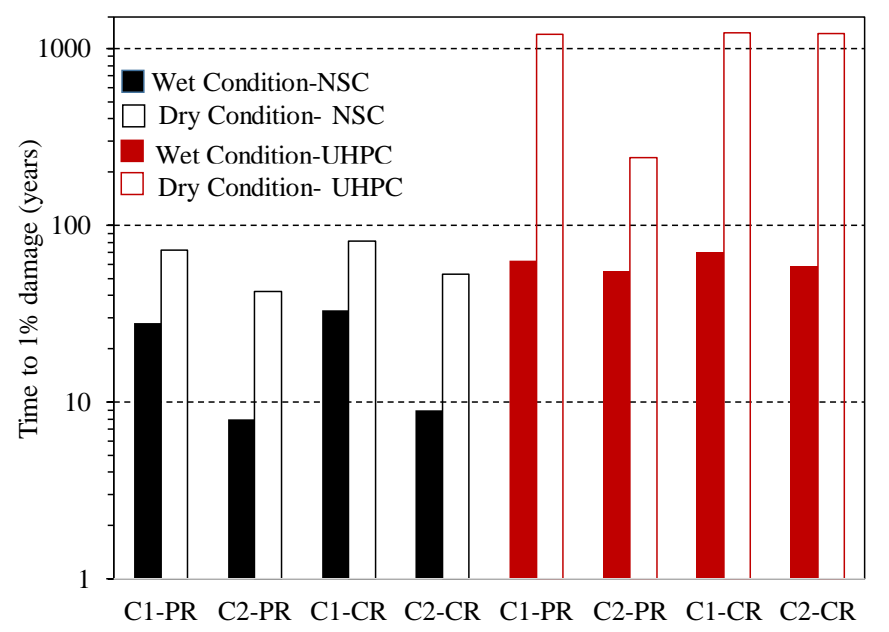

Figure 7-10 Compile graph of calculations for repair service time

*Note: Base Concrete 1, C1 ( $\left.\mathrm{D}=10^{-12} \mathrm{~m} 2 / \mathrm{s}\right)$ and Base Concrete 2, C2 ( $\left.\mathrm{D}=10^{-11} \mathrm{~m} 2 / \mathrm{s}\right)$. PR (partial Repair),

CR (Complete Repair)

\subsubsection{ASSESSMENT OF REPAIR APPLICATION}

Figure 7- 11 shows calculation output results for conjectural cases for 5 different concretes characterized by chloride ion diffusivity ranging from $1.1 \times 10^{-11}$ to $8.8 \times 10^{-11}$ $\left(1 \times 10^{-12} \mathrm{~m}^{2} / \mathrm{s}\right.$ to $\left.8 \times 10^{-11} \mathrm{~m}^{2} / \mathrm{s}\right)$ for $1 \%$ corrosion of rebar after repair with UHPC or NSC. The service life to $1 \%$ corrosion was calculated for various chloride exposure environments characterized by $C_{s}$. Only macrocell currents from laboratory testing in the wet condition were considered here as similar trends but with longer service time were calculated for dry conditions. Generally, the influence of low macrocell currents measured for UHPC samples compared to NSC samples is readily apparent in the calculation results. Much longer time to damage after the repair was calculated for the UHPC repair than NSC concrete repair. 

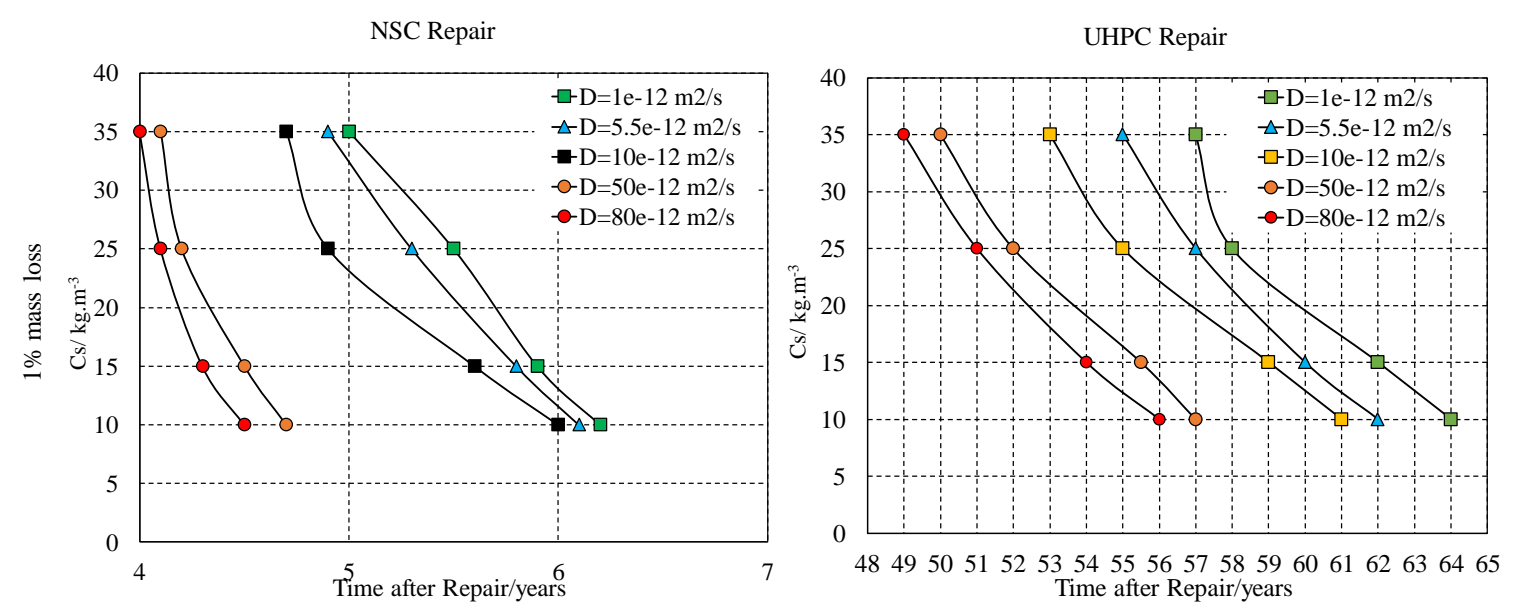

Figure 7-11 Output results for conjectural cases.

The simplifying assumptions in the calculation approach would not necessarily provide accurate service times but the results do provide information to quantitatively compare the effect of repair with UHPC compared to NSC for the given assumptions based on empirical data on macrocell development and mass diffusion. Even though the macrocell current step (used in the calculation for a given chloride level) used current values from laboratory testing at higher chloride levels, the enhancement of the macrocell in the lab sample may not necessarily reflect actual structures since extended cathodes in poor quality substrate concrete where coupling could be enhanced. However, comparative conjectural cases with NSC concrete have similar limitations.

For better utilization of these simplified calculation approaches, consideration of micro-cell corrosion and then enhancement due to macrocell coupling can be considered. Also, the effect of concrete resistance and oxygen availability were not explicitly considered. Beyond the influence on the developed macrocell determined empirically. Another major simplifying assumption that would not be realistic for damage projections for extended times was that corrosion at other locations were discounted and only corrosion at the repair boundary was considered. 
Past experiences with concrete repair with encapsulation materials including highperformance concrete and composite materials have shown mixed results. These experiences must be considered for any repair protocols. Nevertheless, even with these precautions, lab testing and service life calculation with grossly simplified system geometry and simplified treatment of macrocell development, do show trends of benefit provided by UHPC.

\subsection{SUMMARY}

Diffusion equations were used to calculate the service life of the repair. The results clearly show that UHPC, due to its low permeability compared to NSC, will significantly postpone the corrosion initiation at the rebar surface. Using UHPC as the repair material will extend the service life 5 to 10 times, depending on the chloride concentration in the environment.

Although the initial cost of UHPC repair is higher than NSC, the simple cost analysis showed that the total cost of UHPC repair during the life of the structure is way less than NSC.

A simple approach was used to calculate service life of the repair, based on simple diffusion behavior. Based on the results from durability projections for idealized test cases the influence of low macrocell currents measured for UHPC samples compared to NSC samples was clear in the calculation results. Much longer time to damage after the repair was calculated for the UHPC repair than NSC concrete repair. Therefore, service life may be extended in comparison to conventional repair with UHPC. 


\section{CHAPTER 8 PRELIMINARY DESIGN AND CONSTRUCTION RECOMMENDATIONS FOR UHPC REPAIR}

The need for repairs can differ from slight imperfections to significant damage caused by physical or chemical deterioration. Experience has shown that serviceability of the repair is greatly dependent on the repair process is performed carefully. [167].

This chapter reviews current knowledge, and results of the investigation on the application of UHPC for repair of axially loaded bridge elements. The guide terms are applicable for retrofit of deteriorated or damaged concrete structures, rectifying construction or design imperfections, or improving a structure for new applications. Following repair process is outlined to improve the success rate of UHPC repair.

\subsection{Evaluation Of the Substrate Condition}

The concrete substrates are different, in service exposure, age, and quality. Substrates can be either relatively new concrete or a deteriorated one. They may be exposed to different relative humidity, temperatures, electrochemical status, chemically threatening environments, and mechanical loads.

Determination of the origin and extent of the deterioration or distress is of crucial importance to having a successful concrete repair. That helps to establish practical repair goals and develop a plan to address repair demands. To that aim, condition survey compatible with the condition of the structure and the repair objectives should be carried out. 
ACI 562M [168] provides minimum requirements for evaluating existing concrete structures and subsequently developing repair strategies. Evaluation of a structure includes a review of the available documents, such as construction documents, and historical building codes and standards applicable at the time of construction. Construction documents can provide useful details like the size and spacing of reinforcement, geometry, and detailing of connections. However, information about the original construction may have been lost over time, such that verification of the original structure may be required. This may necessitate one or more evaluation methods, including visual inspection, and ferromagnetic surveys of the reinforcement or other non-destructive technique to evaluate the condition of the base structure.

The onsite evaluation should determine the extent of damages and the corresponding level of essential repairs which are needed. Detailed visual inspection is the commonly used evaluation method which delivers valuable information regarding the condition of the structure. However, this method is limited to exposed and accessible surfaces and may be accompanied with mechanical sounding to identify locations of underlying shallow concrete distress, such as delamination occurring due to corrosion of the underlying reinforcement.

There are multiple fields and laboratory tests that can be applied to recognize potentially problematic conditions. This includes carbonation testing, chloride testing, and petrographic analysis. Figure 8- 1 summarizes the typical evaluation process of the existing concrete substrate. 


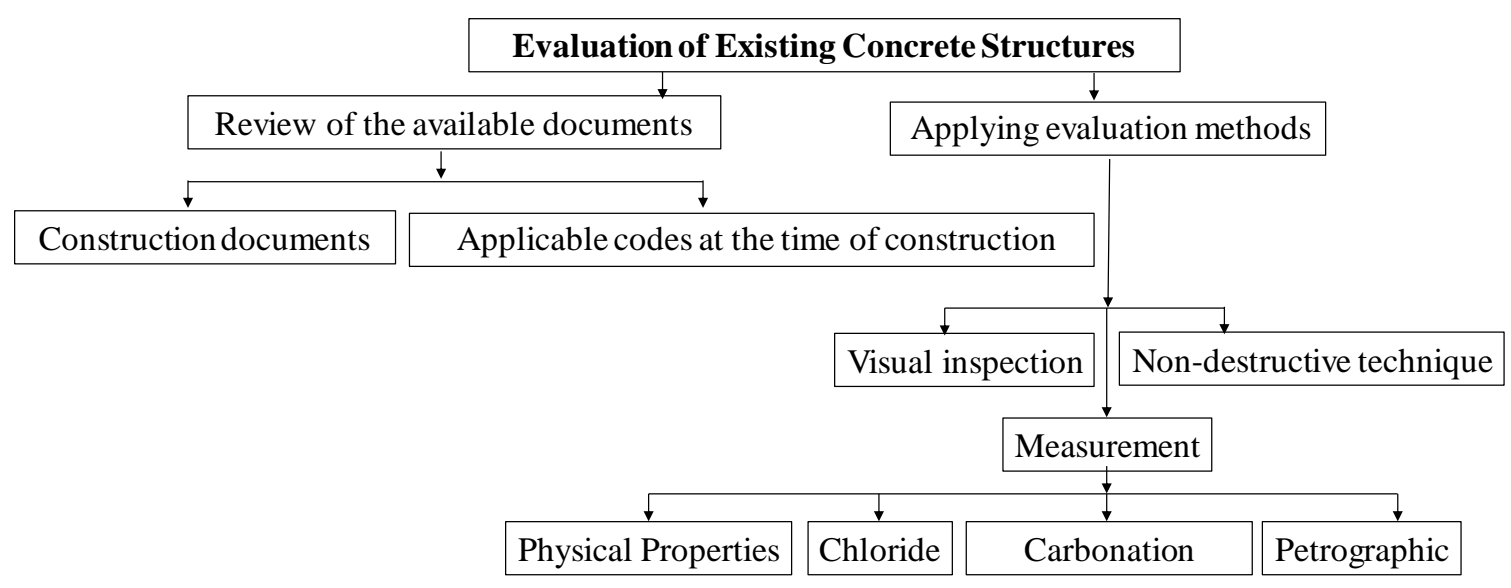

Figure 8- 1 Process of substrate evaluation.

\subsection{Repair Design Precaution}

In the design of a UHPC repair, the aim is to provide a repaired element that is durable, serviceable and has adequate strength to fulfill its intended function. It must also be robust, and satisfy other relevant requirements, such as ease of construction and economy.

A repair is durable if it withstands expected wear and deterioration throughout its intended life without a further need for maintenance. To that aim, the assessment of the application and, exposed service conditions is remarkably important. Prior to repair all the cause of the damage or deterioration, desired service, and durability planning must be ascertained. Moreover, the extent and severity of the damaged component should be assessed to determine the influence of spalled, deteriorated, or damaged concrete on loadbearing capacity. The objective of this evaluation is to decide how much concrete is damaged, and how will this damage disturb serviceability of the structure.

A drawing of the deteriorated or damaged zones of the concrete structure identified during the initial evaluation should be drafted. This will store information for following calculations of the repaired area and volume. The limitations for the concrete depth 
removal and the cross-section reduction should be described prior to the announcement of the repair patch [26]. Figure 8- 2 shows the summary of precautions prior to the announcement of repair.

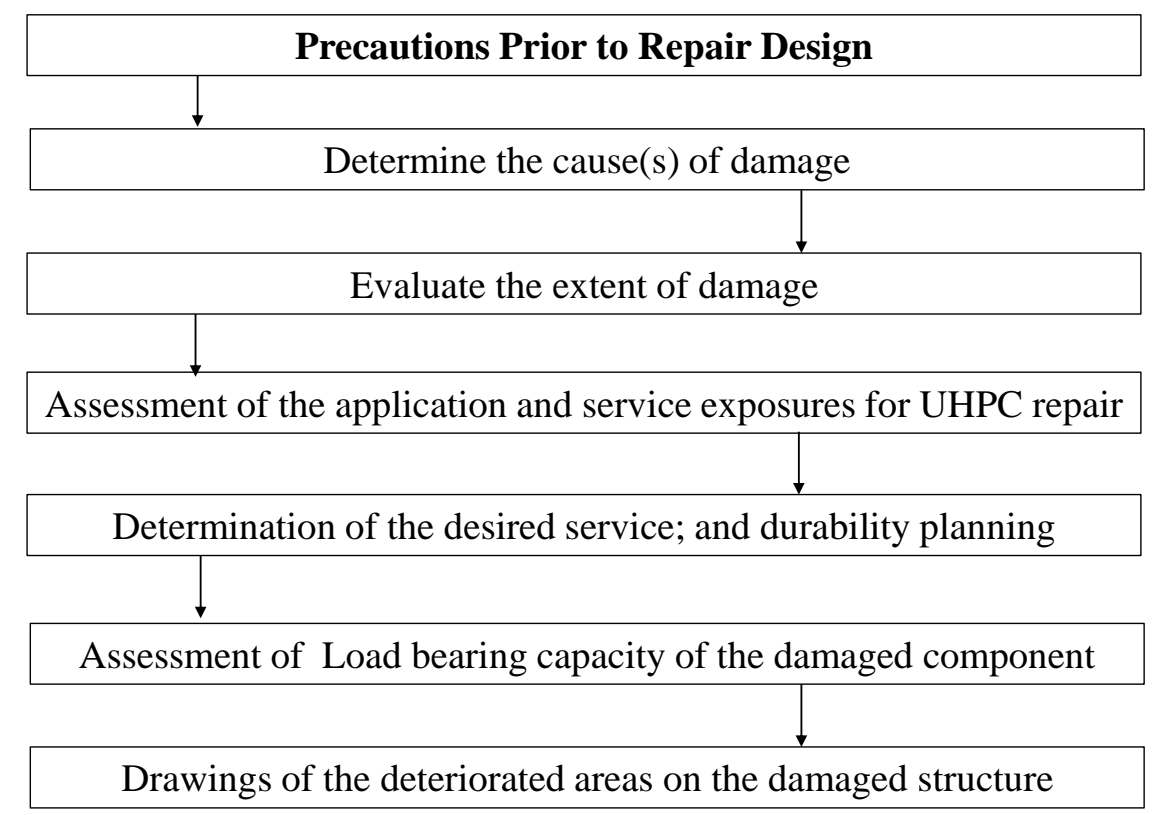

Figure 8- 2 Repair design precaution.

\subsection{REPAIR GEOMETRY}

To accomplish durable repairs, the existing concrete preparation is very important. This step includes removal of all the deteriorated and damaged concrete so that a sound surface is left to have an adequate bond with the repair material. For this step, it is necessary to remove all the unsound or deteriorated concrete before application of UHPC.

The damaged areas that are required to be removed should be modified to provide for simple layouts. It is usually counterproductive to strictly follow the form of the repair area with repetitious short saw cuts, as seen in Figure 8- 3 [26]. Sawing such a detailed shape, most likely costs more than the increased concrete removal. Moreover, multiple corners and angles raise the possibility of cracking in the repair material due to shrinkage, 
stress concentrations and cracking [26] [167]. To obtain good contact between the substrate and patch material, top edges of the repairing areas should be sharp while corners should be rounded. The layouts should be designed to reduce boundary edge length and eliminate acute angles. Excessive or complex edge conditions often result in shrinkage, stress concentrations and cracking [26]. Moreover, the repair geometry may be modified based on the durability plan (Chapter 7) and design considerations regarding the critical section relocation (Chapter 5). The influencing factor on the geometry of the repair is listed in Figure 8- 4.
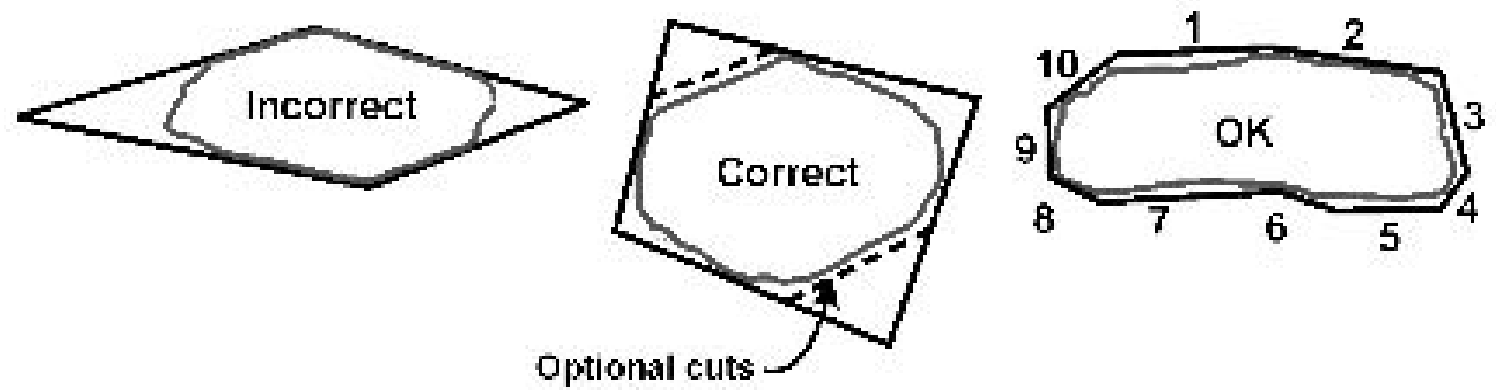

Figure 8- 3 Examples of saw cut shapes [167].

Despite the careful initial evaluation to find the repair geometry, it is common to find the actual volume of damaged concrete exceeding the original estimate. For this reason, it is recommended to overestimate the quantities by 15 to 25 percent to cover overruns [26].

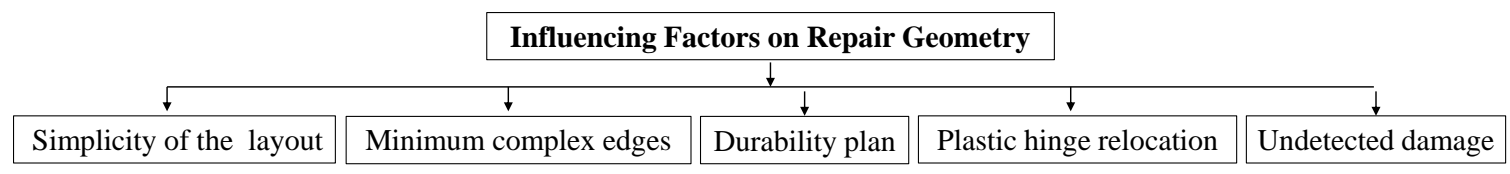

Figure 8- 4 Influencing factors on repair geometry. 


\subsection{CONCRETE REMovaL}

Durable repair of concrete structures cannot be guaranteed except when complete removal of deteriorated concrete is accomplished [26]. This step of repair involves unsound and, if necessary, sound concrete removal. Unsound concrete is described as concrete affected by spalling, delamination, and cracking. Unsound concrete is in a degraded physical condition which is relatively easy to remove. On the other hand, sound concrete may be in a good physical condition requiring considerable effort for its removal.

Although concrete removal mainly includes unsound material, some sound concrete may also be removed to achieve desired repair geometry or to remove contaminated concrete, or even to prepare reinforcements. There are various concrete removal techniques depending on the concrete condition, unsound or sound and a combination of techniques may be required. Figure 8- 5 briefly shows the main concrete removal elements.

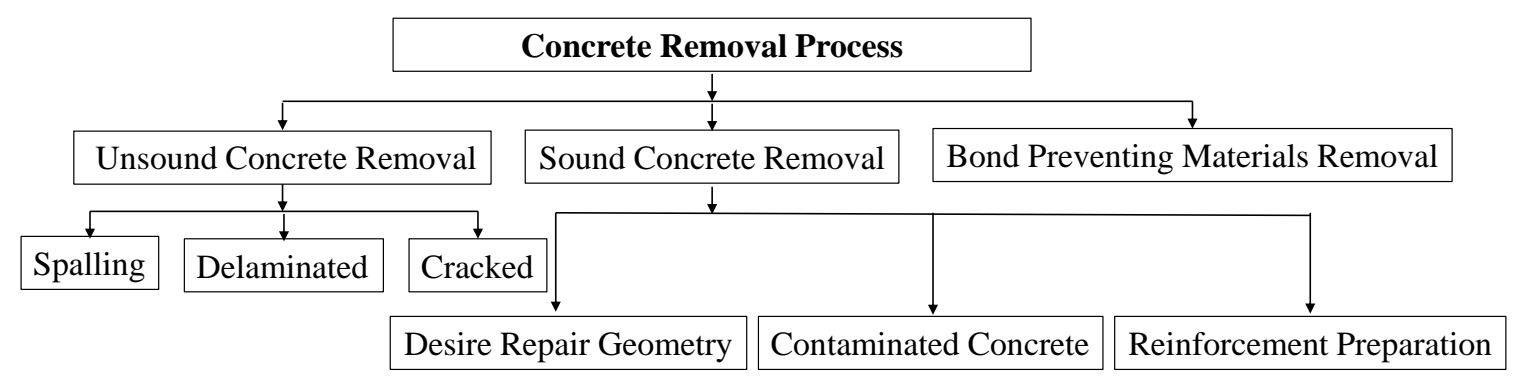

Figure 8- 5 Concrete removal elements.

\subsubsection{Precautions prior to concrete removal}

The structural integrity of a damaged element structure should be carefully reviewed prior to removal of existing concrete. For example, temporary shoring must be 
provided in the case that the concrete or reinforcing steel removal can jeopardize the load carrying capacity of the structure.

Moreover, the regions where concrete is being removed should be carefully monitored for any electrical conduits, utility lines, or another embedment in the concrete which may be damaged during removal.

To avoid any debris and dust outside the work areas, a suitable barrier should be employed. The enclosures should be inspected regularly to assure no leaks. In addition, the impact of the concrete removal operation on the surrounding environment must be minimized. The necessary precautions are summarized in Figure 8- 6.

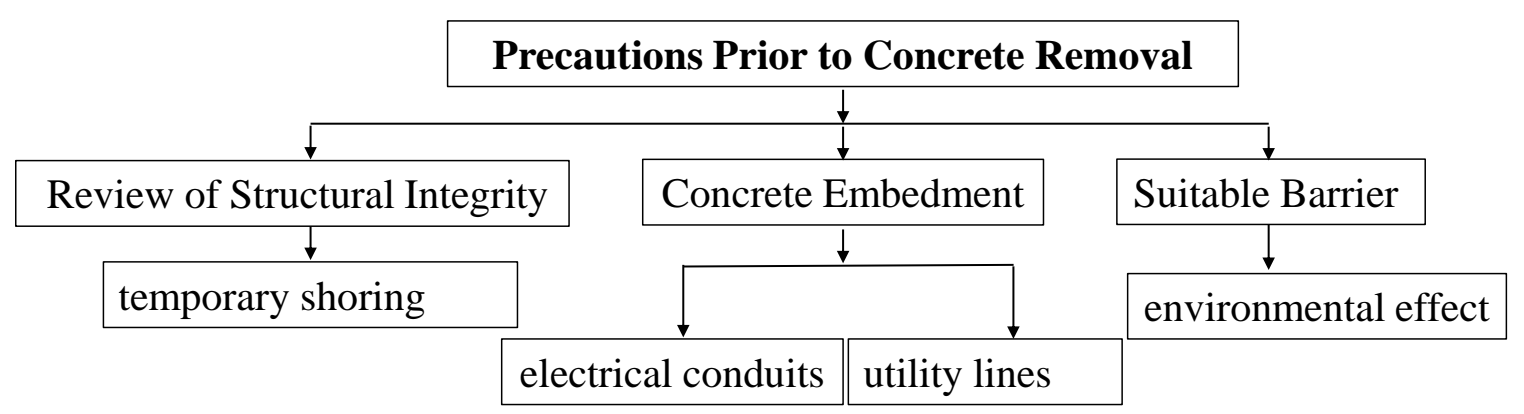

Figure 8- 6 Concrete removal precautions.

\subsubsection{Concrete removal methods}

The general categories of concrete removal methods are blasting, impacting, milling, cutting, abrading, and pre-splitting. ACI 546R [169], presents a description of these removal techniques.

The removal process usually starts with saw cutting the repair area boundaries to a minimum depth of 1 in. $(25.4 \mathrm{~mm})$ [167]. Afterward, the unsound concrete in the middle of the repair area is detached using a light jackhammer. It is recommended to progress the 
concrete removal from the inside toward the edges of the repair [169]. During saw cutting, it is vital to confirm that embedded items, e.g. reinforcing steel, are not damaged.[167].

\subsection{REINFORCEMENTS}

Special treatment is required for reinforcing steel exposed during concrete removal (Figure 8- 7). Generally, if more than $30 \%$ of the steel area is exposed, the concrete around the steel should be completely removed [167]. The depth of removal beyond the reinforcing steel can be chosen based on the desired service life of the repair (Chapter 7).

In case that the steel reinforcing is corroded, all surrounding concrete should be removed, and the reinforcement should be completely exposed, to the point where the concrete is well bonded to the steel, and the steel is not affected by corrosion.

The primary cleaning of exposed steel reinforcements is normally obtained during the cleaning procedures of the concrete surface utilizing blasting techniques. Afterward, steel reinforcements should be carefully examined to decide whether the reinforcing steel can operate as expected by the design. If the cross-section area of the reinforcing steel has been decreased by corrosion by more than $20 \%$, the Engineer shall make the decision on the actions to be taken [167].

Two options when the steel reinforcement has lost cross-section or the existing element is tended to be strengthened are to use supplemental reinforcements or replacement of the existing reinforcing steel. Extra or replacement of longitudinal reinforcement can be placed beside the existing bar with straight overlaps. The lap splice requirement for UHPC is recommended to be equal to $8 \mathrm{~d}_{\mathrm{bl}}$ [170]. Additional transverse reinforcement may also be needed that can be placed using welded splices or approved mechanical connectors. 


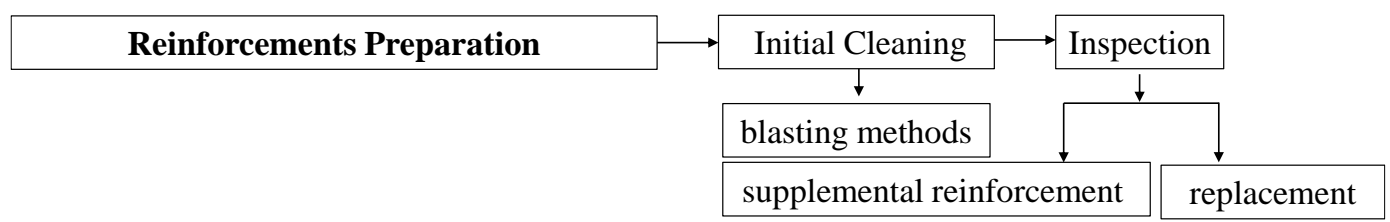

Figure 8- 7 Preparation of reinforcements prior to repair patch placement.

\subsection{Surface Roughening ANd Cleaning}

The purpose of the concrete repair is to strengthen the deteriorated element, recover its stiffness and load-carrying capacity, and prolong the service life. Therefore, composite action between substrate and UHPC is the final aim. A necessity for composite action is an adequate bond between the existing substrate and UHPC.

The process of surface preparation for UHPC repair is to produce sound, clean, and suitably roughened surfaces. Substrate roughness greatly depends on the substrate surface preparation method. In this step partially loosened chips of concrete and any laitance is removed by blasting methods. Blasting techniques include removal of a thin layer of surface concrete using abrasive equipment such as sandblasters, shot blasters, or highpressure water blasters. In these, an abrasive medium at high velocity is propelled against the concrete surface to remove concrete. The process may be performed in one of the three following methods.

- Sandblasting which is the most common blast method to clean the surface of substrate concrete and steel reinforcement. The main abrading agents used in this method are common sand, silica sand, metallic sand or slag.

- Shotblasting equipment cleans the surface of substrate concrete by projecting large number of small steel balls towards the surface. The pulverized concrete is then vacuumed and placed into the machine to be discarded later. The 
balls are also drawn back into the machine to be reused. This technique is a selfcontained operation which is environmentally sound and extremely efficient.

- In water blasting method water is sprayed at pressures between 5,000 and 15,000 psi (35-105 MPa). Sometimes an abrasive, e.g. aluminum oxide, or garnet, is presented into the stream. This technique can clean the concrete surface and remove foreign particles or concrete laitance.

\subsection{Protecting the Prepared Area}

A long duration between cleaning the substrate surface and UHPC placement may cause carbonation, or new contaminants on the surface of substrate concrete, which might interrupt the bond. Therefore, after the preparation of the repair area, it must be kept clean and protected from damage until the UHPC placement. [167].

\subsection{Moisture Conditioning of The Concrete Substrate}

Aforementioned, the factors affecting the bond between UHPC and the substrate are the surface quality of the substrate, moisture content of the substrate and environmental conditions.

The rate of water movement between the substrate and UHPC is determined by the moisture condition of the substrate including the surface moisture and the moisture distribution inside the substrate, and the hydration of the cement paste in UHPC.

Saturated Surface Dry (SSD) moisture conditioning is recommended to be a safe compromise for most of the repair materials including UHPC [161]. This moisture condition is obtained by wetting the surfaces with water for 2 to 24 hours prior to the application of repair material. The substrate surfaces then should be left to start drying 
naturally or by employing oil-free compressed air. This condition provides a damp substrate with no free water on the surface.

\subsection{FORMWORK}

Successful implementation of a UHPC repair project depends on the design of the formworks. Because of the high flow and fiber content of UHPC the hand screeding is not commonly accepted. Self-leveling and self-consolidation characteristic of UHPC result in no internal shear in the plastic state which creates challenges when generating completely enclosed with tight tolerances formworks.

The flowability of UHPC can fill all the cavities between substrate and the

formwork which eases the casting process. However, to accelerate the repair process a formwork which is easy to erect is essential.

\subsection{UHPC MIX}

The design of the concrete mix is based on the intention to reach a compactly dense cementitious matrix. Almost any conventional concrete mixer mixes UHPC [171]. However, it must be acknowledged that UHPC needs larger energy input than the conventional concrete, consequently mixing time is longer. This increased energy input, along with the low water content and excluded coarse aggregate, demands adapted processes to guarantee that the UHPC does not overheat during mix procedure. This issue can be addressed through a high-energy mixer implementation, decreasing the constituent's temperatures, or fully ( or partially) replacement of water with ice [171]. 
The mix design should be strictly followed based on the instruction offered by the UHPC vendor. The suggested designed by Ductal company is explained in detail in Chapter 2.

\subsection{UHPC PLACEMENT}

The UHPC placement may shortly follow mixing or be paused while further mixes are completed. The settling time before the cement hydration reactions are initiated is affected by factors including chemical accelerators and temperature, however, it typically takes several hours before UHPC will undergo initial set [172].

UHPC should be cast slowly to prevent entrapment of air. The process of placing UHPC has an impact on the fibers orientation and distribution [172] affecting long-term durability and mechanical properties of UHPC. The discontinuing of the fiber reinforcement in the mix depends on the rheology of the UHPC mix [173]. Therefore, any vibration on the form, or adjustment of the rheology must be carefully reconsidered. To this respect, no internal vibration of UHPC is not recommended, however, limited external vibration on the form can be employed to facilitate the release of entrapped air [173].

\subsection{UHPC CURING}

Proper curing techniques are necessary for the performance of UHPC. The low water content in UHPC mix demands careful consideration to curing methods ensuring that the included water is not allowed to escape before hydration [173]. Any exposed surface of UHPC should be wrapped instantly after casting with an impermeable layer such as Metal, and plastic. Surface dehydration may result in cracking and degradation of final 
material properties. To avoid that, the cover must rest against the UHPC with no space between the sealing and the fresh UHPC [174].

It should remain wrapped, until it has reached adequate strength to be selfsupported and not self-desiccated. A compressive strength of $14 \mathrm{ksi}$ (97 $\mathrm{MPa}$ ) is recommended as a value to indicate an acceptable level of hydration [23]. It is likely to enhancement the natural curing procedure of UHPC by using a steam treatment [171]. This treatment can both improve and accelerate acquisition of the final durability and mechanical properties of UHPC. This treatment, however, is not essential and can be ignored when the as-cast properties of UHPC are appropriate for the considered application [174].

\subsection{Conclusion}

The ultimate performance and integrity UHPC repairs are mainly determined by the detailed steps of the repair process. To that, It is crucial that care is taken, specifications are followed, the quality of the prepared surface is controlled and all the related decisions are made by qualified personnel Figure $8-8$ outlines the steps that should be followed to have a successful UHPC repair. 


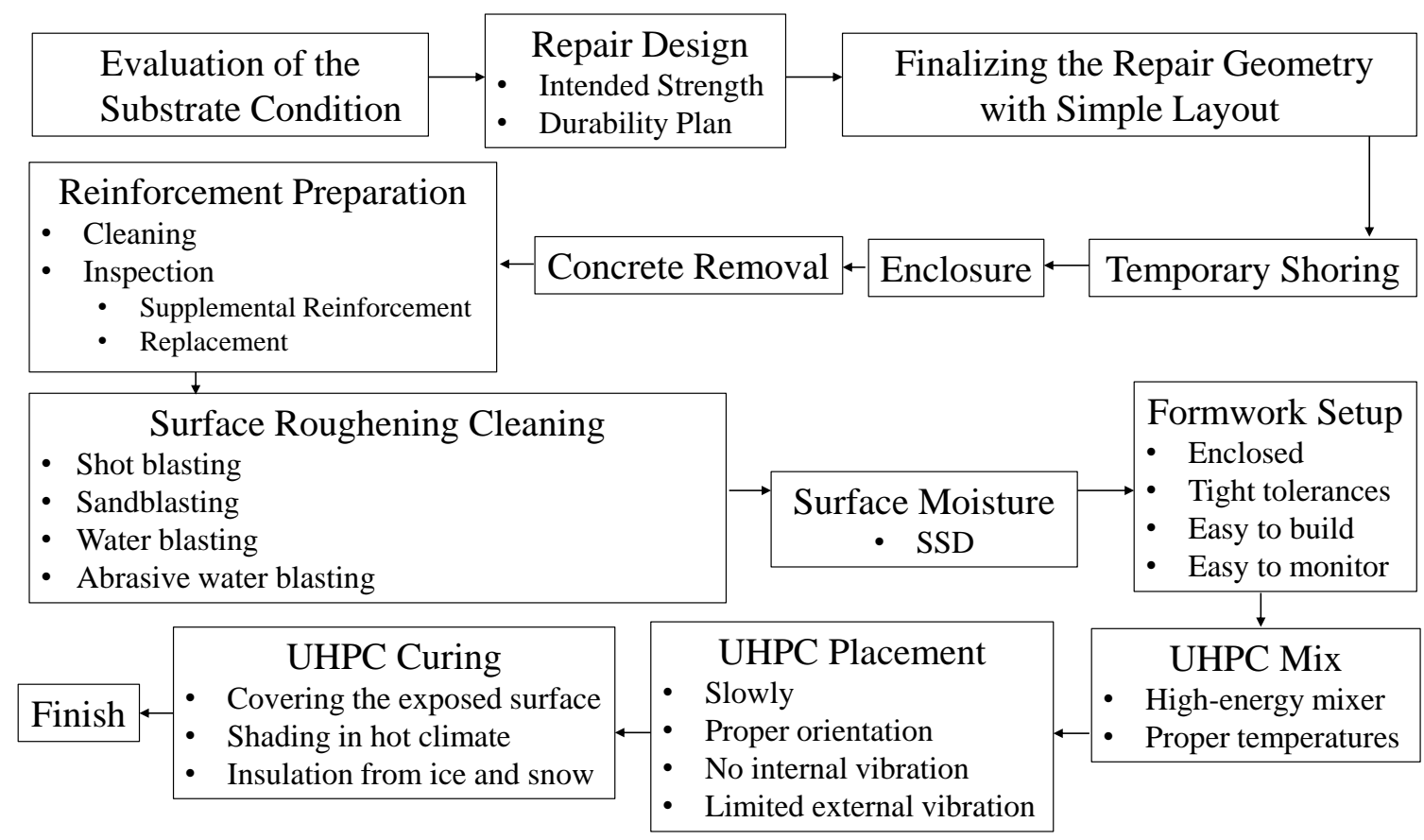

Figure 8- 8 UHPC repair procedure. 


\section{CHAPTER 9 SUMMARY OF THE FINDINGS AND FUTURE STUDY}

The deteriorating status of highway bridges in U.S raised the need for replacement or upgrade of these structures. In today's growing public, the transportation infrastructure cannot be out of service without disruption to critical economic public, civil and commercial activities. This mandates the development of new techniques and materials for accelerated rehabilitation and recovery. To address this issue, a repair method was developed at Florida International University (FIU), using Ultra High-Performance Concrete (UHPC). This research investigated the mechanical and durability performance of the proposed retrofit method through experimental and numerical studies, and the findings are briefly summarized in this chapter.

\subsection{Ultra High-PERformance CONCRETE APPLICATION FOR REPAIR}

UHPC is a cementitious material formulated with an optimized gradation of granular constituents, a water-to-cementitious materials ratio less than 0.2 , and a high percentage of internal fiber reinforcement. The resulting product is concrete with improved strength, ductility, and workability, as well as self-consolidating, and durability relative to normal or even high-performance concrete [32], [33]. Furthermore, UHPC can rapidly gain strength, approximately $68 \mathrm{Mpa}(10 \mathrm{ksi})$ after five days of ambient air curing [34], [35], which is ideal to improve the speed of construction.

The properties of UHPC make it a suitable choice as a repair material for retrofitting the damaged body of the marine piles, and application of UHPC could provide an efficient solution to address the pressing issue of bridge rehabilitation [36]. 


\subsection{Material Properties of UHPC as a Repair Material}

The experimental tests were conducted to evaluate physical properties, and durability properties of UHPC as a repair material. The same tests have been conducted on Normal Strength Concrete (NSC), and the corresponding results have been compared to that of UHPC. The purpose of this part of the research is to quantification of UHPC as repair material per its physical, and durability properties, and to properly assign its repair application.

- Experimental results show that among the two considered material, UHPC had a significant improved performance compared to normal strength concrete. The following conclusions are delivered for strength and corrosion protection based on the results from small scale cast concretes.

- In general, the compressive and tensile strength, ductility and modulus of elasticity of UHPC were notably higher than normal strength concrete.

- $\quad$ The mode of failure and behavior of UHPC test specimens after peak load exhibit the influence of fibers for UHPC. The average compression and tensile strength of tested UHPC compared with normal concrete showed remarkable enhanced material properties of UHPC compared to conventional concrete.

- Only minor to no increase in mass was observed for UHPC in all of the tested moisture exposure conditions possibly due to self-dessication of concrete.

- UHPC showed bulk resistivity up to an order of magnitude larger than the tested conventional concrete, consistent with its higher cement factor and relatively low internal moisture content due to its low permeability. 
- The calculated approximate oxygen diffusivity for UHPC was much lower than the conventional concrete, and lower diffusivity was observed in UHPC exposed in immersed conditions than in ambient humidity conditions. Therefore, development of corrosion cells is expected to be mitigated due to low gas permeability.

- UHPC generally showed lower internal relative humidity consistent with low internal moisture content.

\subsection{BOND STRENGTH AND DURABILITY BETWEEN UHPC AND SUBSTRATE}

The evaluation on the bond strength consists of two sets of experiments. First, the effect of wetness of the substrate as well as the overlay materials were investigated. Second, the bond strength between UHPC and substrate concrete when the substrate is conditioned to various moisture content prior and after UHPC placement was evaluated.

Moreover, the enhanced chloride transport that may occur at the cold joint was examined to evaluate the corrosion durability of steel embedded in dissimilar concretes incorporating UHPC. The effectiveness of the bond at the concrete interface (with various levels of moisture availability at the time of UHPC repair) to minimize chloride penetration was examined.

- $\quad$ Samples with wet surface showed better bond behavior as compared to the dry one. The reason could be attributed to the fact that the moisture condition of the substrate determines the water movement rate from the overlay concrete to the substrate. 
- All specimens exhibited higher bond strength when the overlay material shifted from NSC to UHPC. That indicates the influence of the overlay material on the bond strength.

- The maximum value of the standard variation of each group of tests was calculated and compared. The calculation results show that the flexural test with a maximum standard deviation of $0.03 \mathrm{ksi}(0.2 \mathrm{MPa})$ has the best consistency and slant shear test with $0.5 \mathrm{ksi}(3.5 \mathrm{MPa})$ has the most inconsistent results.

- $\quad$ According to Sprinkel and Ozyildirim categorization, the strength level obtained for most surface moisture content of the the substrate falls under an 'Excellent' bonding category, except the composite samples with $100 \% \mathrm{RH}$ which had a strength value classified as "Good".

- The atained tensile strength of the soaked surface composite cylinders exceeds the tensile splitting strength of the plain NSC cylinders.

- $\quad$ Plain UHPC specimen exhibited significantly lower chloride penetration compared to NSC.

- $\quad$ Chloride penetration was generally observed as bulk transport but there was an indication that non-Fickian chloride transport can occur along the surface of the joint. There was a general indication that moisture transport through the cold joint depends on moisture levels.

\subsection{Mechanical Performance of UHPC Repaired Columns}

The mechanical and durability performance the proposed repair method were experimentally investigated. First, a total of eleven 1/4-scale columns were cast, and typical 
damages were simulated in them. Eight of the damaged columns were repaired with UHPC, one repaired with NSC, and one column, with no repair, was used as the test baseline. Moreover, two intact columns were cast with the substrate concrete as the references. The obtained experimental results reveal that the UHPC shell increases the strength of the damaged elements, without increasing its size.

- $\quad$ Firstly, the repair scheme using the UHPC is rather efficient regarding lateral strength, deformation, energy dissipation capacity, and stiffness degradation. Furthermore, lack of any delamination across the circumferential shell shows the effectiveness of the surface preparation, which is a prerequisite for a successful restoration.

- UHPC shell transforms the sudden cover spalling to a gradual mechanism. This enhancement is due to the ability of the fibers to limit the progression of cracks in the concrete, thereby resulting in greater material integrity at large strains. Regarding the confinement effect of UHPC shell experimental findings indicate that a slight increase of lateral reinforcement significantly improves the cyclic behavior of the specimen, energy dissipation capacity, deformability, and ductility.

- The test results of the units with lap splice in longitudinal reinforcements indicates that with proper design, UHPC is capable of developing bars in repair area with short splice length $\left(8 \mathrm{~d}_{\mathrm{bl}}\right)$. Moreover, from strength stand point UHPC with $2 \%$ or $4 \%$ fiber content resulted in same behavior.

- $\quad$ More importantly, depending on the UHPC shell thickness this method may cause shifting the damage above or below the repair section and that should be a design consideration. 


\subsection{Numerical ANd Analytical Approach}

In Chapter 5, simple formulae were proposed to analyze the ultimate capacity of circular cross-section subjected to axial loads combined with uniaxial bending. A thorough example has also been performed to determine the level of precision of the proposed design formulae. The results obtained for a wide range of design case (corresponding to the most commonly employed in practice) have shown a very good resemblance of the values computed by MATLAB program.

\subsection{Durability Performance of UHPC RePaired ColumnS}

macrocell development between the dissimilar concrete materials was examined to identify possible benefits and challenges of utilizing UHPC as a repair material for reinforced concrete marine bridges. The following conclusions were drawn based on the results from testing repair columns and durability study.

- Low macrocell currents developed in samples with conventional and UHPC repair concrete when the chloride content in the substrate concrete was low. Even though the higher current was observed in wet condition compared to the dry condition, the increase in samples repaired with UHPC this value was significantly lower than the comparative one with NSC.

- At higher chloride contents in the substrate concrete, the macrocell current was enhanced at higher C/A for samples utilizing conventional concrete for the repair concrete and this trend was more highlighted after wetting.

- In context to the local coupling of local anodes to cathodes in repair material, the measured macrocell current was much reduced in samples repaired 
with UHPC even with higher chloride presence in the substrate concrete than the conventional concrete even after wetting the samples.

\subsection{Durability Projections}

Diffusion equations were used to calculate service life of the repair. The results clearly show that UHPC, due to its low permeability compared to NSC, will significantly postpone the corrosion initiation at the rebar surface. Using UHPC as the repair material will extend the service life 5 to 10 times, depending on the chloride concentration in the environment.

Although the initial cost of UHPC repair is higher than NSC, the simple cost analysis showed that the total cost of UHPC repair during the life of the structure is way less than NSC.

A simple approach was used to calculate service life of the repair, based on simple diffusion behavior. Based on the results from durability projections for idealized test cases the influence of low macrocell currents measured for UHPC samples compared to NSC samples was clear in the calculation results. Much longer time to damage after the repair was calculated for the UHPC repair than NSC concrete repair. Therefore, service life may be extended in comparison to conventional repair with UHPC.

\subsection{UHPC REPaIR PROCEDURE}

The integrity and ultimate performance of UHPC repairs and overlays is in large part determined by the quality of the existing concrete surface preparation, as well as UHPC mix design, placement and curing. It is imperative that care be taken, specifications 
followed, and surface preparation quality control and related decisions be made by qualified personnel. Figure 9- 1 summarized the UHPC repair.

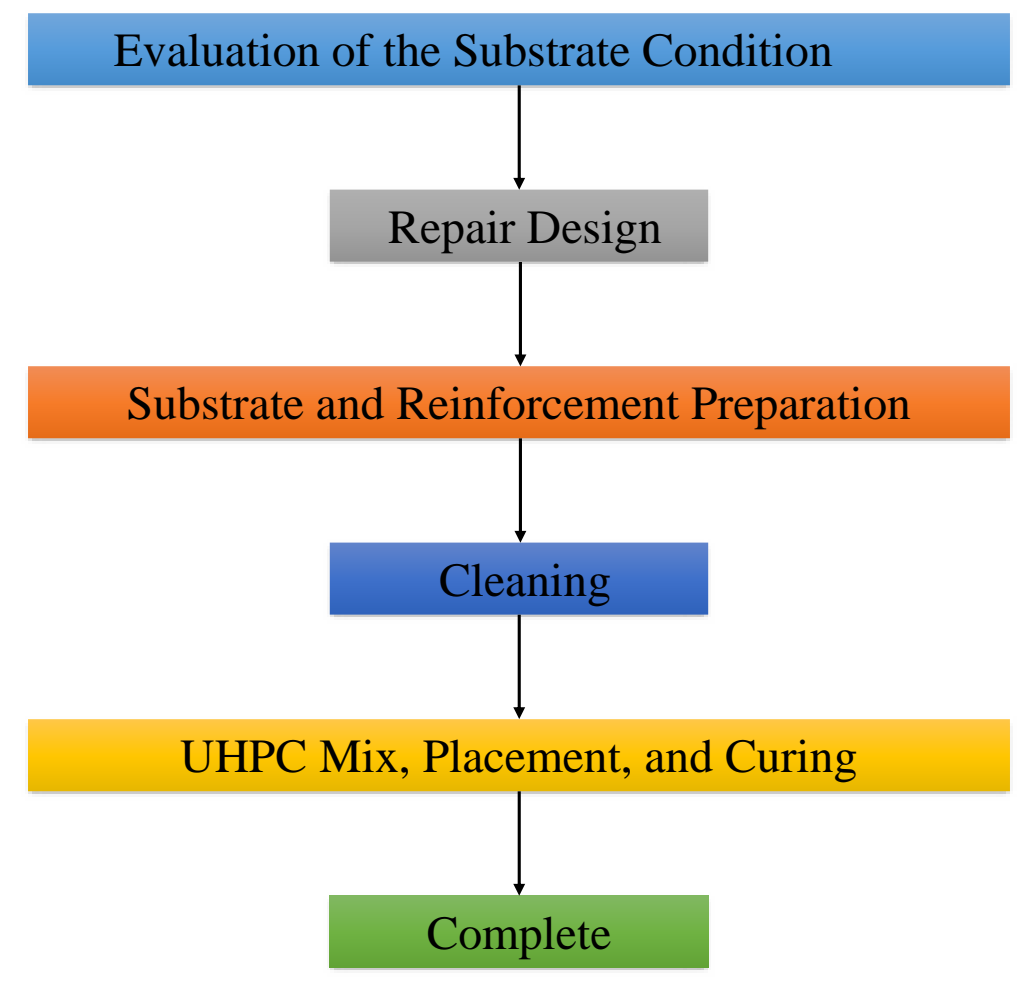

Figure 9- 1 UHPC repair steps.

\subsection{FuTURE RESEARCH}

The focus of this study was to identify relevant characteristics of some of the fundamental factors affecting the mechanical and durability performance of concrete repairs and bonded overlays incorporating UHPC. The focus of the experimental investigation was limited to UHPC as a repair material.

The conclusion presented in this chapter contains the relevant results of the experiments and numerical studies carried out by the author. Nevertheless, it also delivers important information based on a review of the best state-of-the-art knowledge and field 
practices in the concrete repair area. This report should not be considered the final guide to concrete repairs using UHPC.

This dissertation provides a comprehensive experimental and numerical study of the mechanical and durability performance of UHPC repair for axially loaded bridge elements. The moment curvature analysis generally gives a very good estimate of structural behavior of the whole system. The implementation and feasibility of this approach and its structural performance may need some experimental test.

There is a need to test the repair at full scale to understand the field implementation, constructability and possible monitoring of the repaired elements for structural performance and longevity under real conditions. The repaired element can be also instrumented to monitor the corrosion actability. Another area of interest which requires further experimental testing is finding the feasibility and challenges of the UHPC repair subjected to different environmental conditions such as under the water. 


\section{REFERENCES}

[1] American Society of Civil Engineers, “Asce 2017 report card for america's infrastructure," ASCE, 2017.

[2] R. Lampo, A. Maher, J. Busel, and R. Odello, "Design and development of FRP composite piling systems," Plast. Build. Constr., vol. 21, no. 12, p. 9, 1997.

[3] N. Berke, A. Bentur, and S. Diamond, Steel corrosion in concrete: fundamentals and civil engineering practice. CRC, 2014.

[4] J. Broomfield, Corrosion of steel in concrete: understanding, investigation and repair. CRC Press, 2006.

[5] M. F. Petrou, D. Parler, K. A. Harries, and D. C. Rizos, "Strengthening of Reinforced Concrete Bridge Decks Using Carbon Fiber-Reinforced Polymer Composite Materials," J. Bridg. Eng., vol. 13, no. 5, pp. 455-467, 2008.

[6] K. K. Antoniades, T. N. Salonikios, and A. J. Kappos, "Evaluation of hysteretic response and strength of repaired R/C walls strengthened with FRPs," Eng. Struct., vol. 29, no. 9, pp. 2158-2171, 2007.

[7] S. F. Jiang, X. Zeng, S. Shen, and X. Xu, "Experimental studies on the seismic behavior of earthquake-damaged circular bridge columns repaired by using combination of near-surface-mounted BFRP bars with external BFRP sheets jacketing," Eng. Struct., vol. 106, pp. 317-331, 2016.

[8] H. Sezen, M. Asce, and E. A. Miller, "Experimental Evaluation of Axial Behavior of Strengthened Circular Reinforced-Concrete Columns."

[9] A. Griezic, W. D. Cook, and D. Mitchell, "Seismic Behavior and Retrofit of Outrigger Beam-Column Frames," J. Bridg. Eng., vol. 6, no. 5, pp. 340-348, Oct. 2001.

[10] N. K. Shattarat and D. I. McLean, "Seismic Behavior and Retrofit of Outrigger Knee Joints,” J. Bridg. Eng., vol. 12, no. 5, pp. 591-599, Sep. 2007.

[11] M. S. Mohamed Ali, D. J. Oehlers, and M. A. Bradford, "Shear peeling of steel plates adhesively bonded to the sides of reinforced concrete beams," Proc. Inst. Civ. Eng. Build., vol. 140, no. 3, pp. 249-259, 2000.

[12] O. Buyukozturk, O. Gunes, and E. Karaca, "Progress on understanding debonding problems in reinforced concrete and steel members strengthened using FRP composites," Constr. Build. Mater., vol. 18, no. 1, pp. 9-19, 2004.

[13] E. S. Júlio, F. Branco, and V. D. Silva, "Structural rehabilitation of columns with reinforced concrete jacketing," Prog. Struct. Eng. Mater., vol. 5, no. 1, pp. 29-37, 2003. 
[14] E. Denarié, J. S.-R. W. on Bonded, and undefined 2004, "Structural behaviour of bonded concrete overlays," infoscience.epfl.ch.

[15] A. Lampropoulos, ... O. T.-A. M., and undefined 2012, "Biaxial Stress due to Shrinkage in Concrete Jackets of Strengthened Columns.," search.ebscohost.com.

[16] G. Ruano, F. Isla, D. Sfer, and B. Luccioni, "Numerical modeling of reinforced concrete beams repaired and strengthened with SFRC," Eng. Struct., vol. 86, pp. 168-181, 2015.

[17] H. Rodrigues, A. Furtado, A. Arêde, N. Vila-Pouca, and H. Varum, "Experimental study of repaired RC columns subjected to uniaxial and biaxial horizontal loading and variable axial load with longitudinal reinforcement welded steel bars solutions," Eng. Struct., vol. 155, pp. 371-386, 2018.

[18] H. K. Cheong and N. Macalevey, "Experimental Behavior of Jacketed Reinforced Concrete Beams," J. Struct. Eng., vol. 629, 2000.

[19] K. Habel, E. Denarié, and E. Brühwiler, "Structural Response of Elements Combining Ultrahigh-Performance Fiber-Reinforced Concretes and Reinforced Concrete," J. Struct. Eng., vol. 132, no. 11, pp. 1793-1800, 2006.

[20] R. Abbasnia, P. Godossi, and J. Ahmadi, "Prediction of restrained shrinkage based on restraint factors in patching repair mortar," Cem. Concr. Res., vol. 35, no. 10, pp. 1909-1913, 2005.

[21] M. Rapa and W. H. Hartt, "Non-destructive evaluation of jacketed prestressed concrete piles for corrosion damage," Natl. Assoc. Corros. Eng. Corros. 99, p. 24, 1999.

[22] P. Emmons, A. Vaysburd, J. M.-C. International, and undefined 1993, "Rational approach to durable concrete repairs," Concr. Int. , vol. 15, no. 5, pp. 40-45, 1993.

[23] D. R. Morgan, "Compatibility of concrete repair materials and systems," Constr. Build. Mater., vol. 10, no. 1, pp. 57-67, 1995.

[24] H. Beushausen, "The influence of concrete substrate preparation on overlay bond strength," Mag. Concr. Res., vol. 62, no. 11, pp. 845-852, Nov. 2010.

[25] A. Momayez, A. A. Ramezanianpour, H. Rajaie, and M. R. Ehsani, "Bi-Surface Shear Test for Evaluating Bond between Existing and New Concrete," ACI Mater. J., vol. 101, no. 2, pp. 99-106, Mar. 2004.

[26] B. Bissonnette, A. Vaysburd, and K. von Fay, "Best practices for preparing concrete surfaces prior to repairs and overlays," No. MERL 12-17, 2012.

[27] B. Graybeal, "Material property characterization of ultra-high performance concrete," 2006.

[28] M. Shafieifar, M. Farzad, and A. Azizinamini, "Experimental and numerical study on mechanical properties of Ultra High Performance Concrete (UHPC)," Constr. Build. Mater., vol. 156, pp. 402-411, Dec. 2017.

[29] P. Acker and M. Behloul, "Ductal ${ }^{\circledR}$ technology: A large spectrum of properties, a wide range of applications," Proc. Int. Symp. UHPC Kassel, pp. 11-23, 2004. 
[30] M. Farzad, M. Shafieifar, and A. Azizinamini, "Accelerated Retrofitting of Bridge Elements Subjected to Predominantly Axial Load Using UHPC Shell,” 2018.

[31] Z. B. Haber, I. De La Varga, and B. A. Graybeal, "Properties and Behavior of UHPC-Class Materials," no. FHWA-HRT-18-036, p. 153, 2018.

[32] T. L. Vande Voort, M. T. Suleiman, and S. Sritharan, "Design and Performance Verification of Ultra-High Performance Concrete Piles for Deep Foundations," Nov. 2008.

[33] M. Farzad, D. Garber, A. Azizinamini, and K. Lau, "Corrosion Macrocell Development in Reinforced Concrete with Repair UHPC," in Nace International, 2018.

[34] B. A. Graybeal, "Material property characterization of ultra-high performance concrete," No. FHWA-HRT-06-103, 2006.

[35] M. Farzad, M. Shafieifar, and A. Azizinamini, "Accelerated Retrofitting of Bridge Elements Subjected to Predominantly Axial Load Using UHPC Shell," in Transportation Research Record: Journal of the Transportation Research Board, 2018.

[36] M.-A. Dagenais, B. Massicotte, and B.-P. Guillaume, "Seismic Retrofitting of Rectangular Bridge Piers with Deficient Lap Splices Using Ultrahigh-Performance Fiber-Reinforced Concrete," J. Bridg. Eng., vol. 23, no. 2, 2017.

[37] "Bridge Overlays | Ductal® UHPC.” [Online]. Available: https://www.ductal.com/en/engineering/overlays. [Accessed: 06-Feb-2019].

[38] S. Han, Y. Liu, D. Liu, M. An, and Z. Yu, "The Modeling Research on the EarlyAge Shrinkage of UHPFRC in Different Curing Conditions," Adv. Civ. Eng., vol. 2018, 2018.

[39] ASTM, "Standard test method for length change of hardened hydraulic-cement mortar and concrete," ASTM C157-08, 2008.

[40] I. Burkart and H. S. Müller, "Creep and Shrinkage Characteristics of Ultra High Strength Concrete (UHPC)," Proc. Second Int. Symp. Ultra High Perform. Concr., pp. 469-476, 2008.

[41] E. Fehling, T. Leutbecher, K. B.-I. S. on U. High, and undefined 2004, "Design relevant properties of hardened ultra high performance concrete," Int. Symp. Ultra High Perform. Concr., vol. 1, 2004.

[42] P. Acker, "Micromechanical Analysis of Creep and Shrinkage Mechanisms," Creep, Shrinkage Durab. Mech. Concr. other quasi-brittle Mater. Cambridge, MA, pp. 15-25, 2001.

[43] B. Graybeal, "Ultra-high performance concrete," No. FHWA-HRT-11-038, 2011.

[44] H. Russel, G and B. a. Graybeal, "Ultra-High Performance Concrete : A State-ofthe-Art Report for the Bridge Community," No. FHWA-HRT-13-060, no. June, p. $171,2013$. 
[45] P. Acker and M. Behloul, "Ductal ${ }^{\circledR}$ technology: A large spectrum of properties, a wide range of applications," Proc. Int. Symp. UHPC Kassel, Ger., pp. 11-23, 2004.

[46] T. M. Ahlborn, D. L. Misson, E. J. Peuse, and Christopher G. Gilbertson., "Durability and strength characterization of ultra-high performance concrete under variable curing regimes," Proc. 2nd Int. Symp. Ultra High Perform. Concr. Fehling, E., Schmidt, M., Stürwald, S.(Eds.) Kassel, Ger., pp. 197-204, 2008.

[47] J. Piérard, B. Dooms, and N. Cauberg, "Evaluation of durability parameters of UHPC using accelerated lab tests," Proc. 3rd Int. Symp. UHPC Nanotechnol. High Perform. Constr. Mater. Kassel, Ger., pp. 371-376, 2012.

[48] C. Magureanu, I. Sosa, and C. Negrutiu, "Mechanical properties and durability of ultra-high-performance concrete," ACI Mater. J., vol. 109, no. 2, p. 177, 2012.

[49] C. Müller, "Durability of Ultra-High Performance Concrete (UHPC)," Proc. Third Int. fib Congr. Exhib. Inc. PCI Annu. Conv. Natl. Bridg. Conf. Washington, DC, vol. 135, 2010.

[50] S. Aaleti, P. Bradley, and S. Sritharan, "Design guide for precast UHPC waffle deck panel system, including connections," No. FHWA-HIF-13-032, 2013.

[51] B.-I. Bae, H.-K. Choi, and C.-S. Choi, "Flexural Strength Evaluation of Reinforced Concrete Members with Ultra High Performance Concrete," Adv. Mater. Sci. Eng., vol. 2016, pp. 1-10, Feb. 2016.

[52] B. A. Graybeal, "Compression Testing of Ultra-High-Performance Concrete," Adv. Civ. Eng. Mater., vol. 4, no. 2, pp. 102-112, 2017.

[53] D. Y. Yoo, N. Banthia, and Y. S. Yoon, "Predicting the flexural behavior of ultrahigh-performance fiber-reinforced concrete," Cem. Concr. Compos., vol. 74, pp. 71-87, 2016.

[54] AFGC Betons fibres a ultra-hautes performances Ultra High Performance FibreReinforced Concretes Recommendations. 2013.

[55] Building Code Requirements for Structural Concrete (ACI 318-14). 2014.

[56] S. P. Shah, "Design considerations for steel fiber reinforced concrete (ACI Committee 544)," ACI Struct. J., 1988.

[57] A. N. Dancygier and Z. Savir, "Flexural behavior of HSFRC with low reinforcement ratios," Eng. Struct., vol. 28, no. 11, pp. 1503-1512, 2006.

[58] M. Imam, L. Vandewalle, and F. Mortelmans, "Shear--moment analysis of reinforced high strength concrete beams containing steel fibres," Can. J. Civ. Eng., vol. 22, no. 3, pp. 462-470, 1995.

[59] S. Al-Ta' an and J. Al-Feel, "Evaluation of shear strength of fibre-reinforced concrete beams," Cem. Concr. Compos., vol. 12, no. 2, pp. 87-94, 1990. 
[60] S. Sritharan, B. J. Bristow, and V. H. Perry, "Characterizing an Ultra-High Performance Material For Bridge Applications Under Extreme Loads," in 3rd International Symposium on High Performance Concrete, Orlando, FL, 2003.

[61] G. Parra-Montesinos, "Shear strength of beams with deformed steel fibers," Concr. Int., vol. 28.11, 2006.

[62] B. A. Graybeal, "Characterization of the behavior of ultra-high performance concrete," 2005.

[63] D. Harris and C. Roberts-Wollmann, "Characterization of the punching shear capacity of thin ultra-high performance concrete slabs," 2005.

[64] W. Fuchs, R. Eligehausen, and J. Breen, "Concrete capacity design (CCD) approach for fastening to concrete,” Struct. J., vol. 92.1, pp. 73-94, 1995.

[65] J. Yuan and B. Graybeal, "Bond behavior of reinforcing steel in ultra-high performance concrete," 2014.

[66] V. S. Ronanki, S. Aaleti, and D. B. Valentim, "Experimental investigation of bond behavior of mild steel reinforcement in UHPC," Eng. Struct., vol. 176, no. August, pp. 707-718, 2018.

[67] B. Z. Haber, M. S. Saiidi, and D. Sanders, "Seismic Performance of Precast Columns with Mechanically Spliced Column-Footing Connections," ACI Struct. $J ., 2014$.

[68] M. Tazarv, Next generation of bridge columns for accelerated bridge construction in high seismic zones. 2014.

[69] P. Marchand et al., "Bond behaviour of reinforcing bars in UHPFRC," Mater. Struct., vol. 49, no. 5, pp. 1979-1995, May 2016.

[70] M. Alkaysi and S. El-Tawil, "Factors affecting bond development between Ultra High Performance Concrete (UHPC) and steel bar reinforcement," Constr. Build. Mater, vol. 144, pp. 412-422, 2017.

[71] J. Yuan and B. Graybeal, "Bond of Reinforcement in Ultra-High-Performance Concrete.," ACI Struct. J., vol. 112, no. 6, 2015.

[72] V. S. Ronanki, S. Aaleti, and D. B. Valentim, "Experimental investigation of bond behavior of mild steel reinforcement in UHPC," Eng. Struct., vol. 176, pp. 707718, Dec. 2018.

[73] F. Lagier, B. Massicotte, and J.-P. Charron, "Experimental investigation of bond stress distribution and bond strength in unconfined UHPFRC lap splices under direct tension," Cem. Concr. Compos., vol. 74, pp. 26-38, Nov. 2016.

[74] B. A. Graybeal, "Behavior of Ultra-High Performance Concrete connections between precast bridge deck elements," Proc. 2010 Concr. Bridg. Conf. Achiev. Safe, Smart Sustain. Bridg., vol. 24, 2010.

[75] A. Momayez, M. Ehsani, and A. Ramezanianpour, "Comparison of methods for evaluating bond strength between concrete substrate and repair materials," Cem. Concr. Res., vol. 35, no. 5, pp. 748-757, 2005. 
[76] J. Resplendino and F. Toulemonde, Designing and Building with UHPFRC. 2013.

[77] M. Shafieifar, M. Farzad, and A. Azizinamini, "New Connection Detail to Connect Precast Column to Cap Beam Using UHPC in ABC Applications," Transp. Res. Board 97th Annu. Meet. Res. Board, no. 18-04892, 2018.

[78] D. Erhard and G. Chorinsky, "Repair of Concrete Floors with Polymer Modified Cement Mortars," in Adhesion between polymers and concrete / Adhésion entre polymères et béton, Boston, MA: Springer US, 1986, pp. 230-234.

[79] PIGEON and M., "Durability of Repaired Concrete Structure," Adv. Concr. Technol., pp. 741-773.

[80] M. A. Carbonell Muñoz, D. K. Harris, T. M. Ahlborn, and D. C. Froster, "Bond Performance between Ultrahigh-Performance Concrete and Normal-Strength Concrete," J. Mater. Civ. Eng., vol. 26, no. 8, p. 04014031, Aug. 2014.

[81] B. Tayeh, B. Bakar, M. Johari, Y. V.-C. and building, and undefined 2012, "Mechanical and permeability properties of the interface between normal concrete substrate and ultra high performance fiber concrete overlay," Constr. Build. Mater., vol. 36, pp. 538-548, 2012.

[82] Z. B. Haber, J. F. Munoz, I. De la Varga, and B. . Graybeal, "Bond characterization of UHPC overlays for concrete bridge decks: Laboratory and field testing," Constr. Build. Mater., vol. 190, pp. 1056-1068, 2018.

[83] I. De La Varga, Z. B. Haber, and B. A. Graybeal, "Enhancing Shrinkage Properties and Bond Performance of Prefabricated Bridge Deck Connection Grouts: Material and Component Testing," ASCE J. Mater. Civ. Eng., vol. 30, no. 4, p. 12, 2018.

[84] J. Warner, S. Bhuyan, W. G. Smoak, K. R. Hindo, and M. M. Sprinkel, "Surface Preparation for Overlays," Am. Concr. Inst., vol. 20, no. 5, pp. 43-46, 1998.

[85] P. Carter, S. Gurjar, J. W.-C. international, and undefined 2002, "Debonding of highway bridge deck overlays," concrete.org.

[86] M. Sprinkel, "Performance specification for high performance concrete overlays on bridges.," 2004.

[87] A. Sadeghnejad et al., "Non-Destructive Testing (NDT) of a Segmental Concrete Bridge Scheduled for Demolition, with a Focus on Condition Assessment and Corrosion Detection of Internal Tendons," 2017.

[88] D. Garber, J. Gull, M. Sheifiefar, and N. Rezaei, "Compilation of Accelerated Bridge Construction (ABC) Bridges," 2016.

[89] M. Farzad and A. Azizinamini, "Accelerated retrofit of bridge columns using UHPC shell-Phase I: Feasibility Study."

[90] PCI Self-Consolidating Concrete FAST Team, "Interim Guidelines for the Use of Self-Consolidating Concrete in PCI Member Plants," PCI J., vol. 48, no. 3, pp. 14-18, 2003. 
[91] ASTM and C43, "143, Standard Test Method for Slump of Hydraulic Cement Concrete," ASTM Int., 2003.

[92] P. T.-P. Journal and undefined 2003, "Interim Guidelines for the Use of SelfConsolidating Concrete in PCI Member Plants," imcyc.com.

[93] ASTM and C39, “39, Standard test method for compressive strength of cylindrical concrete specimens," ASTM Int., 2001.

[94] P. Emmons and A. Vaysburd, "Performance Criteria for Concrete Repair Materials. Phase 1.," Struct. Preserv. Syst. INC Balt. MD, 1995.

[95] N. K. Emberson and G. C. Mays, "Significance of property mismatch in the patch repair of structural concrete Part 2: Axially loaded reinforced concrete members," Mag. Concr. Res., vol. 42, no. 152, pp. 161-170, Sep. 1990.

[96] P. C. Hewlett and S. A. Hurley, "The consequence of polymer-concrete mismatch. Design Life of Buildings," 1985.

[97] D. Cusson and N. Mailvaganam, "Durability of repair materials," Concr. Int. Constr., vol. 18, no. 3, pp. 34-38, 1996.

[98] P. Mangat, F. O’Flaherty, and undefined 1999, “Long-term performance of highstiffness repairs in highway structures," Mag. Concr. Res. , vol. 51, no. 5, pp. 325339, 1999.

[99] P. Mangat and F. O'Flaherty, "Influence of elastic modulus on stress redistribution and cracking in repair patches," Influ. elastic Modul. Stress Redistrib. Crack. repair patches, vol. 30, no. 1, pp. 125-136, 2000.

[100] P. S. Mangat and F. J. O'Flaherty, "Serviceability characteristics of flowing repairs to propped and unpropped bridge structures," Mater. Struct., vol. 32, no. 9, pp. 663-672, Nov. 1999.

[101] B. Graybeal, "Material property characterization of ultra-high performance concrete," No. FHWA-HRT-06-103, 2006.

[102] L. Aashto, Bridge design specifications. 1998.

[103] “'Astm, C. '1018:'Standard Test Method for Flexural Toughness and First-Crack Strength of Fiber-Reinforced Concrete (Using Beam With Third-Point Loading).' American Society of Testing Materials, USA (1997)."

[104] “AASHTO T132, Standard Method of Test for Tensile Strength of Hydraulic Cement Mortars, In America Association of State Highway and Transportation Officials, Standard Specifications for Transportation Materials and Methods of Sampling and Testing, Washingt."

[105] H. Layssi, P. Ghods, A. R. Alizadeh, and M. Salehi, "Electrical resistivity of concrete," Concr. Int., vol. 37, no. 5, 2015.

[106] P. K. Mehta and P. J. M. Monteiro, "Concrete: structure, properties, and materials,॥ Prentice Hall,” Inc. Englewood Cliffs, New Jersey, 1986. 
[107] H. A. Razak and H. S. Wong, "Strength estimation model for high-strength concrete incorporating metakaolin and silica fume," Cem. Concr. Res., vol. 35, no. 4, pp. 688-695, 2005.

[108] S. Kranc and A. Sagüés, "Computation of corrosion distribution of reinforcing steel in cracked concrete," Proc. Int. Conf. Corros., p. 329, 1998.

[109] ASTM, "F2170: Relative Humidity in Concrete Floor Slabs Using in situ Probes."

[110] C. Vernet, "Nanostructure, porosity, permeability and diffusivity of Ultra High Performance Concretes," Int. Symp. High-performance React. Powder Concr. Canada., 1998.

[111] Euro-International Committee for Concrete and Comité euro-international du béton, Durable concrete structures: design guide. 1992.

[112] A. D. Espeche and J. León, "Estimation of bond strength envelopes for old-to-new concrete interfaces based on a cylinder splitting test," Constr. Build. Mater., vol. 25, no. 3, pp. 1222-1235, 2011.

[113] ASTM C78, "Standard test method for flexural strength of concrete (using simple beam with third-point loading)," Am. Soc. Test. Mater., 1999.

[114] ASTM, "Standard test method for bond strength of epoxy-resin systems used with concrete by slant shear," C882/C882M-05e1, 2005.

[115] D. P. Bentz et al., "Influence of substrate moisture state and roughness on interface microstructure and bond strength: Slant shear vs. pull-off testing," Cem. Concr. Compos., vol. 87, pp. 63-72, Mar. 2018.

[116] ASTM C., "Standard test method for splitting tensile strength of cylindrical concrete," vol. 5, 2011.

[117] M. Sprinkel and C. Ozyildirim, "Evaluation of high performance concrete overlays placed on Route 60 over Lynnhaven Inlet in Virginia.," Virginia Transp. Res. Counc., vol. No. VTRC-01-R1., 2000.

[118] Z. P. Bažant and L. J. Najjar, "Nonlinear water diffusion in nonsaturated concrete," Matériaux Constr., vol. 5, no. 1, pp. 3-20, Jan. 1972.

[119] S. Qian, J. Zhou, E. S.-C. and concrete composites, and undefined 2010, "Influence of curing condition and precracking time on the self-healing behavior of engineered cementitious composites," Elsevier.

[120] S. Yoo and S. Kwon, "Effects of cold joint and loading conditions on chloride diffusion in concrete containing GGBFS," Constr. Build. Mater., vol. 115, pp. 247-255, 2016.

[121] H.-M. Yang, H.-S. Lee, K.-H. Yang, M. A. Ismail, and S.-J. Kwon, "Time and cold joint effect on chloride diffusion in concrete containing GGBFS under various loading conditions," Constr. Build. Mater., vol. 167, pp. 739-748, Apr. 2018.

[122] S.-S. Park, S.-J. Kwon, and S. H. Jung, "Analysis technique for chloride penetration in cracked concrete using equivalent diffusion and permeation," Constr. Build. Mater., vol. 29, pp. 183-192, Apr. 2012. 
[123] S.-J. Kwon and U.-J. Na, "Prediction of Durability for RC Columns with Crack and Joint under Carbonation Based on Probabilistic Approach," Int. J. Concr. Struct. Mater., vol. 5, no. 1, pp. 11-18, Jun. 2011.

[124] N. Build, “492,” Build, N. (1999). 492. Concr. mortar Cem. repair Mater. chloride Migr. Coeff. from non-steady-state Migr. Exp., vol. 3, 1999.

[125] M. Collepardi, A. Marcialis, and R. Turriziani, "The kinetics of penetration of chloride ions into the concrete," ll Cem., vol. 67, no. 4, pp. 157-164, 1970.

[126] N. Otsuki, S. Nagataki, and K. Nakashita, "Evaluation of AgNO3 Solution Spray Method for Measurement of Chloride Penetration into Hardened Cementitious Matrix Materials," ACI Mater. J., vol. 16, no. 1, pp. 53-56, 1992.

[127] T. Luping and L.-O. Nilsson, "Chloride diffusivity in high strength concrete at different ages," Nord. Concr. Res., vol. 11, 1992.

[128] ASTM and C1202, "Standard Test Method for Electrical Indication of Concrete's Ability to Resist Chloride Ion Penetration," Am. Soc. Test. Mater. Stand. Pract. C1202, Philadelphia, PA, 1997.

[129] Build and NordTest, "492, Chloride migration coefficient from non-steady-state migration experiments," Nord. method, 1999.

[130] K. L. Mahsa Farzad, David Garber, Atorod Azizinamini, "Corrosion Macrocell Development in Reinforced Concrete with Repair UHPC," Corros. 2018. NACE Int., 2018.

[131] L. Aashto, "Bridge design specifications," 1998.

[132] M. N. Priestley, F. Seible, and G. M. Calvi, "Seismic design and retrofit of bridges," John Wiley Sons, 1996.

[133] J. B. Mander, M. J. Priestley, and R. Park, "Theoretical stress-strain model for confined concrete," J. Struct. Eng., vol. 114, no. 8, pp. 1804-1826, 1988.

[134] J. B. Mander, "Seismic design of bridge piers," 1983.

[135] S. Aaleti, B. Petersen, and S. Sritharan, "Design guide for precast UHPC waffle deck panel system, including connections," 2013.

[136] Caltrans (California Department of Transportation), "Caltrans seismic design criteria," version 1.7, 2013.

[137] S. Sritharan, M. T. Suleiman, and D. J. White, "Effects of Seasonal Freezing on Bridge Column-Foundation-Soil Interaction and Their Implications," Earthq. Spectra, vol. 23, no. 1, pp. 199-222, Feb. 2007.

[138] M. Ketchum, V. Chang, T. Shantz, and undefined 2004, "Influence of design ground motion level on highway bridge costs," Rep. No. Lifelines 6D01., 2004.

[139] K. Mackie and B. Stojadinovic, "Fragility curves for reinforced concrete highway overpass bridges," 13th World Conf. Earthq. Eng. Vancouver BC, Canada, pp. 16, 2004. 
[140] De Normalisation and Comité Européen, "Eurocode 2: Design of concrete structures-Part 1-1: General rules and rules for buildings," Brussels, Belgium, 2004.

[141] American Concrete Institute, "ACI manual of concrete practice," Am. Concr. Inst., 2002.

[142] M. Shafieifar, M. Farzad, and A. Azizinamini, "A comparison of existing analytical methods to predict the flexural capacity of Ultra High Performance Concrete (UHPC) beams," Constr. Build. Mater., vol. 172, pp. 10-18, 2018.

[143] D.-Y. Yoo and Y.-S. Yoon, "Structural performance of ultra-high-performance concrete beams with different steel fibers," Eng. Struct., vol. 102, pp. 409-423, Nov. 2015.

[144] E. Steinberg, "Structural Reliability of Prestressed UHPC Flexure Models for Bridge Girders," J. Bridg. Eng., vol. 15, no. 1, pp. 65-72, Jan. 2010.

[145] E. Cosenza, C. Galasso, and G. Maddaloni, "Simplified assessment of bending moment capacity for rc members with circular cross-section," Third Int. fib Congr. Exhib. PCI Annu. Conv. Bridg. Conf., 2010.

[146] Y. L. Voo and S. J. Foster, "Characteristics of ultra-high performance 'ductile' concrete and its impact on sustainable construction," IES J. Part A Civ. Struct. Eng., vol. 3, no. 3, pp. 168-187, Aug. 2010.

[147] H. Russell and B. Graybeal, "Ultra-high performance concrete: A state-of-the-art report for the bridge community," 2013.

[148] L. Guingot, D. Dekhil, and P. Soulier, "STRENGTHENING OF HYDRAULIC STRUCTURES WITH UHPC," Toutlemonde F, Resplendino J, eds. Proceed-ings Int. Symp. Ultra-High Perform. Fiber-Reinf. Concr. Marseille, Fr., pp. 137-146, 2013.

[149] J. M. Frederiksen, "Chloride threshold values for service life design," Test. Model. Chloride Ingress into Concr., pp. 397-414, 2000.

[150] Mahima, S., P. V. P. Moorthi, A. Bahurudeen, and A. Gopinath, "Influence of chloride threshold value in service life prediction of reinforced concrete structures," Sädhanā, vol. 43, no. 7, p. 115, 2018.

[151] M. G. Alexander, H. D. Beushausen, F. Dehn, P. Moyo, and Editors, Rehabilitation and Retrofitting III: 3rd International Conference on Concrete Repair, Rehabilitation and Retrofitting. 2012.

[152] C. Alonso, C. Andrade, and J. A. Gonzalez, "Relation between resistivity and corrosion rate of reinforcements in carbonated mortar made with several cement types," Cem. Concr. Res., vol. 18, no. 5, 1988.

[153] J. A. Lopez, W. and Gonzalez, "Influence of the degree of pore saturation on the resistivity of concrete and the corrosion rate of steel reinforcement., Cem. Concr. Res., vol. 23, no. 2, pp. 368-376, 1993. 
[154] G. K. Glass, C. L. Page, and N. R. Short, "Factors affecting the corrosion rate of steel in carbonated mortars.," Corros. Sci., vol. 32, no. 12, pp. 1283-1294, 1991.

[155] S. Feliu, J. A. Gonzalez, S. Feliu, and C. Andrade, "Relationship between conductivity of concrete and corrosion of reinforcing bars," Br. Corros. J., vol. 24, no. 3, pp. 195-198, 1989.

[156] R. Browne, "Marine durability survey of the Tongue Sand Tower," Concr. Ocean Program. No. 5. CIRIA UEG Tech. Rep., 1980.

[157] P. Sandberg, "Durability of concrete in saline environment," Cem. Danderyd Sweden, p. 206, 1996.

[158] K. Lau, A. A. Sagues, L. Yao, and R. G. Powers, "Corrosion performance of concrete cylinder piles,” Corrosion, vol. 63, no. 4, pp. 366-378, 2007.

[159] S. E. Herald et al., "Condition evaluation of concrete bridges relative to reinforcement corrosion. Volume 6: Method for field determination of total chloride content," No. SHRP-S-328, 1992.

[160] F. J. Presuel-Moreno, W. Arias, S. Echevarria, V., Shill, and Y. Y. Wu, "Diffusion vs. Concentration of Chloride Ions in Concrete," No. BDK79-977-03, 2014.

[161] M. Thomas, B. Green, E. O’Neal, V. Perry, S. Hayman, and A. Hossack, "Marine performance of UHPC at Treat Island.," Proc. 3rd Int. Symp. UHPC Nanotechnol. High Perform. Constr. Mater., pp. 365-30, 2012.

[162] J. Crank, The mathematics of diffusion. 1979.

[163] C. Liu and W. . Ball, "Analytical modeling of diffusion-limited contamination and decontamination in a two-layer porous medium.," Adv. Water Resour., vol. 21, no. 4, pp. 297-313, 1998.

[164] H. S. Carslaw and J. C. Jaeger, "Conduction of heat in solids," Oxford Clarendon Press, vol. 2nd ed., 1959.

[165] M. Berry, R. Snidarich, and C. Wood, "Development of Non-Proprietary UltraHigh Performance Concrete," No. FHWA/MT-17-010/8237-001. Mont. Dept. Transp. Res. Programs, 2017.

[166] S. El-Tawil, M. Alkaysi, A. Naaman, W. Hansen, and Z. Liu, "Development, Characterization and Applications of a Non Proprietary Ultra High Performance Concrete for Highway Bridges," o. RC-1637. Michigan. Dept. Transp., 2016.

[167] Kurt F. von Fay, Guide to Concrete Repair, Second. U.S. Department of the Interior Bureau of Reclamation Technical Service Center, 2015.

[168] ACI Committee 562M-13, "Code Requirements for Evaluation, Repair and Rehabilitation of Concrete Buildings and Commentary," Am. Concr. Inst., 2013.

[169] C. Guide, “Concrete Repair,” ACI 546R-04, 2004.

[170] B. A. G. Yuan, Jiqiu, "Bond behavior of reinforcing steel in ultra-high performance concrete," FHWA-HRT-14-090, 2014. 
[171] S. Aaleti, B. Petersen, and S. Sritharan, "Design guide for precast UHPC waffle deck panel system, including connections," No. FHWA-HIF-13-032, 2013.

[172] S. W. M, S. T. Kang, J. J. Park, and G. S. Ryu, "Effect of filling method on fibre orientation and dispersion and mechanical properties of UHPC," Proc. Second Int. Symp. ultra high Perform. Concr. Kassel, Ger., pp. 185-192, 2008.

[173] Association National Precast Concrete, Ultra-high performance concrete (UHPC)-Guide to manufacturing architectural precast UHPC elements. 2013.

[174] B. A. Graybeal and B. Stone, "Compression response of a rapid-strengthening ultra-high performance concrete formulation," US Dep. Transp. Fed. Highw. Adm., 2012. 
VITA

\section{MAHSA FARZAD}

Born, Tehran, Iran

2004-2009

B.Sc., Civil Engineering, Structural Engineering Shahrood University of Technology

Shahrood, Iran

2010-2013

M.S., Civil Engineering, Structural Engineering Sharif University of Technology

Tehran, Iran

$2014-20198$

Ph.D, Civil Engineering, Structural Engineering

Florida International University

Miami, Florida

\section{PUBLICATIONS AND PRESENTATIONS}

Mahsa Farzad, Shafieifar, Mohamadreza, and Atorod Azizinamini. "Experimental and numerical study on an innovative sandwich system utilizing UPFRC in bridge applications." Engineering Structures, 180 (2019): 349-356.

Farzad, Mahsa, Mohamadreza Shafieifar, and Atorod Azizinamini. "Experimental and numerical study on bond strength between conventional concrete and Ultra HighPerformance Concrete (UHPC)." Engineering Structures 186 (2019): 297-305.

Shafieifar, Mohamadreza, Mahsa Farzad, and Atorod Azizinamini. "A comparison of existing analytical methods to predict the flexural capacity of Ultra High Performance Concrete (UHPC) beams." Construction and Building Materials 172 (2018): 10-18.

Shafieifar, Mohamadreza, Mahsa Farzad, and Atorod Azizinamini. "Experimental and numerical study on mechanical properties of Ultra High Performance Concrete (UHPC)." Construction and Building Materials 156 (2017): 402-411.

Shafieifar, Mohamadreza, Mahsa Farzad, and Atorod Azizinamini. "New Connection Detail to Connect Precast Column to Cap Beam Using UHPC in ABC Applications". Journal of the Transportation Research Board, 2018. 
Farzad, Mahsa, David Garber, Atorod Azizinamini, and Kingsley Lau. "Corrosion Macrocell Development in Reinforced Concrete With Repair UHPC." In CORROSION 2018. NACE International, 2018.

Farzad, Mahsa, Atorod Azizinamini. "Accelerated Repair of Existing Bridges Using UHPC”. November Monthly ABC Webinar, 2018.

Mahsa Farzad, Shafieifar, Mohamadreza, and Atorod Azizinamini. "Accelerated Retrofitting of Bridge Elements Subjected to Predominantly Axial Load Using UHPC Shell". TRB Washington D.C 2018.

Shafieifar, Mohamadreza, Mahsa Farzad, and Atorod Azizinamini. "New Connection Detail to Connect Precast Column to Cap Beam Using UHPC in ABC Applications". TRB Washington D.C 2018.

Farzad, Mahsa, and Atorod Azizinamini. "Accelerated Retrofitting of Bridge Elements Subjected to Predominantly Axial Load Using UHPC Shell”. 2017 National Accelerated Bridge Construction Conference, Miami, 2017.

Farzad, Mahsa, Lau, Kingsley and Atorod Azizinamini. "Corrosion Durability of Reinforced Concrete Utilizing UHPC for ABC Applications”. 2017 National Accelerated Bridge Construction Conference, Miami, 2017.

Farzad, Mahsa, Alireza Mohammadi, Mohamadreza Shafieifar, Huy Pham, and Atorod Azizinamini. "Development of Innovative Bridge Systems Utilizing Steel-Concrete-Steel Sandwich System”. TRB 2017, Washington, D.C., 2017.

Shafieifar, Mohamadreza, Mahsa Farzad, and Atorod Azizinamini. "Alternative ABC Connection Utilizing UHPC". TRB 2017, Washington, D.C., 2017.

Shafieifar, Mohamadreza, Mahsa Farzad, and Atorod Azizinamini. "Alternative ABC Connection Using UHPC”. 2017 UTC Spotlight Conference, Washington, D.C., 2017.

Shafieifar, Mohamadreza, Mahsa Farzad, and Atorod Azizinamini. "Alternative ABC Connection Using UHPC”. Western Bridge Engineers 2017, Oregon, 2017. 